\title{
GERAÇÃO DE VIAGENS E DEMANDA POR ESTACIONAMENTO EM SHOPPING CENTERS DO INTERIOR DO ESTADO DE SÃO PAULO
}

\section{Carolina B. Brevis Cárdenas}

ORIENTADOR: Prof. Dr. Antonio Clóvis Pinto Ferraz

Tese apresentada à Escola de Engenharia de São Carlos, da Universidade de São Paulo, como parte dos requisitos para obtenção do título de Doutor em Transportes. 
Ficha catalográfica preparada pela Seção de Tratamento da Informação do Serviço de Biblioteca - EESC/USP

Brevis Cárdenas, Carolina B.

Geração de viagens e demanda por estacionamento em shopping centers do interior do estado de São Paulo / Carolina B. Brevis Cárdena. -- São Carlos, 2003.

Tese (Doutorado -- Escola de Engenharia de São Carlos-Universidade de São Paulo, 2003.

Área: Transportes.

Orientador: Prof. Dr. Antonio Clóvis Pinto Ferraz.

1. Geração de viagens. 2. Demanda por

estacionamento. 3. Shopping centers. I. Título. 
FOLHA DE JULGAMENTO

Candidata: Engenheiro CAROLINA BEATRIZ BREVIS CARDENAS

Tese defendida e julgada em 29-09-2003 perante a Comissão Julgadora:
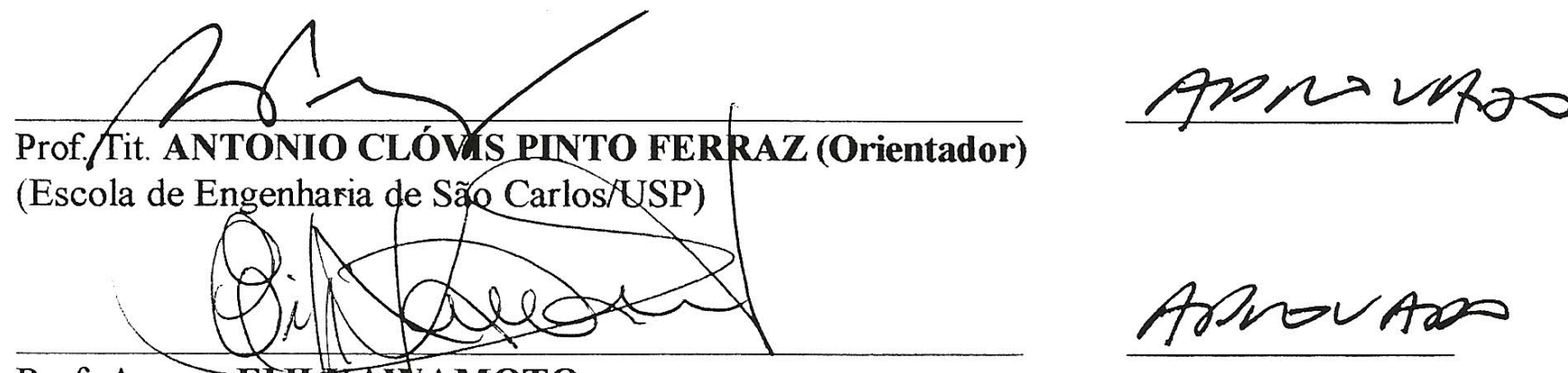

Prof. Assoc. ETJI KAWAMOTO

(Escola de Engenhafia de São Carlos/USP)
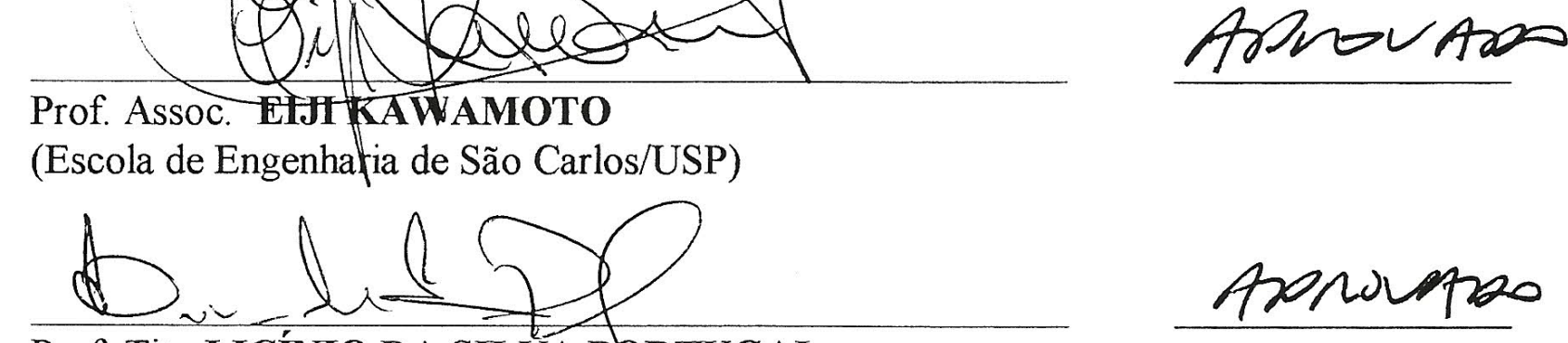

Prof. Tit. LICÍNIO DA SILVA PQRTUGAL

(Universidade Federal do Rio de Janeiro/UFRJ)
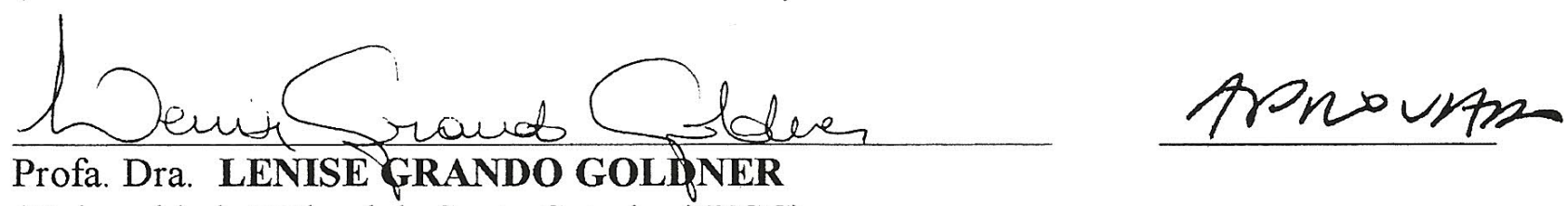

(Universidade Federal do Santa Catarina/UFSC)

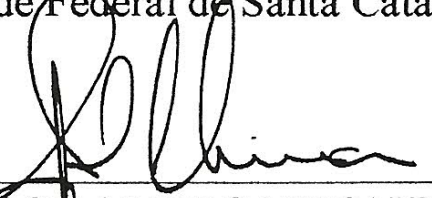

Prof. Dr. JOS ALEX SANT'ANNA

(Universidade de Brasília/UnB)

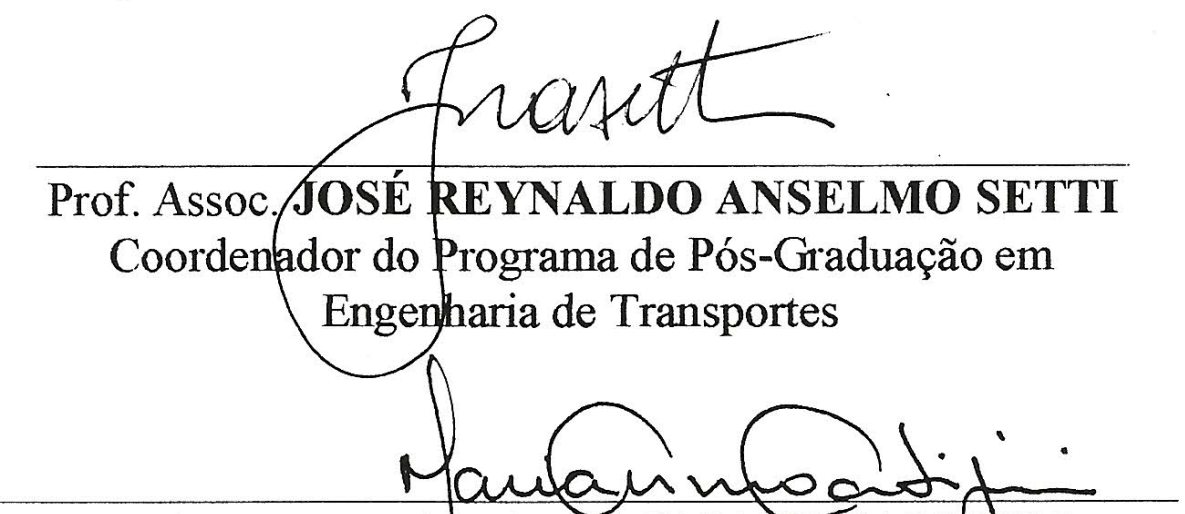

Profa. Assoc. MARIA DO CARMO CALIOURI

Presidente da Comissão de Pós-Graduação da EESC 
A Mónica, minha mãe, que de longe esteve sempre presente e quando junto me confortou com seu apóio, compreensão e amor. 


\section{AGRADECIMENTOS}

A Marcela, minha sobrinha, pela sua colaboração, questionamentos e todos os momentos compartilhados enquanto realizei o doutorado.

A Mónica e Guilherme, minha irmã e meu cunhado, por me oferecerem total apoio, amizade, compreensão e carinho, principalmente no início do doutorado.

A Gregório e Tereza, meu irmão e minha cunhada, que souberam compreender meus momentos de dúvida e me ofereceram apoio para finalizar o trabalho.

A Carmen, Moniquinha e Doris, minha irmã caçula e minhas sobrinhas, pelo ânimo e curiosidade.

A Mariana e Eduardo, meus irmãos, que mesmo estando longe sempre estiveram presentes ao me oferecerem palavras de conforto e ânimo.

A Robert L. Cox, meu grande mestre, que me incentivou a procurar o conhecimento.

A Eiji Kawamoto, pelas conversas, troca de idéias e críticas, que me fizeram refletir.

A Antonio Clóvis Pinto Ferraz, por me atender no momento que precisei e me oferecer seu apoio e orientação, agradeço muito.

A Pastor Willy Gonzáles Taco, pela troca de idéias, comunicação e amizade sempre presente.

A Cynthia Lotti, Cíntia Yumico, Andréa Kobayashi e Márcia Pereira, pela amizade e disponibilidade em colaborar nas coletas de dados.

A Magaly N. Pazzian V. Romão, por toda a amizade e coleguismo, pela ajuda nas coletas de dados, pela troca de idéias e pelos ótimos momentos compartilhados.

A Heloisa Morgado Belo e Elizabete (Bete) Ortega, pela colaboração constante.

Ao CNPq - Conselho Nacional de Desenvolvimento Científico e Tecnológico, que me forneceu o apoio financeiro para realizar o curso de doutorado.

A todos aqueles que não mencionei, amigos, colegas do mestrado e doutorado, que também participaram da minha caminhada, agradeço de coração. 


\section{SUMÁRIO}

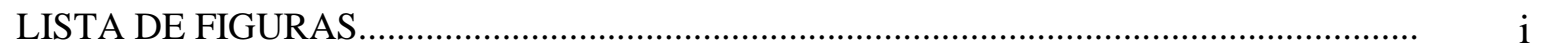

LISTA DE TABELAS.................................................................................................... iv

LISTA DE ABREVIATURAS E SIGLAS ........................................................................ vii

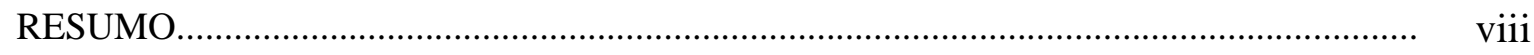

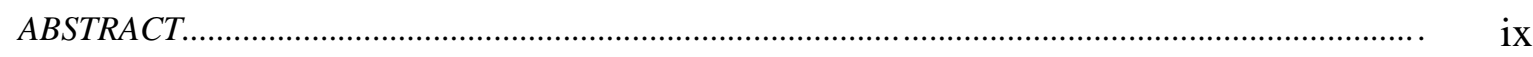

1 INTRODUÇÃO

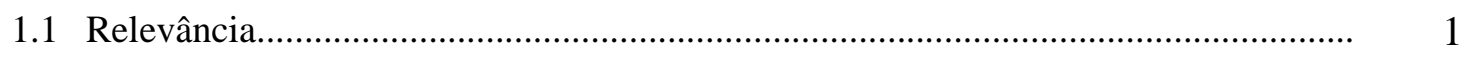

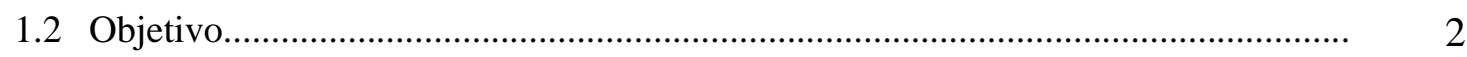

1.3 Descrição do trabalho................................................................................................ 3

2 REVISÃO DA LITERATURA............................................................................... 4

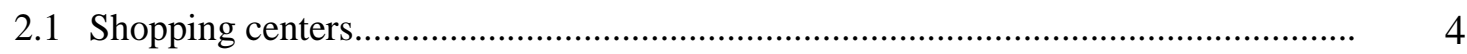

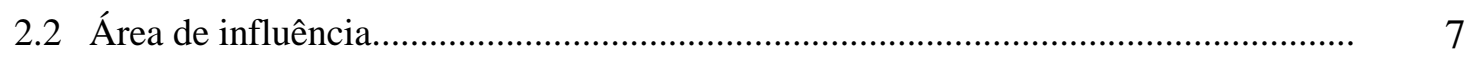

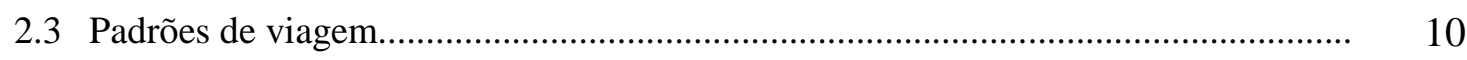

2.4 Variações da demanda de viagens............................................................................ 11

2.4.1 Dia de projeto.............................................................................................. 12

2.4.2 Hora de projeto.................................................................................................. 15

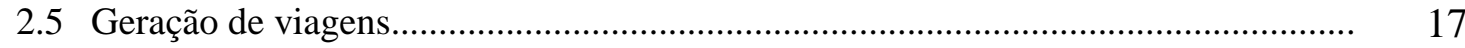

2.6 Categoria de viagens..................................................................................... 20

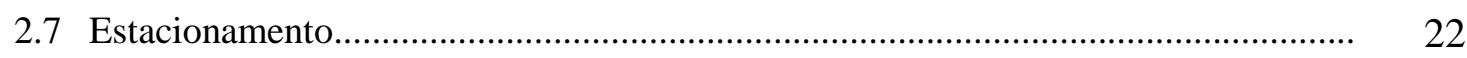

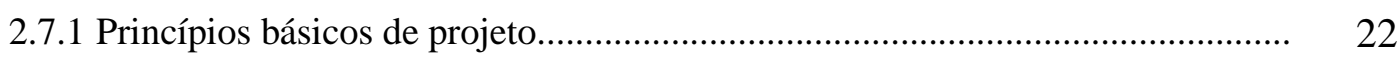

2.7.2 Componentes do projeto............................................................................ 24

2.7.3 Elementos que afetam a demanda................................................................... 27

2.7.4 Critérios utilizados para dimensionar estacionamentos....................................... 29

2.8 Análise da literatura pesquisada.......................................................................... 34

3 METODOLOGIA DAS PESQUISAS REALIZADAS.................................................. 39

3.1 Considerações iniciais............................................................................................ 39

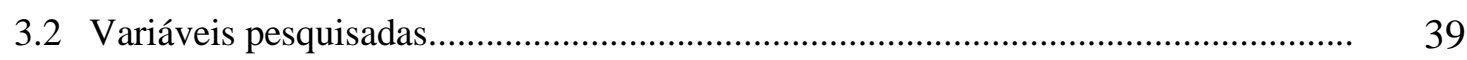

3.3 Métodos de coleta de dados.................................................................................. 40

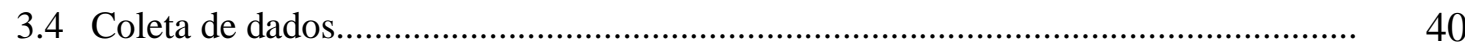

3.5 Processamento dos dados....................................................................................... 41 
4 PESQUISAS EM SHOPPING CENTERS................................................................. 44

4.1 Considerações iniciais....................................................................................... 44

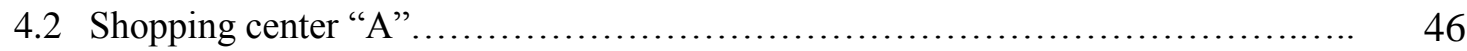

4.2.1 Características do empreendimento............................................................... 46

4.2.2 Coleta de dados no estacionamento................................................................. 47

4.2.2.1 Geração de viagens.................................................................................. 47

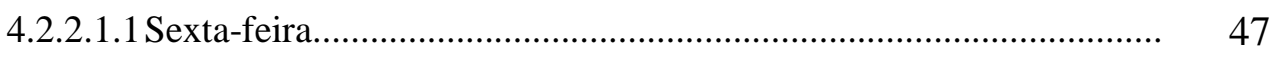

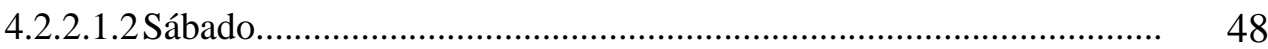

4.2.2.2 Demanda por estacionamento................................................................ $\quad 50$

4.2.2.3 Duração do estacionamento...................................................................... 51

4.2.2.4 Principais resultados obtidos................................................................. 53

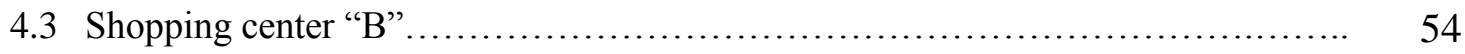

4.3.1 Características do empreendimento.............................................................. 54

4.3.2 Coleta de dados no estacionamento................................................................... 55

4.3.2.1 Geração de viagens........................................................................... 56

4.3.2.1.1 Sexta-feira................................................................................. 56

4.3.2.1.2 Sábado.......................................................................................... 57

4.3.2.2 Demanda por estacionamento............................................................... 58

4.3.2.3 Duração do estacionamento..................................................................... 60

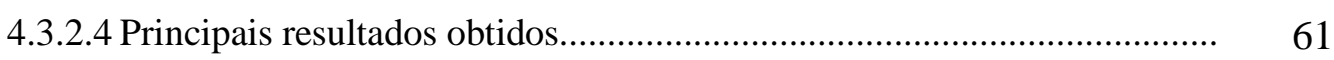

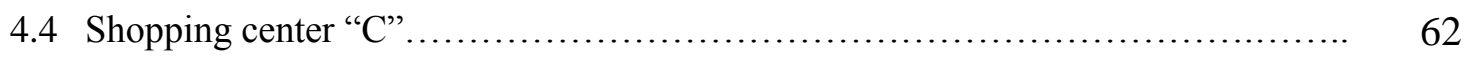

4.4.1 Características do empreendimento..................................................................... 62

4.4.2 Coleta de dados no estacionamento...................................................................... 63

4.4.2.1 Geração de viagens................................................................................... 64

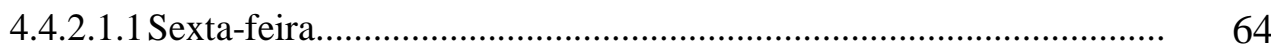

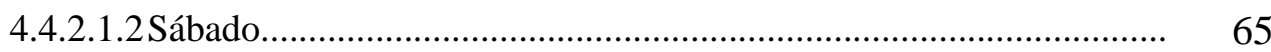

4.4.2.2 Demanda por estacionamento............................................................. 66

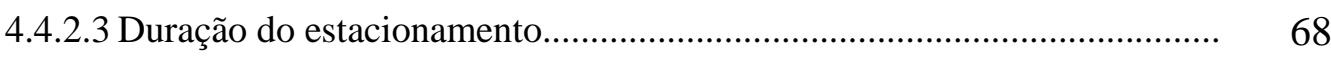

4.4.2.4 Principais resultados obtidos.................................................................. $\quad 70$

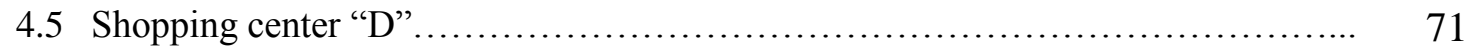

4.6 Shopping center "E"

4.7 Shopping center "F"

4.8 Síntese dos resultados........................................................................................ 74

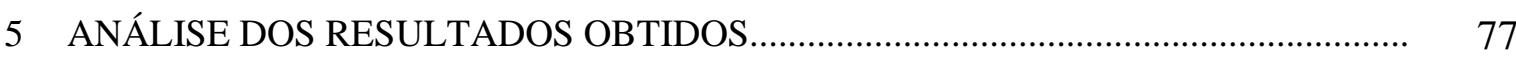

5.1 Relação entre os fluxos da sexta-feira e do sábado.......................................................... 77 
5.2 Relação entre as viagens diárias e o tamanho do shopping center.

5.2.1 Sexta-feira

5.2.2 Sábado

5.3 Fatores de pico horário.

5.3.1 Sexta-feira.

5.3.2 Sábado

5.4 Fatores horários para análise do impacto viário.

5.5 Relação entre o acúmulo máximo de veículos e o tamanho do shopping center 95

5.6 Relação entre o acúmulo máximo de veículos e as viagens diárias no sábado 97

5.7 Tempo médio de permanência dos veículos no estacionamento

5.8 Relação entre o acúmulo máximo de veículos na área de estacionamento com o tempo médio de permanência e as viagens na hora pico

5.9 Relação entre viagens diárias e tamanho dos empreendimentos

102

5.9.1 Viagens diárias x Área bruta locável.

5.9.2 Viagens diárias $x$ Área total construída..

104

5.9.3 Viagens diárias x Áreas desagregadas.

6 COMPARAÇÃO DOS VALORES OBTIDOS COM OS DE OUTROS TRABALHOS NACIONAIS

6.1 Fator hora pico

6.1.1 Sexta-feira.

6.1.2 Sábado

6.2 Fator horário para análise de impacto viário

6.3 Tempo médio de permanência no estacionamento

6.4 Relação entre o número de viagens na sexta-feira e no sábado.

6.5 Função linear relacionando o número diário de viagens e o tamanho do empreendimento

6.5.1 Sexta-feira.

6.5.2 Sábado

7 MÉTODO PROPOSTO PARA DIMENSIONAR ALGUNS PARÂMETROS DE PROJETO DE SHOPPING CENTERS

7.1 Considerações iniciais

7.2 Estudo do dia de projeto.

7.3 Estudo da hora de projeto

7.3.1 Fatores de entrada.

7.3.2 Fatores de saída.

7.3.3 Fatores do total de entrada e saída 
7.3.4 Fatores de acúmulo de veículos.

7.3.5 Fatores de impacto viário

7.4 Estimativa do volume de viagens no sábado médio

7.5 Comparação dos resultados: método proposto x outros modelos desenvolvidos no país.

158

8 CONSIDERAÇÕES FINAIS...

167

REFERÊNCIAS BIBLIOGRÁFICAS.

171

BIBLIOGRAFIA CONSULTADA. 


\section{LISTA DE FIGURAS}

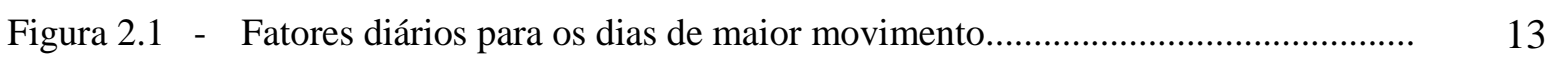

Figura 4.1 - Fluxos de entrada e saída para uma sexta-feira no shopping center "A".......... 48

Figura 4.2 - Fluxos de entrada e saída para um sábado no shopping center "A".................. 49

Figura 4.3 - Veículos acumulados no estacionamento no shopping center "A"................... 51

Figura 4.4 - Fluxos de entrada e saída para uma sexta-feira no shopping center "B"........... 56

Figura 4.5 - Fluxos de entrada e saída para um sábado no shopping center "B"................. 58

Figura 4.6 - Veículos acumulados no estacionamento no shopping center "B"................... 59

Figura 4.7 - Fluxos de entrada e saída para uma sexta-feira no shopping center "C" '........... 65

Figura 4.8 - Fluxos de entrada e saída para um sábado no shopping center "C" ".................. 66

Figura 4.9 - Veículos acumulados no estacionamento no shopping center "C"................... 67

Figura 4.10 - Fluxos de entrada para sexta-feira e sábado no shopping center "F"................ 74

Figura 5.1 - Relação entre as viagens diárias na sexta-feira e no sábado............................. 78

Figura 5.2 - Relação entre as viagens na sexta-feira e a área bruta locável.......................... 79

Figura 5.3 - Relação entre as viagens na sexta-feira e a área total construída....................... 80

Figura 5.4 - Relação entre as viagens no sábado e a área bruta locável................................ 82

Figura 5.5 - Relação entre as viagens no sábado e a área total construída.............................. 83

Figura 5.6 - Fator hora pico de entrada na sexta-feira........................................................ 84

Figura 5.7 - Fator hora pico de saída na sexta-feira.......................................................... 85

Figura 5.8 - Fator hora pico total na sexta-feira................................................................. 87

Figura 5.9 - Fator hora pico de entrada no sábado............................................................. 88

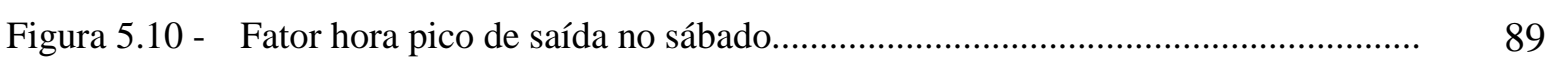

Figura 5.11 - Fator hora pico total no sábado................................................................... 90

Figura 5.12 - Fator horário de entrada no período das 18:00 às 19:00h.................................. 92

Figura 5.13 - Fator horário de saída no período das 18:00 às 19:00h...................................... 93

Figura 5.14 - Fator horário total no período das 18:00 às 19:00h........................................... 94

Figura 5.15 - Relação entre o acúmulo máximo de veículos e a área bruta locável................ 95

Figura 5.16 - Relação entre o acúmulo máximo de veículos e a área total construída............ 97 
Figura 5.17 - Relação entre o acúmulo máximo de veículos e viagens no sábado.................. 98

Figura 5.18 - Relação do tempo médio de permanência dos veículos no sábado..................... 99

Figura 5.19 - Relação entre o acúmulo máximo de veículos no estacionamento com o tempo médio de permanência e as viagens atraídas na hora pico do sábado....

Figura 6.1 - Relação de fatores hora pico na sexta-feira......................................................... 108

Figura 6.2 - Relação de fatores hora pico no sábado............................................................... 110

Figura 6.3 - Relação de fatores horários de entrada das 18:00 às 19:00h............................. 111

Figura 6.4 - Relação de fatores horários de saída das 18:00 às 19:00h................................. 113

Figura 6.5 - Relação de tempos médios de permanência de veículos no estacionamento.... 114

Figura 6.6 - Relação entre as viagens diárias da sexta-feira e do sábado................................ 115

Figura 6.7 - Relação das viagens diárias atraídas na sexta-feira observadas e estimadas pela 116 eq.(27) e modelos nacionais.

Figura 6.8 - Relação das viagens diárias atraídas na sexta-feira observadas e estimadas pelo modelo da CET-SP (2000).

Figura 6.9 - Relação das viagens diárias atraídas na sexta-feira observadas e estimadas pela 118 eq.(31) e modelos nacionais.

Figura 6.10 - Relação das viagens diárias atraídas no sábado observadas e estimadas pela eq.(28) e modelos nacionais.

Figura 6.11 - Relação das viagens diárias atraídas no sábado observadas e estimadas pelo modelo da CET-SP (2000)

Figura 7.1 - Fatores diários para os dias de maior movimento

Figura 7.2 - Fatores horários de entrada.

Figura 7.3 - Fatores de entrada.

Figura 7.4 - Relação dos fatores de entrada para as horas do ano de maior movimento......

Figura 7.5 - Fatores horários de saída.

Figura 7.6 - Fatores de saída.

Figura 7.7 - Relação dos fatores de saída para as horas do ano de maior movimento.

Figura 7.8 - Fatores horários do total de entrada e saída.

Figura 7.9 - Fatores do total de entrada e saída.

Figura 7.10 - Relação dos fatores do total de entrada e saída para as horas do ano de maior movimento.

Figura 7.11 - Fatores horários de acúmulo de veículos

Figura 7.12 - Fatores de acúmulo de veículos.

Figura 7.13 - Relação dos fatores de acúmulo para as horas do ano de maior movimento....

Figura 7.14 - Fatores de impacto para os dias e horas de maior movimento do ano.

Figura 7.15 - Volume de veículos no sábado.

Figura 7.16 - Volume de veículos na sexta-feira.

Figura 7.17 - Volume de chegadas na hora de projeto para dimensionamento da 


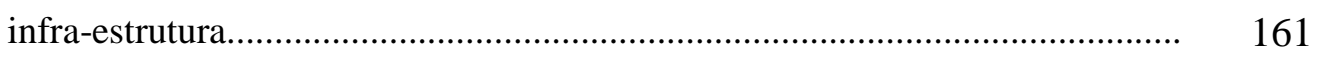

Figura 7.18 - Volume de saídas na hora de projeto para dimensionamento da infra-estrutura.................................................................................. 162

Figura 7.19 - Demanda por estacionamento na hora de projeto........................................... 163

Figura 7.20 - Volume de chegadas na hora de projeto para avaliação do impacto viário....... 164

Figura 7.21 - Volume de saídas na hora de projeto para avaliação do impacto viário............. 165 


\section{LISTA DE TABELAS}

Tabela 2.1 - Critérios utilizados para delimitar áreas de influência

Tabela 2.2 - Relação entre os fluxos nos dias de maior movimento e o sábado médio (VD/Vsm).

Tabela 2.3 - Fator dia típico de projeto (FD)................................................................. 14

Tabela 2.4 - Viagens geradas por hora em relação às viagens diárias (VH/VD)................ 16

Tabela 2.5 - Resumo de estudos de categorias de viagens................................................ 21

Tabela 4.1 - Período de funcionamento do shopping center "A" ".......................................... 46

Tabela 4.2 - Áreas por ramos de atividade para o shopping center "A" ............................. 46

Tabela 4.3 - Fluxos de entrada e saída para uma sexta-feira no shopping center "A"........ 47

Tabela 4.4 - Fluxos de entrada e saída para um sábado no shopping center "A"............... 49

Tabela 4.5 - Veículos acumulados no sábado no shopping center "A"............................... 50

Tabela 4.6 - Tempo de permanência dos veículos no shopping center "A"....................... 52

Tabela 4.7 - Permanência no estacionamento por fração horária no shopping center "A". 53

Tabela 4.8 - Período de funcionamento do shopping center "B"....................................... 55

Tabela 4.9 - Áreas por ramos de atividade para o shopping center "B" "............................. 55

Tabela 4.10 - Fluxos de entrada e saída para uma sexta-feira no shopping center "B"........ 56

Tabela 4.11 - Fluxos de entrada e saída para um sábado no shopping center "B"............... 57

Tabela 4.12 - Veículos acumulados no sábado no shopping center "B".............................. 59

Tabela 4.13 - Tempo de permanência dos veículos no shopping center "B"....................... 60

Tabela 4.14 - Permanência no estacionamento por fração horária no shopping center "B". 61

Tabela 4.15 - Período de funcionamento do shopping center " $\mathrm{C}$ " ........................................ 63

Tabela 4.16 - Áreas por ramos de atividade para o shopping center " $C$ " .............................. 63

Tabela 4.17 - Fluxos de entrada e saída para uma sexta-feira no shopping center "C"........ 64

Tabela 4.18 - Fluxos de entrada e saída para um sábado no shopping center "C"................ 65

Tabela 4.19 - Veículos acumulados no sábado no shopping center "C" "............................. 67

Tabela 4.20 - Tempo de permanência dos veículos no shopping center " $C$ "......................... 68

Tabela 4.21 - Permanência no estacionamento por fração horária no shopping center "C". 69

Tabela 4.22 - Período de funcionamento do shopping center "D"......................................... 71

Tabela 4.23 - Áreas por ramos de atividade para o shopping center "D" 
Tabela 4.24 - Período de funcionamento do shopping center "E". 72

Tabela 4.25 - Áreas por ramos de atividade para o shopping center "E"............................. 72

Tabela 4.26 - Período de funcionamento do shopping center "F"......................................... 73

Tabela 4.27 - Fluxos de entrada para sexta-feira e sábado no shopping center "F".............. 73

Tabela 4.28 - Síntese dos resultados obtidos nos shopping centers pesquisados.................... 75

Tabela 5.1 - Relação entre as viagens diárias realizadas na sexta-feira e no sábado........... 77

Tabela 5.2 - Relação entre as viagens geradas na sexta-feira e a área bruta locável........... 79

Tabela 5.3 - Relação entre as viagens geradas na sexta-feira e a área total construída....... 80

Tabela 5.4 - Relação entre as viagens geradas no sábado e a área bruta locável.................. 81

Tabela 5.5 - Relação entre as viagens geradas no sábado e a área total construída............. 82

Tabela 5.6 - Fator hora pico de entrada na sexta-feira (FHE sexta-feira)............................ 84

Tabela 5.7 - Fator hora pico de saída na sexta-feira (FHS sexta-feira)................................ 85

Tabela 5.8 - Fator hora pico total na sexta-feira (FHT sexta-feira)................................... 86

Tabela 5.9 - Fator hora pico de entrada no sábado (FHE sábado)..................................... 87

Tabela 5.10 - Fator hora pico de saída no sábado (FHS sábado).......................................... 89

Tabela 5.11 - Fator hora pico total no sábado (FHT sábado).............................................. 90

Tabela 5.12 - Fator horário de entrada no período das 18:00 às 19:00h $\left(\mathrm{FHE}_{18-19}\right) \ldots \ldots \ldots \ldots \ldots . . . . . . .91$

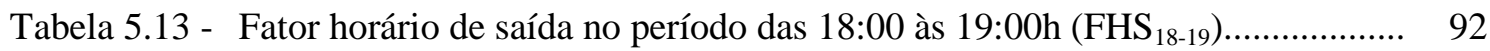

Tabela 5.14 - Fator horário total no período das 18:00 às 19:00h $\left(\mathrm{FHT}_{18-19}\right)$........................ 94

Tabela 5.15 - Relação entre o acúmulo máximo de veículos e a área bruta locável.............. 95

Tabela 5.16 - Relação entre o acúmulo máximo de veículos e a área total construída.......... 96

Tabela 5.17 - Relação entre o acúmulo máximo de veículos e as viagens no sábado........... 98

Tabela 5.18 - Relação do tempo médio de permanência dos veículos no sábado (Tm)........ 99

Tabela 5.19 - Relação entre o acúmulo máximo de veículos com o tempo médio de permanência e as viagens atraídas na hora pico do sábado.............................. 100

Tabela 5.20 - Resultado da calibração do primeiro modelo de regressão linear simples...... 103

Tabela 5.21 - Resultado da calibração do segundo modelo de regressão linear simples...... 104

Tabela 5.22 - Resultado da calibração do terceiro modelo de regressão linear simples....... 104

Tabela 5.23 - Resultado da calibração do quarto modelo de regressão linear simples......... 105

Tabela 5.24 - Distribuição das áreas por ramos de atividade nos shopping centers.............. 105

Tabela 5.25 - Resultado da calibração do primeiro modelo de regressão linear múltipla..... 106

Tabela 5.26 - Resultado da calibração do segundo modelo de regressão linear múltipla..... 106

Tabela 6.1 - Relação de fatores hora pico na sexta-feira (FHPsex)................................... 108

Tabela 6.2 - Relação de fatores hora pico no sábado (FHPsab)....................................... 110

Tabela 6.3 - Relação de fatores horários de entrada na sexta-feira $\left(\mathrm{FHE}_{18-19}\right)$.................... 111

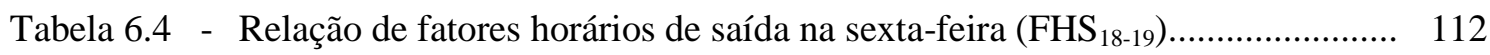

Tabela 6.5 - Relação de tempos médios de permanência de veículos (Tm)....................... 113 
Tabela 6.6 - Relação entre as viagens diárias da sexta-feira e do sábado (VDsex/VDsab). 115

Tabela 6.7 - Relação das viagens diárias atraídas na sexta-feira e desvios de estimativas do modelo da eq.(27) e modelos nacionais (VDsex).................................... 116

Tabela 6.8 - Relação das viagens diárias atraídas na sexta-feira e desvios de estimativas do modelo da CET-SP (2000) (VDsex)

Tabela 6.9 - Relação das viagens diárias atraídas na sexta-feira e desvios de estimativas do modelo da eq.(31) e modelos nacionais (VDsex).

Tabela 6.10 - Relação das viagens diárias atraídas no sábado e desvios de estimativas do modelo da eq.(28) e modelos nacionais (VDsab).

Tabela 6.11 - Relação das viagens diárias atraídas no sábado e desvios de estimativas do modelo da CET-SP (2000) (VDsab)

Tabela 7.1 - Fatores diários e desvios.

Tabela 7.2 - Fatores horários de entrada $\left(\mathrm{FHE}_{\mathrm{j}}^{\mathrm{sm}}\right)$.....

Tabela 7.3 - Fatores de entrada $\left(\mathrm{FHE}_{\mathrm{j}}^{\mathrm{i}}\right)$ 128

Tabela 7.4 - Relação dos fatores de entrada para as horas de maior movimento (FHE).... 129

Tabela 7.5 - Valores dos fatores de entrada x Número de horas não atendidas 131

Tabela 7.6 - Fatores horários de saída $\left(\mathrm{FHS}_{\mathrm{j}}^{\mathrm{sm}}\right)$ 134

Tabela 7.7 - Fatores de saída $\left(\mathrm{FHS}_{\mathrm{j}}{ }^{\mathrm{i}}\right)$ 135

Tabela 7.8 - Relação dos fatores de saída para as horas de maior movimento (FHS). 136

Tabela 7.9 - Valores dos fatores de saída x Número de horas não atendidas. 138

Tabela 7.10 - Fatores horários do total de entrada e saída $\left(\mathrm{FHT}_{\mathrm{j}}^{\mathrm{sm}}\right)$ 140

Tabela 7.11 - Fatores do total de entrada e saída $\left(\mathrm{FHT}_{\mathrm{j}}^{\mathrm{i}}\right)$ 142

Tabela 7.12 - Relação dos fatores do total para as horas de maior movimento (FHT)... 143

Tabela 7.13 - Valores dos fatores do total x Número de horas não atendidas. 145

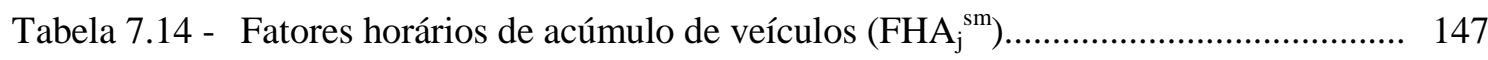

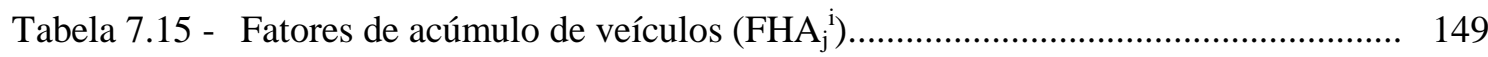

Tabela 7.16 - Relação dos fatores de acúmulo para as horas de maior movimento (FHA)... 150

Tabela 7.17 - Valores dos fatores de acúmulo x Número de horas não atendidas.................. 152

Tabela 7.18 - Fatores de impacto(FHI)........................................................................ 155

Tabela 7.19 - Valores dos fatores de impacto x Número de horas não atendidas................... 156

Tabela 7.20 - Síntese dos resultados obtidos...................................................................... 158 


\title{
LISTA DE ABREVIATURAS E SIGLAS
}

\author{
ABRASCE - Associação Brasileira de Shopping Centers \\ ABL - Área Bruta Locável \\ AC - Área Computável \\ ATC - Área Total Construída \\ AT - Área do Terreno \\ AV - Área de Vendas \\ CET - Companhia de Engenharia de Tráfego \\ DENATRAN - Departamento Nacional de Trânsito \\ EMBRAPLAN - Empresa Brasileira de Planejamento \\ FHGV - Fator Horário de Geração de Viagens \\ ICSC - International Council of Shopping Centers \\ ITE - Institute of Transportation Engineers \\ PPH - Porcentagem de Pico Horário \\ ULI - Urban Land Institute
}




\section{RESUMO}

BREVIS, C. C. B. (2003). Geração de viagens e demanda por estacionamento em shopping centers do interior do estado de São Paulo. São Carlos, 2003. 177p. Tese (Doutorado) Escola de Engenharia de São Carlos, Universidade de São Paulo.

Neste trabalho é apresentado estudo sobre a geração de viagens e a demanda por estacionamento em seis shopping centers localizados em cidades de porte médio do interior do estado de São Paulo. Em três deles foram realizadas pesquisas de campo detalhadas. Os outros três não permitiram a realização de pesquisas, mas forneceram dados globais sobre a geração de viagens e a demanda por estacionamento. Com base nos dados obtidos, são determinados os principais parâmetros relacionados com a geração de viagens e a demanda por estacionamento para cada um dos empreendimentos, bem como analisados os conjuntos de valores desses parâmetros utilizando conceitos básicos da Estatística. Na sequência, é verificado se os principais padrões de geração de viagem apresentados nos modelos desenvolvidos no país representam adequadamente a realidade no caso do universo estudado. Em seguida, à luz dos resultados obtidos nas pesquisas realizadas, dos resultados apresentados em outros trabalhos e das análises efetuadas, é proposto e desenvolvido um novo método para definir alguns parâmetros de projeto para shopping centers localizados no interior do estado de São Paulo. Por último, os principais parâmetros que caracterizam a geração de viagens e a demanda por estacionamento, obtidos com a aplicação do novo método proposto, são comparados com os valores fornecidos por outros modelos desenvolvidos no Brasil.

Palavras-chave: geração de viagens, demanda por estacionamento, shopping centers. 


\section{ABSTRACT}

BREVIS, C. C. B. (2003). Trip generation and parking demand in shopping centers in the country side of the state of Sao Paulo. São Carlos, 2003. 177p. Ph.D. Thesis - Escola de Engenharia de São Carlos, Universidade de São Paulo.

In this work, a study about trip generation and parking demand in six shopping centers located in Brazilian medium sized cities in the country side of the state of Sao Paulo is presented. In three of them detailed field researches were accomplished. The other three didn't allow the realization of researches, but they provided global data about trip generation and parking demand. Base on the obtained data, the main parameters related to the trip generation and parking demand for each one of the enterprises are determined, as well as, the group of results of those parameters using basic Statistics concepts are analyzed. In the sequence, it is verified if the main patterns for trips to the shopping centers and the new models developed at the country represent adequately the reality in the studied universe. Afterwards, due to the survey data collected in this study, to the results presented in other studies and to the effectuated analysis, a new method to measure some project parameters is developed and proposed for shopping centers located in Brazilian medium sized cities, in the country side of the state of Sao Paulo. Finally, the main parameters that characterize the trip generation and parking demand, obtained with the application of the new proposed method, are compared to the furnished values by other models developed in Brazil.

Keywords: trip generation, parking demand, shopping centers. 


\section{INTRODUÇÃO}

\subsection{RELEVÂNCIA}

Shopping centers são empreendimentos constituídos por um conjunto planejado de estabelecimentos que apresentam diversas atratividades, tais como: compras, lazer, alimentação, entre outros. Esses empreendimentos surgiram com o propósito de concentrar atividades em um mesmo local, com facilidade de acesso e estacionamento.

Atualmente, observa-se no Brasil um crescimento acelerado desses empreendimentos, não somente nas grandes cidades como também em cidades de médio porte. Segundo a ABRASCE (2003), existem 240 shopping centers no país, dos quais 27 localizam-se no estado do Rio de Janeiro e 61 no estado de São Paulo, representando 11,25\% e 25,42\%, respectivamente do total de shopping centers.

Dos empreendimentos localizados no estado de São Paulo, estado com maior número de shopping centers do país, aproximadamente 50\% (31 shopping centers) localizam-se em cidades de médio porte no interior do estado, representando $12,92 \%$ do total de empreendimentos no país.

Em algumas dessas cidades, a implantação de shopping centers vem gerando alguns problemas, tais como: impacto no trânsito das vias adjacentes, mau dimensionamento das instalações e equipamentos nos acessos de entrada e saída do estacionamento e da capacidade do estacionamento, provocando congestionamentos, filas e estacionamento irregular no entorno aos empreendimentos.

Essas questões têm assumido importância devido ao crescente aumento de shopping centers nos últimos anos, à integração de vários ramos de negócios para ampliar o público consumidor, e principalmente ao fato de existirem deficiências na legislação do país, na lei de zoneamento e código de edificações, com ausência de parâmetros e elementos de projeto para implantação de shopping centers na maioria das cidades; ainda, acrescenta-se a falta de planejamento urbano, o incremento de veículos na área urbana e o crescimento populacional. 
Alguns estudos vêm sendo realizados no país, no intuito de evitar ou amenizar esses problemas, principalmente nas grandes cidades do país, como identificados nos trabalhos de CET (1983), GRANDO (1986), GOLDNER (1994), CET (2000), DENATRAN (2001) e PORTUGAL \& GOLDNER (2003). No entanto, as cidades do interior do estado de São Paulo, principalmente as cidades de médio porte, onde a quantidade de shopping centers é representativa e o crescimento desses empreendimentos tem sido significativo, não existem estudos que definam padrões de viagens e representem o comportamento da demanda de veículos provocada pela implantação desses empreendimentos.

Nessas cidades, a maioria dos órgãos municipais carece de legislação para regulamentar os shopping center e os empreendedores carecem de conhecimentos que possibilitem minimizar o impacto provocado pela implantação desses empreendimentos, criando muitas vezes sérios problemas ao tráfego local, penalizando a população no seu entorno.

Nesse contexto, pressupõe-se que as viagens geradas por shopping centers dependem das características regionais das cidades onde esses empreendimentos foram implantados e pressupõe-se, ainda, que as cidades localizadas no interior do estado de São Paulo apresentam características semelhantes. Assim, considera-se apropriado realizar estudos em empreendimentos do interior do estado de São Paulo, de modo a identificar padrões de comportamento de viagens que possibilitem evitar o minimizar o impacto gerado pela implantação dos mesmos no meio urbano e possam definir elementos de projeto, principalmente para os acessos e capacidade do estacionamento.

\subsection{OBJETIVO}

Este trabalho tem como objetivos: identificar padrões da geração de viagens e da demanda por estacionamento em shopping centers localizados em cidades de porte médio do interior do estado de São Paulo; verificar se os modelos desenvolvidos no país, para estimativas da geração de viagens e demanda por estacionamento representam adequadamente a realidade do universo estudado; e, à luz dos resultados obtidos e das análises efetuadas, desenvolver novos modelos de geração de viagens e propor um novo método para definir parâmetros de projeto para avaliação do impacto viário, dimensionamento de instalações de acessos e capacidade do estacionamento de shopping centers localizados em cidades de médio porte, no interior do estado de São Paulo. 


\subsection{DESCRIÇÃO DO TRABALHO}

Inicialmente, neste capítulo 1, são colocados a relevância do tema, os objetivos da pesquisa e a forma como o trabalho foi desenvolvido e organizado.

No capítulo 2, é apresentada uma revisão bibliográfica sobre o assunto, a descrição dos principais modelos desenvolvidos no país para a estimativa da geração de viagens e da demanda por estacionamento em shopping centers, e uma análise da literatura pesquisada de forma a identificar e selecionar variáveis que interferem nas viagens geradas por shopping centers para realizar pesquisas de campo.

O terceiro capítulo contém a metodologia da pesquisa de campo a ser utilizada em três shopping centers, isto é, as variáveis a serem pesquisadas, as técnicas usadas para coleta de dados e os procedimentos para análise e processamento dos dados.

No capítulo 4 são apresentados os resultados das pesquisas de campo realizadas nos três shopping centers localizados em cidades de porte médio do interior do estado de São Paulo, bem como os dados globais fornecidos por outros três shopping centers também localizados no mesmo espaço geográfico. Também são determinados, para cada empreendimento, os principais parâmetros que caracterizam a geração de viagens e a demanda por estacionamento.

No capítulo 5 são analisados os conjuntos de valores desses parâmetros utilizando conceitos básicos da Estatística.

No sexto capítulo, os resultados dos principais padrões de viagens observados nos empreendimentos estudados são comparados com os valores propostos em outros trabalhos desenvolvidos no país.

À luz dos resultados obtidos e das análises efetuadas, no capítulo 7 é desenvolvido e proposto um novo método para definir parâmetros de projeto para avaliação do impacto viário, dimensionamento de instalações de acessos e capacidade do estacionamento de shopping centers localizados em cidades de médio porte, no interior do estado de São Paulo. Também neste capítulo, os principais parâmetros que caracterizam a geração de viagens e a demanda por estacionamento, obtidos com a aplicação do novo método proposto, são comparados com os valores fornecidos pelos modelos existentes no país.

No oitavo e último capítulo, são feitas algumas considerações que se tornaram relevantes no contexto do trabalho. 


\section{REVISÃO DA LITERATURA}

Neste capítulo é apresentada uma revisão bibliográfica da literatura que serviu de base de conhecimento para o trabalho realizado.

\subsection{SHOPPING CENTERS}

Os shopping centers são empreendimentos que surgiram como possibilidade de concentrar atividades de compras em um único local, com facilidade de acesso e estacionamento disponível, evitando e minimizando o tráfego de veículos nas áreas centrais das cidades, onde existe congestionamento e falta de estacionamento.

Segundo BARRET (1975), os shopping centers foram criados para atender a demanda por ambientes com tráfego desobstruído, acesso fácil e áreas de estacionamento adequadas, procurando oferecer aos seus clientes um sistema com todas as facilidades de acesso e estacionamento, situando-se geralmente em locais distantes do centro.

DICK $^{1}$ apud GONÇALVES (1990, p.7), define shopping center como um empreendimento comercial que oferece ao cliente as seguintes facilidades:

- Realizar compras num mesmo local e ao mesmo tempo;

- Comparar produtos e seus preços;

- Desfrutar de um local confortável e descontraído;

- Oferta de estacionamento em local próximo e de fácil acesso; e

- Carregamento de produtos de maneira rápida e segura.

Atendendo a esses propósitos, CONCEIÇÃO (1984) destaca que em 1966 foi implantado o primeiro shopping center no Brasil, e a partir daí a sua evolução foi progressiva.

\footnotetext{
${ }^{1}$ DICK, A. C. (1971). Transportation aspects of new shopping developments, Traffic Engineering and Control.
} 
Atualmente, segundo a Associação Brasileira de Shopping Centers, ABRASCE, existem 240 shopping centers no Brasil, 217 em operação e 23 em construção. Desses empreendimentos, 170 shopping centers são filiados a essa entidade que têm padronizado os mesmos com base na experiência americana, em acordo com o International Council of Shopping Centers, ICSC.

Os shopping centers surgiram inicialmente nos Estados Unidos, em 1956, e o sucesso e aceitação fez esses empreendimentos surgirem em outros países. Nos Estados Unidos existem aproximadamente 44.000 shopping centers, com incremento anual de 1,9\%, estando grande parte desses empreendimentos concentrada no estado da Califórnia: cerca de 6.000 unidades. O acelerado aumento de shopping centers naquele país fez surgir o ICSC, através do qual foram padronizados e classificados esses empreendimentos de acordo com a configuração arquitetônica, ramos de negócios oferecidos e tamanho do empreendimento.

No Brasil, visando os mesmos objetivos do ICSC, surgiu a ABRASCE, a qual tem definido os shopping centers como sendo "empreendimentos constituídos por um conjunto planejado de lojas destinadas à exploração de ramos diversificados ou especializados de comercio e prestação de serviços, oferecendo estacionamento compatível com a área de lojas e afluência de veículos".

A ABRASCE (2002) define seis principais tipos de shopping centers no Brasil: regional, comunitário, de vizinhança, especializado, outlet e festival center. Os principais determinantes em classificar estes centros são sua orientação mercadológica, tipo de produtos e serviços oferecidos e tamanho do empreendimento. A ABRASCE define esses centros como:

- Shopping Regional - Empreendimentos que oferecem mercadorias em geral (alta porcentagem de vestuário) e serviços completos e variados. Apresentam como atração principal lojas âncoras tradicionais, lojas de departamentos e/ou hipermercados. É geralmente fechado, com as lojas voltadas para um pátio interno. Atualmente, existem 94 empreendimentos desse tipo associados à ABRASCE.

- Shopping Comunitário - Empreendimentos que geralmente oferecem grande porcentagem de vestuário e outras mercadorias. Entre as lojas âncoras mais comuns estão os supermercados e lojas de departamentos, encontrando-se algumas vezes varejistas de "offprice" vendendo itens como roupas, objetos e móveis para casa, brinquedos, artigos eletrônicos e/ou artigos para esporte. Associados à ABRASCE, há 51 empreendimentos dessa classe.

- Shopping de Vizinhança - Empreendimentos que oferecem conveniência na compra de necessidades diárias. Apresentam como âncora um supermercado. A âncora tem o apoio de 
lojas oferecendo outros artigos de conveniência. Existem 12 empreendimentos associados à ABRASCE nessa categoria.

- Shopping Especializado - Empreendimentos que apresentam um mix específico de lojas de um determinado grupo de atividades, tais como: moda, decoração, náutica, esportes ou automóveis, entre outros. Associados à ABRASCE, há 8 shopping centers dessa espécie.

- Outlet Center - Empreendimentos que apresentam lojas de fabricantes vendendo suas próprias marcas com desconto, além de varejistas de "off-price". Existem 3 empreendimentos desse tipo associados à ABRASCE.

- Festival Center - Empreendimentos basicamente voltados para atividades de lazer, com restaurantes, "fast-food", cinemas e outras diversões. Localiza-se geralmente em áreas turísticas. Existem 2 empreendimentos associados à ABRASCE dessa classe.

Cabe notar, que a classificação de shopping centers apresentada somente faz referência aos diversos ramos de negócios oferecidos, não considerando a sua localização, área de influência e oferta de estacionamento; este último no que diz respeito a configuração e tamanho que, segundo a definição de shopping centers, deveria ser compatível à configuração e tamanho do empreendimento.

Segundo LIMA² apud CONCEIÇÃO (1984, p.44) “... torna-se difícil classificar os shopping center com relação aos seus padrões de localização, principalmente porque diferentes tipos de shopping centers se localizam em áreas com características iguais".

GRUEN \& SMITH $^{3}$ apud CONCEIÇÃO (1984, p.44) explicam que a localização é inerente a uma análise econômica, cujo estudo depende dos seguintes fatores: população, renda, poder de compra, facilidades competitivas, acessibilidade e outras considerações correlatas.

Visto a carência de padrões que definam mais aprimoradamente os shopping centers e a importância que assumem os mesmos na avaliação das viagens geradas, demanda por estacionamento e impacto do tráfego provocado, a seguir são apresentados alguns estudos realizados em shopping centers visando a sua análise e caracterização.

\footnotetext{
${ }^{2}$ LIMA FILHO, ALBERTO DE OLIVEIRA (1971). Shopping Centers - EUA vs Brasil - Uma Análise Mercadológica Comparativa. Rio de Janeiro, Fundação Getúlio Vargas, p.85.

${ }^{3}$ GRUEN, V. \& SMITH, L. (1960). Shopping Towns USA. New York. Reinhold. p.30.
} 


\section{2 ÁREA DE INFLUÊNCIA}

Dentro do contexto de pólos geradores de tráfego, a área de influência é de vital importância no que diz respeito às variáveis intervenientes na estimativa de geração de viagens e, conseqüentemente, na previsão da demanda por estacionamento e na avaliação do impacto de tráfego provocado por esses empreendimentos.

Existem diversas definições de áreas de influência, adotadas por alguns autores nacionais e internacionais, sendo algumas delas relacionadas a seguir:

- URBAN LAND INSTITUTE (1971) - Define a área de influencia ou área de mercado como sendo aquela área da qual se obtém a maior proporção de clientes atraídos pelo shopping center.

- CONCEIÇÃO (1984) - Adota o conceito da EMBRAPLAN ${ }^{4}$ que caracteriza a área de influência como sendo a "Área onde esta contida a maioria dos consumidores que irão fazer compras no shopping center. Na sua determinação considera: tempo de duração das viagens, barreiras naturais, limitação das distâncias, força e atratividade do futuro shopping center". E, concordando com o critério adotado por $\mathrm{ULI}^{5}$, subdivide esta área em três zonas ou áreas de influencia: área primária ${ }^{6}$, área secundária ${ }^{7}$ e área terciária ${ }^{8}$

- GRANDO (1986) - Adota o critério de KEEFER", o qual diz: “denomina-se área de influência de um shopping center, também conhecida como área de mercado, a área geograficamente definida, na qual um conjunto varejista atrai a maior parte de seus clientes". E acrescenta, ainda, algumas variáveis a serem consideradas para delimitação da área de influência, tais como: distância de viagem, tempo de viagem, barreiras físicas, distância ao centro da cidade e aos principais competidores e atratividade do futuro shopping center.

- SILVEIRA (1991) - Define como área de influência de um shopping center, a área que representa a "delimitação física do alcance do atendimento da maior parte de sua demanda".

${ }^{4}$ EMPRESA BRASILEIRA DE PLANEJAMENTO. (1981). Análise de mercado do Parkshopping de Brasília. Rio de Janeiro.

${ }^{5}$ URBAN LAND INSTITUTE. (1977). Shopping Center Development Handbook. Washington, D. C.

${ }^{6}$ Área na qual os consumidores têm como primeira opção de compra, em termos de acesso, o futuro shopping center, captando a maior parte da procura de mercadorias e serviços (bens de conveniência e bens de comparação).

${ }^{7}$ Área que se estende logo após a área primária, entre 15 e 20 km do shopping center.

${ }^{8}$ Área que se estende a partir da área secundária até $30 \mathrm{~km}$.

${ }^{9}$ KEEFER, L. E. (1966). Urban Travel Patterns for Airport, Shopping Centers and Industrial Plants. Highway Research Board, n.24. Washington, D. C. 
- GOLDNER (1994) - Destaca como área de influência aquela que representa a área geográfica da qual origina-se a maior parte dos consumidores e, conseqüentemente, das viagens ao shopping center - sendo a mesma delimitada pelo traçado de Isócronas ${ }^{10} \mathrm{e}$ Isócotas ${ }^{11}$, associado ainda ao levantamento do mercado competitivo obtido do estudo de viabilidade econômica.

Na Tabela 2.1 encontra-se um resumo dos critérios utilizados por diversos autores, nacionais e internacionais, para delimitar a área de influência e distribuição de viagens em shopping centers.

Tabela 2.1 - Critérios utilizados para delimitar áreas de influência.

\begin{tabular}{|c|c|c|c|c|c|}
\hline Critérios & Área primária & Área secundária & Área terciária & Fora da área & $\begin{array}{c}\text { Características do } \\
\text { shopping }\end{array}$ \\
\hline \multirow[t]{2}{*}{ Keefer (1966) } & \multicolumn{3}{|c|}{ até $8 \mathrm{~km}$} & & \\
\hline & \multicolumn{3}{|c|}{ até 20 minutos } & & \\
\hline $\begin{array}{l}\text { Urban Land } \\
\text { Institute(1971) }\end{array}$ & até 5 min. & 15 a $20 \mathrm{~min}$. & até $27 \mathrm{~min}$. & & \\
\hline \multirow{2}{*}{$\begin{array}{l}\text { Urban Land } \\
\text { Institute(1977) }\end{array}$} & 6 a $10 \mathrm{~km}$ & 15 a $20 \mathrm{~km}$ & até $30 \mathrm{~km}$ & & \\
\hline & até $10 \mathrm{~min}$. & 15 a $20 \mathrm{~min}$. & até $30 \mathrm{~min}$. & & \\
\hline \multirow[t]{2}{*}{ Rocca (1980) } & 4,8 a $8 \mathrm{~km}$ & $8 \mathrm{a} 11 \mathrm{~km}$ & $24 \mathrm{~km}$ & & \\
\hline & até $10 \mathrm{~min}$ & 15 a $20 \mathrm{~min}$ & até $30 \mathrm{~min}$. & & \\
\hline \multirow[t]{2}{*}{ CET/SP* (1983) } & \multicolumn{3}{|c|}{ até $5 \mathrm{~km}, 60 \%$ das viagens } & & \\
\hline & \multicolumn{3}{|c|}{ até $8 \mathrm{~km}, 80 \%$ das viagens } & & \\
\hline \multirow[t]{2}{*}{ Conceição* (1984) } & $6 \mathrm{a} 10 \mathrm{~km}$ & 15 a $20 \mathrm{~km}$ & até $30 \mathrm{~km}$ & & \\
\hline & até $10 \mathrm{~min}$. & 15 a 20 min. & até $30 \mathrm{~min}$. & & \\
\hline \multirow{2}{*}{$\begin{array}{l}\text { Dunn e Hamilton } \\
\text { (1986) }\end{array}$} & \multicolumn{3}{|c|}{ de $80 \%$ a $90 \%$ das vendas } & & \\
\hline & até $10 \mathrm{~min}$. & 10 a $20 \mathrm{~min}$. & 20 a $30 \mathrm{~min}$ & & \\
\hline \multirow[t]{2}{*}{ Grando* (1986) } & $45 \%$ das viagens & $40 \%$ das viagens & $8,3 \%$ das viagens & $\begin{array}{c}6,7 \% \text { das } \\
\text { viagens }\end{array}$ & \\
\hline & até $10 \mathrm{~min}$. & 10 a $20 \mathrm{~min}$. & $20 \mathrm{a} 30 \mathrm{~min}$ & & \\
\hline \multirow[t]{2}{*}{ Soares* (1990) } & até $8 \mathrm{~km}$ & 8 a $11 \mathrm{~km}$ & até $24 \mathrm{~km}$ & & \\
\hline & até $10 \mathrm{~min}$. & 10 a $20 \mathrm{~min}$. & 20 a $30 \mathrm{~min}$ & & \\
\hline \multirow[t]{2}{*}{ Silveira* (1991) } & $\begin{array}{c}37,7 \% \text { das } \\
\text { viagens }\end{array}$ & $24,5 \%$ das viagens & $\begin{array}{c}20,8 \% \text { das } \\
\text { viagens }\end{array}$ & $17 \%$ das viagens & \\
\hline & até $10 \mathrm{~min}$. & 10 a $20 \mathrm{~min}$. & 20 a $30 \mathrm{~min}$ & & \\
\hline \multirow[t]{3}{*}{ Goldner* (1994) } & $\begin{array}{c}55,4 \% \text { das } \\
\text { viagens }\end{array}$ & $36,2 \%$ das viagens & $7,2 \%$ das viagens & $\begin{array}{l}1,2 \% \text { das } \\
\text { viagens }\end{array}$ & dentro da área urbana \\
\hline & $\begin{array}{c}48,3 \% \text { das } \\
\text { viagens }\end{array}$ & $20,1 \%$ das viagens & $\begin{array}{c}18,3 \% \text { das } \\
\text { viagens }\end{array}$ & $\begin{array}{c}13,3 \% \text { das } \\
\text { viagens }\end{array}$ & fora da área urbana \\
\hline & até $10 \mathrm{~min}$. & 10 a $20 \mathrm{~min}$. & 20 a $30 \mathrm{~min}$ & & \\
\hline \multirow[t]{3}{*}{ Martins (1996) } & \multicolumn{3}{|c|}{$83 \%$ das viagens até $2 \mathrm{~km}$} & $17 \%$ das viagens & $\begin{array}{l}\text { com escritórios, localizado } \\
\text { em área residencial. }\end{array}$ \\
\hline & \multicolumn{3}{|c|}{$\begin{array}{l}34 \% \text { das viagens até } 1 \mathrm{~km} \\
17 \% \text { das viagens de } 1 \text { a } 3 \mathrm{~km} \\
18 \% \text { das viagens de } 3 \text { a } 5 \mathrm{~km} \\
29 \% \text { das viagens de } 5 \text { a } 17 \mathrm{~km}\end{array}$} & $2 \%$ das viagens & $\begin{array}{l}\text { com escritórios, localizado } \\
\text { em área comercial. }\end{array}$ \\
\hline & \multicolumn{3}{|c|}{$95 \%$ das viagens } & $5 \%$ das viagens & $\begin{array}{l}\text { localizado em área } \\
\text { comercial }\end{array}$ \\
\hline $\begin{array}{l}\text { Correa e Goldner* } \\
(1999)\end{array}$ & 5 a $10 \mathrm{~min}$. & 10 a $20 \mathrm{~min}$. & 20 a $30 \mathrm{~min}$ & & \\
\hline
\end{tabular}

Nota: *autores brasileiros.

${ }^{10}$ Linhas de tempo iguais, marcadas de 5 em 5 minutos até o tempo de 20 a 30 minutos.

${ }^{11}$ Linhas de distâncias iguais, traçadas de $1 \mathrm{em} 1 \mathrm{~km}$ como um circulo cujo centro é o local onde situa-se o shopping center, normalmente até $8 \mathrm{~km}$. 
Segundo CORREA e GOLDNER (1999), em shopping centers nas cidades de médio porte, sem um shopping center competidor dentro da isócrona de 20 minutos e com área total construída entre 30.000 a $85.000 \mathrm{~m}^{2}$, as áreas de influência apresentam as seguintes características:

- Área primária - O usuário atinge o shopping center entre 5 a 10 minutos de viagem por automóvel, variando com as condições apresentadas pelo tráfego e o acesso da região. O principal centro de comércio da cidade e pólos geradores de tráfego que venham a apresentar concorrência direta ao futuro shopping center não devem fazer parte desta área. A população residente nesta área tem renda elevada e pertence a classes sociais média e alta. A densidade residencial é elevada; e a oferta de transporte coletivo por ônibus e o índice de motorização deverão ser elevados.

- Área secundária - O usuário atinge o shopping center entre 10 a 20 minutos de viagem por automóvel, variando em função das condições apresentadas pelo tráfego e vias de acesso da região. Subdividida em área $A$ e $B$. A área $A$ é próxima ao principal centro comercial da cidade, apresenta população com renda elevada e classe social média e alta (com a alta em menor índice); boa oferta de transporte coletivo e alguns estabelecimentos comerciais na região. A área $B$ não engloba o principal centro de comercio da cidade, não apresenta outros pólos concorrentes; apresenta área residencial densamente povoada e população pertencente à classe média e baixa (com a média em maior índice).

- Área terciária - O usuário atinge o shopping center entre 20 a 30 minutos de viagem por automóvel, variando com as condições apresentadas pelo tráfego e as vias de acesso à região. Subdividida em área $A$ e $B$. A área $A$ abrange o principal centro de comercio da cidade, região altamente comercial, podendo apresentar áreas residenciais pouco densas, apresenta população pertencente à classe social média e alta (com a média em maior índice). A área $B$ possui comercio local altamente competitivo, como hipermercados, supermercados, complexos de lojas e outros tipos de comercio em geral, apresenta população pertencente à classe social média e baixa (com a média em maior índice), com áreas de elevada densidade residencial.

Os critérios descritos apresentam discrepâncias no cálculo das áreas de influência, considerando como variáveis a distância ao shopping center, tempo de viagem por automóvel, localização do empreendimento e distribuição de viagens. Constata-se uma abrangência máxima da área de influência de até $30 \mathrm{~km}$ em torno a um shopping center, 30 minutos de tempo de viagem por automóvel e $98 \%$ das viagens para shopping centers dentro da área urbana. As diferenças constatadas nos valores apresentados pressupõem-se que se devam às características dos empreendimentos, tipo de atratividade, características da população local, 
características do sistema de transportes e características espaciais das cidades, não definidas nos critérios adotados.

\subsection{PADRÕES DE VIAGEM}

Os padrões de viagem correspondem às principais características qualitativas das viagens, que permitem conhecer aspectos do transporte de pessoas e mercadorias.

KEEFER $^{12}$ apud GRANDO (1986, p.13), analisando shopping centers nos Estados Unidos, considerou que as viagens a esses empreendimentos podem ser sub-divididas em:

- Viagens de veículos de carga e táxi.

- Viagens de trabalho, calculando a distribuição das viagens por grupo ocupacional: funcionários administrativos, técnicos, vendedores, operários e outros.

- Viagens de compras, calculando a distribuição das viagens por sexo dos viajantes: homens e mulheres; e a distribuição das viagens por origem: casa, trabalho, compras, escola, lazer, refeição, negócios pessoais, médico, dentista e passageiros em serviço.

- Viagens com outros propósitos, tais como lazer, negócios pessoais, passageiros em serviço, escola e refeição.

Tendo em vista essas características, GRANDO (1986) detectou deficiências em estudos sobre as características de viagem dos shopping centers no Brasil.

Segundo SILVEIRA (1991), os padrões de viagem que caracterizam as viagens geradas por shopping centers são:

- Dia da semana e período do dia que registra maior número de viagens;

- Distribuição das viagens segundo a classe sócio-econômica dos clientes;

- Distribuição das viagens por modo de transporte;

- Distribuição das viagens segundo a origem;

- Distribuição de viagem segundo o destino; e

- Distribuição das viagens segundo o motivo ou propósito que as originou.

${ }^{12}$ KEEFER, R.W. (1966). Urban travel patterns for airports, shopping centers and industrial plants. Highway Research Record. N.24, p.33-116. Washington D. C. 
SILVEIRA (1991) destaca ainda que essas características contribuem ao planejamento urbano e de transporte na adoção de medidas disciplinares adequadas e para evitar ou minimizar os possíveis impactos ambientais relacionados.

Para GOLDNER (1994), os padrões de viagem correspondem à:

- Distribuição de viagem por classe econômica;

- Distribuição de viagem por origem;

- Distribuição de viagem por destino;

- Distribuição de viagem por motivo ou propósito; e

- Dia da semana e período do dia que registra maior número de viagens.

Segundo HARRIS \& ANDREW ${ }^{13}$ apud PORTUGAL \& GOLDNER (2003, p.208), os fatores que atraem os compradores aos shopping centers são:

- Preços baixos;

- Variedade de mercadorias;

- Facilidade de estacionamento; e

- Conveniente localização.

Dessa forma, conclui-se que os padrões de viagem caracterizam as viagens quanto a flutuações da geração de viagens e distribuição das viagens, relacionadas às características do empreendimento, usuário e transporte.

\subsection{VARIAÇÕES DA DEMANDA DE VIAGENS}

Através de análise dos dados sobre os movimentos diários de viagens por automóvel nos anos de 1983 e 1984 no shopping center Rio Sul, no estado do Rio de Janeiro, GRANDO (1986) verificou que a demanda de viagens de um shopping center sofre variações em função do mês, do dia e do horário. A autora constatou que:

- O mês de maior movimento é dezembro, principalmente na semana que antecede o Natal;

- Durante a semana, a sexta feira e o sábado são os dias mais movimentados, sendo o sábado o dia de maior movimento;

- Existem diferenças razoáveis entre o movimento do dia médio de sábado em relação ao movimento médio diário; e

\footnotetext{
${ }^{13}$ HARRIS, M. R. \& ANDREW, H. R. (1979). The traffic implications of hypermarket development. Traffic Engineering and Control, Londres, Jan.
} 
- A hora de maior movimento varia em função do dia da semana e do horário de funcionamento do shopping center.

\subsubsection{DIA DE PROJETO}

Na movimentação diária de veículos no shopping center Rio Sul, nos anos de 1983 e 1984, GRANDO (1986) identificou o dia típico de projeto. Ao relacionar o movimento diário com o volume do sábado médio verificou que essa relação representava uma curva que se assemelhava a uma hipérbole, mostrando que o volume no dia de maior movimento chega a ser 2,3 vezes maior que o volume médio diário e que durante mais de 45 dias no ano o volume diário é maior que o volume médio diário. Isso também foi constatado pela autora no shopping center Recife, no ano de 1985, no estado de Pernambuco. A autora identificou, ainda, que existem diferenças razoáveis entre o movimento diário e o movimento do sábado médio. Esses valores são apresentados na Tabela 2.2 e representados graficamente na Figura 2.1.

Tabela 2.2 - Relação entre os fluxos nos dias de maior movimento e o sábado médio (VD/Vsm)

\begin{tabular}{|c|c|c|c|}
\hline \multirow{2}{*}{ Dia } & \multicolumn{3}{|c|}{ FD = VD / Vsm } \\
\hline & S. C. Rio Sul (1983) & S. C. Rio Sul (1984) & S. C. Recife (1985) \\
\hline 1 & 1,86 & 1,68 & 1,83 \\
\hline 2 & 1,84 & 1,65 & 1,54 \\
\hline 3 & 1,82 & 1,50 & 1,51 \\
\hline 4 & 1,79 & 1,49 & 1,41 \\
\hline 5 & 1,75 & 1,43 & 1,40 \\
\hline 6 & 1,64 & 1,39 & 1,38 \\
\hline 7 & 1,58 & 1,37 & 1,33 \\
\hline 8 & 1,56 & 1,34 & 1,32 \\
\hline 9 & 1,54 & 1,33 & 1,30 \\
\hline 10 & 1,50 & 1,31 & 1,28 \\
\hline 11 & 1,36 & 1,30 & 1,26 \\
\hline 12 & 1,34 & 1,28 & 1,25 \\
\hline 13 & 1,30 & 1,27 & 1,24 \\
\hline 14 & 1,29 & 1,26 & 1,22 \\
\hline 15 & 1,28 & 1,24 & 1,17 \\
\hline 16 & 1,24 & 1,23 & 1,17 \\
\hline 17 & 1,24 & 1,16 & 1,12 \\
\hline 18 & 1,22 & 1,15 & 1,11 \\
\hline 19 & 1,20 & 1,14 & 1,09 \\
\hline 20 & 1,16 & 1,14 & 1,07 \\
\hline 21 & 1,15 & 1,13 & 1,06 \\
\hline 22 & 1,14 & 1,12 & 1,06 \\
\hline 23 & 1,13 & 1,11 & 1,05 \\
\hline 24 & 1,12 & 1,10 & 1,05 \\
\hline 25 & 1,12 & 1,07 & 1,05 \\
\hline 26 & 1,10 & 1,05 & 1,05 \\
\hline 27 & 1,09 & 1,04 & 1,05 \\
\hline 28 & 1,06 & 1,03 & 1,04 \\
\hline 29 & 1,04 & 1,02 & 1,04 \\
\hline 30 & 1,03 & 1,02 & 1,04 \\
\hline 31 & 1,02 & 1,01 & 1,03 \\
\hline 32 & 1,02 & 1,01 & 1,02 \\
\hline 33 & 1,02 & 1,00 & 1,02 \\
\hline 34 & 1,00 & 1,00 & 1,02 \\
\hline 35 & 0,99 & 1,00 & 1,02 \\
\hline 36 & 0,98 & 0,99 & 1,02 \\
\hline 37 & 0,95 & 0,99 & 1,01 \\
\hline 38 & 0,95 & 0,99 & 1,01 \\
\hline 39 & 0,94 & 0,98 & 1,01 \\
\hline 40 & 0,94 & 0,98 & 1,00 \\
\hline 41 & 0,93 & 0,98 & 0,99 \\
\hline
\end{tabular}




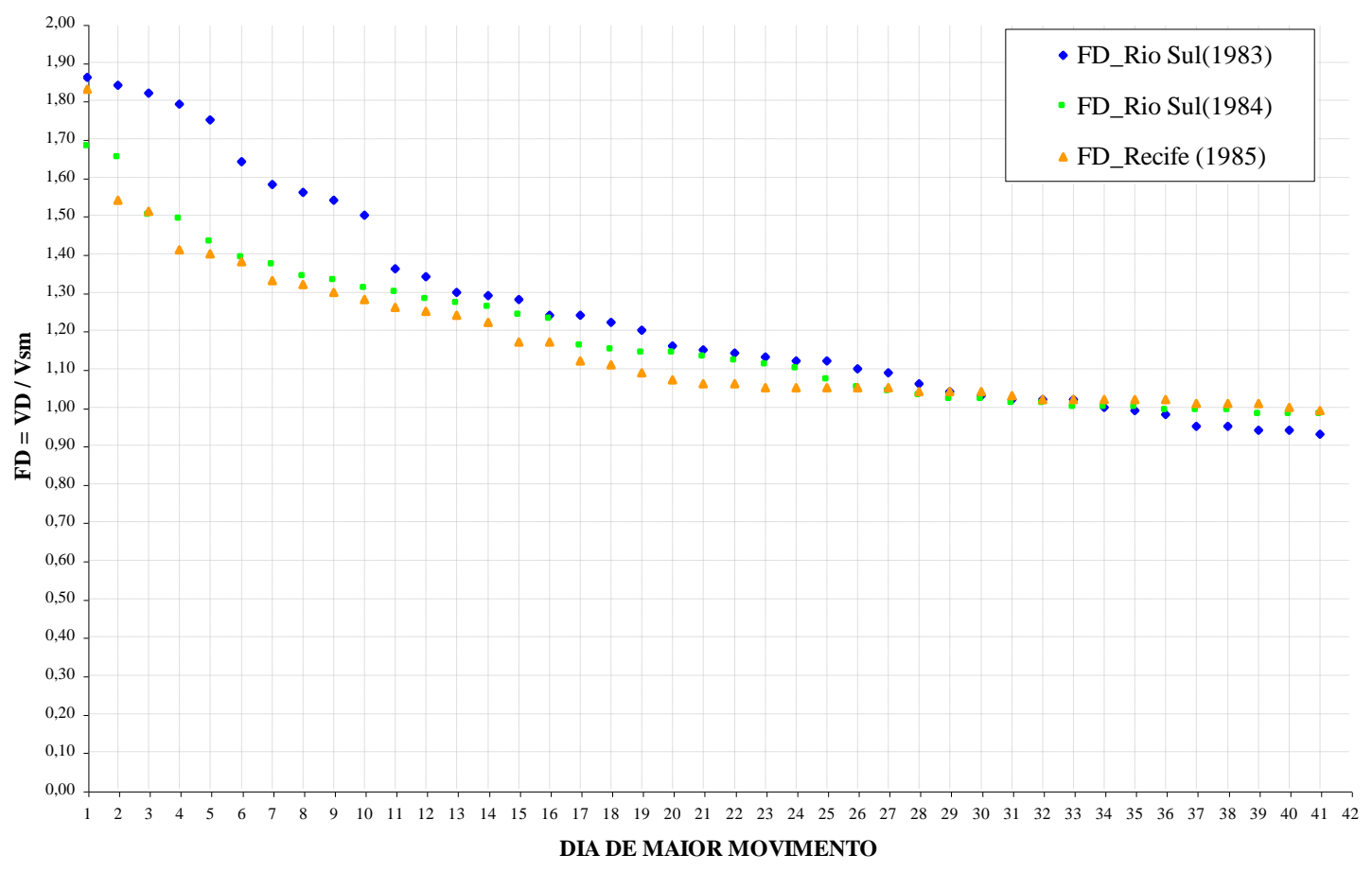

Figura 2.1 - Fatores diários para os dias de maior movimento.

A autora definiu como fator dia típico de projeto (FD) a relação do movimento diário de veículos com o volume do sábado médio, atendendo à seguinte equação:

$$
V D=F D \times V s m
$$

Sendo, Vsm: volume de viagens no sábado médio [viagens/dia].

$F D$ : fator dia típico de projeto.

$V D$ : volume diário de projeto [viagens/dia].

Fazendo analogia com o método de dimensionamento de terminais rodoviários proposto por MESQUITA ${ }^{14}$ apud GRANDO (1986, p.100), o qual sugere o $37^{0}$ dia mais carregado como o dia típico de projeto, ficando apenas $10 \%$ da demanda anual não atendida, Grando constatou, através da movimentação diária de veículos no shopping center Rio Sul, que o movimento do $37^{0}$ dia mais carregado em relação ao sábado médio é inadequado para o dimensionamento do número ótimo de vagas de estacionamento, sendo satisfatório somente para análise do impacto no sistema viário.

Em analogia com o dimensionamento de rodovias, que procura o ponto de inflexão da curva para a definição da hora de projeto (no caso $30^{\mathrm{a}}$ hora),

14 MESQUITA, L. B. (1981). Dimensionamento de plataformas de embarque e desembarque em terminais rodoviários de passageiros. Tese de Mestrado, USP. 
VOORHEES \& CROW (1966), em pesquisas realizadas em shopping centers nos Estados Unidos, para o Urban Land Institute, ULI, identificaram que a $30^{\mathrm{a}}$ maior hora de demanda corresponde aproximadamente ao $6^{\underline{0}}$ dia mais movimentado. Esses autores consideraram como hora de projeto a $10^{\mathrm{a}}$ maior hora de volume de tráfego.

No entanto, estudos mais recentes realizados por ULI (1982) recomendam a diminuição do índice anterior e sugerem a $19^{\mathrm{a}}$ maior hora do ano como hora de projeto.

Contudo, GRANDO (1986) assume como dia de projeto para o dimensionamento do número mínimo de vagas a média dos sábados do ano, pois permite atender $90 \%$ da demanda anual do shopping center; $60 \%$ dos valores dos sábados do ano estão acima do valor médio diário e apenas em $9 \%$ dos dias do ano o volume diário é maior que o volume médio do sábado. Para o dimensionamento do número ótimo de vagas de estacionamento a autora sugere entre o $5^{-0}$ e o $10^{0}$ dia mais movimentado como dia de projeto, ficando em torno de $3 \%$ dos dias do ano não atendidos pela demanda.

$\mathrm{Na}$ movimentação diária dos shopping centers pesquisados por GRANDO (1986), entre o $5^{\underline{0}}$ e o $10^{\underline{0}}$ dia mais movimentado, a autora identificou os fatores diários mostrados na Tabela 2.3.

Tabela 2.3 - Fator dia típico de projeto (FD).

\begin{tabular}{|c|c|c|}
\hline \multirow{2}{*}{ Shopping center } & \multicolumn{2}{|c|}{ FD } \\
\cline { 2 - 3 } & Variação entre o 10 $\mathbf{0}$ e o 50 $\mathbf{~ d i a}$ & média \\
\hline Rio Sul (1983) & $1,50-1,64$ & 1,57 \\
\hline Rio Sul (1984) & $1,31-1,43$ & 1,37 \\
\hline Recife (1985) & $1,28-1,40$ & 1,34 \\
\hline
\end{tabular}

Para estimar o impacto de tráfego provocado pelo shopping center, Grando assume como dia de projeto a sexta feira média do ano, pois neste dia se superpõem o já elevado movimento natural de veículos com o tráfego gerado pelo shopping center.

GOLDNER (1994), em estudo realizado no Norteshopping, no estado do Rio de Janeiro, nos anos de 1988 a 1989, identificou que a movimentação diária de veículos apresentava um comportamento similar aos empreendimentos estudados por GRANDO (1986). Assim, define também como dias típicos de projeto o sábado médio e a sexta-feira média. $\mathrm{O}$ sábado para ser usado no dimensionamento do estacionamento, por ser o dia de maior movimento da semana, e a sexta-feira para avaliação do impacto do shopping center na via, por ser o dia em que o tráfego nas vias do entorno é maior, tornando a situação mais crítica. 


\subsubsection{HORA DE PROJETO}

Para uma amostra de dados obtidos de 13 shopping centers, localizados nas capitais das maiores cidades do país, e associados à ABRASCE, GRANDO (1986) define um fator hora de projeto ou fator hora de pico. Esse fator relaciona o volume horário de projeto com o volume do dia típico de projeto (para o estacionamento) ou com o volume do sábado médio (para o impacto no sistema viário), como apresentado a seguir.

$$
V H P=F H \times V D
$$

Sendo, VHP: volume horário de projeto para o estacionamento [viagens/hora].

$F H$ : fator hora de pico.

$V D$ : volume diário de projeto [viagens/dia].

$$
V H I=F H \times V s m
$$

Sendo, VHI: volume horário de projeto para o impacto no sistema viário [viagens/hora].

$F H$ : fator hora de projeto.

Vsm: volume do sábado médio [viagens/dia].

Para a amostra estudada pela autora, os valores para o fator hora típica de projeto variaram entre $6,83 \%$ e $13,3 \%$, com média de $10,5 \%$.

GRANDO (1986), nos empreendimentos por ela pesquisados, observou que o pico de entrada no sábado ocorre entre 16:00 e 18:00h e na sexta-feira o horário de pico é menos definido, variando entre 13:00 e 20:00h. Identificou, ainda, no shopping center Recife, localizado no estado de Pernambuco, que as viagens de saída na hora pico de entrada representam aproximadamente $80 \%$ do fluxo de entrada. Assim, sugere para sexta-feira o horário entre 17:00 e 18:00h, buscando a coincidência com o pico da rodovia, ou utilizar o valor médio de $10,5 \%$ como fator horário, para os fluxos de entrada de veículos na sexta-feira e no sábado.

GOLDNER (1994), visando aperfeiçoar os estudos realizados por Grando, identificou que na sexta-feira o horário de maior movimento é entre 19:00 e 20:00h, para empreendimentos localizados na cidade do Rio de Janeiro, quando o tráfego da via já esta bem diluído, correspondendo a 10,11\% do fluxo total, para avaliação do impacto de shopping centers no sistema viário dentro da área urbana. Nessas condições sugere a utilização da porcentagem de pico horário entre 18:00 e 19:00h, que apresenta o valor médio de 9,88\%, constatado em estudo realizado no shopping center Rio Sul, e que a contagem na via seja feita no mesmo horário, considerando que nesse horário o fluxo da via apresenta-se pouco diluído. 
Para sábado, no mesmo empreendimento, localizado dentro da área urbana na cidade do Rio de Janeiro, Goldner identificou dois picos de entrada: um pela manhã, das 11:00 às 12:00h, com valor médio de 8,29\% e outro à tarde, das 18:00 às 19:00h, com valor médio de $8,98 \%$. Portanto, sugere que se realize um estudo completo de tráfego, confrontando o pico de compras com o pico da via, adicionando-os para obter o impacto global. Para empreendimentos localizados fora da área urbana sugere que se utilize o valor adotado por GRANDO (1986). E, para o pico de saída sugere, também, adotar a relação obtida por Grando de $80 \%$ do fluxo de entrada na hora pico.

A CET-SP (2000), para obter o volume horário de veículos gerado pelo shopping center ( $\mathrm{VH})$, sugere identificar os dias e períodos de interesse através dos valores dos fatores horários médios (FH), apresentados na Tabela 2.4, obtidos através de registros realizados em três empreendimentos na cidade de São Paulo, que correspondem às viagens horárias de entrada ou saída em relação às viagens diárias (VD), para sexta-feira e sábado.

Tabela 2.4 - Viagens geradas por hora em relação às viagens diárias (VH/VD).

\begin{tabular}{|c|c|c|c|c|}
\hline \multirow{2}{*}{ Período [hora] } & \multicolumn{4}{|c|}{ FH [\%] = ( VH / VD ) x 100 } \\
\cline { 2 - 5 } & \multicolumn{2}{|c|}{ FH [\%] para sexta-feira } & \multicolumn{2}{c|}{ FH [\%] para sábado } \\
\cline { 2 - 5 } & entrada & saída & entrada & saída \\
\hline $09: 00-10: 00$ & 1,25 & 0,09 & 1,57 & ----- \\
\hline $10: 00-11: 00$ & 6,04 & 1,56 & 6,09 & 3,66 \\
\hline $11: 00-12: 00$ & 7,05 & 3,96 & 7,07 & 5,78 \\
\hline $12: 00-13: 00$ & 8,89 & 6,06 & 8,54 & 6,91 \\
\hline $13: 00-14: 00$ & 8,74 & 6,57 & 8,85 & 7,53 \\
\hline $14: 00-15: 00$ & 8,68 & 8,55 & 8,72 & 8,97 \\
\hline $15: 00-16: 00$ & 8,79 & 6,82 & 9,77 & 8,74 \\
\hline $16: 00-17: 00$ & 6,95 & 8,67 & 8,40 & 8,93 \\
\hline $17: 00-18: 00$ & 6,76 & 9,19 & 9,04 & 10,18 \\
\hline $18: 00-19: 00$ & 9,42 & 7,78 & 8,58 & 7,87 \\
\hline $19: 00-20: 00$ & 12,88 & 9,45 & 8,47 & 7,89 \\
\hline $20: 00-21: 00$ & 9,78 & 11,09 & 9,15 & 8,95 \\
\hline $21: 00-22: 00$ & 4,77 & 12,48 & 5,83 & 100,00 \\
\hline total & 100,00 & 100,00 & 100,00 & \\
\hline
\end{tabular}

Fonte: CET-SP (2000)

Assim, identificado o valor das viagens horárias em relação às viagens diárias, CET-SP (2000) sugere aplicar a seguinte equação para o fluxo de veículos gerado pelo shopping center:

$$
V H=F H \times V D
$$

Sendo, $V H$ : volume horário de veículos gerado pelo shopping center, na sexta-feira ou no sábado, para análise de impacto viário [viagens/hora].

$F H$ : fator horário ou viagens geradas por hora em relação às viagens diárias.

$V D$ : viagens diárias geradas pelo shopping center, na sexta-feira ou no sábado [viagens/dia]. 


\subsection{GERAÇÃO DE VIAGENS}

A estimativa do número de viagens de automóvel atraídas por shopping centers é essencial para poder relacionar a intensidade de viagens de e para o empreendimento, dimensionar adequadamente os estacionamentos e avaliar o impacto de tráfego provocado por esses empreendimentos.

$\mathrm{Na}$ literatura pesquisada, os modelos de geração de viagens variam desde modelos de regressão linear simples a modelos dinâmicos, mais sofisticados. No Brasil, ainda são escassos os dados sobre geração de viagens para shopping centers.

Para a CET-SP (1983), o número médio de viagens de automóvel atraídas por um pólo gerador de tráfego na hora de pico, para qualquer dia é estimado pelo seguinte modelo:

$$
V H P=(0,124 A T C+1.550) 0,25
$$

Sendo, VHP: viagens atraídas pelo shopping center na hora pico [viagens/hora] $A T C$ : área total construída $\left[\mathrm{m}^{2}\right]$

Segundo CONCEIÇÃO (1984), baseado em dados estatísticos disponíveis, o valor do número de viagens geradas por dia nos shopping centers no Brasil, está compreendido entre 22 e 36 viagens por $100 \mathrm{~m}^{2}$ de Área Bruta Locável ${ }^{15}$ (ABL), variando com as características de cada empreendimento. Para o autor, a geração de viagens atraídas por shopping centers é função do tipo de lojas no empreendimento, da população e renda da área de influência, das facilidades de transporte e do tempo de viagem.

GRANDO (1986) sugere modelos econométricos de geração de viagens para o dia de projeto, isto é, para a média dos sábados do ano; e definir o horário do pico de entrada e saída do empreendimento, assim como o volume horário de projeto para a sexta-feira e o sábado, identificados como os dias de maior frequiência. Sendo os dados de sexta-feira utilizados para avaliar o impacto urbano e os de sábado para dimensionar o estacionamento de shopping centers. Os modelos sugeridos pela autora são de regressão linear simples, relacionando a geração de viagens com o tamanho do empreendimento, diferenciados quanto ao dia e estimados para qualquer empreendimento, independente da sua localização, baseada em amostras a nível nacional. Esses modelos são traduzidos pelas equações:

15 definida como a área bruta de cada loja, incluindo a área de vendas e de depósito, de administração, sanitários e outros que estejam dentro ou fora da loja, desde que descritos no contrato de locação. 


$$
\begin{gathered}
V s m=-2.066,639+0,3968842 A B L \\
V s e x m=0,74 \mathrm{Vsm}
\end{gathered}
$$

Sendo, Vsm: fluxo de veículos atraídos pelo shopping center no sábado médio [viagens/dia] $\left(\right.$ com $\mathrm{R}^{2}=0,785$; erro padrão $=3889,4$; teste $\mathrm{t}=5,72>\mathrm{t}_{\min }=1,94$; teste $\left.\mathrm{F}=32,73>\mathrm{F}_{\min }=5,99\right)$;

Vsexm: fluxo de veículos atraídos pelo shopping center na sexta-feira média do ano [viagens/dia]; e

$A B L$ : área bruta locável $\left[\mathrm{m}^{2}\right]$

Cabe destacar que o valor definido por GRANDO (1986), para a relação entre os fluxos de veículos na sexta-feira e no sábado, de 0,74 , corresponde a um valor médio obtido através dos valores apresentados em 13 empreendimentos, que apresentaram valores entre 0,48 e 1,07. Destaca-se, ainda, que nessa amostra os shopping centers localizam-se em diferentes regiões do país, principalmente em cidades de grande porte, com área bruta locável variando de 5.045 a $64.000 \mathrm{~m}^{2}$.

GOLDNER (1994), aperfeiçoando os modelos de Grando, através de uma amostra de 15 shopping centers localizados em diferentes regiões do país, com área bruta locável variando de 15.000 a $62.000 \mathrm{~m}^{2}$, também sugere modelos de regressão linear simples para estimar a geração de viagens, diferenciados quanto a localização e atratividade (com ou sem supermercado), relacionando o número de automóveis com o tamanho do empreendimento. Os modelos de regressão linear simples obtidos pela autora, para shopping centers localizados dentro da área urbana ${ }^{16}$, são os seguintes:

$$
\begin{aligned}
& V s m=2.057,3977+0,3080 A B L \\
& V s e x m=433,1448+0,2597 A B L
\end{aligned}
$$

Sendo, Vsm: fluxo diário de veículos atraídos pelo shopping center sem supermercado, no sábado médio do ano [viagens/dia] (com $\mathrm{R}^{2}=0,7698 ; \mathrm{R}=0,8774$; erro padrão $=2783,6$; teste $\left.\mathrm{t}=4,84>\mathrm{t}_{\min }=2,365\right)$;

Vsexm: fluxo diário de veículos atraídos pelo shopping center sem supermercado, na sexta-feira média do ano [viagens/dia] (com $\mathrm{R}^{2}=0,6849 ; \mathrm{R}=0,8276$; erro padrão $=2912,05$; teste $\left.\mathrm{t}=3,90>\mathrm{t}_{\min }=2,365\right)$; $\mathrm{e}$

$A B L$ : área bruta locável, $A B L \leq 46.704\left[\mathrm{~m}^{2}\right]$

\footnotetext{
${ }^{16} \mathrm{O}$ autor considera áreas urbanas, locais com maior acesso a transporte público.
} 


$$
\begin{aligned}
& V s m=1.732,7276+0,3054 A B L \\
& V s e x m=0,74 \mathrm{Vsm}
\end{aligned}
$$

Sendo, Vsm: fluxo diário de veículos atraídos pelo shopping center com supermercado, no sábado médio do ano [viagens/dia] (com $\mathrm{R}^{2}=0,8941 ; \mathrm{R}=0,9456$; erro padrão $=2192,33$; teste $\left.t=5,032>t_{\min }=3,182\right)$;

Vsexm: fluxo diário de veículos atraídos pelo shopping center com supermercado, na sexta-feira média do ano [viagens/dia]; e

$A B L$ : área bruta locável, $A B L \leq 41.797\left[\mathrm{~m}^{2}\right]$

GOLDNER (1994) ainda sugere, para shopping centers localizados fora da área urbana e sem supermercados, a aplicação dos modelos desenvolvidos por GRANDO (1986).

Em estudo mais recente, mediante pesquisa em três shopping centers localizados na cidade de São Paulo, a CET-SP (2000), considerando que a geração de viagens diária de veículos é função do tamanho do empreendimento e analisando o montante de área computável por veículo atraído durante uma sexta-feira e um sábado qualquer, desenvolveu os seguintes modelos:

$$
\begin{aligned}
& V D s a b=0,33 A C-2.347,55 \\
& \text { VDsex }=0,28 A C-1.366,12
\end{aligned}
$$

Sendo, VDsab: viagens diárias atraídas pelo shopping center, para um sábado qualquer [viagens/dia] (com $\left.\mathrm{R}^{2}=0,98\right)$;

VDsex: viagens diárias atraídas pelo shopping center, para uma sexta-feira qualquer [viagens/dia] (com $\left.\mathrm{R}^{2}=0,99\right)$; $\mathrm{e}$

$A C$ : área computável $\left[\mathrm{m}^{2}\right]$, correspondendo à área total construída menos as áreas construídas de garagens, de ático e de caixas de água.

Nos Estados Unidos, o ITE (1997) recomenda as seguintes fórmulas para calcular a geração de viagens para shopping centers:

$$
\operatorname{Ln}(V D s a b)=0,651 \operatorname{Ln}(A B L)+3,773
$$

Sendo, VDsab: viagens diárias atraídas pelo shopping center, para sábado [viagens/dia]; e $A B L$ : área bruta locável

$$
\operatorname{Ln}(V H P s a b)=0,628 \operatorname{Ln}(A B L)+6,229
$$

Sendo, VHPsab: viagens na hora pico atraídas pelo shopping center, para sábado [viagens/hora]; e

$A B L$ : área bruta locável 
$\mathrm{Na}$ literatura pesquisada, foi constatado que os órgãos do governo americano usam e sugerem a utilização das taxas e equações do livro "Trip Generation" publicado pelo ITE, onde são encontradas as formulas anteriormente apresentadas. Cabe considerar que essas taxas e equações são consideradas para estacionamentos não pagos.

Em Singapura, FAN e LAM (1997) utilizaram a regressão linear para relacionar a geração de viagens com o tamanho do shopping center e a localização do empreendimento. As equações obtidas são as seguintes:

$$
\begin{aligned}
& V D=32,8+11,55 A T C-128,9 D \\
& V D=31,3+16,93 A B L-126,1 D
\end{aligned}
$$

Sendo, VD: viagens diárias atraídas pelo shopping center [viagens/dia];

$A T C$ : área total construída $\left[\mathrm{m}^{2}\right]$;

$A B L$ : área bruta locável $\left[\mathrm{m}^{2}\right] ; \mathrm{e}$

$D$ : variável Dummy, que indica a localização do shopping center ( $D=0$ se fora da área central de negócios, e $D=1$ se dentro da área).

AL-MASAEID et al. (1999), em estudos realizados em shopping centers da Jordânia, desenvolveu a seguinte equação de regressão linear para estimar a geração de viagens a esses empreendimentos:

$$
V H P=18,19+0,008 A T C+16,76 D
$$

Sendo, VHP: viagens atraídas na hora pico [viagens/hora];

$A T C$ : área total construída $\left[\mathrm{m}^{2}\right]$; e

$D$ : variável Dummy, que indica o tipo de shopping center ( $D=0$ se shopping militar, e $D=1$ se particular).

\subsection{CATEGORIAS DE VIAGENS}

A classificação das viagens em categorias está relacionada com a intenção do usuário ao ir ao shopping center, isto é, o que direciona o usuário a realizar a viagem.

SLADE e GOROVE ${ }^{17}$ apud GOLDNER (1994, p.25) sugerem três categorias de viagens a shopping centers:

- Viagens primárias - São as novas viagens geradas pelo shopping center e correspondem às viagens com origem e destino na residência.

${ }^{17}$ SLADE, L. J. \& GOROVE, F. E. (1981). Reduction in estimatives of traffic impacts of regional shopping centers. ITE Journal, January. 
- Viagens desviadas - São viagens existentes, que param no shopping center como consequiência de outras paradas da viagem, e quando a parada requer uma diversificação da rota.

- Viagens não desviadas - São viagens existentes, onde para a parada no shopping center não é necessário alteração da rota.

As viagens novas e desviadas devem ser consideradas na análise do impacto de tráfego provocado por shopping centers, conforme CONCEIÇÃO (1984), GRANDO (1986), SMITH (1986) e GOLDNER (1994), para serem acrescentadas ao carregamento total das vias adjacentes. Segundo SMITH (1986), as viagens desviadas são redistribuídas e as novas são somadas ao volume de viagens previsto nas vias do entorno.

A Tabela 2.5 apresenta um resumo de estudos de categorias de viagens realizados em shopping centers no Brasil.

Tabela 2.5 - Resumo de estudos de categoria de viagens.

\begin{tabular}{|l|c|c|c|l|}
\hline \multirow{2}{*}{ Autores } & \multicolumn{3}{|c|}{ Categoria das viagens } & \multirow{2}{*}{ Observações } \\
\cline { 2 - 5 } & Primária & Desviada & Não-desviada & \\
\hline Conceição (1984) & $70 \%$ & $10 \%$ & $20 \%$ & Para sexta-feira \\
\hline Grando (1986) & $70 \%$ & $10 \%$ & $20 \%$ & Para sexta-feira \\
\hline Silveira (1991) & $72 \%$ & ------ & ------ & $\begin{array}{l}\text { Para quinta-feira, sexta-feira e } \\
\text { sábado }\end{array}$ \\
\hline Goldner (1994) & $48 \%$ & $38 \%$ & $14 \%$ & $\begin{array}{l}\text { Para sexta-feira, shopping } \\
\text { center na área urbana }\end{array}$ \\
\cline { 2 - 5 } & $70 \%$ & $26 \%$ & $4 \%$ & $\begin{array}{l}\text { Para sábado, shopping center } \\
\text { na área urbana }\end{array}$ \\
\cline { 2 - 5 } & $43 \%$ & $24 \%$ & $33 \%$ & $\begin{array}{l}\text { Para sexta-feira, shopping } \\
\text { center fora da área urbana }\end{array}$ \\
\hline
\end{tabular}

Para CONCEIÇÃO (1984) e GRANDO (1986), 80\% das viagens geradas no sábado são consideradas para avaliar o impacto viário provocado por shopping centers. No entanto, para GOLDNER (1994) esse valor varia entre 67\% e 86\% para shopping centers localizados fora e dentro da área urbana, respectivamente. Isso faz notar que para GOLDNER (1994) as viagens novas atraídas por um shopping center são maiores quando este se localiza dentro da área urbana.

Cabe ressaltar que esses estudos foram realizados em shopping centers localizados na cidade do Rio de Janeiro, e foram os únicos encontrados em nível nacional. As divergências observadas pressupõem a necessidade de mais estudos. Identifica-se que a categoria de viagens representa uma variável que interfere no impacto provocado pelo shopping centers, mas a sua determinação requer um estudo aprimorado do fluxo nas vias adjacentes ao empreendimento. 


\subsection{ESTACIONAMENTO}

$\mathrm{O}$ estacionamento representa um dos principais fatores que atraem os
compradores para um shopping center. Assim, tem-se tornado uma preocupação para planejadores que desejam otimizar o desempenho dos mesmos, compatível às necessidades requeridas.

Segundo GONÇALVES (1990), a capacidade estática ${ }^{18}$ e dinâmica ${ }^{19}$ nos estacionamentos devem ser dimensionadas para atender adequada e suficientemente a demanda por estacionamento em shopping centers. Porém, tais capacidades são limitadas pelos componentes do estacionamento e pelos níveis de integração e harmonia entre eles. Dessa forma, torna-se necessário considerar nesse contexto os princípios e componentes básicos que norteiam o projeto de estacionamento, e que podem interferir no sistema.

\subsubsection{PRINCIPIOS BÁSICOS DE PROJETO}

Segundo a CET-SP (1983), para obter o melhor desempenho de estacionamentos em pólos geradores de tráfego devem ser considerados:

- Acessibilidade adequada para as manobras de entrada e saída do estacionamento;

- Definição da quantidade e posição de acessos;

- Áreas de acomodação nas entradas;

- Projeto geométrico de acessos, raios de curvatura e larguras apropriadas;

- Composição adequada entre vagas de automóveis, que contemple o dimensionamento de vagas, circulação e manobras dos veículos;

- Projetos para rampas;

- Espaços adequados para operações de carga e descarga de mercadorias;

- Espaços para embarque e desembarque de passageiros;

- Dispositivos de proteção aos pedestres; e

- Áreas reservadas para pontos de ônibus e táxis.

\footnotetext{
18 expressa em número de vagas.

${ }^{19}$ expressa em taxa de escoamento ou de absorção de veículos por unidade de tempo.
} 
Ao se projetar estacionamentos em shopping centers, segundo ELLSON ${ }^{20}$ e CHODASH $^{21}$ apud GONÇALVES (1990, p.14), deve-se procurar:

- Otimizar o espaço destinado para fins de estacionamento, maximizando o número de vagas e a sua capacidade dinâmica;

- Minimizar o desconforto de motoristas, provocados pela procura de vagas e realizando manobras de entrada e saída de vagas;

- Minimizar a interferência com o tráfego das vias adjacentes.

Dessa forma, considerando os princípios básicos de projeto, é necessário definir a localização e tipo de estacionamento, e conseqüentemente os elementos de projeto que atendam a esses requisitos, de forma adequada e segura.

Para CLIVE ${ }^{22}$ apud CONCEIÇÃO (1984, p.120), a localização do estacionamento em shopping centers depende dos seguintes fatores:

- Sistema viário que o circundará;

- Planejamento do local para estacionamento;

- Outros desenvolvimentos na área;

- Situação topográfica;

- Custo do terreno; e

- Viabilidade.

Segundo DUNN \& HAMILTON ${ }^{23}$ apud CONCEIÇÃO (1984, p.119), o espaço de estacionamento pode ser provido por:

- Estacionamento térreo - É o menos dispendioso e assim o mais preferido. Sua orientação preferida para o corredor é no sentido perpendicular aos acessos do shopping center, assim o usuário tem acesso direto do shopping center ao veículo, sem ter que caminhar entre os veículos.

${ }^{20}$ ELLSON, D. R. (1969). Parking: Dynamic Capacities of Car Parks, Road Research Laboratory Report LR 221.

${ }^{21}$ CHODASH, I. L. (1986). Relative efficiencies of various parking angles, ITE Journal, March.

${ }^{22}$ CLIVE, D. (1972). Enclosed Shopping Centers. Architectural Pres. London, p.80.

23 DUNN, R. C. M. \& HAMILTON, G. D. (1971). Transportation Engineering Design for shopping Centers. Traffic Engineering and Control. Nov. 
- Estacionamento coberto - Apesar de ser mais dispendioso que o térreo, é usado com frequiência em shopping centers de muitos andares.

- Edifício garagem - É o mais dispendioso destes tipos porque é necessário prover iluminação extra, ventilação, proteção contra o fogo e um sistema de circulação. Apresenta ainda restrição do acesso para usuários.

\subsubsection{COMPONENTES DO PROJETO}

A concentração de atividades comerciais em um shopping center provoca um alto volume de tráfego, o qual requer nos estacionamentos um projeto mais sofisticado, que contemple uma capacidade suficiente para acomodar a demanda por estacionamento, em equilíbrio e harmonia com os componentes de projeto. Por tanto, os elementos de projeto deveram ser projetados de forma segura e eficientemente.

Segundo GERN (1975), são fatores que influenciam a localização de acessos:

- O volume de tráfego gerado pelo empreendimento;

- O volume de tráfego das vias adjacentes;

- A distribuição de viagens de entrada e saída do empreendimento;

- Os movimentos nos acessos;

- Necessidades de uso do solo adjacente para o shopping center; e

- A localização e geometria das vias adjacentes ao empreendimento e o relacionamento com a distância de interseções.

O fator mais importante em determinar o número de acessos requerido para o estacionamento é o volume de tráfego gerado pelo shopping center, que depende do tamanho e composição do empreendimento. A quantidade de tráfego que pode ser acomodada em um único acesso varia consideravelmente e depende principalmente do projeto de estacionamento, da distribuição direcional de veículos entrando e saindo, e do tipo de controle de tráfego utilizado (GERN, 1975).

Para DICK ${ }^{24}$ apud CONCEIÇÃO (1984, p.110), o projeto de acesso deve ser acessível em todas as dimensões e deverá no mínimo existir dois pontos de acesso ao shopping center, para que seja mantida uma via de escoamento caso a rua ou rodovia apresente um

${ }^{24}$ DICK, A. C. (1971). Transportation Aspects of New Shopping Development. Traffic Engineering \& Control. Oct. 
bloqueio. Isso, se o volume de tráfego para um acesso exceder de 500 a 800 veículos por hora, caso de shopping regional.

Segundo CONCEIÇÃO (1984), para determinar o projeto de escoamento do shopping center por direção de acesso, torna-se necessário definir a extensão da área de influência e estabelecer os fluxos de entrada e saída do shopping center durante a hora pico de entrada e saída e a hora pico das ruas e/ou rodovias adjacentes. O fluxo de tráfego gerado pelo shopping center no pico de entrada e saída é usado para o dimensionamento de acessos e dimensionamento do estacionamento. O fluxo combinado da hora pico das ruas e/ou rodovias com a hora de movimento do shopping center é usado para o projeto de ruas e/ou rodovias.

De acordo com GONÇALVES (1990), para que o sistema operacional nos acessos funcione adequadamente é necessário providenciar:

- Áreas de acumulação para os veículos;

- Canalização das entradas e saídas; e

- Previsão de tráfego por hora e em cada dia da semana, o que depende do seu potencial de comércio, grau de acessibilidade e competidores.

A circulação interna nos estacionamentos compreende uma via de circulação principal e vias secundárias. A via principal consiste num circuito que deverá permitir um movimento livre desde o acesso até qualquer parte do estacionamento e vice-versa, permitindo também o acesso a vias secundárias. As vias secundárias são de menor tráfego, e devem permitir a distribuição de veículos nas áreas de estacionamento de maneira rápida e segura.

Segundo CONCEIÇÃO (1984), a circulação ou anel de circulação dentro do estacionamento, usual em Regional Shopping, deve ser adequadamente planejada de modo a facilitar o acesso a toda a área de estacionamento do shopping center, tendo ainda a função de disciplinar o trânsito de veículos dentro da área de estacionamento, bem como o fluxo de entrada e saída de veículos.

Segundo ELLSON ${ }^{25}$ apud GONÇALVES (1990, p.27), as vias de circulação são hierarquizadas para cumprirem harmoniosamente as funções de coleta e distribuição do tráfego, e de acessos e manobras às vagas. Dessa forma, procura-se minimizar os possíveis conflitos e separar os movimentos de naturezas e necessidades diferentes, tais como: fluxo de veículos entrando e saindo, tráfego veicular e de pedestres, transporte de passageiros e de carga, fluxo de automóveis, táxis e coletivos.

${ }^{25}$ op. citada. 
Assim, a circulação interna deverá garantir uma distribuição uniforme dos veículos nos espaços disponíveis para estacionamento, evitando congestionamentos desnecessários. Para tal, as áreas dos acessos ao estacionamento deverão ser destinadas exclusivamente para circulação, garantindo trânsito livre nos acessos e evitando retenções e congestionamentos nas vias de circulação.

A disposição das vagas deve ser concebida com o objetivo de reduzir os conflitos entre veículos, minimizar retenções, facilitar manobras operacionais e ainda obter um melhor aproveitamento da área. Deve ainda ser concebida de modo a minimizar a distância de caminhada, desde o veículo estacionado até as lojas, facilitando o carregamento dos produtos adquiridos. Segundo CHODASH ${ }^{26}$ apud GONÇALVES (1990, p.19), deve-se procurar o equilíbrio entre a maximização da capacidade estática do estacionamento, as facilidades de manobrar os veículos e a circulação do tráfego de pedestres e veículos no estacionamento.

As dimensões das vagas e das vias de circulação são influenciadas pelo ângulo de estacionamento e pelo veículo-padrão adotado. Considerar vagas com dimensões diferentes não é usualmente aceita em função das dificuldades operacionais. Adota-se como padrão as seguintes dimensões: 2,40m de largura, 5,00m de comprimento e 6,00m de largura da via de circulação, consideradas para veículos grandes e utilitários (CET-SP, 1986).

Uma análise desenvolvida por CHODASH ${ }^{27}$ apud GONÇALVES (1990, p.26) revelou que o ângulo de 90 graus é o que produz maior número de vagas em 67\% dos casos pesquisados; entretanto, são restringidas as operações em mão dupla. Na prática, em shopping centers no Brasil, têm-se assumido que o ângulo de 90 graus é o mais eficiente, sendo constatado o seu uso em praticamente todos os shopping centers no país.

As áreas imediatamente em frente às entradas do shopping center devem ser restritas ao trânsito de pedestres. Esta restrição pode ser obtida através de sinalização, obstruindo o acesso de veículos a estes pontos, mas possibilitando o livre acesso de pedestres. Um apropriado sistema de informação, controle e sinalização, é necessário para a segurança e proteção de pedestres.

O dimensionamento adequado do número de vagas de estacionamento para um shopping center significa fornecer boas condições de compras para os clientes e atratividade para novos consumidores. Assim, a estimativa da demanda por estacionamento constitui um fator fundamental para atender às necessidades dos usuários. Definida a demanda por vagas, é

\footnotetext{
${ }^{26}$ op. citada
}

27 op. citada. 
fundamental distribuir e organizar adequadamente essas vagas e assegurar a adequada harmonia entre os diferentes componentes do estacionamento.

Apesar da importância que envolve o projeto de estacionamento em shopping centers, os estudos a respeito são escassos no Brasil.

\subsubsection{ELEMENTOS QUE AFETAM A DEMANDA}

VOORHEES e CROW (1966), em pesquisas realizadas em shopping centers nos Estados Unidos e Canadá, identificaram que existe uma forte correlação entre o volume de tráfego entrando no estacionamento e o acúmulo de veículos no pico horário de estacionamento. Estabeleceram, ainda, os seguintes fatores envolvidos na demanda por estacionamento:

- Localização do empreendimento em relação à área central de comércio e negócios, interferências quanto à acessibilidade e barreiras físicas;

- Tamanho do empreendimento;

- Características da população da área de influência;

- Modos de transporte;

- Hábitos de estacionamento;

- Tipos de estabelecimentos, varejista e/ou não-varejistas; e

- Localização e influência de centros competidores.

Estudos em shopping centers nos Estados Unidos, descritos por HIGHWAY RESEARCH RECORD (1971), identificaram como elementos que interferem na demanda por estacionamento:

- Características do usuário: tamanho da família, faixa etária, renda e propriedade de veículo;

- Atratividade do empreendimento: comércio, serviços, entretenimentos, eventos, teatro, cinema, entre outros;

- Modos de transporte: disponibilidade de alternativas de meios de transporte de chegada e saída, seja a pé, táxi, carona, ônibus, metrô e/ou trem;

- Acesso ao tráfego: capacidade de acessar vias dentro de um aceitável limite de tempo;

- Congestionamentos: esperas longas para entrar ou sair de áreas de estacionamento, seja por causa de operação de tráfego deficiente, inadequada sinalização e deficientes parâmetros geométricos, entre outros; 
- Oferta de estacionamento: número de vagas disponíveis para atender a demanda;

- Localização do estacionamento: em relação ao destino do usuário;

- Custo: estacionamentos pagos geralmente reduzem a demanda;

- Administração local: medidas de segurança, sinalização, iluminação, conforto, comodidade e sistema operacional do estacionamento.

Para CONCEIÇÃO (1984), a demanda por estacionamento é baseada em:

- Chegada e saída de veículos do shopping center;

- Circulação dentro da área de estacionamento; e

- Flutuações horárias e diárias.

Segundo GRANDO (1986), o principal elemento que afeta a demanda por estacionamento em um shopping center é o tempo médio de permanência do automóvel no estacionamento.

JONES $^{28}$ apud GRANDO (1986, p.66) destaca que a demanda por estacionamento depende de:

- Número de clientes que vem por transporte particular;

- Número de compradores por veículos;

- Rotatividade das vagas;

- Tipos de lojas; e

- Incidência e amplitude dos picos.

Em estudos mais recentes realizados em shopping centers nos Estados Unidos, STEINER (1998) identifica para Shopping de Vizinhança ${ }^{29}$ as seguintes variáveis a serem consideradas na estimativa de geração de viagens a esses empreendimentos:

- Número e tamanho de lojas no empreendimento;

- Atratividade do shopping center;

- Instalações de acesso a transportes;

${ }^{28}$ JONES, C. S. (1969). Regional shopping centers - their location, planning and design, London.

29 Projetado para fornecer conveniência na compra de necessidades diárias e próximas ao bairro. Ancorado por um supermercado e farmácia, suportadas por lojas oferecendo refeições e serviços pessoais. Usualmente configurado em linha reta, sem corredor de circulação de pedestres ou área de mall. 
- Inventario do uso do solo no local;

- Análise de mercado;

- Densidade demográfica;

- Comportamento dos usuários;

- Informações sócio-econômicas dos usuários;

- Padrões de viagens e atitudes dos usuários.

Cabe ainda acrescentar, em shopping centers nos Estados Unidos, variáveis identificadas por GHEZAWI et al. (1998) nas áreas do entorno ao empreendimento, que afetam o número de viagens geradas por Shopping de Vizinhança ${ }^{30}$. São elas:

- Tráfego das ruas adjacentes, contribuindo nas viagens diárias geradas pelo empreendimento e viagens nos horários de pico;

- Índice de acessibilidade, definido em função de unidades domiciliares e tempo de viagem ao empreendimento; e

- Competição com outros empreendimentos, explicando a geração de viagens diárias durante a semana e comportamento dos clientes nos horários de pico à tarde.

Constata-se que dos elementos que afetam a demanda por estacionamento são identificadas características próprias do empreendimento, características do usuário do estacionamento e características da área externa adjacente ao empreendimento. Nesse contexto, a oferta de vagas representa um dos fatores principais a ser considerado para absorver a demanda por estacionamento em shopping centers.

\subsubsection{CRITÉRIOS UTILIZADOS PARA DIMENSIONAR ESTACIONAMENTOS}

Para estimar o número de vagas que devem ser oferecidas pelos shopping centers, um dos critérios mais utilizados é o índice de estacionamento, que relaciona o número de vagas com o tamanho do empreendimento.

Em shopping centers nos Estados Unidos, o índice mais utilizado é aquele que relaciona o número de vagas com a Área Bruta Locável ${ }^{31}$ (ABL). Este índice de estacionamento é calculado através da seguinte formula:

\footnotetext{
${ }^{30}$ op. citada

31 definida como a área bruta da cada loja, incluindo a área de vendas e de depósito, de administração, sanitários e outros que estejam dentro ou fora da loja, desde que descritos no contrato de locação.
} 
Um outro índice de estacionamento é aquele que relaciona o número de vagas com a Área Total Construída (ATC). Este índice é calculado através da seguinte fórmula:

$$
\text { Índice de estacionamento }=\text { número de vagas } / \text { ATC } / 100 m^{2}
$$

$\mathrm{Na}$ Inglaterra, LEAKE e TURNER ${ }^{32}$ apud CONCEIÇÃO (1984, p.115) identificaram como índice de estacionamento padrão utilizado em shopping centers aquele que relaciona o número de vagas com a Área de Vendas ${ }^{33}$ (AV). O índice de estacionamento, neste caso, é calculado através da seguinte formula:

$$
\text { Índice de estacionamento }=\text { número de vagas } / \mathrm{AV} / 100 \mathrm{~m}^{2}
$$

No Brasil, em pesquisas realizadas em pólos geradores de tráfego na cidades de Curitiba, São Paulo e Distrito Federal, o DENATRAN (2001) identificou que esses índices correspondem a: 8 vagas por $100 \mathrm{~m}^{2}$ de AV para empreendimentos na cidade de Curitiva, 6,67 vagas por $100 \mathrm{~m}^{2}$ de área comercial para empreendimentos com área comercial inferior a $20.000 \mathrm{~m}^{2}$ e 5 vagas por $100 \mathrm{~m}^{2}$ de área comercial para empreendimentos com área comercial superior a $20.000 \mathrm{~m}^{2}$, localizados na cidade de São Paulo, e 4 vagas por $100 \mathrm{~m}^{2}$ de ATC para empreendimentos com ATC superior a $5.000 \mathrm{~m}^{2}$ e inferior a $10.000 \mathrm{~m}^{2}$ e 5 vagas por $100 \mathrm{~m}^{2}$ de ATC para empreendimentos com ATC superior a $10.000 \mathrm{~m}^{2}$, localizados no Distrito Federal.

No Brasil, também, foram desenvolvidos quatro modelos para estimar o número mínimo de vagas necessárias para atender a demanda por estacionamento: CET-SP (1983) para qualquer Pólo Gerador de Tráfego ${ }^{34}$, GRANDO (1986), GOLDNER (1994) e CET-SP (2000).

Os modelos da CET-SP (1983), de GRANDO (1986) e GOLDNER (1994) relacionam a geração de viagens com o tempo médio de permanência nas vagas de estacionamento, obedecendo à seguinte relação:

\footnotetext{
${ }^{32}$ LEAKE, G. R. \& TURNER, D. J. (1982). Shopper and vehicle characteristics at Large Retail Shopping Centers. Traffic Engineering and Control. Jan., pp.8-13.

33 definida como a área bruta locável menos a área de depósitos.

34 considerados como edificações ou instalações que exercem grande atividade sobre a população, mediante a concentração de bens e serviços, gerando elevado número de viagens, com substanciais interferências no tráfego do entorno e necessidade de grandes espaços para estacionamento ou carga e descarga.
} 


$$
N v=\operatorname{Tm} x \operatorname{VHP}
$$

Sendo, $N v$ : número mínimo de vagas;

Tm: tempo médio de permanência na vaga [hora]; e $V H P$ : viagens atraídas na hora pico [viagens/hora].

Para a CET (1983):

$V H P=(0,124 A T C+1.550) 0,25$ [viagens/hora] e $T m=1$ [hora].

\section{Para GRANDO (1986):}

$V H P=V s m \times P P H, \quad$ sendo $P P H=10,5 \%$ a porcentagem de pico horário para sábado, $V s m=-2.066,639+0,3968842 A B L$ [viagens/dia], considerado para qualquer tipo de shopping centers e adotando $T m=1,96$ [horas], valor identificado no shopping center Rio Sul, localizado na cidade do Rio de Janeiro.

\section{Para GOLDNER (1994):}

$V H P=V s m \times P P H$, considerando $P P H=8,98 \%$ a porcentagem de pico horário para sábado, $V s m=1.732,73+0,3054 A B L$ [viagens/dia] para shopping centers localizados dentro da área urbana, com supermercado e ABL menor que $41.793 \mathrm{~m}^{2}$ ou $V s m=2.057,3977+0,3080 A B L$ [viagens/dia] para shopping centers sem supermercado e com ABL inferior ou igual a $46.704 \mathrm{~m}^{2}$ e para ambos casos adotando $T m=1,96$ [horas], valor identificado por Grando. Para shopping centers fora da área urbana é adotado como volume horário de projeto o modelo realizado por Grando e $P P H=10,5 \%$.

A CET-SP (2000) propõe o seguinte método:

$$
\begin{gathered}
N v=\text { maior entre } N v_{l} e N v_{2} \\
N v_{l}=R D A \times V D s a b \\
N v_{2}=A C / R A C
\end{gathered}
$$

Sendo, $N v$ : número mínimo de vagas;

$N v_{1}$ : número de vagas;

$N v_{2}$ : número de vagas;

$R D A$ : relação entre ocupação máxima de vagas e demanda diária de veículos atraídos, correspondendo a 0,16 [vagas/viagens dia];

$V D s a b$ : viagens atraídas ao shopping no sábado, $V D s a b=0,33 A C-2.347,55$ [viagens/dia];

$A C$ : área computável $\left[\mathrm{m}^{2}\right]$, correspondente à área total construída menos as áreas de garagens, de ático e de caixas de água; e

$R A C$ : relação entre a área computável e a ocupação máxima do estacionamento, correspondendo a $23\left[\mathrm{~m}^{2} /\right.$ vagas $]$ 
Esses modelos preocupam-se em estimar o número mínimo de vagas de estacionamento através de variáveis simples de obter. Para a CET-SP (1983), GRANDO (1986) e GOLDNER (1994) as variáveis explicativas para determinar o número de vagas são o tempo médio de permanência dos veículos nas vagas e o volume horário de projeto, conforme os modelos de geração de viagens de cada autor. Para a CET-SP (2000) o número mínimo de vagas esta condicionado à demanda diária de veículos atraídos pelo empreendimento, à área computável e à ocupação máxima do estacionamento.

$\mathrm{Na}$ bibliografia foram identificados outros índices de estacionamento adotados por alguns autores para determinar o número de vagas de estacionamento em shopping centers, bem como algumas técnicas de análise do sistema de estacionamento. Identificaram-se modelos determinísticos e modelos que utilizam técnicas de simulação. A seguir são comentados os modelos levantados.

\section{Modelos determinísticos}

- VOORHEES \& CROW (1966) recomendam para shopping centers nos Estados Unidos e Canadá o índice de 5,5 vagas por $100 \mathrm{~m}^{2}$ de ABL.

- ULI (1977) recomenda 5 a 9 vagas por $100 \mathrm{~m}^{2}$ de ABL para shopping centers nos Estados Unidos.

- GERN (1978) recomenda 5 vagas por $100 \mathrm{~m}^{2}$ de ABL para shopping centers nos Estados Unidos, com ABL $>80.000 \mathrm{~m}^{2}$.

- LEAKE \& TURNER (1982) recomendam para shopping centers nos Estados Unidos 5 a 6 vagas por $100 \mathrm{~m}^{2}$ de ABL para Shopping Regional $\left(27.000 \mathrm{~m}^{2}<\mathrm{ABL}<93.000 \mathrm{~m}^{2}\right), 7$ vagas por $100 \mathrm{~m}^{2}$ de ABL para Shopping Comunitário $\left(9.000 \mathrm{~m}^{2}<\mathrm{ABL}<27.000 \mathrm{~m}^{2}\right)$, e 8 vagas por $100 \mathrm{~m}^{2}$ de ABL para Shopping de Vizinhança $\left(3.000 \mathrm{~m}^{2}<\mathrm{ABL}<9.000 \mathrm{~m}^{2}\right)$.

- LEAKE \& TURNER (1982) através de estudos realizados no Multiple Shop Federation, na Inglaterra, identificaram 4 vagas por $100 \mathrm{~m}^{2}$ de área de venda em locais de baixa renda; 5,25 vagas por $100 \mathrm{~m}^{2}$ de área de venda em locais de renda média, e 6,25 vagas por $100 \mathrm{~m}^{2}$ de área de venda em locais de renda alta.

- LEAKE \& TURNER (1982) através de estudos realizados em National Economic Development Office, na Inglaterra, recomendam 5,38 vagas por $100 \mathrm{~m}^{2}$ de área de venda para Shopping Regional, 6,19 vagas por $100 \mathrm{~m}^{2}$ de área de venda em shopping center localizado na área central e 9,15 vagas por $100 \mathrm{~m}^{2}$ de área de venda em shopping center localizado fora da área central. 
- ULI (1982) recomenda 3,44 a 4,30 vagas por $100 \mathrm{~m}^{2}$ de área total construída, no pico, para shopping centers nos Estados Unidos.

- SMITH (1983) recomenda para shopping centers nos Estados Unidos 4 a 5 vagas por $100 \mathrm{~m}^{2}$ de ABL para shopping centers com $\mathrm{ABL}<60.000 \mathrm{~m}^{2}$ e 5 vagas por $100 \mathrm{~m}^{2}$ de $\mathrm{ABL}$ para shopping centers com ABL variando entre $60.000 \mathrm{~m}^{2}$ a $150.000 \mathrm{~m}^{2}$.

- ITE (1987) recomenda 3,34 vagas por $100 \mathrm{~m}^{2}$ de área total construída, 3,5 vagas por $100 \mathrm{~m}^{2}$ de área bruta locável para dia da semana e 4,3 vagas por $100 \mathrm{~m}^{2}$ de ABL para sábado, no pico, para shopping centers nos Estados Unidos.

- YOUNG (1987) indica de 2,4 a 4,5 vagas por $100 \mathrm{~m}^{2}$ de ATC para shopping centers nos Estados Unidos, com ATC variando linearmente de $4.645 \mathrm{~m}^{2}$ a $116.129 \mathrm{~m}^{2}$

- MACKENZIE \& EASTMAN (1992) indicam 3,5 a 5,0 vagas por $100 \mathrm{~m}^{2}$ de ABL, no pico, para shopping centers nos Estados Unidos.

- FAN \& LAM (1997) recomendam 1,25 vagas por $100 \mathrm{~m}^{2}$ de ABL e 0,86 vagas por $100 \mathrm{~m}^{2}$ de área total construída (ATC), para shopping center na área central; e 2,00 vagas por $100 \mathrm{~m}^{2}$ de ABL e 1,45 vagas por $100 \mathrm{~m}^{2}$ de ATC, para shopping center fora da área central. Independente da localização adotam 1,13 vagas por $100 \mathrm{~m}^{2}$ de ATC e 1,59 vagas por $100 \mathrm{~m}^{2}$ de ABL, para shopping centers em Singapura.

- DENATRAN (2001) indicam 8 vagas por $100 \mathrm{~m}^{2}$ de AV para empreendimentos na cidade de Curitiba, 6,67 vagas por $100 \mathrm{~m}^{2}$ de área comercial para empreendimentos com área inferior a $20.000 \mathrm{~m}^{2}$ e 5 vagas por $100 \mathrm{~m}^{2}$ de área comercial para empreendimentos com área superior a $20.000 \mathrm{~m}^{2}$, localizados na cidade de São Paulo, e 4 vagas por $100 \mathrm{~m}^{2} \mathrm{de}$ ATC para empreendimentos com ATC superior a $5.000 \mathrm{~m}^{2}$ e inferior a $10.000 \mathrm{~m}^{2}$ e 5 vagas por $100 \mathrm{~m}^{2}$ de ATC para empreendimentos com ATC superior a $10.000 \mathrm{~m}^{2}$, localizados no Distrito Federal.

\section{Modelos que utilizam técnicas de simulação}

- Modelo ParkSIM/1 (1986), Austrália - Fornece uma análise detalhada do nível de serviço oferecido pelo estacionamento, a distribuição espacial de tráfego, movimentos dos veículos e compara o desempenho de várias configurações, determinando a mais apropriada.

- Modelo CLAMP (Computer Based Local Area Parking Behavior), Inglaterra - Permite variações na disponibilidade de estacionamento, no volume e na composição de fluxo de tráfego. Focaliza principalmente o comportamento da rede viária quando submetida a diferentes políticas de estacionamento. 
- Modelo de simulação da operação de um Pólo Gerador de Tráfego, CET-SP, Brasil Analisa as condições de operação de um pólo gerador de tráfego, a fila de acumulação, o número de vagas de estacionamento e impactos causados por veículos estacionados em locais proibidos.

- Modelo ESTSIM (1990), COPPE/UFRJ, Brasil - Prevê dois acessos para o estacionamento no interior do shopping center e possibilita para cada acesso uma taxa de chegada diferente. Ao chegar em um dos acessos, o veículo pode-se dirigir para o interior do shopping ou para as áreas externas do estacionamento, em função da taxa de ocupação do estacionamento. Se o veículo se dirigir para o interior do shopping, ele fica na fila de entrada até que possa ocupar uma vaga. Nesse caso, há um tempo de permanência na vaga e em seguida ele deixa o sistema. Se o veículo se dirigir para as áreas externas de estacionamento, uma distribuição de probabilidade indica para qual área de estacionamento o veículo se encaminha.

- Modelo SAPTSIM (1996), Austrália - Analisa o impacto devido a mudanças no projeto de shopping centers, através de padrões de tráfego. Determina a interação entre a localização de estabelecimentos no shopping, o projeto de estacionamento e o sistema de tráfego no entorno, com movimentos no estacionamento. A interação entre esses elementos e o layout dos estabelecimentos no shopping define a rota escolhida pelos usuários do estacionamento.

Os índices apresentados foram determinados para shopping centers no Canadá, Estados Unidos, Inglaterra, Singapura e no Brasil. Observa-se que alguns são diferenciados quanto a tipo de shopping center (Regional, de Vizinhança, Comunitário), outros quanto a tamanho do empreendimento (ABL, ATC) e outros quanto a características sócio-econômicas da área de influência e localização. Como se pode observar esses índices apresentam grandes discrepâncias.

Cabe destacar, que os modelos que utilizam simulação, nacionais e internacionais, são apropriados para avaliar o impacto provocado pela implantação de shopping centers e para avaliar o desempenho do sistema operacional do estacionamento, sob determinadas condições. Entretanto, não determinam especificamente a demanda por estacionamento para esses empreendimentos.

\subsection{ANÁLISE DA LITERATURA PESQUISADA}

$\mathrm{Na}$ literatura pesquisada, foi constatado que os shopping centers, atendendo ao propósito de evitar congestionamentos e impactos de tráfego, inicialmente foram localizados afastados das áreas centrais. No entanto, com o crescimento das cidades, alguns desses 
empreendimentos passaram a se integrar ao meio urbano, o que tem provocado problemas no tráfego das vias adjacentes e dificuldades quanto a estacionamentos.

Da classificação de shopping centers realizada pela ABRASCE, pressupõe-se que os shopping centers regionais e comunitários, representando 53,46\% e 32,08\% respectivamente do total de empreendimentos, sejam os que apresentam maiores problemas, devido ao tamanho e quantidade de bens e serviços oferecidos, gerando maior preocupação na oferta de estacionamento requerida. Constatou-se que, dentro da classificação de shopping centers adotada pela ABRASCE, os empreendimentos são diferenciados quanto a tipo de estabelecimentos, porém não apresentam diferenciações quanto a tamanho, localização e oferta de estacionamento - que se acredita serem características importantes a serem consideradas.

Nos estudos de áreas de influência, nota-se, como consenso dos autores, que a mesma representa a área geográfica que atrai a maior quantidade de clientes ao shopping center. No entanto, quanto aos critérios adotados para delimitar a área de influência, observam-se divergências entre os autores. Isso verificado quanto à distância máxima entre 8 e $30 \mathrm{~km}$, e quanto à distribuição das viagens nas áreas primárias, secundárias e terciárias. As diferenças constatadas pressupõem-se que se devam às características dos empreendimentos, tipo de atratividade, características da população local e características do sistema de transportes. Cabe destacar que a área de influência representa um dos principais fatores que interfere nas viagens geradas por shopping centers, no entanto, para ser estimada requer da análise de variáveis que nem sempre podem ser facilmente estimadas.

Constatou-se que os padrões de viagem são os que caracterizam um shopping center quanto a distribuição de viagens e flutuações de geração de viagens. Esses padrões caracterizam-se quanto ao motivo das viagens, à modalidade de transporte, às características sócio-econômicas dos clientes, ao origem e destino das viagens, e distribuição temporal das viagens durante o dia, durante a semana, durante o mês e durante o ano. No Brasil, ainda, são escassos os estudos realizados, identificando-se alguns padrões de viagens para empreendimentos localizados na cidade do Rio de Janeiro.

Nos estudos de variação da demanda de tráfego em shopping centers identificou-se que o movimento de veículos varia em relação ao mês, dia e hora. O mês mais movimentado é dezembro, o dia mais movimentado é o sábado, seguido pela sexta-feira. Constatou-se que os critérios para adotar o dia típico de projeto variam: $37^{0}$ dia mais carregado, $6^{0}$ dia mais movimentado, sábado médio do ano (para o dimensionamento do número de vagas de estacionamento), sexta-feira média do ano (para análise de impacto viário) e entre o $5^{0}$ e o $10^{0}$ dia mais movimentado (para dimensionar o número ótimo de vagas). No entanto, esses dias 
podem ser de difícil determinação devido a que a maioria dos shopping centers no país não apresentam registros de dados anuais do fluxo de veículos atraídos pelo empreendimento, e muitas vezes nem sequer apresentam registros diários de movimentação de veículos.

Identificou-se, ainda, que para alguns autores a hora típica de projeto corresponde à $30^{\mathrm{a}}$ maior hora do ano, à $19^{\mathrm{a}}$ maior hora e à $10^{\mathrm{a}}$ maior hora de volume de tráfego.

Para avaliação de impacto viário gerado pelo empreendimento, constatou-se que existem dois critérios adotados: um desses sugere o período das 18:00 às 19:00h na sexta-feira, devido a que o fluxo nas vias é maior na sexta-feira e pouco diluído nesse horário, e o outro sugere uma análise geral do fluxo da via e do empreendimento, para sexta-feira e sábado, de modo a verificar o período de maior carregamento na via - o que induz a um estudo aprimorado do movimento de tráfego para esses dias.

Nas categorias de viagens identificou-se que somente as viagens novas e desviadas são consideradas na análise do impacto do tráfego provocado por shopping centers. Isto é, na situação em que o fluxo total de veículos gerado pelo empreendimento é considerado para avaliar o impacto de tráfego, isto leva a um sobre-carregamento de tráfego nas vias, sem necessidade. Cabe, nesses casos considerar uma porcentagem da geração de viagens, porém, existe a necessidade de mais estudos, visto as divergências encontradas por alguns autores e considerando que os estudos em shopping centers foram realizados em empreendimentos localizados na mesma cidade, no Rio de Janeiro, podendo apresentar um comportamento diferente em outras cidades devido às características da população local.

Constatou-se que para os shopping centers, visto a sua complexidade, os projetos de estacionamento são mais sofisticados, devendo os componentes do projeto ser dimensionados de forma adequada. Nesse contexto, o volume de tráfego gerado foi identificado como o principal elemento para definir os acessos e número de vagas requeridas para um estacionamento. Definidos esses parâmetros, as vagas deverão ser distribuídas e organizadas adequadamente em harmonia com os diferentes componentes do estacionamento, tais como: acessos de veículos e pedestres, disposição de vagas, vias de circulação interna, canalização do tráfego e sinalização, entre outros.

Conforme verificado nos critérios adotados para estimar o número de vagas de estacionamento em shopping centers, as variáveis utilizadas são: taxa de chegada dos veículos no estacionamento, tamanho do empreendimento, seja através da área bruta locável, área total construída ou área de vendas; e tempo de permanência dos veículos no estacionamento. No entanto, na literatura pesquisada foram identificadas outras variáveis que afetam a demanda por estacionamento, tais como: tipos de estabelecimentos (varejistas e não-varejistas), número e 
tamanho de lojas, atratividade do empreendimento (comercio, serviços, trabalho, entretenimento, teatros, cinemas, restaurantes, fast food, entre outros), comportamento e atitudes dos usuários do estacionamento, padrões de viagens (incidência e amplitude dos picos, rotatividade das vagas, flutuações horárias e diárias, chegada e saída de veículos do estacionamento), entre outras.

Dessa forma, torna-se necessário considerar outras características para analisar a demanda por estacionamento, de forma a proporcionar modelos mais eficientes para calcular a número de vagas requeridas por esses empreendimentos. Políticas administrativas, localização do empreendimento em relação à área central, disponibilidade de alternativas de meio de transporte, interferências quanto à acessibilidade e barreiras físicas, localização de competidores, características da população da área de influência, condições sócio-econômicas e densidade demográfica local também são fatores que afetam a demanda por estacionamento, porém, variam para cada empreendimento, não permitindo generalizar e, principalmente, especificar índices de estacionamento considerando essas variáveis.

Nos critérios e modelos adotados para prever a demanda por estacionamento em shopping centers, foram identificados índices de estacionamento que consideram como variável unicamente o tamanho do empreendimento. Os modelos de geração de viagens, propostos pela maioria dos autores nacionais, consideram como variáveis a geração de viagens e o tempo de permanência dos veículos no estacionamento, outros levam em consideração, além da demanda de veículos atraídos, a área computável do empreendimento e a ocupação máxima do estacionamento. Observou-se que nenhum dos modelos contempla variáveis explicativas associadas à demanda por estabelecimentos ofertados pelo shopping center. Isto é, o número de viagens atraídas seria o mesmo se o shopping center apresenta-se somente áreas de lazer ou de compras. Foram identificados, ainda, alguns modelos utilizando técnicas de simulação, os quais permitem avaliar o desempenho do estacionamento e o impacto causado ao meio urbano, sob determinadas condições, porém, não oferecem informações gerais válidas para qualquer empreendimento.

Nesse contexto, cabe ainda considerar as condições sócio-políticas e econômicas próprias de cada país, que interferem no desenvolvimento das cidades, no sistema de transporte, no poder de compras dos clientes, na aquisição de automóveis, entre outros, inviabilizando a aplicação de alguns critérios utilizados para prever a geração de viagens e a demanda por estacionamento desenvolvidos em países com características diferentes. Da mesma forma, pressupõe-se que as condições sócio-políticas próprias de cada região, estado e cidade do país, interferem nas viagens diárias geradas por shopping centers, podendo inviabilizar o uso de 
modelos de geração de viagens desenvolvidos a nível nacional e/ou desenvolvidos para determinadas cidades.

Assim, para atender ao objetivo proposto de identificar alguns padrões da geração de viagens e da demanda por estacionamento em shopping centers, localizados em cidades de porte médio do interior do estado de São Paulo, selecionou-se uma amostra de treze shopping centers, com área bruta locável variando entre 4.200 a $108.600 \mathrm{~m}^{2}$, de um total de 30 empreendimentos localizados no interior do estado de São Paulo. Para verificar se os modelos desenvolvidos no país, para estimativas da geração de viagens e demanda por estacionamento, representam adequadamente a realidade da amostra selecionada, selecionaram-se como variáveis a serem pesquisadas nesses empreendimentos as que se apresentaram de mais fácil obtenção, devido a limitações de tempo e custo. E, para propor um novo método para definir parâmetros de projeto de shopping centers, com as características apresentadas, selecionaram-se os fatores horários e diários de projeto. 


\section{METODOLOGIA DAS PESQUISAS REALIZADAS}

\subsection{CONSIDERAÇÕES INICIAIS}

Atendendo aos objetivos do trabalho, de identificar padrões da geração de viagens e da demanda por estacionamento em shopping centers localizados no interior do estado de São Paulo, verificar se os modelos de geração de viagens e demanda por estacionamento desenvolvidos no país representam a realidade do universo estudado, desenvolver novos modelos de geração de viagens e propor um novo método para definir parâmetros de projeto para implantação de shopping centers, foram selecionados 13 empreendimentos localizados em cidades de médio porte, no interior do estado de São Paulo. No entanto, dessa amostra só foi possível realizar pesquisas em seis shopping centers, localizados em cidades distintas.

Estudos realizados por GRANDO (1986) e aperfeiçoados por GOLDNER (1994), indicam a média anual dos sábados e das sextas-feiras como os dias de projeto para estimar a demanda por estacionamento e avaliar o impacto de tráfego, respectivamente, em shopping centers. No entanto, neste trabalho, foram pesquisados apenas a sexta-feira e o sábado de um mês normal de funcionamento, devido à falta de contadores de tráfego nos acessos de entrada e saída do estacionamento, o que impossibilitou registros anuais dos empreendimentos.

\subsection{VARIÁVEIS PESQUISADAS}

Considerando a facilidade, rapidez e custo na obtenção das informações, as variáveis pesquisadas nos shopping centers foram as seguintes:

- Tamanho do empreendimento, considerando a área bruta locável e a área total construída, de modo a relacionar essas variáveis com a geração de viagens;

- Oferta de vagas de estacionamento, de modo a identificar o atendimento à demanda por estacionamento; 
- Horários de funcionamento, de modo a estabelecer o período de coleta de dados e identificar possíveis causas para o comportamento da demanda;

- Tamanho dos estabelecimentos, em área bruta locável, de modo a permitir relacionar as áreas desagregadas por ramos de atividade com a geração de viagens;

- Entrada e saída de veículos no estacionamento por fração horária, para sexta-feira e sábado, de modo a permitir obter o fluxo horário de veículos durante o dia e identificar os picos, permitindo ainda comparar esses valores com os identificados e adotados em outros estudos desenvolvidos no país;

- Tempo de permanência dos veículos no estacionamento, de modo a relacionar essa variável com a demanda por estacionamento e permitir ainda comparar esse valor com os identificados e adotados em outros estudos.

\subsection{MÉTODOS DE COLETA DE DADOS}

Nas pesquisas utilizaram-se técnicas de Preferência Revelada, já empregadas por BREVIS e FERRAZ (2001), considerando que as mesmas baseiam-se no comportamento observado dos usuários, conseqüentemente apresentando informações mais confiáveis. Esses procedimentos são apresentados a seguir.

- Levantamento do volume de tráfego - Realizado nos acessos de entrada e saída do estacionamento, através de contadores e manualmente, realizando registros em intervalos de 15 em 15 minutos. Dessa forma, foi determinado o volume de entrada e saída do estacionamento por intervalo de tempo, a variação da demanda, o acúmulo de veículos no estacionamento por intervalo de tempo e a incidência e amplitude dos picos horários de tráfego.

- Leitura de placas - Realizada nos acessos do estacionamento, através do registro de placas dos veículos nas entradas e saídas do estacionamento, de forma contínua, abrangendo todo o período de funcionamento do empreendimento, e realizando registros em intervalos de 15 minutos. Dessa forma, foi obtida a distribuição de tempo de permanência dos veículos no estacionamento, por intervalo horário, e a média ponderada do tempo de permanência.

\subsection{COLETA DE DADOS}

A coleta de dados constou dos seguintes levantamentos, realizados para cada shopping center pesquisado: 
- Informações coletadas no órgão municipal da cidade em que se encontra localizado o empreendimento;

- Entrevista com o administrador do shopping center; e

- Coleta de dados no estacionamento dos shopping centers.

As informações coletadas na Prefeitura da cidade em que se localiza o empreendimento foram: características locais e regionais onde se encontra inserido o empreendimento e características sócio-econômicas da população.

As informações coletadas junto à administração do shopping center foram as seguintes: área do terreno, área total construída, área bruta locável, período de funcionamento dos estabelecimentos, áreas dos estabelecimentos e oferta de vagas de estacionamento.

A coleta de dados no estacionamento foi realizada no período completo de funcionamento do empreendimento e incluiu os seguintes levantamentos: registro de entrada e saída de veículos do estacionamento e registro de placas dos veículos no estacionamento. Para o registro de entrada e saída de veículos do estacionamento foi utilizada a técnica de levantamento de volume de tráfego e para a distribuição de tempo de permanência dos veículos no estacionamento foi usada a técnica de leitura de placas.

\subsection{PROCESSAMENTO DOS DADOS}

Os dados coletados foram processados de tal forma a obter valores para alguns padrões de viagem e análise do comportamento da demanda por estacionamento em cada shopping center, para posteriormente realizar análises comparativas entre eles e com os modelos nacionais desenvolvidos para estimar a geração de viagens e demanda por estacionamento nesses empreendimentos.

Com os dados fornecidos pelas administrações dos shopping centers, quanto a tamanho dos estabelecimentos, foram agregadas as áreas dos estabelecimentos por ramos de atividade, de modo a obter o tamanho, em área bruta locável, das atividades de comércio, lazer e serviços oferecidos pelos empreendimentos, para posteriormente analisar a influência dessas variáveis na estimativa da geração de viagens e demanda por estacionamento.

Os registros de fluxos de entrada e saída de veículos do estacionamento foram tabelados e relacionados por hora. Em seguida, foram realizadas somatórias dos dados individuais de modo a obter o volume diário de veículos para sexta-feira e sábado. Para os 
registros de fluxos horários de entrada e saída foram realizadas somatórias por hora, de modo a obter o fluxo total por hora, de entrada e saída de veículos.

Com os dados de registro de entrada e saída de veículos, para sexta-feira e sábado, foram identificadas: as viagens diárias na sexta-feira e no sábado, a amplitude e incidência das viagens geradas na hora pico de entrada, saída e total, na sexta-feira e no sábado; as viagens horárias de entrada, saída e total, no período das 18:00 às 19:00h, para análise de impacto viário; e a taxa de atratividade.

Nos registros de fluxos de entrada e saída no sábado foram realizadas somatórias acumuladas das diferenças de entrada e saída por hora, de modo a permitir identificar o acúmulo máximo de veículos no estacionamento.

Os registros de leitura de placas de entrada e saída do estacionamento foram tabulados de forma a relacionar as mesmas placas de entrada e saída, com seus respectivos horários. Com esses dados foram determinados os tempos de permanência dos veículos no estacionamento. Em seguida, esses dados foram agrupados por fração horária, de modo a obter a quantidade de veículos que permaneceram no estacionamento por fração horária.

Com os dados de permanência dos veículos no estacionamento, por fração horária, determinou-se a média ponderada do tempo de permanência dos veículos no estacionamento, através da seguinte equação:

$$
T m=\sum T i V i / N
$$

Sendo, Tm: média ponderada do tempo de permanência dos veículos no estacionamento [hora]

Ti: tempo de permanência no estacionamento [hora];

$V i$ : quantidade de veículos no estacionamento por fração horária;

$N$ : total de veículos registrados no estacionamento.

Os valores identificados nos registros de fluxos de entrada e saída foram convertidos em valores relativos, de modo a relacioná-los posteriormente com os outros empreendimentos pesquisados e com padrões adotados por autores nacionais.

Para os valores identificados em cada empreendimento, foram relacionados: fluxo diário de sexta-feira e sábado, fluxo diário e o tamanho do empreendimento, fatores de pico horário, fatores horários para análise de impacto, acúmulo máximo de veículos com o fluxo diário, tempo médio de permanência dos veículos no estacionamento, e acúmulo máximo de veículos com o tempo médio de permanência e as viagens na hora pico. Para os resultados obtidos determinou-se a média, identificando algumas medidas de dispersão em relação aos 
valores observados, tais como: desvio médio, desvio padrão, coeficiente de variação e valores máximos e mínimos (amplitude dos desvios).

Nessas análises, como adotado por muitos analistas, foi considerada a média de seguinte forma: com baixa dispersão quando o coeficiente de variação é igual ou inferior a 15\%, com dispersão média quando o coeficiente de variação é superior a $15 \%$ e igual ou inferior a $30 \%$, e grande dispersão quando o coeficiente de variação é superior a $30 \%$.

Com os valores observados das viagens geradas na sexta-feira e no sábado foram desenvolvidos modelos de estimativas de viagens através de regressão linear simples e múltipla, considerando como variáveis independentes o tamanho geral e as áreas desagregadas por ramos de atividade dos empreendimentos pesquisados.

Os valores médios obtidos para o fator hora pico, fator horário de geração de viagens e tempo médio de permanência foram comparados com valores adotados por autores nacionais, de modo a identificar os valores que apresentam melhor desempenho.

Com os valores observados de fluxo de veículos diários na sexta-feira e sábado, nos shopping centers pesquisados, foram realizadas comparações com a aplicação de modelos nacionais e modelos desenvolvidos através da amostra pesquisada, de modo a identificar o desempenho dos modelos. 


\section{PESQUISAS NOS SHOPPING CENTERS}

\subsection{CONSIDERAÇÕES INICIAIS}

Para a realização das pesquisas de campo, inicialmente foi encaminhada documentação à administração de treze shopping centers localizados no interior do estado de São Paulo. Foi enviada carta de apresentação da EESC/USP, enfatizando a necessidade de uma pesquisa de tráfego em cada empreendimento, especificamente na área de estacionamento, detalhando as informações solicitadas e oferecendo disponibilidade para realizar pesquisa de campo para obter informações inexistentes, caso necessário.

Num primeiro momento, todos os empreendimentos se negaram a participar da pesquisa, e nenhum deles apresentou registro das informações solicitadas quanto à geração de viagens e demanda por estacionamento. Após insistência e negociação, foi possível obter informações de seis empreendimentos, com área bruta locável variando de 4.200 a $108.600 \mathrm{~m}^{2}$. Os shopping centers denominados "A", "B", “C", "D", "E" e "F" ofereceram informações através da administração e somente três deles, os empreendimentos "A", "B" e "C", autorizaram a realização de pesquisas de campo.

Para obter essa autorização foi estabelecido junto às administrações o seguinte acordo: nenhuma interferência com os clientes, sigilo absoluto na identificação de cada shopping center e fornecimento de relatório dos dados levantados no final da pesquisa.

Os três shopping centers, "A", "B" e "C", que autorizaram a pesquisa foram inicialmente visitados, obtendo-se informações preliminares quanto a características dos empreendimentos. Foram coletadas junto à administração informações quanto a: atratividade do empreendimento, horários de funcionamento, tamanho do empreendimento, áreas por ramo de atividades, número de vagas ofertadas e estimativas dos fluxos de tráfego para os dias mais movimentados.

Em seguida, foram analisadas características dos estacionamentos de forma a prever como informações inexistentes, quanto a fluxo de tráfego nos acessos do estacionamento 
e registro de placas dos veículos, poderiam ser coletadas sem interferir com os clientes. Isto é, evitando qualquer contato com os usuários dos veículos, de forma a atender ao acordo feito com as administrações dos shopping centers.

Dessa forma, foram selecionados os acessos de entrada e saída do estacionamento de cada empreendimento para programar e realizar as pesquisas de campo, levantamento de informações quanto a fluxo e movimentação de veículos nas áreas de estacionamento.

Para viabilizar o registro de informações, foram realizados formulários específicos para as características apresentadas nas áreas de estacionamento de cada empreendimento, de modo a facilitar a obtenção das informações desejadas. Assim, cada pesquisador alocado nos acessos de entrada e saída das áreas de estacionamento teve condições de realizar ambos registros, levantamento de volume de tráfego e leitura de placas dos veículos.

As pesquisas de campo foram realizadas nos meses de agosto, outubro e novembro de 2002, em sextas-feiras e sábados normais, isto é, sem programação de eventos e nem comemoração de feriado. As informações registradas, nos locais de acesso aos estacionamentos, foram tabuladas e analisadas de forma a obter os padrões de viagens dos usuários do estacionamento e comportamento da demanda, ao longo do período pesquisado.

A seguir são apresentadas as informações fornecidas pelas administrações dos shopping centers e os dados obtidos nas pesquisas realizadas nos estacionamentos dos empreendimentos "A", "B" e "C", que forneceram autorização para a realização de pesquisas de campo. Na seqüência, são apresentadas as informações fornecidas pelas administrações dos shopping centers "D", "E" e "F", que não permitiram a realização de pesquisas na área de estacionamento, mas que forneceram alguns dados gerais.

Características quanto às cidades em que se localizam os empreendimentos foram suprimidas para não expor a identidade dos mesmos, devido a que três deles são únicos nas cidades em que se localizam. No entanto, é possível destacar que os shopping centers não apresentam concorrentes no seu entorno e localizam-se em cidades de porte médio, com área territorial variando entre 580 a $795 \mathrm{~km}^{2}$. 


\subsection{SHOPPING CENTER "A"}

\subsubsection{CARACTERÍSTICAS DO EMPREENDIMENTO}

O shopping center "A" localiza-se num terreno de $74.800 \mathrm{~m}^{2}$, possuindo $64.000 \mathrm{~m}^{2}$ de ATC e $20.356 \mathrm{~m}^{2}$ de ABL. Oferece como atratividade lojas de artigos diversos, atividades de lazer, serviços e supermercado. As áreas de estacionamento de veículos apresentam-se distribuídas em dois níveis, subsolo e térreo, apresentando como oferta total de estacionamento 2.000 vagas. O período de funcionamento do empreendimento é apresentado na Tabela 4.1.

Tabela 4.1 - Período de funcionamento do shopping center " $A$ ".

\begin{tabular}{|l|c|c|}
\hline Horários & sexta- feira & sábado \\
\hline Comércio & $9: 00-23: 00$ & $8: 00-23: 00$ \\
\hline Serviços & $10: 00-22: 00$ & $10: 00-22: 00$ \\
\hline Lazer & $10: 00-22: 00$ & $10: 00-22: 00$ \\
\hline
\end{tabular}

O empreendimento, na ocasião da pesquisa, apresentava-se em processo de expansão, com obras de futuras instalações.

Cabe destacar que somente o supermercado permanece funcionando até as 23:00h, o fluxo de veículos de entrada após as 22:00h é muito reduzido e o fluxo de saída declina gradualmente até as 24:00h.

Na Tabela 4.2 são registrados os valores absolutos e relativos das áreas dos estabelecimentos por ramos de atividade, agrupados conforme segue. Na área de comércio correspondem: lojas de departamento, vestuário, artigos do lar, artigos eletrônicos, esportivos, perfumaria, lojas de brinquedos e supermercado. Na área de lazer encontram-se: diversões para crianças e brinquedos. Na área de serviços estão: fast food, choperias, cafeterias, administração, farmácias e drogarias, foto revelação, xerox, gráficas e dry wash.

Tabela 4.2 - Áreas por ramos de atividade para o shopping center "A".

\begin{tabular}{|l|c|c|}
\hline Ramos de Atividade & Área $\left[\mathbf{m}^{2}\right]$ & Área [\%] \\
\hline Comércio & 19486,57 & 95,73 \\
\hline Lazer & 244,33 & 1,20 \\
\hline Serviços $\quad$ Total & 625,34 & 3,07 \\
\hline \multicolumn{1}{|c|}{$\quad 20.356,24$} & 100,00 \\
\hline
\end{tabular}


Observa-se que, dos ramos de atividade, o que apresenta maior tamanho é o ramo de comércio com $95,73 \%$ da área bruta total do empreendimento. O setor de serviços junto com as áreas de lazer soma apenas 4,27\%.

\subsubsection{COLETA DE DADOS NO ESTACIONAMENTO}

A pesquisa de campo foi realizada no mês de agosto, numa sexta-feira e num sábado, num período contínuo das 8:00 às 22:00h (depois das 22:00h o número de viagens atraídas é bastante reduzido, segundo informações no local pelo pessoal de operação). Incluiu os seguintes levantamentos: registros de entrada e saída de veículos no estacionamento e registro de leitura de placas dos veículos que circularam pela área de estacionamento. Os dados obtidos foram processados e permitiram determinar alguns parâmetros que interferem na geração de viagens e na demanda por estacionamento.

\subsubsection{GERAÇÃO DE VIAGENS}

\subsection{SEXTA-FEIRA}

Os dados coletados na sexta-feira são mostrados na Tabela 4.3 e na Figura 4.1, e permitem identificar os fluxos de entrada e saída, incidência e amplitude dos picos horários e dos fatores horários adotados para análise de impacto viário.

Tabela 4.3 - Fluxos de entrada e saída para uma sexta-feira no shopping center " $A$ "

\begin{tabular}{|c|c|c|c|c|c|c|}
\hline $\begin{array}{c}\text { Período } \\
\text { [horas] }\end{array}$ & $\begin{array}{c}\text { Fluxo de } \\
\text { entrada } \\
\text { [veículos/hora] }\end{array}$ & $\begin{array}{c}\text { Fluxo de } \\
\text { entrada } \\
{[\%]}\end{array}$ & $\begin{array}{c}\text { Fluxo de saída } \\
\text { [veículos/hora] }\end{array}$ & $\begin{array}{c}\text { Fluxo de } \\
\text { saída } \\
{[\%]}\end{array}$ & $\begin{array}{c}\text { Entrada mais } \\
\text { saída } \\
\text { [veículos/hora] }\end{array}$ & $\begin{array}{c}\text { Entrada } \\
\text { mais saída } \\
\text { [\%] }\end{array}$ \\
\hline $08: 00-09: 00$ & 62 & 1,63 & 36 & 0,94 & 98 & 1,28 \\
\hline $09: 00-10: 00$ & 139 & 3,64 & 62 & 1,63 & 201 & 2,63 \\
\hline $10: 00-11: 00$ & 158 & 4,14 & 122 & 3,20 & 280 & 3,67 \\
\hline $11: 00-12: 00$ & 206 & 5,40 & 172 & 4,51 & 378 & 4,95 \\
\hline $12: 00-13: 00$ & 270 & 7,08 & 193 & 5,06 & 463 & 6,07 \\
\hline $13: 00-14: 00$ & 253 & 6,63 & 284 & 7,44 & 537 & 7,04 \\
\hline $14: 00-15: 00$ & 277 & 7,26 & 273 & 7,16 & 550 & 7,21 \\
\hline $15: 00-16: 00$ & 263 & 6,89 & 296 & 7,76 & 559 & 7,33 \\
\hline $16: 00-17: 00$ & 275 & 7,21 & 368 & 9,65 & 643 & 8,43 \\
\hline $17: 00-18: 00$ & 333 & 8,73 & 356 & 9,33 & 689 & 9,03 \\
\hline $18: 00-19: 00$ & 451 & 11,82 & 362 & 9,49 & 813 & 10,66 \\
\hline $19: 00-20: 00$ & 514 & 13,47 & 417 & 10,93 & 931 & 12,20 \\
\hline $20: 00-21: 00$ & 381 & 9,99 & 437 & 11,45 & 818 & 10,72 \\
\hline $21: 00-22: 00$ & 233 & 6,11 & 435 & 11,40 & 668 & 8,75 \\
\hline Após 22:00 & ----- & ----- & 2 & 0,05 & 2 & 0,03 \\
\hline Total & 3.815 & 100,00 & 3.815 & 100,00 & 7.630 & 100,00 \\
\hline
\end{tabular}




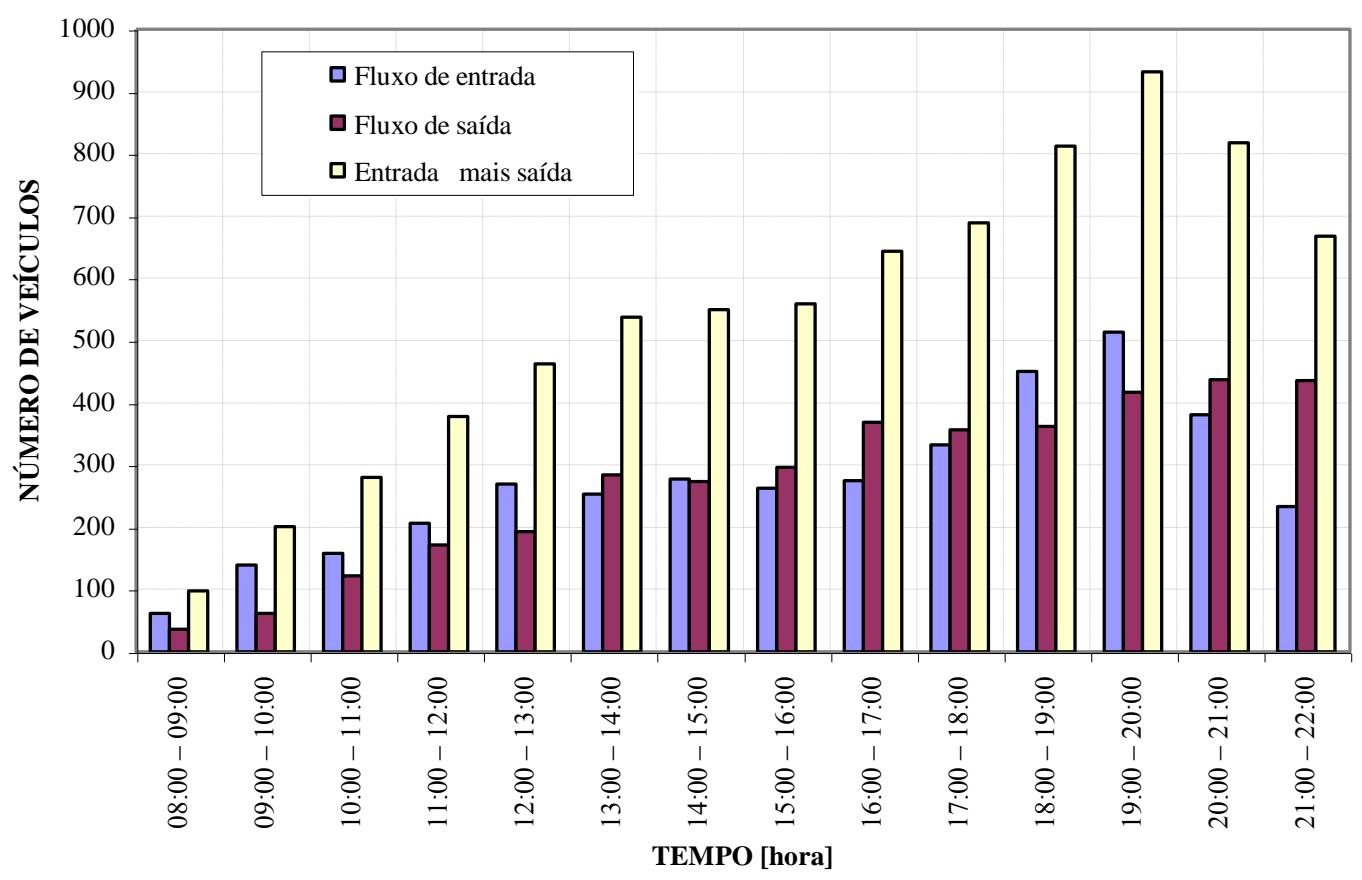

Figura 4.1 - Fluxos de entrada e saída para uma sexta-feira no shopping center "A”.

O pico horário do tráfego atraído ocorre entre 19:00 e 20:00h, correspondendo ao fluxo de entrada de 514 veículos por hora (13,47\% do total do dia), o pico horário de saída ocorre entre 20:00 e 21:00h, correspondendo a 437 veículos por hora (11,45\% do total do dia) e o pico horário total acontece entre 19:00 e 20:00h, correspondendo a 931 veículos por hora (12,20\% do total de entrada e saída do dia).

Contudo, como visto, para efeito de análise de impacto no trânsito, o período crítico é das 18:00 às 19:00h, quando o fluxo de entrada corresponde a 451 veículos por hora $(11,82 \%$ do fluxo total diário), o fluxo de saída corresponde a 362 veículos por hora (9,49\% do fluxo total diário) e o fluxo total corresponde a 813 veículos por hora (10,66\% do fluxo total de entrada e saída do dia).

\subsection{SÁBADO}

Os dados coletados no sábado são mostrados na Tabela 4.4 e na Figura 4.2, e permitem identificar os fluxos de entrada e saída, incidência e amplitude dos picos horários e taxa de atratividade. 
Tabela 4.4 - Fluxos de entrada e saída para um sábado no shopping center "A".

\begin{tabular}{|c|c|c|c|c|c|c|}
\hline $\begin{array}{c}\text { Período } \\
\text { [horas] }\end{array}$ & $\begin{array}{c}\text { Fluxo de } \\
\text { entrada } \\
\text { [veículos/hora] }\end{array}$ & $\begin{array}{c}\text { Fluxo de } \\
\text { entrada } \\
{[\%]}\end{array}$ & $\begin{array}{c}\text { Fluxo de saída } \\
\text { [veículos/hora] }\end{array}$ & $\begin{array}{c}\text { Fluxo de } \\
\text { saída } \\
{[\%]}\end{array}$ & $\begin{array}{c}\text { Entrada mais } \\
\text { saída } \\
\text { [veículos/hora] }\end{array}$ & $\begin{array}{c}\text { Entrada } \\
\text { mais saída } \\
\text { [\%] }\end{array}$ \\
\hline $08: 00-09: 00$ & 90 & 1,46 & 37 & 0,60 & 127 & 1,03 \\
\hline $09: 00-10: 00$ & 259 & 4,21 & 117 & 1,90 & 376 & 3,06 \\
\hline 10:00-11:00 & 388 & 6,31 & 269 & 4,37 & 657 & 5,34 \\
\hline 11:00-12:00 & 383 & 6,22 & 396 & 6,44 & 779 & 6,33 \\
\hline 12:00-13:00 & 396 & 6,44 & 373 & 6,06 & 769 & 6,25 \\
\hline 13:00-14:00 & 411 & 6,68 & 412 & 6,70 & 823 & 6,69 \\
\hline 14:00-15:00 & 456 & 7,41 & 466 & 7,57 & 922 & 7,49 \\
\hline 15:00-16:00 & 588 & 9,56 & 466 & 7,57 & 1.054 & 8,56 \\
\hline 16:00-17:00 & 515 & 8,37 & 566 & 9,20 & 1.081 & 8,78 \\
\hline 17:00-18:00 & 531 & 8,63 & 506 & 8,22 & 1.037 & 8,43 \\
\hline 18:00-19:00 & 592 & 9,62 & 530 & 8,61 & 1.122 & 9,12 \\
\hline 19:00-20:00 & 651 & 10,58 & 547 & 8,89 & 1.198 & 9,74 \\
\hline 20:00-21:00 & 619 & 10,06 & 568 & 9,23 & 1.187 & 9,65 \\
\hline 21:00-22:00 & 274 & 4,45 & 578 & 9,39 & 852 & 6,92 \\
\hline Após 22:00 & ----- & ---- & 322 & 5,23 & 322 & 2,62 \\
\hline Total & 6.153 & 100,00 & 6.153 & 100,00 & 12.306 & 100,00 \\
\hline
\end{tabular}

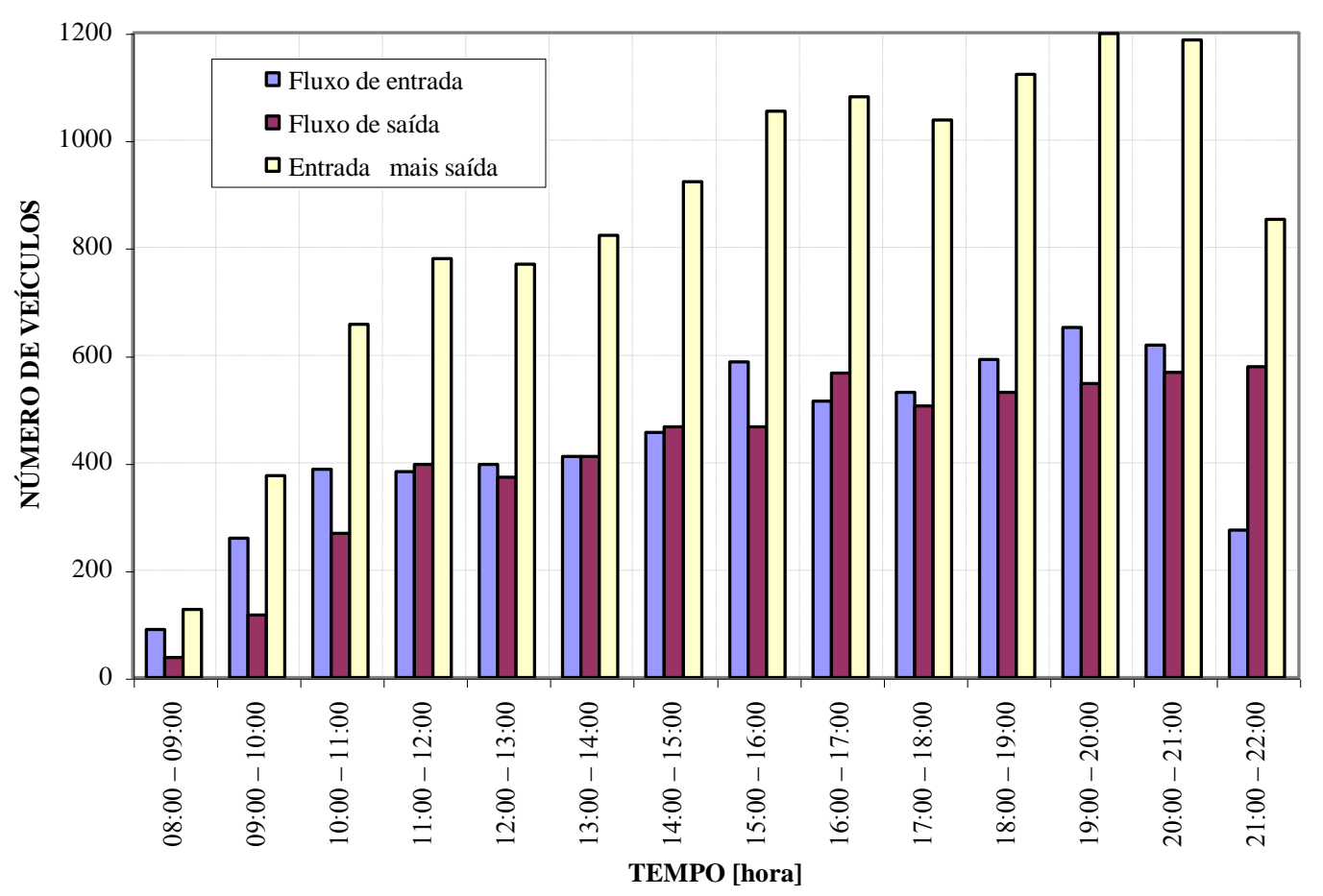

Figura 4.2 - Fluxos de entrada e saída para um sábado no shopping center "A". 
O pico horário do tráfego ocorre entre 19:00 e 20:00h, correspondendo ao fluxo de entrada de 651 veículos por hora (10,58\% do total do dia), o pico horário de saída ocorre entre 21:00 e 22:00h, correspondendo ao fluxo de saída de 578 veículos por hora $(9,39 \%$ do total diário) e o pico horário total acontece entre 19:00 e 20:00h, correspondendo a 1.198 veículos por hora $(9,74 \%$ do total de entrada e saída diário).

Conforme esperado, esses dados mostram que as viagens atraídas no sábado, das 8:00 às 22:00h, são $61,28 \%$ maior que na sexta-feira no mesmo período.

A taxa de atratividade do shopping center, que relaciona o maior fluxo de veículos atraídos por dia com o tamanho do empreendimento, corresponde a 30,23 veículos por $100 \mathrm{~m}^{2}$ de ABL.

\subsubsection{DEMANDA POR ESTACIONAMENTO}

A Tabela 4.5 e a Figura 4.3 mostram os valores do acúmulo de veículos no estacionamento por hora, no sábado. Permitem verificar o comportamento da demanda por estacionamento, observar os picos e ainda identificar a maior demanda por estacionamento.

Tabela 4.5 - Veículos acumulados no sábado no shopping center "A".

\begin{tabular}{|c|c|c|c|c|c|}
\hline $\begin{array}{c}\text { Período } \\
\text { [horas] }\end{array}$ & $\begin{array}{c}\text { Fluxo de } \\
\text { entrada } \\
\text { [veículos/hora] }\end{array}$ & $\begin{array}{c}\text { Fluxo de saída } \\
\text { [veículos/hora] }\end{array}$ & $\begin{array}{c}\text { Entrada } \\
\text { menos saída } \\
\text { [veículos/hora] }\end{array}$ & $\begin{array}{c}\text { Acúmulo de } \\
\text { veículos no } \\
\text { estacionamento } \\
\text { [veículos/hora] }\end{array}$ & $\begin{array}{c}\text { Porcentagem em } \\
\text { relação ao } \\
\text { acúmulo máximo } \\
\text { [\%] }\end{array}$ \\
\hline $08: 00-09: 00$ & 90 & 37 & 53 & 53 & 8,47 \\
\hline $09: 00-10: 00$ & 259 & 117 & 142 & 195 & 31,15 \\
\hline $10: 00-11: 00$ & 388 & 269 & 119 & 314 & 50,16 \\
\hline $11: 00-12: 00$ & 383 & 396 & -13 & 301 & 48,08 \\
\hline $12: 00-13: 00$ & 396 & 373 & 23 & 324 & 51,76 \\
\hline $13: 00-14: 00$ & 411 & 412 & -1 & 323 & 51,60 \\
\hline $14: 00-15: 00$ & 456 & 466 & -10 & 313 & 50,00 \\
\hline $15: 00-16: 00$ & 588 & 466 & 122 & 435 & 69,49 \\
\hline $16: 00-17: 00$ & 515 & 566 & -51 & 384 & 61,34 \\
\hline $17: 00-18: 00$ & 531 & 506 & 25 & 409 & 65,34 \\
\hline $18: 00-19: 00$ & 592 & 530 & 62 & 471 & 75,24 \\
\hline $19: 00-20: 00$ & 651 & 547 & 104 & 575 & 91,85 \\
\hline 20:00-21:00 & 619 & 568 & 51 & 626 & 100,00 \\
\hline $21: 00-22: 00$ & 274 & 578 & -304 & 322 & 51,44 \\
\hline Após 22:00 & ----- & 322 & -322 & 0 & 0,00 \\
\hline Total & 6.153 & 6.153 & 0 & ---- & ---1 \\
\hline
\end{tabular}




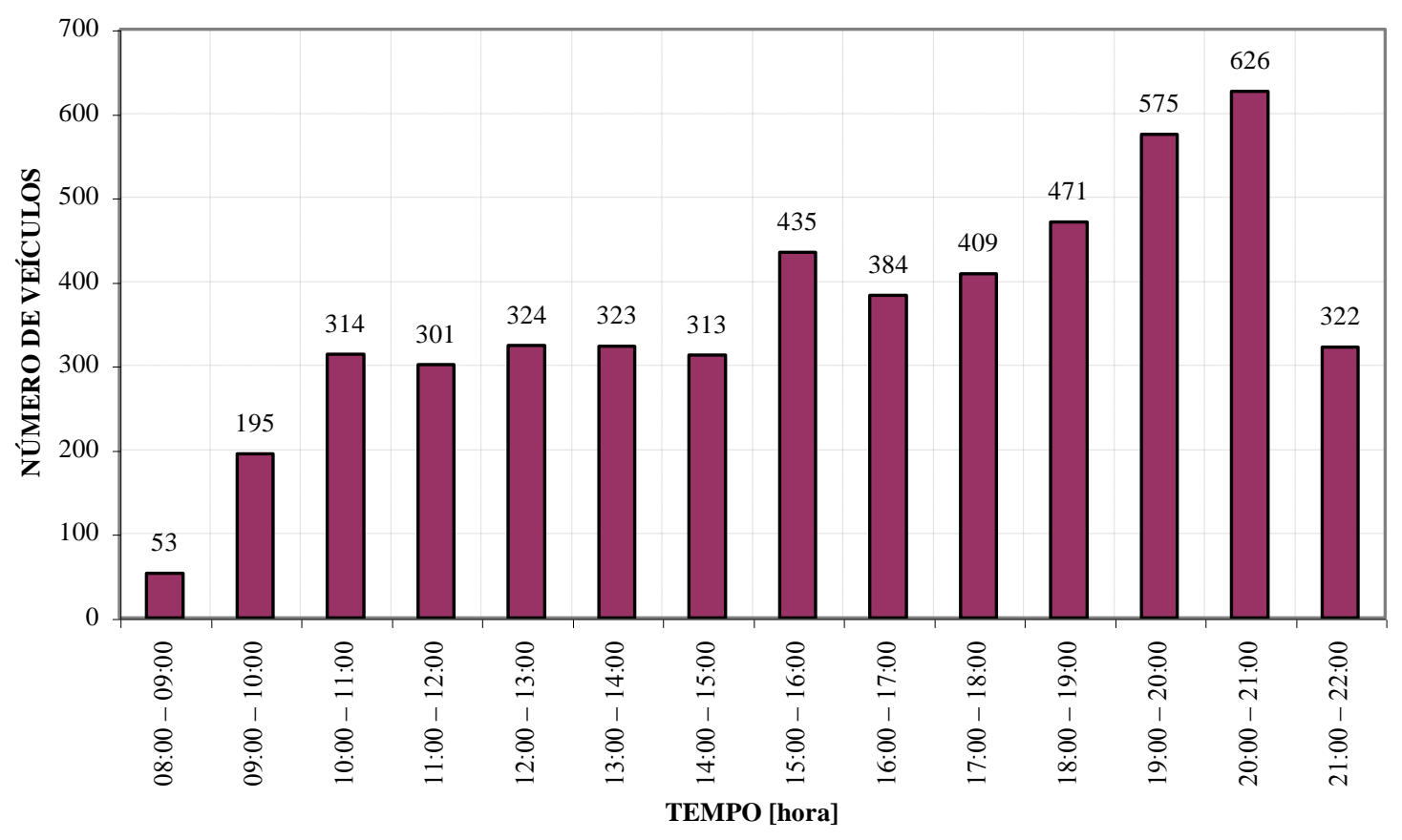

Figura 4.3 - Veículos acumulados no estacionamento no shopping center " $A$ ".

Observa-se que o maior acúmulo de veículos no estacionamento ocorre no período das 20:00 às 21:00h, totalizando 626 veículos.

\subsubsection{DURAÇÃO DO ESTACIONAMENTO}

O registro de leitura de placas dos veículos, para obter a distribuição do tempo de permanência na área de estacionamento, foi realizado no sábado, num período contínuo das 8:00 às 22:00h. Os dados coletados representam uma amostra de $41 \%$ do total de viagens atraídas pelo empreendimento durante o dia da pesquisa.

A Tabela 4.6 mostra os valores obtidos para o tempo que os veículos permaneceram na área de estacionamento. 
Tabela 4.6 - Tempo de permanência dos veículos no shopping center "A".

\begin{tabular}{|c|c|c|}
\hline Tempo de permanência [hora] & Veículos [\%] & Veículos acumulados [\%] \\
\hline $0,00-0,25$ & 24,29 & 24,29 \\
\hline $0,25-0,50$ & 16,87 & 41,16 \\
\hline $0,50-0,75$ & 14,24 & 55,40 \\
\hline $0,75-1,00$ & 10,53 & 65,93 \\
\hline $1,00-1,25$ & 9,33 & 75,27 \\
\hline $1,25-1,50$ & 7,10 & 82,37 \\
\hline $1,50-1,75$ & 5,38 & 87,75 \\
\hline $1,75-2,00$ & 4,03 & 91,78 \\
\hline $2,00-2,25$ & 2,39 & 94,17 \\
\hline $2,25-2,50$ & 1,48 & 95,65 \\
\hline $2,50-2,75$ & 1,36 & 97,01 \\
\hline $2,75-3,00$ & 0,52 & 97,52 \\
\hline $3,00-3,25$ & 0,32 & 97,84 \\
\hline $3,25-3,50$ & 0,32 & 98,16 \\
\hline $3,50-3,75$ & 0,24 & 98,40 \\
\hline $3,75-4,00$ & 0,24 & 98,64 \\
\hline $4,00-4,25$ & 0,24 & 98,88 \\
\hline $4,25-4,50$ & 0,32 & 99,20 \\
\hline $4,50-4,75$ & 0,04 & 99,24 \\
\hline $4,75-5,00$ & 0,16 & 99,40 \\
\hline $5,00-5,25$ & 0,04 & 99,44 \\
\hline $5,25-5,50$ & 0,04 & 99,48 \\
\hline $5,50-5,75$ & 0,04 & 99,52 \\
\hline $5,75-6,00$ & 0,12 & 99,64 \\
\hline $6,50-6,75$ & 0,08 & 99,72 \\
\hline $8,50-8,75$ & 0,08 & 99,80 \\
\hline $8,75-9,00$ & 0,04 & 99,84 \\
\hline $10,50-10,75$ & 0,04 & 99,88 \\
\hline $10,75-11,00$ & 0,04 & 99,92 \\
\hline $11,25-11,50$ & 0,04 & 99,96 \\
\hline $12,25-12,50$ & 0,04 & 100,00 \\
\hline Total & 100,00 & \\
\hline
\end{tabular}

Esses dados indicam que 24,29\% dos veículos permanecem no local de estacionamento no máximo 15 minutos, 16,87\% permanecem entre 15 e 30 minutos no máximo e $14,24 \%$ permanecem entre 30 e 45 minutos; representando em conjunto mais de $55 \%$ do total de veículos que passam pelo estacionamento. Observa-se também que mais de 91,78\% dos usuários permanecem no máximo 2 horas. Cabe notar, ainda, que 0,36\% dos veículos permanecem por tempo superior a 6 horas, provavelmente associado a viagens por motivo de trabalho.

Com base nos dados registrados na Tabela 4.7, apresentada a seguir, foi determinada a média ponderada do tempo de permanência dos veículos na área de estacionamento, no sábado. 
Tabela 4.7 - Permanência no estacionamento por fração horária no shopping center "A".

\begin{tabular}{|c|c|c|}
\hline Permanência [hora] $(\mathrm{Ti})$ & Veículos $(V i)$ & $T i \times V i$ \\
\hline 0,13 & 609 & 76,13 \\
\hline 0,38 & 423 & 158,63 \\
\hline 0,63 & 357 & 223,13 \\
\hline 0,88 & 264 & 231,00 \\
\hline 1,13 & 234 & 263,25 \\
\hline 1,38 & 178 & 244,75 \\
\hline 1,63 & 135 & 219,38 \\
\hline 1,88 & 101 & 189,38 \\
\hline 2,13 & 60 & 127,50 \\
\hline 2,38 & 37 & 87,88 \\
\hline 2,63 & 34 & 89,25 \\
\hline 2,88 & 13 & 37,38 \\
\hline 3,13 & 8 & 25,00 \\
\hline 3,38 & 8 & 27,00 \\
\hline 3,63 & 6 & 21,75 \\
\hline 3,88 & 6 & 23,25 \\
\hline 4,13 & 6 & 24,75 \\
\hline 4,38 & 8 & 35,00 \\
\hline 4,63 & 1 & 4,63 \\
\hline 4,88 & 4 & 19,50 \\
\hline 5,13 & 1 & 5,13 \\
\hline 5,38 & 1 & 5,38 \\
\hline 5,63 & 1 & 5,63 \\
\hline 5,88 & 3 & 17,63 \\
\hline 6,63 & 2 & 13,25 \\
\hline 8,63 & 2 & 17,25 \\
\hline 8,88 & 1 & 8,88 \\
\hline 10,63 & 1 & 10,63 \\
\hline 10,88 & 1 & 10,88 \\
\hline 11,38 & 1 & 11,38 \\
\hline 12,38 & 1 & 12,38 \\
\hline$\Sigma$ & 2.507 & $2.246,88$ \\
\hline
\end{tabular}

O tempo médio de permanência dos veículos no estacionamento no sábado corresponde a 0,90 horas, isto é, os veículos permanecem em média 54 minutos no estacionamento.

\subsubsection{PRINCIPAIS RESULTADOS OBTIDOS}

Os principais valores obtidos nas pesquisas realizadas na sexta-feira e no sábado foram os seguintes:

- Viagens diárias atraídas pelo empreendimento: 6.153 veículos no sábado e 3.815 na sextafeira, representando o volume de sexta-feira $62,00 \%$ do volume do sábado.

- Incidência do maior pico horário na sexta-feira: entre 19:00 e 20:00h na entrada, entre 20:00 e 21:00h na saída e entre 19:00 e 20:00h para os fluxos de entrada e saída. 
- Porcentagem de pico horário na sexta-feira: $13,47 \%$ do total de veículos na entrada, $11,45 \%$ do total de veículos na saída e 12,20\% do total de veículos que entraram e saíram do estacionamento.

- Fator horário de geração de viagens para efeito de análise do impacto no trânsito: $11,82 \%$ do total de veículos na entrada, 9,49\% do total de veículos na saída e $10,66 \%$ do total de veículos de entrada e saída, na sexta-feira, entre 18:00 e 19:00h.

- Incidência do maior pico horário no sábado: entre 19:00 e 20:00h na entrada, entre 21:00 e 22:00h na saída e entre 19:00 e 20:00h para os fluxos de entrada e saída.

- Porcentagem de pico horário no sábado: $10,58 \%$ do total de veículos na entrada, 9,39\% do total de veículos na saída e $9,74 \%$ do total de veículos que entraram e saíram do estacionamento.

- Taxa de atratividade: 30,23 veículos por $100 \mathrm{~m}^{2}$ de ABL no sábado.

- Incidência horária do maior acúmulo de veículos: entre 20:00 e 21:00h no sábado.

- Porcentagem do maior pico horário no acúmulo de veículos: 10,06\% do fluxo total atraído no sábado.

- Demanda máxima por estacionamento: 626 vagas no sábado.

- Tempo médio de permanência dos veículos no estacionamento: 0,90h (54 minutos) no sábado.

\subsection{SHOPPING CENTER "B"}

\subsubsection{CARACTERÍSTICAS DO EMPREENDIMENTO}

O shopping center "B" localiza-se num terreno de $22.000 \mathrm{~m}^{2}$, possuindo $11.600 \mathrm{~m}^{2}$ de ATC e $4.200 \mathrm{~m}^{2}$ de ABL. Oferece como atratividade lojas de artigos diversos, atividades de lazer e serviços. As áreas de estacionamento de veículos são distribuídas no entorno ao empreendimento, apresentando como oferta total de estacionamento 200 vagas. No entanto, existe uma área próxima ao empreendimento, com capacidade para mais de 50 vagas, da qual os clientes do shopping center fazem uso, quando a demanda por estacionamento supera a capacidade ofertada. O período de funcionamento do empreendimento é apresentado na Tabela 4.8. 
Tabela 4.8 - Período de funcionamento do shopping center "B".

\begin{tabular}{|l|c|c|}
\hline Horários & sexta-feira & sábado \\
\hline Comércio & $10: 00-22: 00$ & $10: 00-22: 00$ \\
\hline Serviços & $10: 00-22: 00$ & $10: 00-22: 00$ \\
\hline Lazer & $10: 00-23: 00$ & $10: 00-23: 00$ \\
\hline
\end{tabular}

Cabe destacar que somente os cinemas permanecem funcionando até as 23:00h, o fluxo de veículos de entrada após as 22:00h é reduzido e o fluxo de saída declina gradualmente até as 02:00h, devido a que a área de estacionamento, no momento em que os cinemas fecham, é utilizada por um público jovem como área de lazer.

Na Tabela 4.9 são registrados os valores absolutos e relativos das áreas dos estabelecimentos por ramos de atividade, agrupados conforme a seguir. $\mathrm{Na}$ área de comércio correspondem: lojas de vestuário, artigos do lar, artigos eletrônicos, esportivos, perfumaria e lojas de brinquedos. No ramo de serviços estão: restaurantes, fast food, choperias e cafeterias, administração, farmácias e drogarias, foto revelação e xerox. Na área de lazer encontram-se: cinemas, diversões para crianças e brinquedos.

Tabela 4.9 - Áreas por ramos de atividade para o shopping center "B".

\begin{tabular}{|c|c|c|}
\hline Ramos de Atividade & Área $\left[m^{2}\right]$ & Área [\%] \\
\hline Comércio & $2.438,00$ & 58,05 \\
\hline Lazer & 993,00 & 23,64 \\
\hline Serviços & 769,00 & 18,31 \\
\hline Total & $4.200,00$ & 100,00 \\
\hline
\end{tabular}

Observa-se que, dos ramos de atividade, o que apresenta maior tamanho é o setor de comércio com $58,05 \%$ da área total, ficando em segundo lugar a área de lazer com $23,64 \%$ da área bruta total do empreendimento. O setor de serviços também apresenta área significativa, correspondendo a $18,31 \%$ do total.

\subsubsection{COLETA DE DADOS NO ESTACIONAMENTO}

A pesquisa de campo foi realizada no mês de outubro, num período contínuo das 9:00 às 22:00h, numa sexta-feira e num sábado. Incluiu os seguintes levantamentos: fluxos de entrada e saída de veículos no estacionamento e registro de leitura de placas dos veículos que circularam pela área de estacionamento. 


\subsubsection{GERAÇÃO DE VIAGENS}

\subsection{SEXTA-FEIRA}

Os dados coletados na sexta-feira são mostrados na Tabela 4.10 e na Figura 4.4, e permitem identificar os fluxos de entrada e saída, incidência e amplitude dos picos horários e dos fatores horários de geração de viagens para análise de impacto viário.

Tabela 4.10 - Fluxos de entrada e saída para uma sexta-feira no shopping center "B".

\begin{tabular}{|c|c|c|c|c|c|c|}
\hline $\begin{array}{c}\text { Período } \\
\text { [horas] }\end{array}$ & $\begin{array}{c}\text { Fluxo de } \\
\text { entrada } \\
\text { [veículos/hora] }\end{array}$ & $\begin{array}{c}\text { Fluxo de } \\
\text { entrada } \\
{[\%]}\end{array}$ & $\begin{array}{c}\text { Fluxo de saída } \\
\text { [veículos/hora] }\end{array}$ & $\begin{array}{c}\text { Fluxo de } \\
\text { saída } \\
{[\%]}\end{array}$ & $\begin{array}{c}\text { Entrada mais } \\
\text { saída } \\
\text { [veículos/hora] }\end{array}$ & $\begin{array}{c}\text { Entrada } \\
\text { mais saída } \\
{[\%]}\end{array}$ \\
\hline $09: 00-10: 00$ & 25 & 1,75 & 7 & 0,49 & 32 & 1,12 \\
\hline $10: 00-11: 00$ & 52 & 3,63 & 41 & 2,86 & 93 & 3,25 \\
\hline $11: 00-12: 00$ & 53 & 3,70 & 43 & 3,00 & 96 & 3,35 \\
\hline $12: 00-13: 00$ & 72 & 5,03 & 58 & 4,05 & 130 & 4,54 \\
\hline $13: 00-14: 00$ & 58 & 4,05 & 72 & 5,03 & 130 & 4,54 \\
\hline $14: 00-15: 00$ & 77 & 5,38 & 60 & 4,19 & 137 & 4,78 \\
\hline $15: 00-16: 00$ & 133 & 9,29 & 95 & 6,63 & 228 & 7,96 \\
\hline $16: 00-17: 00$ & 90 & 6,28 & 84 & 5,87 & 174 & 6,08 \\
\hline $17: 00-18: 00$ & 91 & 6,35 & 82 & 5,73 & 173 & 6,04 \\
\hline $18: 00-19: 00$ & 189 & 13,20 & 136 & 9,50 & 325 & 11,35 \\
\hline $19: 00-20: 00$ & 195 & 13,62 & 110 & 7,68 & 305 & 10,65 \\
\hline $20: 00-21: 00$ & 204 & 14,25 & 184 & 12,85 & 388 & 13,55 \\
\hline $21: 00-22: 00$ & 193 & 13,48 & 213 & 14,87 & 406 & 14,18 \\
\hline Após 22:00 & ----- & ----- & 247 & 17,25 & 247 & 8,62 \\
\hline Total & 1.432 & 100,00 & 1.432 & 100,00 & 2864 & 100,00 \\
\hline
\end{tabular}

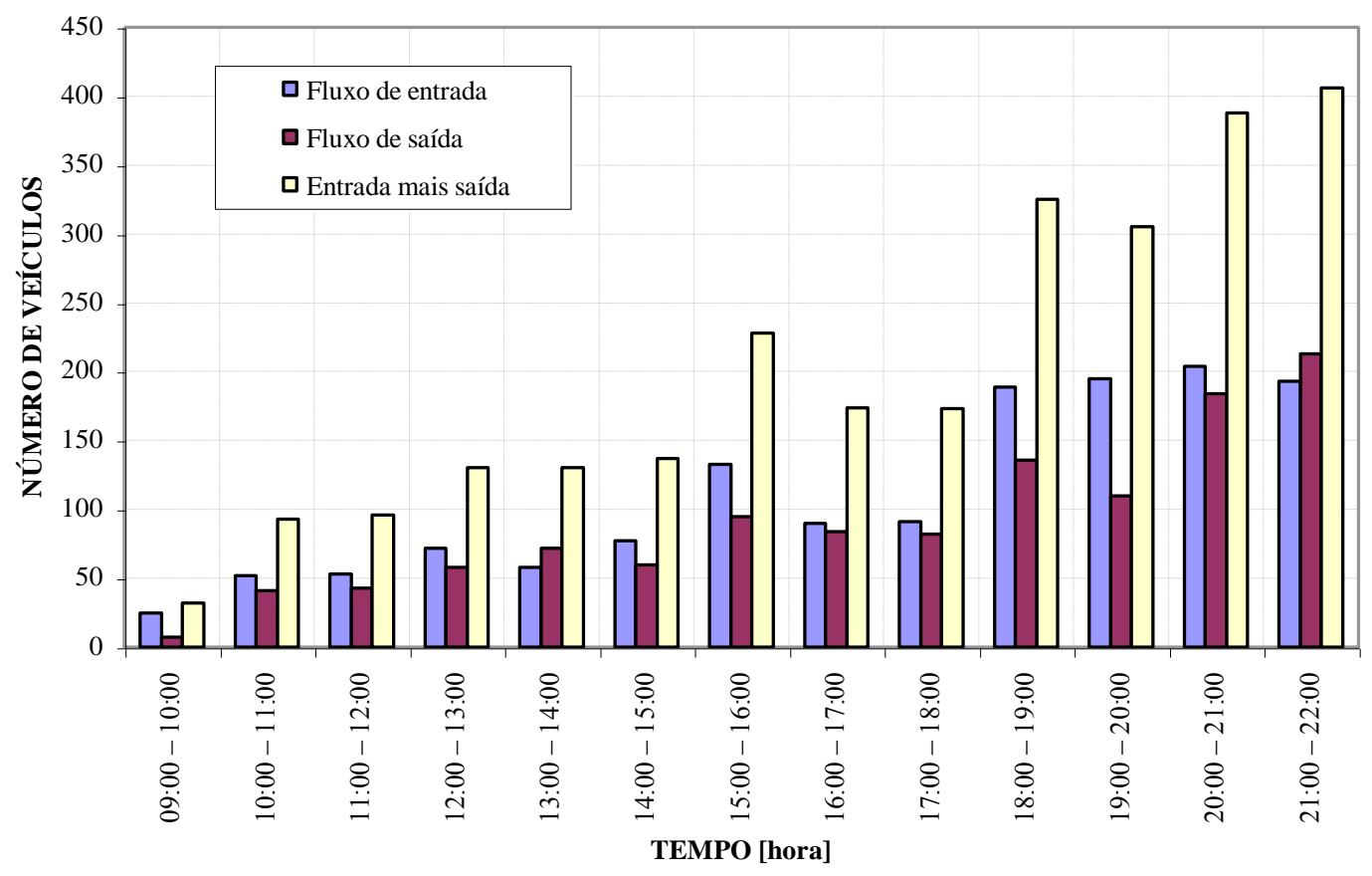

Figura 4.4 - Fluxos de entrada e saída para uma sexta-feira no shopping center "B". 
O pico horário do tráfego atraído ocorre entre 20:00 e 21:00h, correspondendo ao fluxo de entrada de 204 veículos por hora (14,25\% do total do dia), o pico horário de saída ocorre entre 21:00 e 22:00h, correspondendo a 213 veículos por hora (14,87\% do total do dia), e o pico horário total acontece entre 21:00 e 22:00h, correspondendo a 406 veículos por hora (12,20\% do total de entrada e saída do dia).

Para efeito de análise de impacto no trânsito, no horário das 18:00 às 19:00h, o fluxo de entrada corresponde a 189 veículos por hora (13,20\% do fluxo total diário), o fluxo de saída corresponde a 136 veículos por hora (9,50\% do fluxo total diário) e o fluxo total corresponde a 325 veículos por hora $(11,35 \%$ do fluxo total de entrada e saída do dia).

\subsection{SÁBADO}

Os dados coletados no sábado são mostrados na Tabela 4.11 e na Figura 4.5, e permitem identificar os fluxos de entrada e saída, taxa de atratividade e incidência e amplitude dos picos horários.

Tabela 4.11 - Fluxos de entrada e saída para um sábado no shopping center "B".

\begin{tabular}{|c|c|c|c|c|c|c|}
\hline $\begin{array}{c}\text { Período } \\
\text { [horas] }\end{array}$ & $\begin{array}{c}\text { Fluxo de } \\
\text { entrada } \\
\text { [veículos/hora] }\end{array}$ & $\begin{array}{c}\text { Fluxo de } \\
\text { entrada } \\
{[\%]}\end{array}$ & $\begin{array}{c}\text { Fluxo de saída } \\
\text { [veículos/hora] }\end{array}$ & $\begin{array}{c}\text { Fluxo de } \\
\text { saída } \\
{[\%]}\end{array}$ & $\begin{array}{c}\text { Entrada mais } \\
\text { saída } \\
\text { [veículos/hora] }\end{array}$ & $\begin{array}{c}\text { Entrada } \\
\text { mais saída } \\
\text { [\%] }\end{array}$ \\
\hline 09:00-10:00 & 54 & 3,10 & 15 & 0,86 & 69 & 1,98 \\
\hline $10: 00-11: 00$ & 82 & 4,70 & 60 & 3,44 & 142 & 4,07 \\
\hline $11: 00-12: 00$ & 73 & 4,19 & 55 & 3,16 & 128 & 3,67 \\
\hline $12: 00-13: 00$ & 93 & 5,34 & 77 & 4,42 & 170 & 4,88 \\
\hline $13: 00-14: 00$ & 93 & 5,34 & 81 & 4,65 & 174 & 4,99 \\
\hline $14: 00-15: 00$ & 117 & 6,71 & 86 & 4,93 & 203 & 5,82 \\
\hline $15: 00-16: 00$ & 198 & 11,36 & 136 & 7,80 & 334 & 9,58 \\
\hline $16: 00-17: 00$ & 102 & 5,85 & 134 & 7,69 & 236 & 6,77 \\
\hline $17: 00-18: 00$ & 103 & 5,91 & 131 & 7,52 & 234 & 6,71 \\
\hline $18: 00-19: 00$ & 212 & 12,16 & 115 & 6,60 & 327 & 9,38 \\
\hline $19: 00-20: 00$ & 119 & 6,83 & 136 & 7,80 & 255 & 7,31 \\
\hline $20: 00-21: 00$ & 227 & 13,02 & 162 & 9,29 & 389 & 11,16 \\
\hline $21: 00-22: 00$ & 270 & 15,49 & 241 & 13,83 & 511 & 14,66 \\
\hline Após 22:00 & ---- & ----- & 314 & 18,01 & 314 & 9,01 \\
\hline Total & 1.743 & 100,00 & 1.743 & 100,00 & 3486 & 100,00 \\
\hline
\end{tabular}

O pico horário do tráfego ocorre entre 21:00 e 22:00h, correspondendo ao fluxo de entrada de 270 veículos por hora (15,49\% do total do dia), o pico horário de saída ocorre entre 21:00 e 22:00h, correspondendo ao fluxo de saída de 241 veículos por hora (13,83\% do total diário), e o pico horário total acontece entre 21:00 e 22:00h, correspondendo a 511 veículos por hora (14,66\% do total de entrada e saída diário). 
Conforme esperado, esses dados mostram que as viagens atraídas no sábado, das 8:00 às 22:00h, são $21,72 \%$ maior que na sexta-feira no mesmo período.

A taxa de atratividade do shopping center corresponde a 41,50 veículos por $100 \mathrm{~m}^{2}$ de $\mathrm{ABL}$.

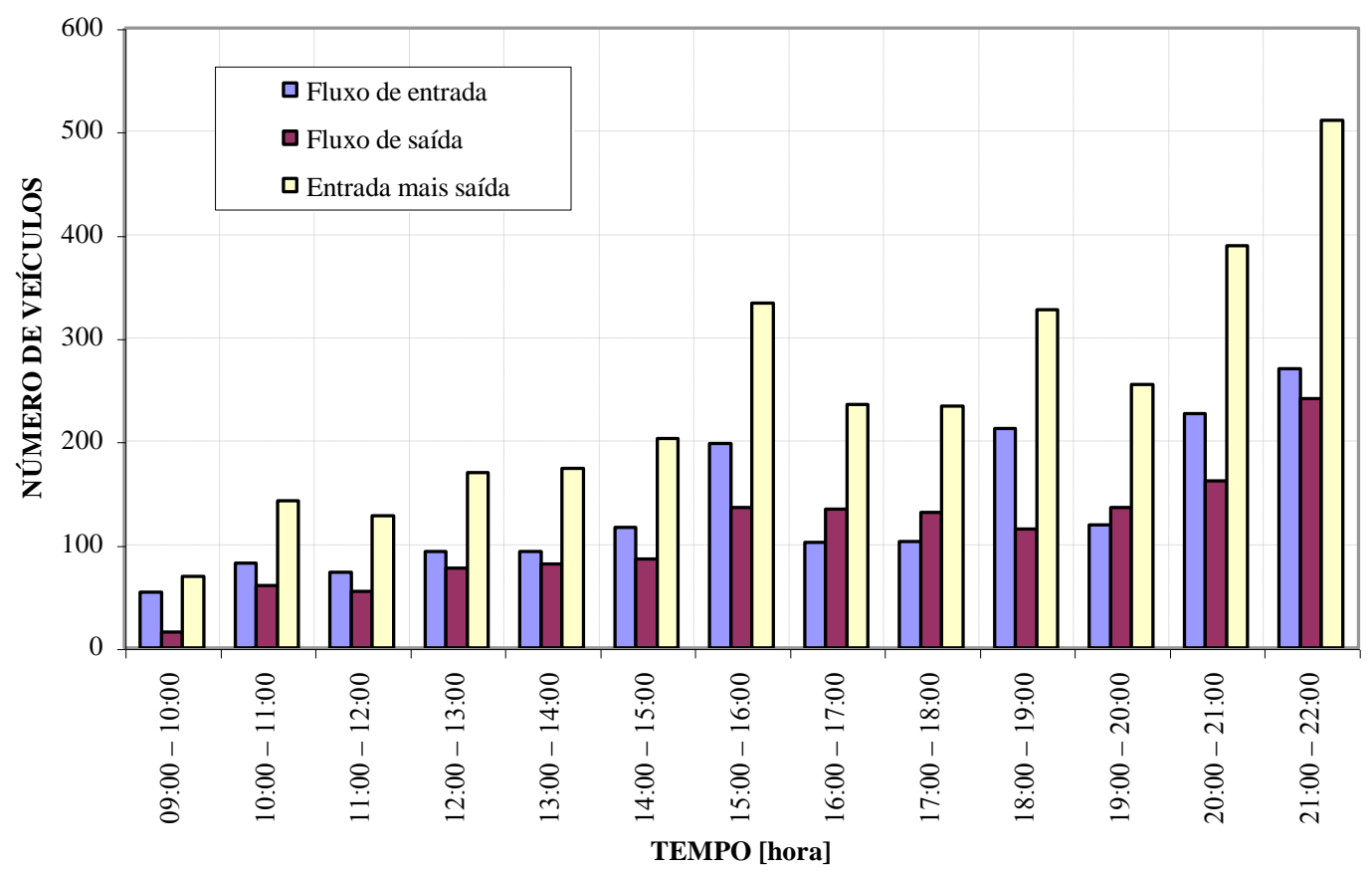

Figura 4.5 - Fluxos de entrada e saída para um sábado no shopping center "B".

\subsubsection{DEMANDA POR ESTACIONAMENTO}

A Tabela 4.12 e a Figura 4.6 mostram os valores do acúmulo de veículos no estacionamento por hora, no sábado. Permitem verificar o comportamento da demanda por estacionamento, observar os picos e ainda identificar a maior demanda por estacionamento. 
Tabela 4.12 - Veículos acumulados no sábado no shopping center "B".

\begin{tabular}{|c|c|c|c|c|c|}
\hline $\begin{array}{c}\text { Período } \\
\text { [horas] }\end{array}$ & $\begin{array}{c}\text { Fluxo de } \\
\text { entrada } \\
\text { [veículos/hora] }\end{array}$ & $\begin{array}{c}\text { Fluxo de saída } \\
\text { [veículos/hora] }\end{array}$ & $\begin{array}{c}\text { Entrada } \\
\text { menos saída } \\
\text { [veículos/hora] }\end{array}$ & $\begin{array}{c}\text { Acúmulo de } \\
\text { veículos no } \\
\text { estacionamento } \\
\text { [veículos/hora] }\end{array}$ & $\begin{array}{c}\text { Porcentagem em } \\
\text { relação ao } \\
\text { acúmulo máximo } \\
\text { [\%] }\end{array}$ \\
\hline 09:00-10:00 & 54 & 15 & 39 & 39 & 12,42 \\
\hline $10: 00-11: 00$ & 82 & 60 & 22 & 61 & 19,43 \\
\hline $11: 00-12: 00$ & 73 & 55 & 18 & 79 & 25,16 \\
\hline $12: 00-13: 00$ & 93 & 77 & 16 & 95 & 30,25 \\
\hline $13: 00-14: 00$ & 93 & 81 & 12 & 107 & 34,08 \\
\hline $14: 00-15: 00$ & 117 & 86 & 31 & 138 & 43,95 \\
\hline $15: 00-16: 00$ & 198 & 136 & 62 & 200 & 63,69 \\
\hline $16: 00-17: 00$ & 102 & 134 & -32 & 168 & 53,50 \\
\hline $17: 00-18: 00$ & 103 & 131 & -28 & 140 & 44,59 \\
\hline $18: 00-19: 00$ & 212 & 115 & 97 & 237 & 75,48 \\
\hline $19: 00-20: 00$ & 119 & 136 & -17 & 220 & 70,06 \\
\hline 20:00-21:00 & 227 & 162 & 65 & 285 & 90,76 \\
\hline $21: 00-22: 00$ & 270 & 241 & 29 & 314 & 100,00 \\
\hline Após 22:00 & ----- & 314 & -314 & 0 & 0,00 \\
\hline Total & 1.743 & 1.743 & 0 & ----- & ---- \\
\hline
\end{tabular}

Observa-se que o acúmulo máximo de veículos no estacionamento ocorre no período das 21:00 às 22:00h e totalizando 314 veículos.

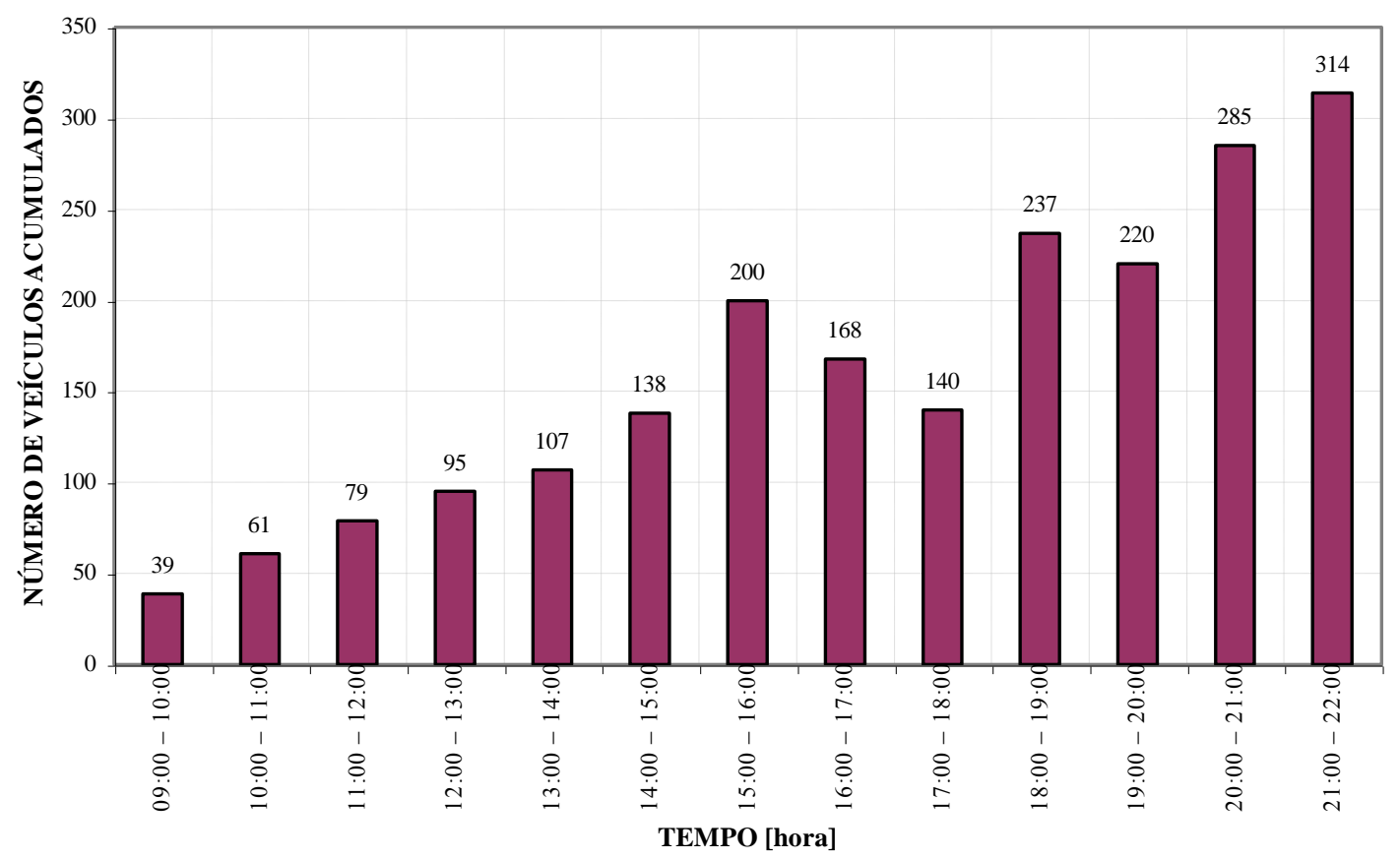

Figura 4.6 - Veículos acumulados no estacionamento no shopping center "B". 


\subsubsection{DURAÇÃO DO ESTACIONAMENTO}

O registro de leitura de placas dos veículos, para obter a distribuição do tempo de permanência na área de estacionamento, foi realizado no sábado, num período contínuo das 9:00 às 22:00h. Os dados coletados representam uma amostra de 45,04\% do total de viagens atraídas pelo empreendimento durante o dia.

A Tabela 4.13 mostra os valores obtidos para o tempo que os veículos permaneceram na área de estacionamento.

Tabela 4.13 - Tempo de permanência dos veículos no shopping center "B".

\begin{tabular}{|c|c|c|}
\hline Tempo de permanência [hora] & Veículos [\%] & Veículos acumulados [\%] \\
\hline $0,00-0,25$ & 42,55 & 42,55 \\
\hline $0,25-0,50$ & 14,65 & 57,20 \\
\hline $0,50-0,75$ & 11,08 & 68,28 \\
\hline $0,75-1,00$ & 6,50 & 74,78 \\
\hline $1,00-1,25$ & 6,88 & 81,66 \\
\hline $1,25-1,50$ & 4,20 & 85,86 \\
\hline $1,50-1,75$ & 2,42 & 88,28 \\
\hline $1,75-2,00$ & 1,27 & 89,55 \\
\hline $2,00-2,25$ & 1,40 & 90,96 \\
\hline $2,25-2,50$ & 1,15 & 92,10 \\
\hline $2,50-2,75$ & 0,38 & 92,48 \\
\hline $2,75-3,00$ & 0,51 & 92,99 \\
\hline $3,00-3,25$ & 0,64 & 93,63 \\
\hline $3,25-3,50$ & 0,25 & 93,89 \\
\hline $3,50-3,75$ & 1,02 & 94,90 \\
\hline $3,75-4,00$ & 0,76 & 95,67 \\
\hline $4,00-4,25$ & 0,25 & 95,92 \\
\hline $4,25-4,50$ & 0,38 & 96,31 \\
\hline $4,50-4,75$ & 0,89 & 97,20 \\
\hline $4,75-5,00$ & 0,25 & 97,45 \\
\hline $5,00-5,25$ & 0,38 & 97,83 \\
\hline $5,25-5,50$ & 0,51 & 98,34 \\
\hline $5,75-6,00$ & 0,38 & 98,73 \\
\hline $6,00-6,25$ & 0,25 & 98,98 \\
\hline $6,50-6,75$ & 0,13 & 99,11 \\
\hline $7,00-7,25$ & 0,38 & 99,49 \\
\hline $7,25-7,50$ & 0,13 & 99,62 \\
\hline $9,00-9,25$ & 0,13 & 99,75 \\
\hline $10,00-10,25$ & 0,25 & 100,00 \\
\hline Total & 100,00 & \\
\hline
\end{tabular}

Esses dados indicam que $41,75 \%$ dos veículos permanecem no local de estacionamento no máximo 15 minutos; $14,65 \%$ permanecem no máximo 30 minutos; $11,08 \%$ permanecem até 45 minutos; representando em conjunto mais de $68 \%$ do total de veículos que circulam pelo estacionamento. Observa-se também que mais de $90 \%$ dos usuários permanecem 
no máximo 2 horas e 15 minutos. Cabe notar ainda que 1,27\% dos veículos permanecem por tempo superior a 6 horas, estes provavelmente associados ao motivo de viagens a trabalho.

Com base nos dados registrados na Tabela 4.14 , foi determinada a média ponderada do tempo de permanência dos veículos na área de estacionamento no sábado.

Tabela 4.14 - Permanência no estacionamento por fração horária no shopping center "B".

\begin{tabular}{|c|c|c|}
\hline Permanência [hora] $(\mathrm{Ti})$ & Veículos (Vi) & $T i \times V i$ \\
\hline 0,13 & 334 & 41,75 \\
\hline 0,38 & 115 & 43,13 \\
\hline 0,63 & 87 & 54,38 \\
\hline 0,88 & 51 & 44,63 \\
\hline 1,13 & 54 & 60,75 \\
\hline 1,38 & 33 & 45,38 \\
\hline 1,63 & 19 & 30,88 \\
\hline 1,88 & 10 & 18,75 \\
\hline 2,13 & 11 & 23,38 \\
\hline 2,38 & 9 & 21,38 \\
\hline 2,63 & 3 & 7,88 \\
\hline 2,88 & 4 & 11,50 \\
\hline 3,13 & 5 & 15,63 \\
\hline 3,38 & 2 & 6,75 \\
\hline 3,63 & 8 & 29,00 \\
\hline 3,88 & 6 & 23,25 \\
\hline 4,13 & 2 & 8,25 \\
\hline 4,38 & 3 & 13,13 \\
\hline 4,63 & 7 & 32,38 \\
\hline 4,88 & 2 & 9,75 \\
\hline 5,13 & 3 & 15,38 \\
\hline 5,38 & 4 & 21,50 \\
\hline 5,88 & 3 & 17,63 \\
\hline 6,13 & 2 & 12,25 \\
\hline 6,63 & 1 & 6,63 \\
\hline 7,13 & 3 & 21,38 \\
\hline 7,38 & 1 & 7,38 \\
\hline 9,13 & 1 & 9,13 \\
\hline 10,13 & 2 & 20,25 \\
\hline$\Sigma$ & 785 & 673,38 \\
\hline
\end{tabular}

O tempo médio de permanência dos veículos no estacionamento no sábado corresponde a 0,86 horas, isto é, os veículos permanecem em média aproximadamente 52 minutos.

\subsubsection{PRINCIPAIS RESULTADOS OBTIDOS}

Os principais valores obtidos nas pesquisas realizadas na sexta-feira e no sábado foram os seguintes: 
- Viagens diárias atraídas pelo empreendimento: 1.743 viagens atraídas no sábado e 1.432 na sexta-feira, representado o volume de sexta-feira $82 \%$ do volume de sábado.

- Incidência do maior pico horário na sexta-feira: entre 20:00 e 21:00h na entrada, entre 21:00 e 22:00h na saída e para o total de fluxos de entrada e saída.

- Porcentagem de pico horário na sexta-feira: $14,25 \%$ do total de veículos na entrada, $14,87 \%$ do total de veículos na saída e $14,18 \%$ do total de veículos de entrada e saída.

- Fator horário de geração de viagens para efeito de análise do impacto no trânsito: 13,20\% do total de veículos na entrada, 9,50\% do total de veículos na saída e 11,35\% do total de veículos de entrada e saída, na sexta-feira, entre 18:00 e 19:00h.

- Incidência do maior pico horário no sábado: entre 21:00 e 22:00h na entrada, saída e no total de fluxos de entrada e saída.

- Porcentagem de pico horário no sábado: $15,49 \%$ do total de veículos na entrada, $13,83 \%$ do total de veículos na saída e $14,66 \%$ do total de veículos de entrada e saída.

- Taxa de atratividade: 41,50 veículos por $100 \mathrm{~m}^{2}$ de ABL no sábado.

- Incidência horária do maior acúmulo de veículos: entre 21:00 e 22:00h no sábado

- Porcentagem do maior pico horário no acúmulo de veículos: $15,49 \%$ do fluxo total atraído no sábado.

- Demanda máxima por estacionamento: 314 vagas no sábado.

- Tempo médio de permanência dos veículos no estacionamento: 0,86h (52 minutos), para o sábado.

\subsection{SHOPPING CENTER "C"}

\subsubsection{CARACTERÍSTICAS DO EMPREENDIMENTO}

O shopping center "C" localiza-se num terreno de $70.000 \mathrm{~m}^{2}$, possuindo atualmente $28.160 \mathrm{~m}^{2}$ de Área Total Construída e $17.992 \mathrm{~m}^{2}$ de Área Bruta Locável. Oferece como atratividade lojas de artigos diversos, amplas áreas de lazer, serviços e supermercado. As vagas de estacionamento de veículos no shopping são distribuídas no entorno ao 
empreendimento, apresentando como oferta total de estacionamento 1.100 vagas. O período de funcionamento do empreendimento é apresentado na Tabela 4.15.

Tabela 4.15 - Período de funcionamento do shopping center "C".

\begin{tabular}{|l|c|c|}
\hline Horários & sexta-feira & sábado \\
\hline Comércio & $9: 00-22: 00$ & $9: 00-22: 00$ \\
\hline Serviços & $10: 00-22: 00$ & $10: 00-22: 00$ \\
\hline Lazer & $13: 00-23: 00$ & $13: 00-23: 00$ \\
\hline
\end{tabular}

Cabe destacar que somente os cinemas permanecem funcionando até as 23:00h, o fluxo de veículos de entrada após as 22:00h é muito reduzido e o fluxo de saída declina gradualmente até as 24:00h.

Na Tabela 4.16 são registradas as áreas dos estabelecimentos por ramos de atividade, agrupados conforme segue. Na área de comércio correspondem: lojas de departamento, vestuário, artigos do lar, artigos eletrônicos, esportivos, perfumaria, lojas de brinquedos e supermercado. $\mathrm{Na}$ área de lazer estão: cinemas, diversões para crianças e brinquedos. No ramo de serviços encontram-se: restaurantes, fast food, choperias, sorveterias, cafeterias, administração, farmácias, drogarias, foto revelação, xerox e dry wash para os veículos.

Tabela 4.16 - Áreas por ramos de atividade para o shopping center "C".

\begin{tabular}{|l|c|c|}
\hline Ramos de Atividade & Área $\left[\mathbf{m}^{\mathbf{2}}\right]$ & Área [\%] \\
\hline Comércio & $13.631,31$ & 75,76 \\
\hline Lazer & $2.939,93$ & 16,34 \\
\hline Serviços Total & $1.420,76$ & 7,90 \\
\hline \multicolumn{2}{|c|}{ Tor } & 100,00 \\
\hline
\end{tabular}

Observa-se que, dos ramos de atividade, o que apresenta maior tamanho é o setor de comércio com $75,76 \%$ da área bruta total do empreendimento. Em segundo lugar esta a área de lazer com 16,34\% de área total. A área de serviço também apresenta uma área significativa, mas pequena em relação às outras.

\subsubsection{COLETA DE DADOS NO ESTACIONAMENTO}

A pesquisa no estacionamento foi realizada no mês de novembro, num período contínuo de treze horas, das 9:00 às 22:00h, para sexta-feira e sábado. Incluiu os seguintes levantamentos: registro de entrada e saída de veículos no estacionamento e registro de leitura de placas dos veículos que circularam pela área de estacionamento. 


\subsubsection{GERAÇÃO DE VIAGENS}

\subsection{SEXTA-FEIRA}

Os dados obtidos na sexta-feira são mostrados na Tabela 4.17 e na Figura 4.7, e permitem identificar os fluxos de entrada e saída, incidência e amplitude dos picos horários e do fator de geração de viagens para análise de impacto viário.

Tabela 4.17 - Fluxos de entrada e saída para uma sexta-feira no shopping center "C".

\begin{tabular}{|c|c|c|c|c|c|c|}
\hline $\begin{array}{c}\text { Período } \\
\text { [horas] }\end{array}$ & $\begin{array}{c}\text { Fluxo de } \\
\text { entrada } \\
\text { [veículos/hora] }\end{array}$ & $\begin{array}{c}\text { Fluxo de } \\
\text { entrada } \\
{[\%]}\end{array}$ & $\begin{array}{c}\text { Fluxo de saída } \\
\text { [veículos/hora] }\end{array}$ & $\begin{array}{c}\text { Fluxo de } \\
\text { saída } \\
{[\%]}\end{array}$ & $\begin{array}{c}\text { Entrada mais } \\
\text { saída } \\
\text { [veículos/hora] }\end{array}$ & $\begin{array}{c}\text { Entrada } \\
\text { mais saída } \\
\text { [\%] }\end{array}$ \\
\hline 09:00-10:00 & 122 & 2,94 & 40 & 0,97 & 162 & 1,95 \\
\hline 10:00-11:00 & 180 & 4,34 & 114 & 2,75 & 294 & 3,55 \\
\hline $11: 00-12: 00$ & 239 & 5,77 & 173 & 4,17 & 412 & 4,97 \\
\hline $12: 00-13: 00$ & 246 & 5,93 & 234 & 5,65 & 480 & 5,79 \\
\hline $13: 00-14: 00$ & 267 & 6,44 & 267 & 6,44 & 534 & 6,44 \\
\hline 14:00-15:00 & 267 & 6,44 & 232 & 5,60 & 499 & 6,02 \\
\hline 15:00-16:00 & 320 & 7,72 & 268 & 6,47 & 588 & 7,09 \\
\hline 16:00-17:00 & 308 & 7,43 & 338 & 8,15 & 646 & 7,79 \\
\hline 17:00-18:00 & 315 & 7,60 & 320 & 7,72 & 635 & 7,66 \\
\hline 18:00-19:00 & 326 & 7,86 & 303 & 7,31 & 629 & 7,59 \\
\hline 19:00-20:00 & 422 & 10,18 & 312 & 7,53 & 734 & 8,85 \\
\hline 20:00-21:00 & 636 & 15,34 & 397 & 9,58 & 1033 & 12,46 \\
\hline 21:00-22:00 & 497 & 11,99 & 484 & 11,68 & 981 & 11,83 \\
\hline Após 22:00 & ------ & ------- & 663 & 16,00 & 663 & 8,00 \\
\hline Total & 4.145 & 100,00 & 4.145 & 100,00 & 8290 & 100,00 \\
\hline
\end{tabular}

O pico horário do tráfego atraído ocorre entre 20:00 e 21:00h, correspondendo ao fluxo de entrada de 636 veículos por hora (15,34\% do total do dia), o pico horário de saída ocorre entre 21:00 e 22:00h, correspondendo a 484 veículos por hora (11,68\% do total do dia), e o pico horário total acontece entre 20:00 e 21:00h, correspondendo a 1.033 veículos por hora $(12,46 \%$ do total de entrada e saída do dia).

Para efeito de análise de impacto no trânsito, no horário das 18:00 às 19:00h, o fluxo de entrada corresponde a 326 veículos por hora (7,86\% do fluxo total diário), o fluxo de saída corresponde a 303 veículos por hora (7,31\% do fluxo total diário) e o fluxo total de entrada e saída corresponde a 629 veículos por hora $(7,59 \%$ do fluxo total de entrada e saída no dia). 


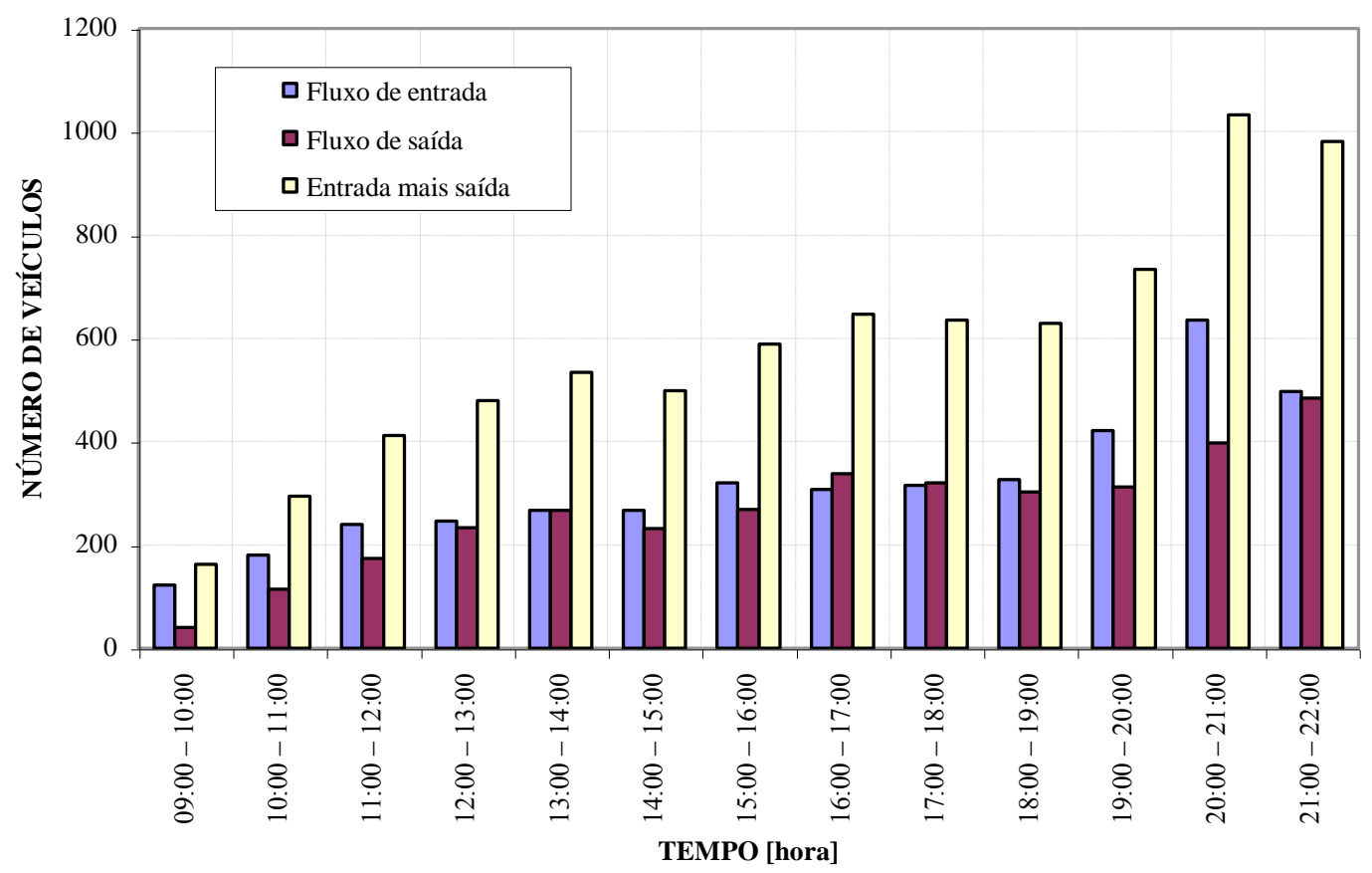

Figura 4.7 - Fluxos de entrada e saída para uma sexta-feira no shopping center "C".

\subsection{SÁBADO}

Os dados coletados no sábado são mostrados na Tabela 4.18 e na Figura 4.8, e permitem identificar os fluxos de entrada e saída, taxa de atratividade e incidência e amplitude dos picos horários.

Tabela 4.18 - Fluxos de entrada e saída para um sábado no shopping center "C".

\begin{tabular}{|c|c|c|c|c|c|c|}
\hline $\begin{array}{c}\text { Período } \\
\text { [horas] }\end{array}$ & $\begin{array}{c}\text { Fluxo de } \\
\text { entrada } \\
\text { [veículos/hora] }\end{array}$ & $\begin{array}{c}\text { Fluxo de } \\
\text { entrada } \\
{[\%]}\end{array}$ & $\begin{array}{c}\text { Fluxo de saída } \\
\text { [veículos/hora] }\end{array}$ & $\begin{array}{c}\text { Fluxo de } \\
\text { saída } \\
{[\%]}\end{array}$ & $\begin{array}{c}\text { Entrada mais } \\
\text { saída } \\
\text { [veículos/hora] }\end{array}$ & $\begin{array}{c}\text { Entrada } \\
\text { mais saída } \\
\text { [\%] }\end{array}$ \\
\hline 09:00-10:00 & 131 & 2,10 & 43 & 0,69 & 174 & 1,39 \\
\hline 10:00-11:00 & 285 & 4,56 & 136 & 2,18 & 421 & 3,37 \\
\hline $11: 00-12: 00$ & 383 & 6,13 & 255 & 4,08 & 638 & 5,11 \\
\hline 12:00-13:00 & 475 & 7,60 & 328 & 5,25 & 803 & 6,43 \\
\hline 13:00-14:00 & 498 & 7,97 & 355 & 5,68 & 853 & 6,83 \\
\hline 14:00-15:00 & 496 & 7,94 & 464 & 7,43 & 960 & 7,68 \\
\hline 15:00-16:00 & 552 & 8,84 & 476 & 7,62 & 1.028 & 8,23 \\
\hline 16:00-17:00 & 447 & 7,16 & 526 & 8,42 & 973 & 7,79 \\
\hline 17:00-18:00 & 416 & 6,66 & 503 & 8,05 & 919 & 7,36 \\
\hline 18:00-19:00 & 486 & 7,78 & 468 & 7,49 & 954 & 7,64 \\
\hline 19:00-20:00 & 619 & 9,91 & 478 & 7,65 & 1.097 & 8,78 \\
\hline 20:00-21:00 & 782 & 12,52 & 538 & 8,61 & 1.320 & 10,57 \\
\hline 21:00-22:00 & 677 & 10,84 & 593 & 9,49 & 1.270 & 10,16 \\
\hline Após 22:00 & ----- & ----- & 1.084 & 17,35 & 1.084 & 8,68 \\
\hline Total & 6.247 & 100,00 & 6.247 & 100,00 & 12.494 & 100,00 \\
\hline
\end{tabular}




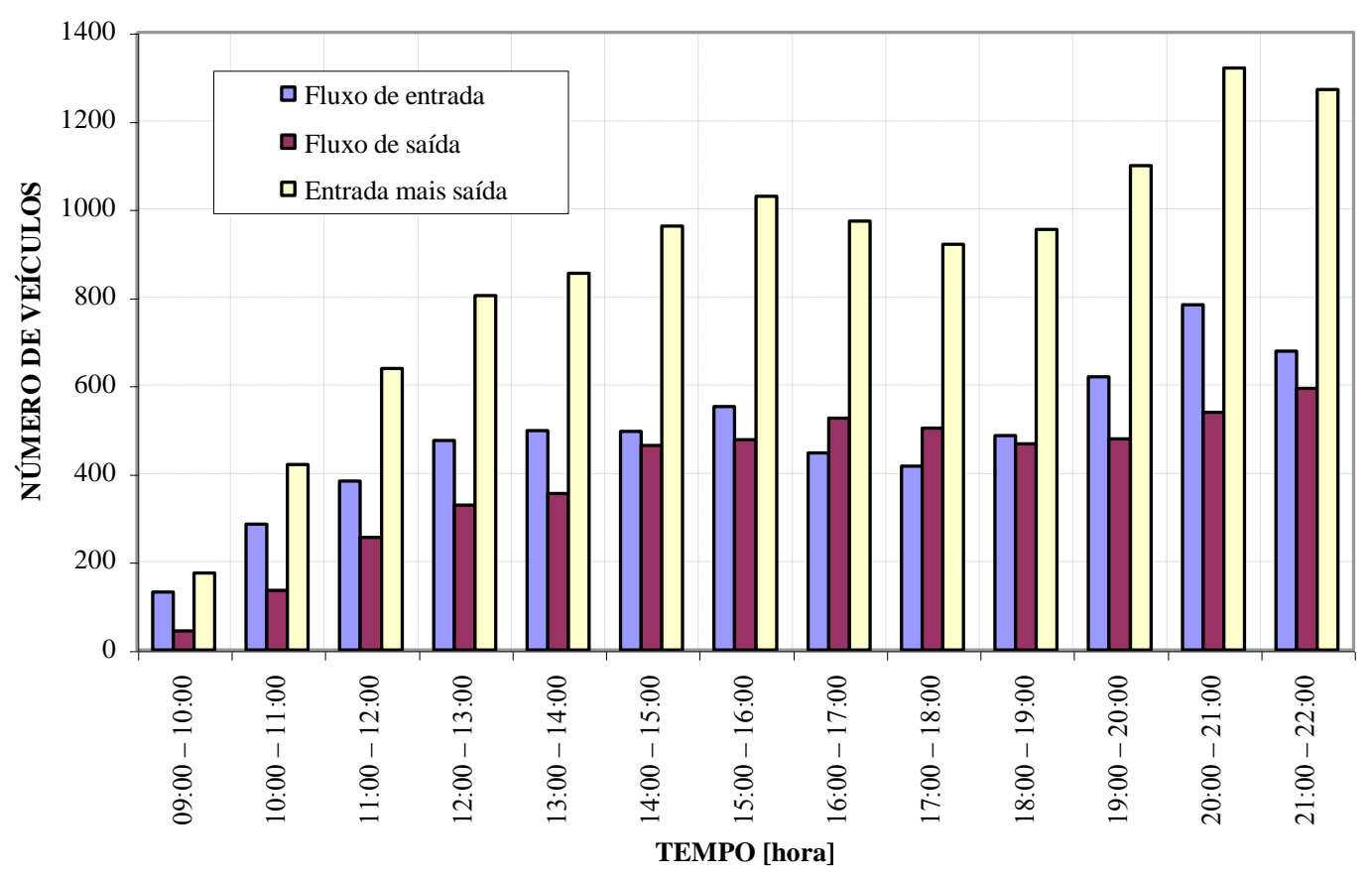

Figura 4.8 - Fluxos de entrada para um sábado no shopping center "C".

O pico horário do tráfego ocorre entre 20:00 e 21:00h, correspondendo ao fluxo de entrada de 782 veículos por hora (12,52\% do total do dia), o pico horário de saída ocorre entre 21:00 e 22:00h, correspondendo ao fluxo de saída de 593 veículos por hora (9,49\% do total diário), e o pico horário total de entrada e saída acontece entre 20:00 e 21:00h, correspondendo a 1.320 veículos por hora (10,57\% do total de entrada e saída no dia).

Conforme esperado, esses dados mostram que as viagens atraídas no sábado, das 8:00 às 22:00h, são 50,71\% maior que na sexta-feira no mesmo período.

A taxa de atratividade do shopping center corresponde a 34,72 veículos por $100 \mathrm{~m}^{2}$ de ABL.

\subsubsection{DEMANDA POR ESTACIONAMENTO}

A Tabela 4.19 e a Figura 4.9 mostram os valores do acúmulo de veículos no estacionamento por hora, no sábado. Permitem verificar o comportamento da demanda por estacionamento, observar os picos e ainda identificar a maior demanda por estacionamento. 
Tabela 4.19 - Veículos acumulados no sábado no shopping center "C".

\begin{tabular}{|c|c|c|c|c|c|}
\hline $\begin{array}{c}\text { Período } \\
\text { [horas] }\end{array}$ & $\begin{array}{c}\text { Fluxo de } \\
\text { entrada } \\
\text { [veículos/hora] }\end{array}$ & $\begin{array}{c}\text { Fluxo de saída } \\
\text { [veículos/hora] }\end{array}$ & $\begin{array}{c}\text { Entrada } \\
\text { menos saída } \\
\text { [veículos/hora] }\end{array}$ & $\begin{array}{c}\text { Acúmulo de } \\
\text { veículos no } \\
\text { estacionamento } \\
\text { [veículos/hora] }\end{array}$ & $\begin{array}{c}\text { Porcentagem em } \\
\text { relação ao } \\
\text { acúmulo máximo } \\
\text { [\%] }\end{array}$ \\
\hline 09:00-10:00 & 131 & 43 & 88 & 88 & 8,12 \\
\hline $10: 00-11: 00$ & 285 & 136 & 149 & 237 & 21,86 \\
\hline $11: 00-12: 00$ & 383 & 255 & 128 & 365 & 33,67 \\
\hline $12: 00-13: 00$ & 475 & 328 & 147 & 512 & 47,23 \\
\hline $13: 00-14: 00$ & 498 & 355 & 143 & 655 & 60,42 \\
\hline $14: 00-15: 00$ & 496 & 464 & 32 & 687 & 63,38 \\
\hline $15: 00-16: 00$ & 552 & 476 & 76 & 763 & 70,39 \\
\hline $16: 00-17: 00$ & 447 & 526 & -79 & 684 & 63,10 \\
\hline $17: 00-18: 00$ & 416 & 503 & -87 & 597 & 55,07 \\
\hline $18: 00-19: 00$ & 486 & 468 & 18 & 615 & 56,73 \\
\hline $19: 00-20: 00$ & 619 & 478 & 141 & 756 & 69,74 \\
\hline 20:00-21:00 & 782 & 538 & 244 & 1000 & 92,25 \\
\hline $21: 00-22: 00$ & 677 & 593 & 84 & 1084 & 100,00 \\
\hline Após 22:00 & ----- & 1084 & -1084 & 0 & 0,00 \\
\hline Total & 6.247 & 6247 & 0 & ----- & ---- \\
\hline
\end{tabular}

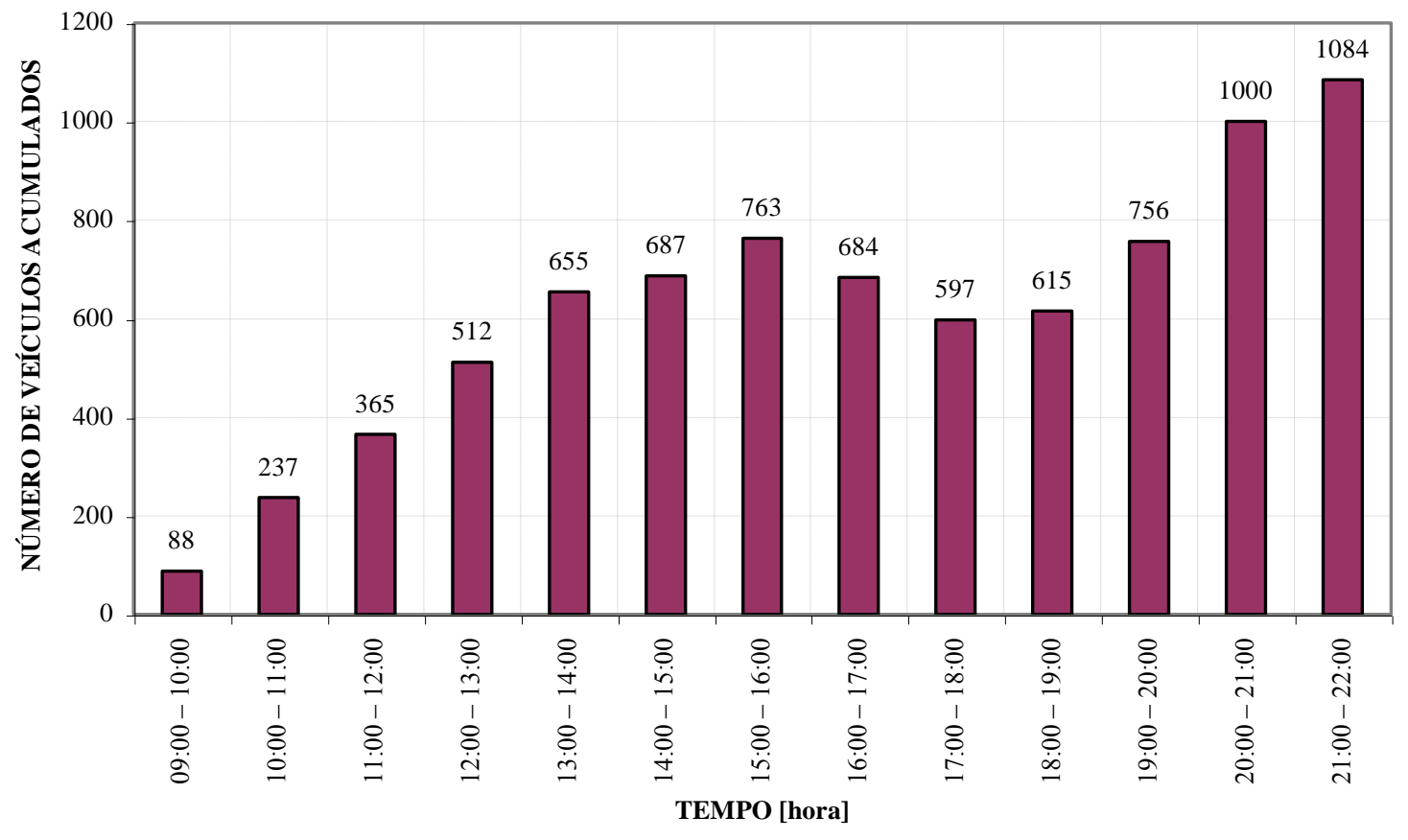

Figura 4.9 - Veículos acumulados no estacionamento no shopping center "C".

Identifica-se que o maior acúmulo de veículos no estacionamento acontece no período das 21:00 às 22:00h, totalizando 1.084 veículos. 


\subsubsection{DURAÇÃO DO ESTACIONAMENTO}

O registro de leitura de placas dos veículos foi realizado no sábado, num período contínuo das 9:00 às 22:00h. Os dados representam uma amostra de 66,43\% do total de viagens atraídas pelo empreendimento durante o dia.

A Tabela 4.20 mostra os valores obtidos para o tempo de permanência.

Tabela 4.20 - Tempo de permanência dos veículos no shopping center "C".

\begin{tabular}{|c|c|c|}
\hline Tempo de permanência [hora] & Veículos [\%] & Veículos acumulados [\%] \\
\hline $0,00-0,25$ & 24,99 & 24,99 \\
\hline $0,25-0,50$ & 12,92 & 37,90 \\
\hline $0,50-0,75$ & 12,05 & 49,95 \\
\hline $0,75-1,00$ & 10,89 & 60,84 \\
\hline $1,00-1,25$ & 9,20 & 70,05 \\
\hline $1,25-1,50$ & 6,94 & 76,99 \\
\hline $1,50-1,75$ & 5,08 & 82,07 \\
\hline $1,75-2,00$ & 4,31 & 86,39 \\
\hline $2,00-2,25$ & 3,08 & 89,47 \\
\hline $2,25-2,50$ & 2,24 & 91,71 \\
\hline $2,50-2,75$ & 1,52 & 93,23 \\
\hline $2,75-3,00$ & 1,11 & 94,34 \\
\hline $3,00-3,25$ & 0,84 & 95,18 \\
\hline $3,25-3,50$ & 0,67 & 95,86 \\
\hline $3,50-3,75$ & 0,77 & 96,63 \\
\hline $3,75-4,00$ & 0,51 & 97,13 \\
\hline $4,40-4,25$ & 0,48 & 97,61 \\
\hline $4,25-4,50$ & 0,43 & 98,05 \\
\hline $4,50-4,75$ & 0,24 & 98,29 \\
\hline $4,75-5,00$ & 0,29 & 98,58 \\
\hline $5,00-5,25$ & 0,29 & 98,87 \\
\hline $5,25-5,50$ & 0,12 & 98,99 \\
\hline $5,50-5,75$ & 0,19 & 99,18 \\
\hline $5,75-6,00$ & 0,07 & 99,25 \\
\hline $6,00-6,25$ & 0,12 & 99,37 \\
\hline $6,25-6,50$ & 0,05 & 99,42 \\
\hline $6,50-6,75$ & 0,05 & 99,47 \\
\hline $6,75-7,00$ & 0,05 & 99,52 \\
\hline $7,00-7,25$ & 0,05 & 99,57 \\
\hline $7,25-7,50$ & 0,05 & 99,61 \\
\hline $7,50-7,75$ & 0,02 & 99,64 \\
\hline $8,00-8,25$ & 0,02 & 99,66 \\
\hline $8,25-8,50$ & 0,05 & 99,71 \\
\hline $8,50-8,75$ & 0,05 & 99,76 \\
\hline $8,75-9,00$ & 0,05 & 99,81 \\
\hline $9,25-9,50$ & 0,05 & 99,86 \\
\hline $9,50-9,75$ & 0,02 & 99,88 \\
\hline $9,75-10,00$ & 0,05 & 99,93 \\
\hline $10,00-10,25$ & 0,02 & 99,95 \\
\hline $10,25-10,50$ & 0,02 & 99,98 \\
\hline $10,75-11,00$ & 0,02 & 100,00 \\
\hline Total & 100,00 & \\
\hline
\end{tabular}


Esses dados indicam que 24,99\% dos veículos permanecem no local de estacionamento no máximo 15 minutos, 12,92\% permanecem entre 15 e 30 minutos, e 12,05\% permanecem entre 30 e 45 minutos; representando em conjunto aproximadamente $50 \%$ do total de veículos. Identifica-se ainda que $0,75 \%$ dos veículos permanecem por tempo superior a 6 horas, estes provavelmente associados ao motivo de viagens a trabalho.

Com base nos dados registrados na Tabela 4.21, foi determinada a média ponderada do tempo de permanência dos veículos na área de estacionamento no sábado.

Tabela 4.21 - Permanência no estacionamento por fração horária no shopping center "C".

\begin{tabular}{|c|c|c|}
\hline Permanência [hora] (Ti) & Veículos (Vi) & $T i \times V i$ \\
\hline 0,13 & 1.037 & 129,63 \\
\hline 0,38 & 536 & 201,00 \\
\hline 0,63 & 500 & 312,50 \\
\hline 0,88 & 452 & 395,50 \\
\hline 1,13 & 382 & 429,75 \\
\hline 1,38 & 288 & 396,00 \\
\hline 1,63 & 211 & 342,88 \\
\hline 1,88 & 179 & 335,63 \\
\hline 2,13 & 128 & 272,00 \\
\hline 2,38 & 93 & 220,88 \\
\hline 2,63 & 63 & 165,38 \\
\hline 2,88 & 46 & 132,25 \\
\hline 3,13 & 35 & 109,38 \\
\hline 3,38 & 28 & 94,50 \\
\hline 3,63 & 32 & 116,00 \\
\hline 3,88 & 21 & 81,38 \\
\hline 4,13 & 20 & 82,50 \\
\hline 4,38 & 18 & 78,75 \\
\hline 4,63 & 10 & 46,25 \\
\hline 4,88 & 12 & 58,50 \\
\hline 5,13 & 12 & 61,50 \\
\hline 5,38 & 5 & 26,88 \\
\hline 5,63 & 8 & 45,00 \\
\hline 5,88 & 3 & 17,63 \\
\hline 6,13 & 5 & 30,63 \\
\hline 6,38 & 2 & 12,75 \\
\hline 6,63 & 2 & 13,25 \\
\hline 6,88 & 2 & 13,75 \\
\hline 7,13 & 2 & 14,25 \\
\hline 7,38 & 2 & 14,75 \\
\hline 7,63 & 1 & 7,63 \\
\hline 8,13 & 1 & 8,13 \\
\hline 8,38 & 2 & 16,75 \\
\hline 8,63 & 2 & 17,25 \\
\hline 8,88 & 2 & 17,75 \\
\hline 9,38 & 2 & 18,75 \\
\hline 9,63 & 1 & 9,63 \\
\hline 9,88 & 2 & 19,75 \\
\hline 10,13 & 1 & 10,13 \\
\hline 10,38 & 1 & 10,38 \\
\hline 10,88 & 1 & 10,88 \\
\hline$\sum$ & 4.150 & $4.398,00$ \\
\hline
\end{tabular}


O tempo médio de permanência dos veículos no estacionamento no sábado corresponde a 1,06 horas, isto é, os veículos permanecem em média aproximadamente 1 hora e 4 minutos.

\subsubsection{PRINCIPAIS RESULTADOS OBTIDOS}

Os principais valores obtidos nas pesquisas realizadas na sexta-feira e no sábado foram os seguintes:

- Viagens diárias atraídas pelo empreendimento: 6.247 veículos atraídos no sábado e 4.145 na sexta-feira, correspondendo o volume de sexta-feira a $66 \%$ do volume do sábado.

- Incidência do maior pico horário na sexta-feira: entre 20:00 e 21:00h na entrada, entre 21:00 e 22:00h na saída e entre 20:00 e 21:00h para o total de fluxos de entrada e saída.

- Porcentagem de pico horário na sexta-feira: $15,34 \%$ do total de veículos na entrada, $11,68 \%$ do total de veículos na saída e $12,46 \%$ do total de veículos de entrada e saída.

- Fator horário de geração de viagens para efeito de análise do impacto no trânsito: 7,86\% do total de veículos na entrada, 7,31\% do total de veículos na saída e 7,59\% do total de veículos de entrada e saída, na sexta-feira, entre 18:00 e 19:00h.

- Incidência do maior pico horário no sábado: entre 20:00 e 21:00h na entrada, entre 21:00 e 22:00h na saída e entre 20:00 e 21:00h no total de fluxos de entrada e saída.

- Porcentagem de pico horário no sábado: $12,52 \%$ do total de veículos na entrada, 9,49\% do total de veículos na saída e $10,57 \%$ do total de veículos de entrada e saída.

- Taxa de atratividade: 34,72 veículos por $100 \mathrm{~m}^{2}$ de ABL no sábado.

- Incidência horária do maior acúmulo de veículos: entre 21:00 e 22:00h no sábado.

- Porcentagem do maior pico horário no acúmulo de veículos: 10,84\% do fluxo total atraído no sábado.

- Demanda máxima por estacionamento: 1.084 vagas no sábado.

- Tempo médio de permanência dos veículos no estacionamento: 1,06h (1 hora e 4 minutos) no sábado. 


\subsection{SHOPPING CENTER "D"}

O shopping center "D" localiza-se num terreno de $8.580 \mathrm{~m}^{2}$, possuindo $63.600 \mathrm{~m}^{2}$ de Área Total Construída (ATC) e $27.549 \mathrm{~m}^{2}$ de Área Bruta Locável (ABL). Oferece como atratividade lojas de artigos diversos, áreas de lazer, cinemas, restaurantes, fast food, serviços e supermercado. As vagas de estacionamento de veículos são distribuídas em três níveis no sub-solo do empreendimento, apresentando uma oferta total de 796 vagas. O período de funcionamento dos estabelecimentos é apresentado na Tabela 4.22.

Tabela 4.22 - Período de funcionamento do shopping center "D".

\begin{tabular}{|l|c|c|}
\hline Horários & sexta-feira & sábado \\
\hline Comércio & $9: 00-22: 00$ & $9: 00-22: 00$ \\
\hline Serviços & $10: 00-22: 30$ & $10: 00-22: 30$ \\
\hline Lazer & $10: 00-24: 00$ & $10: 00-24: 00$ \\
\hline
\end{tabular}

Na Tabela 4.23 são registradas as áreas dos estabelecimentos por ramos de atividade, agrupadas conforme segue. $\mathrm{Na}$ área de comércio estão: lojas de departamento, vestuário, artigos do lar, artigos eletrônicos, esportivos, perfumaria, lojas de brinquedos e supermercado. No ramo de serviços encontram-se: restaurantes, fast food, choperias, sorveterias, cafeterias, administração, ensino, bancos, farmácias, drogarias, instituto de beleza, foto revelação, xerox, papelaria e dry wash. Na área de lazer correspondem: cinemas, bingo e fun station.

Tabela 4.23 - Áreas por ramos de atividade para o shopping center "D".

\begin{tabular}{|l|c|c|}
\hline Ramos de Atividade & Área $\left[\mathbf{m}^{\mathbf{2}}\right]$ & Área [\%] \\
\hline Comércio & $14.693,00$ & 53,33 \\
\hline Lazer & $6.405,00$ & 23,24 \\
\hline Serviços Total & $6.451,00$ & 23,42 \\
\hline \multicolumn{1}{|c|}{$27.549,00$} & 100,00 \\
\hline
\end{tabular}

Observa-se que, dos ramos de atividade, o que apresenta maior tamanho é o setor de comércio, com $53,33 \%$ da área total. A área de serviço fica em segundo lugar com $23,42 \%$ e a área de lazer em último com 23,24\% de área.

De acordo com informações fornecidas pela administração do empreendimento, a estimativa do fluxo total de veículos atraídos nos sábados é de 8.100 veículos e nas sextas-feiras de 6.760 veículos. Assim, as viagens atraídas no sábado são 19,82\% superiores às atraídas na sexta-feira.

A taxa de atratividade do empreendimento corresponde a 29,40 veículos por $100 \mathrm{~m}^{2}$ de ABL. 


\subsection{SHOPPING CENTER "E"}

O shopping center "E" localiza-se num terreno de $78.125 \mathrm{~m}^{2}$, possuindo $38.920 \mathrm{~m}^{2}$ de Área Total Construída (ATC) e $18.494 \mathrm{~m}^{2}$ de Área Bruta Locável (ABL). Oferece como atratividade lojas de artigos diversos, amplas áreas de lazer, academia de ginástica, restaurantes, fast food, serviços e ensino. As vagas de estacionamento de veículos são distribuídas no entorno do empreendimento, apresentando uma oferta total de 1.230 vagas. $\mathrm{O}$ período de funcionamento dos estabelecimentos é como mostrado na Tabela 4.24.

Tabela 4.24 - Período de funcionamento do shopping center "E".

\begin{tabular}{|l|c|c|}
\hline Horários & sexta-feira & sábado \\
\hline Comércio & $10: 00-22: 00$ & $10: 00-22: 00$ \\
\hline Serviços & $10: 00-23: 00$ & $10: 00-22: 00$ \\
\hline Lazer & $13: 00-23: 00$ & $13: 00-23: 00$ \\
\hline
\end{tabular}

$\mathrm{Na}$ Tabela 4.25 são registradas as áreas dos estabelecimentos por ramos de atividade, agrupadas conforme segue. Na área de comércio consideram-se: lojas de vestuário, calçados, artigos do lar, artigos eletrônicos, esportivos, perfumaria e lojas de brinquedos. No ramo de serviços estão: restaurantes, fast food, choperias, cafeterias, administração, academia de ginástica, farmácias, drogarias, serviços financeiros, foto revelação, tabacaria, cabeleireiro e ensino. Na área de lazer encontram-se: cinemas e diversões para crianças.

Tabela 4.25 - Áreas por ramos de atividade para o shopping center "E".

\begin{tabular}{|l|c|c|}
\hline Ramos de Atividade & Área $\left[\mathbf{m}^{\mathbf{2}}\right.$ ] & Área [\%] \\
\hline Comércio & $6.222,88$ & 33,65 \\
\hline Lazer & $3.518,31$ & 19,02 \\
\hline Serviços Total & $8.752,10$ & 47,33 \\
\hline \multicolumn{1}{|c|}{$\quad 18.493,29$} & 100,00 \\
\hline
\end{tabular}

Observa-se que, dos ramos de atividade, o que apresenta maior tamanho é o setor de serviços com $47,33 \%$ da área bruta total do empreendimento. O setor de comércio esta em segundo lugar, com $33,65 \%$ da área total. A área de lazer também é significativa, representando $19,02 \%$ da área total do empreendimento.

De acordo com informações fornecidas pela administração do empreendimento, a estimativa do fluxo total de veículos atraídos nos sábados é de 6.400 veículos e nas sextasfeiras de 4.500 veículos. Portanto, as viagens atraídas no sábado são 42,22\% superiores às atraídas na sexta-feira.

A taxa de atratividade do empreendimento corresponde a 33,77 veículos por $100 \mathrm{~m}^{2}$ de ABL. 


\subsection{SHOPPING CENTER "F"}

O shopping center "F" localiza-se num terreno de $70.000 \mathrm{~m}^{2}$, possuindo $33.000 \mathrm{~m}^{2}$ de Área Total Construída (ATC) e $17.334 \mathrm{~m}^{2}$ de Área Bruta Locável (ABL). Oferece como atratividade lojas de artigos diversos, áreas de lazer, restaurantes, fast food, serviços, discoteca e supermercado. As vagas de estacionamento de veículos são distribuídas no entorno do empreendimento, apresentando uma oferta total de 1.067 vagas. O período de funcionamento dos estabelecimentos é apresentado na Tabela 4.26.

Tabela 4.26 - Período de funcionamento do shopping center "F".

\begin{tabular}{|l|c|c|}
\hline Horários & sexta-feira & sábado \\
\hline Comércio & $10: 00-22: 00$ & $10: 00-22: 00$ \\
\hline Serviços & $10: 00-22: 00$ & $10: 00-22: 00$ \\
\hline Lazer & $11: 00-24: 00$ & $11: 00-24: 00$ \\
\hline
\end{tabular}

Na Tabela 4.27 e na Figura 4.10 são registrados os fluxos de veículos atraídos pelo shopping center para uma sexta-feira e um sábado, fornecidos pela administração do empreendimento. Os dados apresentam o período total de movimento de veículos, que vai até o horário de saída da discoteca, às 03:00h da madrugada.

Tabela 4.27 - Fluxos de entrada para sexta-feira e sábado no shopping center "F"

\begin{tabular}{|c|c|c|c|c|}
\hline $\begin{array}{c}\text { Período } \\
\text { [horas] }\end{array}$ & $\begin{array}{c}\text { Fluxo de entrada } \\
\text { sexta-feira } \\
\text { [veículos/hora] }\end{array}$ & $\begin{array}{c}\text { Fluxo de entrada } \\
\text { sexta-feira } \\
{[\%]}\end{array}$ & $\begin{array}{c}\text { Fluxo de entrada } \\
\text { sábado } \\
\text { [veículos/hora] }\end{array}$ & $\begin{array}{c}\text { Fluxo de entrada } \\
\text { sábado } \\
{[\%]}\end{array}$ \\
\hline $09: 00-10: 00$ & 289 & 6,36 & 204 & 2,75 \\
\hline $10: 00-11: 00$ & 183 & 4,02 & 419 & 3,92 \\
\hline $11: 00-12: 00$ & 190 & 4,18 & 450 & 5,64 \\
\hline $12: 00-13: 00$ & 259 & 5,70 & 477 & 6,06 \\
\hline $13: 00-14: 00$ & 257 & 5,65 & 434 & 6,42 \\
\hline $14: 00-15: 00$ & 248 & 5,45 & 483 & 5,84 \\
\hline $15: 00-16: 00$ & 265 & 5,83 & 532 & 6,50 \\
\hline $16: 00-17: 00$ & 248 & 5,45 & 513 & 7,16 \\
\hline $17: 00-18: 00$ & 263 & 5,78 & 499 & 6,90 \\
\hline $18: 00-19: 00$ & 361 & 7,94 & 661 & 6,72 \\
\hline $19: 00-20: 00$ & 532 & 11,70 & 852 & 8,90 \\
\hline $20: 00-21: 00$ & 521 & 11,46 & 643 & 11,47 \\
\hline $21: 00-22: 00$ & 446 & 9,81 & 273 & 8,65 \\
\hline $22: 00-23: 00$ & 262 & 5,76 & 315 & 3,67 \\
\hline $23: 00-24: 00$ & 130 & 2,86 & 230 & 4,24 \\
\hline $24: 00-01: 00$ & 83 & 1,83 & 110 & 3,10 \\
\hline $01: 00-02: 00$ & 56 & 1,23 & 45 & 1,48 \\
\hline $02: 00-03: 00$ & 6 & 0,13 & 7.431 & 0,61 \\
\hline Total & 4547 & 100,00 & & 100,00 \\
\hline & & & & \\
\hline
\end{tabular}




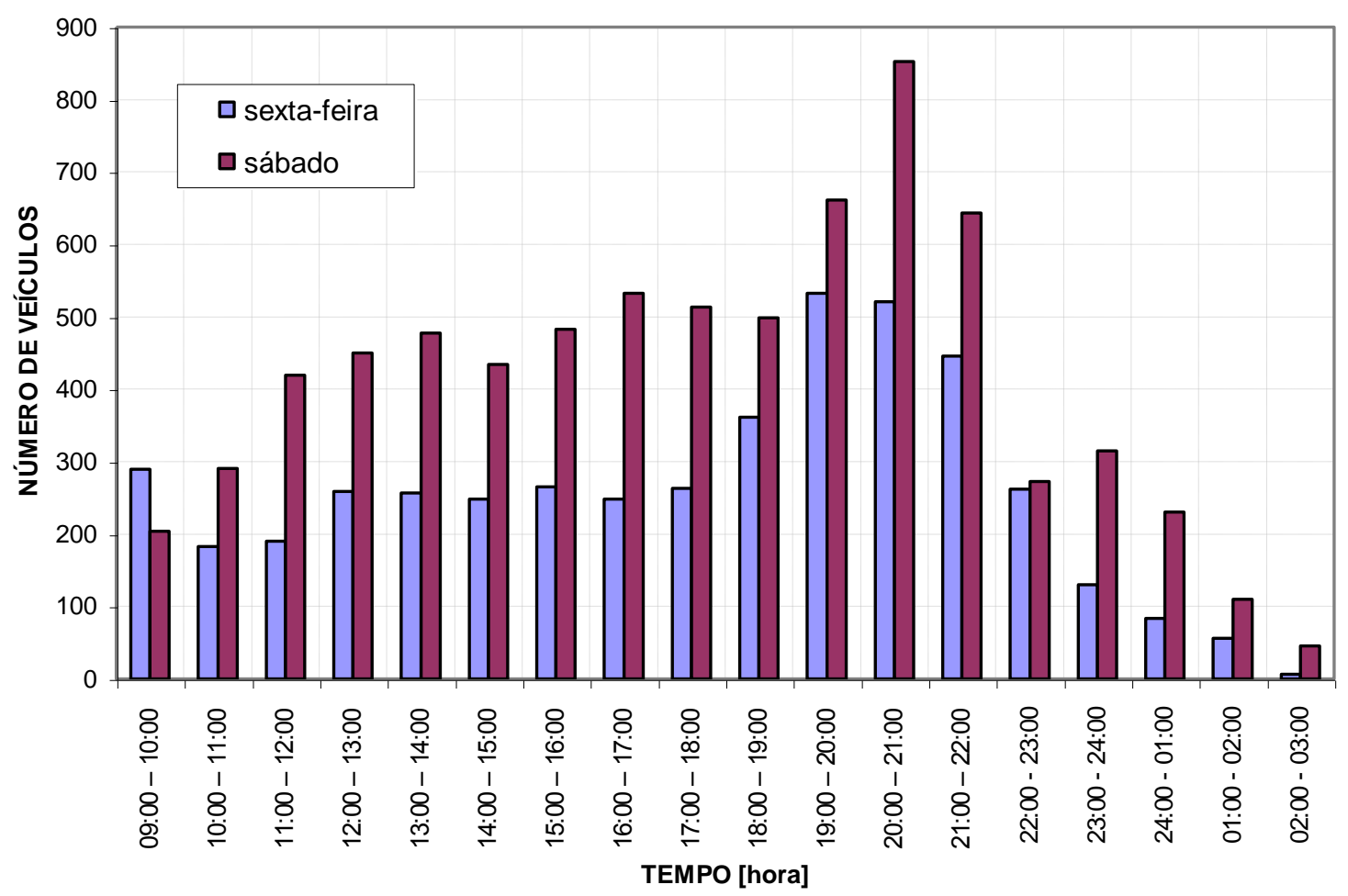

Figura 4.10 - Fluxos de entrada para sexta-feira e sábado no shopping center "F".

O pico horário das viagens atraídas na sexta-feira ocorre entre 19:00 e 20:00h, com um fluxo de 532 veículos por hora (11,70\% do total do dia). No sábado o pico horário ocorre entre 20:00 e 21:00h, com um fluxo de 852 veículos por hora (11,47\% do total do dia).

Esses dados mostram, ainda, que o total de viagens atraídas no sábado, das 9:00 às 03:00h, são 63,43\% maior que as atraídas na sexta-feira.

A taxa de atratividade do empreendimento corresponde a 42,87 veículos por $100 \mathrm{~m}^{2}$ de ABL.

Considerando o fluxo de veículos atraídos na sexta-feira, no horário das 18:00 às 19:00h, como fator horário de geração de viagens, este fator corresponde a 7,94\% das viagens geradas na sexta-feira.

\subsection{SÍNTESE DOS RESULTADOS OBTIDOS}

A Tabela 4.28 apresenta resumidamente as informações obtidas nos seis empreendimentos pesquisados. 
Tabela 4.28 - Síntese dos resultados obtidos nos shopping centers pesquisados.

\begin{tabular}{|c|c|c|c|c|c|c|c|}
\hline \multirow{2}{*}{\multicolumn{2}{|c|}{ Informações }} & \multicolumn{6}{|c|}{ SHOPPING CENTERS } \\
\hline & & "A" & "B" & ${ }^{6} \mathrm{C}^{\prime \prime}$ & "D" & "E" & "F" \\
\hline \multicolumn{2}{|l|}{ Área Total Construída $\left[\mathrm{m}^{2}\right]$} & 64.000 & 11.600 & 28.160 & 63.600 & 38.920 & 33.000 \\
\hline \multicolumn{2}{|l|}{ Área Bruta Locável $\left[\mathrm{m}^{2}\right]$} & 20.356 & 4.200 & 17.992 & 27.549 & 18.949 & 17.334 \\
\hline \multicolumn{2}{|l|}{$\begin{array}{l}\text { Viagens geradas sexta-feira } \\
\text { [veículos/dia] }\end{array}$} & 3.815 & 1.432 & 4.145 & 6.760 & 4.500 & 4.547 \\
\hline \multicolumn{2}{|l|}{$\begin{array}{l}\text { Viagens geradas sábado } \\
\text { [veículos/dia] }\end{array}$} & 6.153 & 1.743 & 6.247 & 8.100 & 6.400 & 7.431 \\
\hline \multirow{3}{*}{$\begin{array}{l}\text { Viagens na hora pico } \\
\text { sexta-feira } \\
\text { [veículos/hora] }\end{array}$} & Entrada & 514 & 204 & 636 & & & 532 \\
\hline & Saída & 437 & 213 & 484 & & & \\
\hline & Total & 931 & 406 & 1.033 & & & \\
\hline \multirow{3}{*}{$\begin{array}{l}\text { Fator hora pico sexta-feira } \\
{[\%]}\end{array}$} & Entrada & 13,47 & 14,25 & 15,34 & & & 11,70 \\
\hline & Saída & 11,45 & 14,87 & 11,68 & & & \\
\hline & Total & 12,20 & 14,18 & 12,46 & & & \\
\hline \multirow{3}{*}{$\begin{array}{l}\text { Incidência da hora pico } \\
\text { sexta-feira } \\
\text { [hora] }\end{array}$} & Entrada & 19:00-20:00 & 20:00-21:00 & 20:00-21:00 & & & 19:00-20:00 \\
\hline & Saída & 20:00-21:00 & 21:00-22:00 & 21:00-22:00 & & & \\
\hline & Total & 19:00-20:00 & 21:00-22:00 & 20:00-21:00 & & & \\
\hline \multirow{3}{*}{$\begin{array}{l}\text { Viagens horárias sexta- } \\
\text { feira, das 18:00 às 19:00h } \\
\text { [veículos/hora] }\end{array}$} & Entrada & 451 & 189 & 326 & & & 361 \\
\hline & Saída & 362 & 136 & 303 & & & \\
\hline & Total & 813 & 325 & 629 & & & \\
\hline \multirow{3}{*}{$\begin{array}{l}\text { Fator horário sexta-feira, } \\
\text { das 18:00 às 19:00h } \\
{[\%]}\end{array}$} & Entrada & 11,82 & 13,20 & 7,86 & & & 7,94 \\
\hline & Saída & 9,49 & 9,50 & 7,31 & & & \\
\hline & Total & 10,66 & 11,35 & 7,59 & & & \\
\hline \multirow{3}{*}{$\begin{array}{l}\text { Viagens na hora pico } \\
\text { sábado [veículos/hora] }\end{array}$} & Entrada & 651 & 270 & 782 & & & 852 \\
\hline & Saída & 578 & 241 & 593 & & & \\
\hline & Total & 1.198 & 511 & 1.320 & & & \\
\hline \multirow{3}{*}{$\begin{array}{l}\text { Fator hora pico sábado } \\
\text { [\%] }\end{array}$} & \begin{tabular}{|l} 
Entrada \\
\end{tabular} & 10,58 & 15,49 & 12,52 & & & 11,47 \\
\hline & Saída & 9,39 & 13,83 & 9,49 & & & \\
\hline & Total & 9,74 & 14,66 & 10,57 & & & \\
\hline \multirow{3}{*}{$\begin{array}{l}\text { Incidência da hora pico } \\
\text { sábado } \\
\text { [hora] }\end{array}$} & Entrada & 19:00-20:00 & 21:00-22:00 & 20:00-21:00 & & & 20:00-21:00 \\
\hline & Saída & 21:00-22:00 & 21:00-22:00 & 21:00-22:00 & & & \\
\hline & Total & 19:00-20:00 & 21:00-22:00 & $20: 00-21: 00$ & & & \\
\hline \multicolumn{2}{|c|}{$\begin{array}{l}\text { Taxa de atratividade } \\
\left.\text { [veículos por } 100 \mathrm{~m}^{2} \text { de } \mathrm{ABL}\right]\end{array}$} & 30,23 & 41,50 & 34,72 & 29,40 & 33,77 & 42,87 \\
\hline \multicolumn{2}{|c|}{ Oferta de estacionamento [vagas] } & 2.000 & 200 & 1.100 & 796 & 1.230 & 1.067 \\
\hline \multicolumn{2}{|c|}{ Demanda por estacionamento [vagas] } & 626 & 314 & 1.084 & & & \\
\hline \multicolumn{2}{|c|}{$\begin{array}{l}\text { Incidência do maior acúmulo de } \\
\text { veículos no estacionamento [hora] }\end{array}$} & 20:00-21:00 & 21:00-22:00 & 21:00-22:00 & & & \\
\hline \multicolumn{2}{|c|}{ Tempo médio de permanência [hora] } & 0,90 & 0,86 & 1,06 & & & \\
\hline
\end{tabular}

Identifica-se, junto a todas as informações obtidas nos empreendimentos pesquisados, que a incidência dos picos horários das viagens para sexta-feira, na entrada varia entre 19:00 e 21:00h, na saída varia entre 20:00 e 22:00h, e no total varia entre 19:00 e 22:00h. Para sábado, observa-se que a incidência dos picos horários na entrada varia entre 19:00 e 22:00h, na saída varia entre 21:00 e 22:00h, e no total das viagens varia entre 19:00 e 22:00h. E, 
constata-se, ainda, que a incidência do acúmulo máximo de veículos no estacionamento varia entre 20:00 e 22:00h.

As diferenças apresentadas em relação à demanda e oferta de vagas de estacionamento, para cada empreendimento pesquisado, levam a crer que o empreendimento "A" apresenta estacionamento super-dimensionado, o shopping "B" apresenta déficit de vagas e o empreendimento " $\mathrm{C}$ " apresenta estacionamento adequado para atender a demanda.

Cabe destacar que, as amostras de identificação de placas dos veículos na entrada e saída dos estacionamentos em cada empreendimento, obtidas para um sábado, apresentaram variação entre 41 e $67 \%$ do total de veículos atraídos pelo empreendimento valores altamente significativos se comparados com os obtidos por outros pesquisadores, que consideram como aceitável uma amostra de 2 a $5 \%$ do fluxo total de veículos, conforme GOLDNER (1994). 


\section{ANÁLISE DOS RESULTADOS OBTIDOS}

Neste capítulo são analisados os valores obtidos para os principais padrões de viagens referentes aos empreendimentos estudados.

\subsection{RELAÇÃO ENTRE OS FLUXOS DA SEXTA-FEIRA E DO SÁBADO}

Na Tabela 5.1 são apresentados os valores da relação entre as viagens na sextafeira (VDsex) e no sábado (VDsab) e alguns parâmetros estatísticos pertinentes. Na Figura 5.1 os resultados são representados graficamente.

Tabela 5.1 - Relação entre as viagens diárias realizadas na sexta-feira e no sábado.

\begin{tabular}{|l|c|c|}
\hline Shopping centers & VDsex / VDsab & Desvio [\%] \\
\hline Shopping center “A" & 0,6200 & $-12,56$ \\
\hline Shopping center "B" & 0,8216 & 15,86 \\
\hline Shopping center "C" & 0,6635 & $-6,43$ \\
\hline Shopping center "D" & 0,8346 & 17,69 \\
\hline Shopping center "E" & 0,7031 & $-0,84$ \\
\hline Shopping center "F" & 0,6119 & $-13,71$ \\
\hline Média & $\mathbf{0 , 7 0 9 1}$ & $-13,71$ \\
\hline Valor mínimo & 0,6119 & 17,69 \\
\hline Valor máximo & 0,8346 & \\
\hline Desvio médio & 0,0793 & \\
\hline Desvio padrão & 0,0979 & \\
\hline Coeficiente de Variação $\{\%\}$ & 13,801 & \\
\hline
\end{tabular}

A relação dos valores observados entre as viagens diárias realizadas na sexta-feira e sábado possui média igual a 0,7091. Isto é, esses valores estão em torno de 0,7091 e o grau de concentração é de 0,0793 , medido pelo desvio médio, e de 0,0978, medido pelo desvio padrão.

Observa-se que os graus de variabilidade dos valores observados em torno da média apresentam dispersão baixa, se considerado o coeficiente de variação, que se apresenta inferior a $15 \%$. 


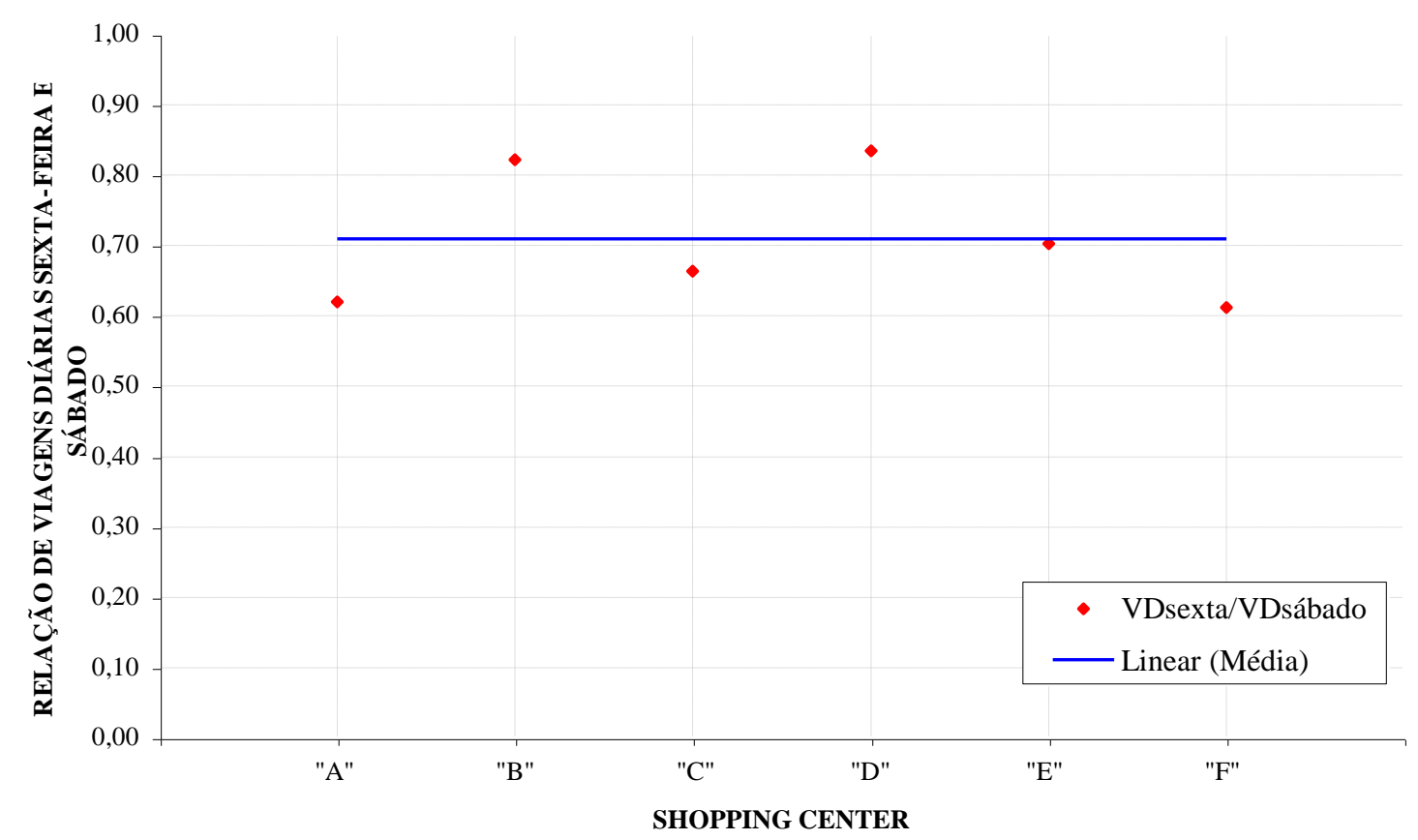

Figura 5.1 - Relação entre as viagens diárias na sexta-feira e no sábado.

Assim, considera-se o valor médio de 0,71 , com amplitude dos desvios variando de $-13,71 \%$ a $17,69 \%$, como um valor aceitável para relacionar as viagens geradas na sexta-feira e sábado.

\subsection{RELAÇÃO ENTRE AS VIAGENS DIÁRIAS E O TAMANHO DO SHOPPING CENTER}

Neste item são determinadas e analisadas as relações entre as viagens diárias e a área bruta locável e entre as viagens diárias e a área total construída, para a sexta-feira e o sábado.

\subsubsection{SEXTA-FEIRA}

Na Tabela 5.2 são apresentados os valores da relação entre as viagens na sextafeira (VDsex) e a Área Bruta Locável (ABL) e alguns parâmetros estatísticos pertinentes. Na Figura 5.2 os resultados são representados graficamente. 
Tabela 5.2 - Relação entre as viagens na sexta-feira e a área bruta locável.

\begin{tabular}{|l|c|c|}
\hline Shopping centers & VDsex / ABL / 100 & Desvio [\%] \\
\hline Shopping center "A" & 18,7414 & $-25,52$ \\
\hline Shopping center "B" & 34,0952 & 35,50 \\
\hline Shopping center "C" & 23,0380 & $-8,44$ \\
\hline Shopping center "D" & 24,5381 & $-2,48$ \\
\hline Shopping center "E" & 24,3322 & $-3,3$ \\
\hline Shopping center "F" & 26,2317 & 4,25 \\
\hline Média & $\mathbf{2 5 , 1 6 2 8}$ & $-25,52$ \\
\hline Valor mínimo & & 35,50 \\
\hline Valor máximo & 18,7414 & \\
\hline Desvio médio & 34,0952 & \\
\hline Desvio padrão & 3,3338 & \\
\hline Coeficiente de Variação [\%] & 5,0549 & \\
\hline
\end{tabular}

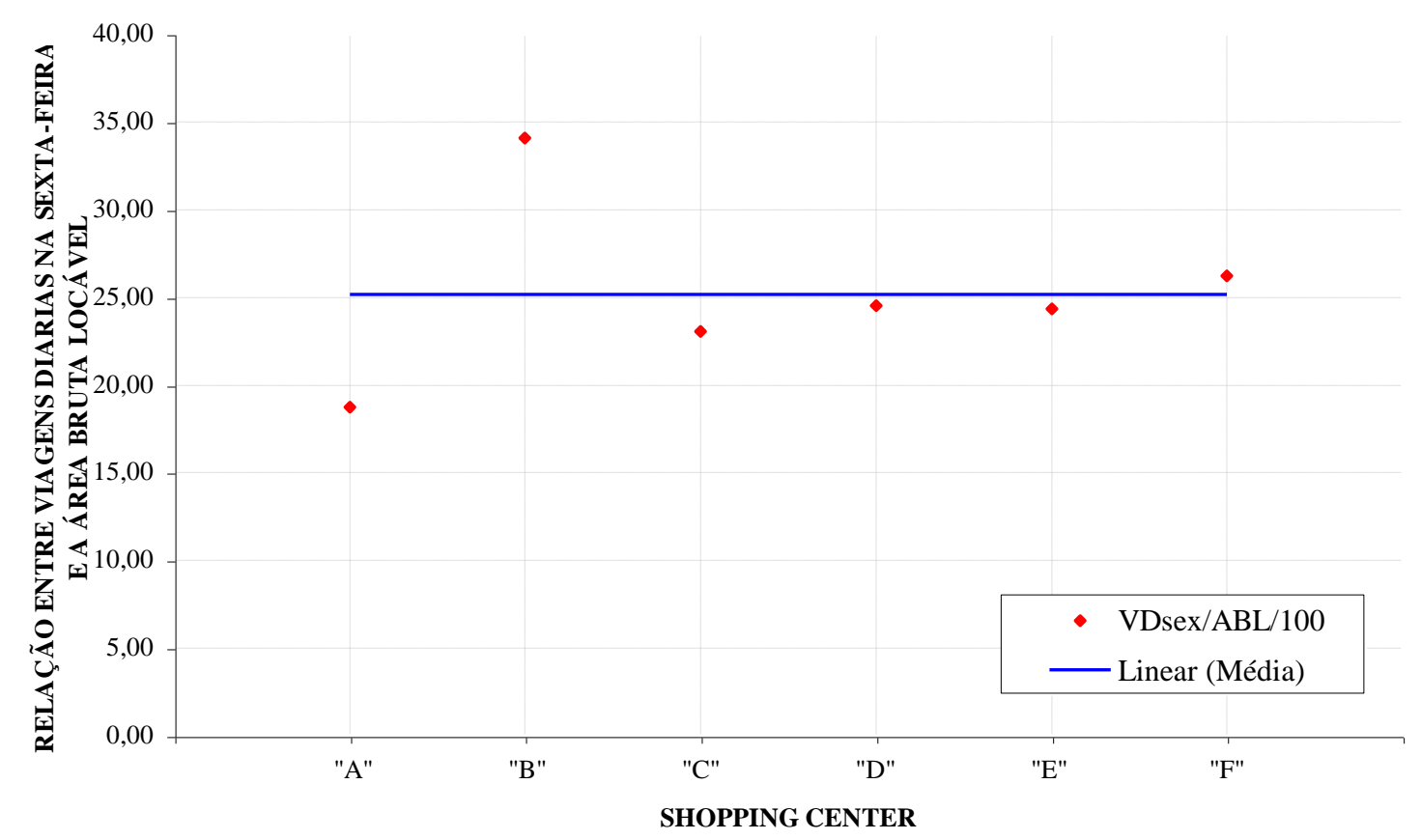

Figura 5.2 - Relação entre as viagens na sexta-feira e a área bruta locável.

A relação dos valores observados entre as viagens diárias realizadas na sexta-feira e a área bruta locável possui média igual a 25,163 e grau de concentração de 3,334, medido pelo desvio médio, e de 5,055, medido pelo desvio padrão.

Observa-se que os graus de variabilidade dos valores observados em torno da média apresentam dispersão média, se considerado o coeficiente de variação, que se apresenta superior a $15 \%$ e inferior a $30 \%$. Nota-se, ainda, que os valores mais discrepantes são apresentados pelos shopping centers "A" e "B". No entanto, os valores apresentados nos empreendimentos “C”, "D", “E” e "F" apresentam baixa dispersão. 
Assim, considera-se o valor médio de 25,1628 veículos por $100 \mathrm{~m}^{2}$ de ABL, com amplitude dos desvios variando de $-25,52 \%$ a $35,50 \%$, como um valor aceitável para relacionar as viagens geradas na sexta-feira com a área bruta locável.

Na Tabela 5.3 são apresentados os valores da relação entre as viagens na sextafeira (VDsex) e a Área Total Construída (ATC) e alguns parâmetros estatísticos pertinentes. Na Figura 5.3 os resultados são representados graficamente.

Tabela 5.3 - Relação entre as viagens geradas na sexta-feira e a área total construída.

\begin{tabular}{|l|c|c|}
\hline Shopping centers & VDsex / ATC / 100 & Desvio [\%] \\
\hline Shopping center "A" & 5,9609 & $-48,16$ \\
\hline Shopping center "B" & 12,3448 & 7,35 \\
\hline Shopping center "C" & 14,7195 & 28,00 \\
\hline Shopping center "D" & 10,6289 & $-7,57$ \\
\hline Shopping center "E" & 11,5622 & 0,55 \\
\hline Shopping center "F" & 13,7788 & 19,82 \\
\hline Média & $\mathbf{1 1 , 4 9 9 2}$ & \\
\hline Valor mínimo & 5,9609 & $-48,16$ \\
\hline Valor máximo & 14,7195 & 28,00 \\
\hline Desvio médio & 2,1362 & \\
\hline Desvio padrão & 3,0892 & \\
\hline Coeficiente de Variação [\%] & 26,8644 & \\
\hline
\end{tabular}

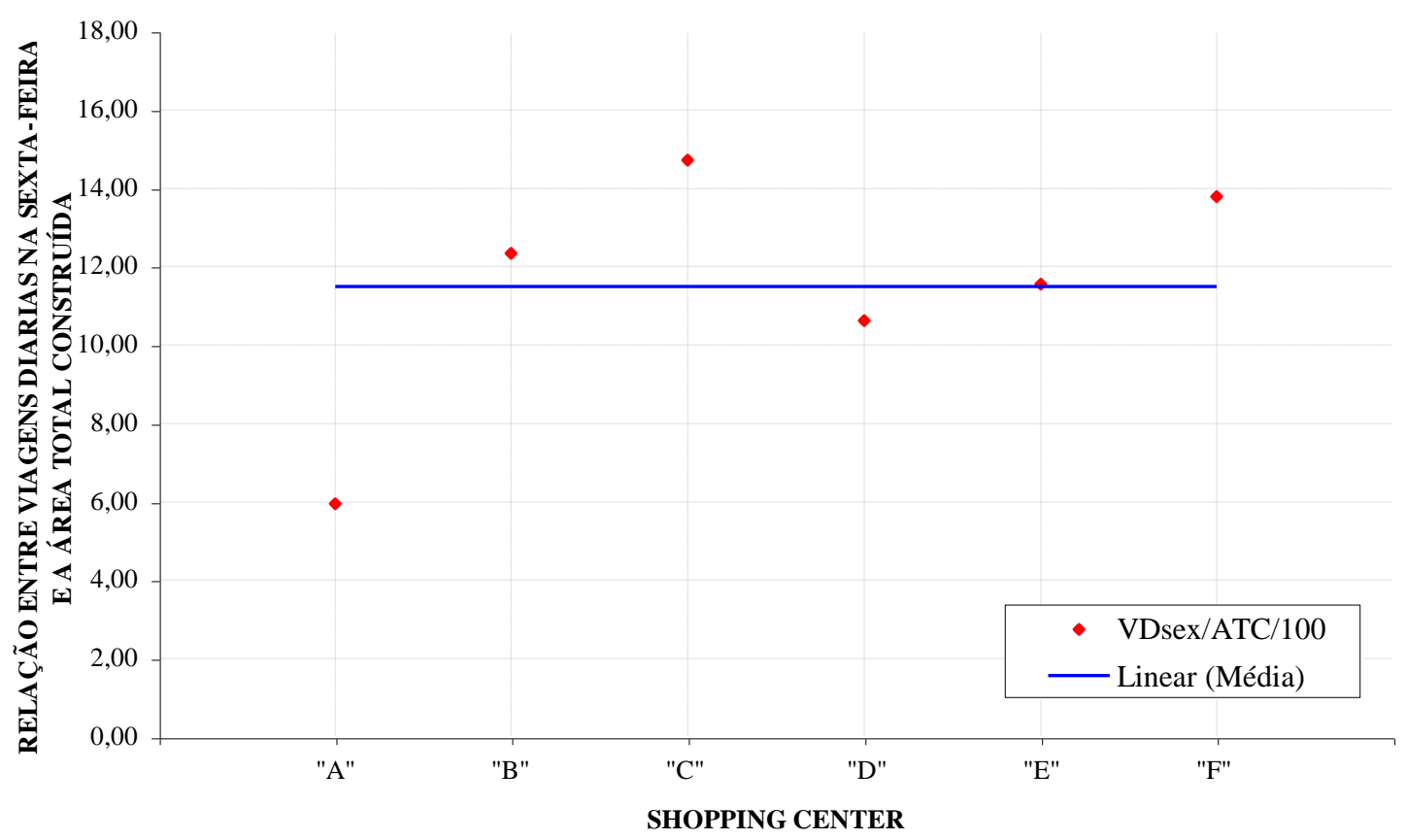

Figura 5.3 - Relação entre as viagens na sexta-feira e a área total construída. 
A relação dos valores observados entre as viagens diárias realizadas na sexta-feira e a área total construída possui média igual a 11,4992 e grau de concentração de 2,1362, medido pelo desvio médio, e de 3,0892, medido pelo desvio padrão.

Observa-se que os graus de variabilidade dos valores observados em torno da média apresentam dispersão média, se considerado o coeficiente de variação, que se apresenta superior a $15 \%$ e inferior a $30 \%$. Nota-se, ainda, que o valor mais discrepante é apresentado pelo shopping center "A". No entanto, os valores apresentados nos empreendimentos "B" e "E" apresentam baixa dispersão.

Assim, considera-se o valor médio de 11,4992 veículos por $100 \mathrm{~m}^{2}$ de ATC, com amplitude dos desvios variando de $-48,16 \%$ a $28,00 \%$, como um valor aceitável para relacionar as viagens geradas na sexta-feira com a área total construída.

\subsubsection{SÁBADO}

Na Tabela 5.4 são apresentados os valores da relação entre as viagens no sábado (VDsab) e a Área Bruta Locável (ABL) e alguns parâmetros estatísticos pertinentes. Na Figura 5.4 os resultados são representados graficamente.

Tabela 5.4 - Relação entre as viagens geradas no sábado e a área bruta locável.

\begin{tabular}{|l|c|c|}
\hline Shopping centers & VDsab / ABL / 100 & Desvio [\%] \\
\hline Shopping center "A" & 30,2270 & $-14,98$ \\
\hline Shopping center "B" & 41,5000 & 16,72 \\
\hline Shopping center "C" & 34,7210 & $-2,34$ \\
\hline Shopping center "D" & 29,4022 & $-17,30$ \\
\hline Shopping center "E" & 34,6058 & $-2,67$ \\
\hline Shopping center "F" & 42,8695 & 20,58 \\
\hline Média & $\mathbf{3 5 , 5 5 4 2}$ & \\
\hline Valor mínimo & 29,4022 & $-17,30$ \\
\hline Valor máximo & 42,8695 & 20,58 \\
\hline Desvio médio & 4,4203 & \\
\hline Desvio padrão & 5,5980 & \\
\hline Coeficiente de Variação [\%] & 15,7449 & \\
\hline
\end{tabular}

A relação dos valores observados entre as viagens diárias realizadas no sábado e a área bruta locável possui média igual a 35,5542 e grau de concentração de 4,4203, medido pelo desvio médio, e de 5,5980, medido pelo desvio padrão.

Observa-se que os graus de variabilidade dos valores observados em torno da média apresentam dispersão média, se considerado o coeficiente de variação, que se apresenta superior a $15 \%$ e inferior a $30 \%$. Nota-se, ainda, que os valores mais discrepantes são 
apresentados pelos shopping centers "B" e "F". No entanto, os valores apresentados nos empreendimentos "C" e "E" apresentam baixa dispersão.

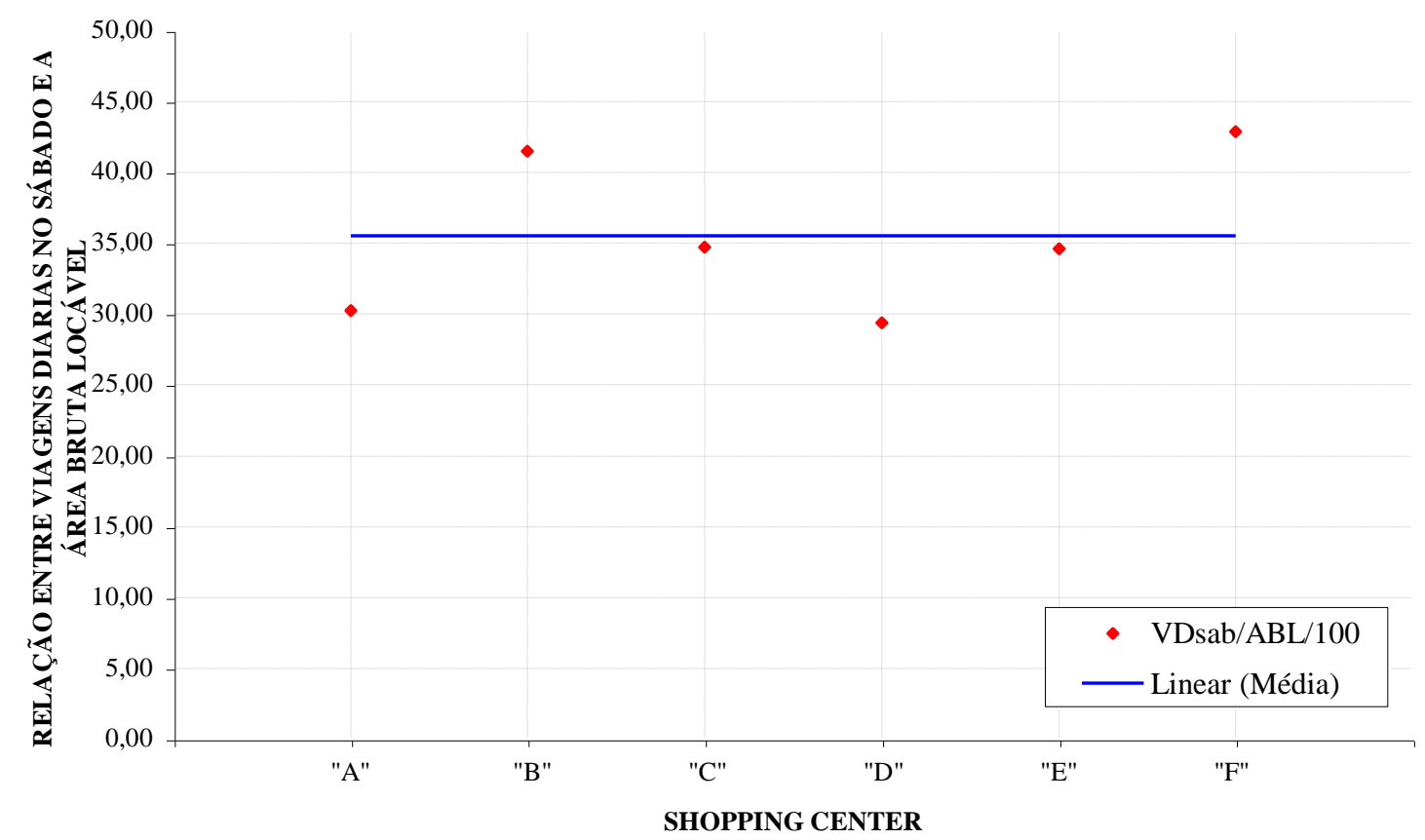

Figura 5.4 - Relação entre as viagens no sábado e a área bruta locável.

Assim, considera-se o valor médio de 35,5542 veículos por $100 \mathrm{~m}^{2}$ de ABL, com amplitude dos desvios variando de $-17,30 \%$ a $20,58 \%$, como um valor aceitável para relacionar as viagens geradas no sábado com a área bruta locável.

Na Tabela 5.5 são apresentados os valores da relação entre as viagens no sábado (VDsab) e a Área Total Construída (ATC) e alguns parâmetros estatísticos pertinentes. Na Figura 5.5 os resultados são representados graficamente.

Tabela 5.5 - Relação entre as viagens geradas no sábado e a área total construída.

\begin{tabular}{|l|c|c|}
\hline Shopping centers & \multicolumn{1}{|c|}{ VDsab / ATC / 100 } & Desvio [\%] \\
\hline Shopping center "A" & 9,6141 & $-41,45$ \\
\hline Shopping center "B" & 15,0259 & $-8,49$ \\
\hline Shopping center "C" & 22,1839 & 35,10 \\
\hline Shopping center "D" & 12,7358 & $-22,44$ \\
\hline Shopping center "E" & 16,4440 & 0,14 \\
\hline Shopping center "F" & \multicolumn{1}{|c|}{$\mathbf{1 6 , 4 2 0 3}$} & 37,14 \\
\hline Média & & $-41,45$ \\
\hline Valor mínimo & 9,6141 & 35,10 \\
\hline Valor máximo & 22,5182 & \\
\hline Desvio médio & 3,9617 & \\
\hline Desvio padrão & 5,1429 & \\
\hline Coeficiente de Variação [\% & 31,3206 & \\
\hline
\end{tabular}




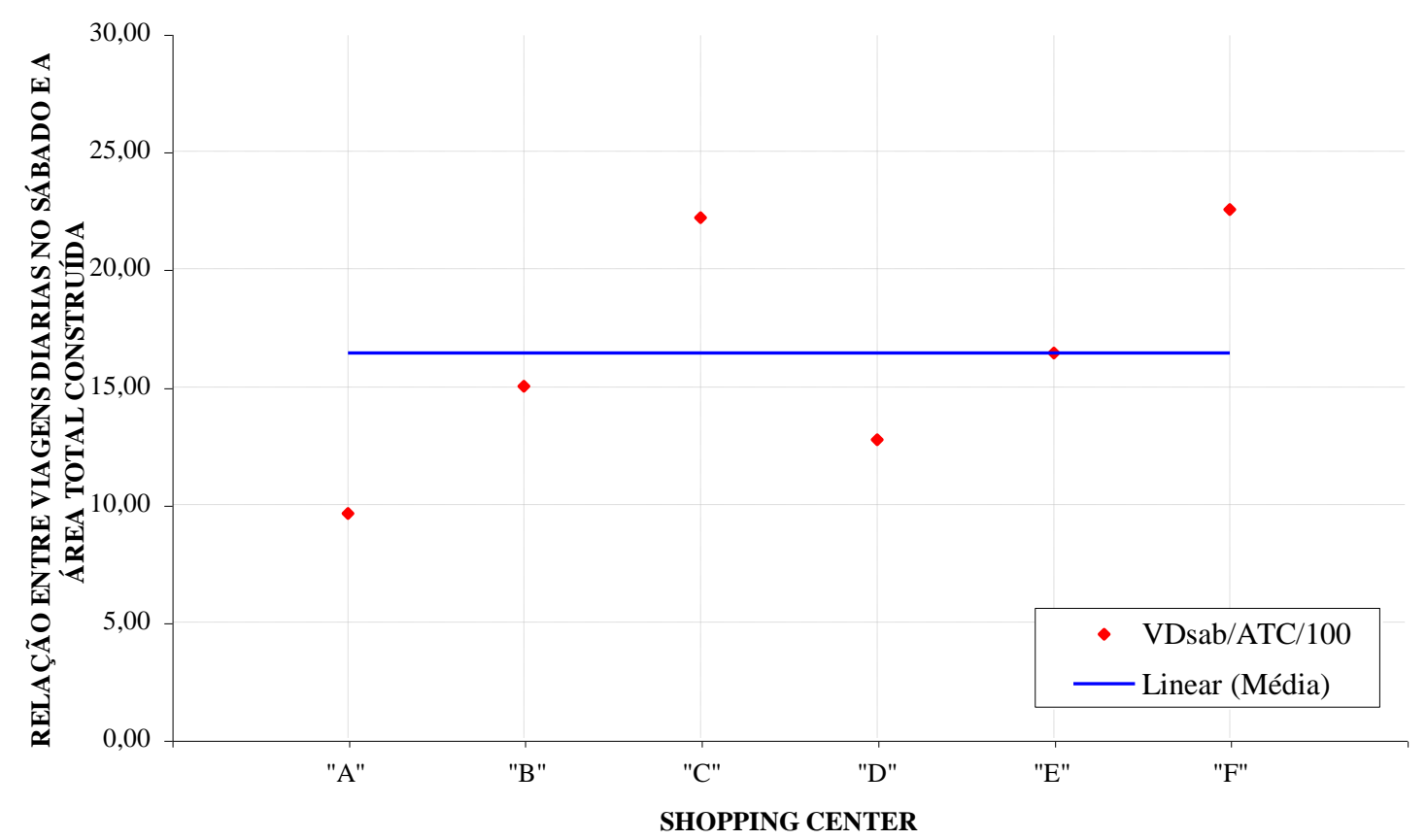

Figura 5.5 - Relação entre as viagens no sábado e a área total construída.

A relação dos valores observados entre as viagens diárias realizadas no sábado e a área total construída possui média igual a 16,4203 e grau de concentração de 3,9617, medido pelo desvio médio, e de 5,1429, medido pelo desvio padrão.

Observa-se que os graus de variabilidade dos valores observados em torno da média apresentam dispersão alta, se considerado o coeficiente de variação, que se apresenta superior a 30\%. Nota-se, ainda, que os valores mais discrepantes são apresentados pelos shopping centers "A", "C" e "F", no entanto, o valor apresentado no empreendimento "E" apresenta baixa dispersão.

Assim, considera-se o valor médio de 16,4203 veículos por $100 \mathrm{~m}^{2}$ de ATC, com amplitude dos desvios variando de $-41,45 \%$ a $35,10 \%$, como um valor não recomendável para relacionar as viagens geradas no sábado com a área total construída.

No geral, conclui-se que o valor médio correspondente a 35,55 viagens por $100 \mathrm{~m}^{2}$ de ABL, apresentado para sábado, é o valor que melhor relaciona as viagens diárias por veículos com o tamanho do empreendimento. No entanto, apresenta dispersão média de 15,75\% para os empreendimentos pesquisados. 


\subsection{FATORES DE PICO HORÁRIO}

Neste item são determinados e analisados os fatores de pico horário (relação entre o número de viagens na hora pico e o total de viagens no dia), para a sexta-feira e o sábado.

\subsubsection{SEXTA-FEIRA}

Na Tabela 5.6 são apresentados os valores da relação entre as viagens na hora pico de entrada e as viagens na sexta-feira (FHE sexta-feira) e alguns parâmetros estatísticos pertinentes. Na Figura 5.6 os resultados são representados graficamente.

Tabela 5.6 - Fator hora pico de entrada na sexta-feira (FHE sexta-feira).

\begin{tabular}{|c|c|c|}
\hline Shopping centers & \multicolumn{1}{|c|}{ FHE sexta-feira } & Desvio [\%] \\
\hline Shopping center “A” & 0,1347 & $-1,61$ \\
\hline Shopping center "B" & 0,1425 & 4,09 \\
\hline Shopping center “C” & 0,1534 & 12,05 \\
\hline Shopping center "F" & 0,1170 & $-14,54$ \\
\hline Média & \multicolumn{1}{|c|}{$\mathbf{0 , 1 3 6 9}$} & $-14,54$ \\
\hline Valor mínimo & & 12,05 \\
\hline Valor máximo & 0,1170 & \\
\hline Desvio médio & 0,1534 & \\
\hline Desvio padrão & 0,0110 & \\
\hline Coeficiente de Variação [\%] & 0,0153 & \\
\hline
\end{tabular}

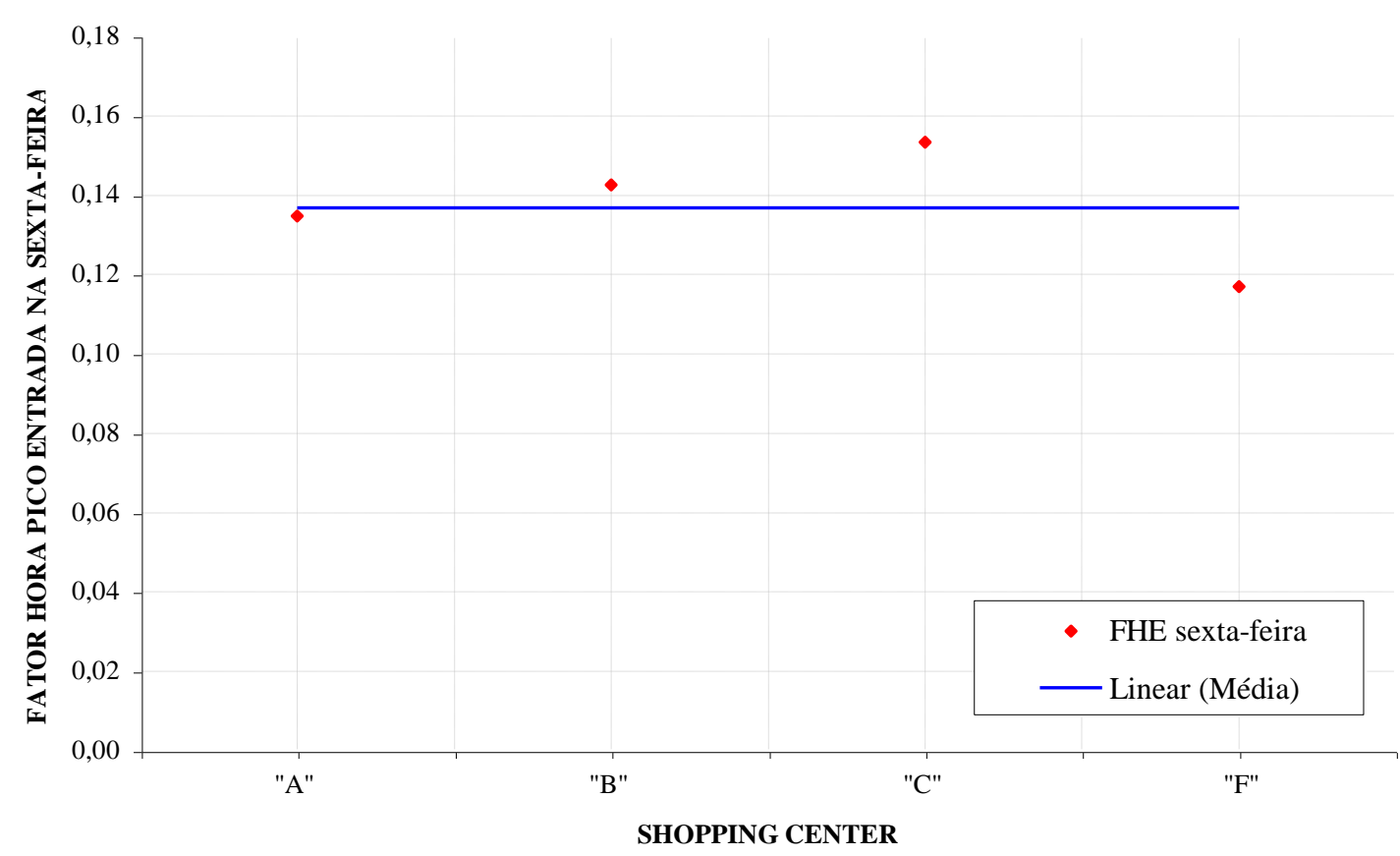

Figura 5.6 - Fator hora pico de entrada na sexta-feira. 
A relação dos valores observados dos fatores hora pico de entrada na sexta-feira possui média igual a 0,1369 e grau de concentração de 0,0110, medido pelo desvio médio, e de 0,0153, medido pelo desvio padrão.

Observa-se que os graus de variabilidade dos valores observados em torno da média apresentam dispersão baixa, se considerado o coeficiente de variação, que se apresenta inferior a $15 \%$.

Assim, considera-se o valor médio de 0,1369, com amplitude dos desvios variando de $-14,54 \%$ a $12,05 \%$, como um valor aceitável para estimar as viagens geradas na hora pico de entrada em relação ao fluxo total de entrada na sexta-feira.

Na Tabela 5.7 são apresentados os valores da relação entre as viagens na hora pico de saída e as viagens na sexta-feira (FHS sexta-feira) e alguns parâmetros estatísticos pertinentes. Na Figura 5.7 os resultados são representados graficamente.

Tabela 5.7 - Fator hora pico de saída na sexta-feira (FHS sexta-feira).

\begin{tabular}{|l|l|c|}
\hline Shopping centers & \multicolumn{1}{|c|}{ FHS sexta-feira } & Desvio [\%] \\
\hline Shopping center "A" & 0,1145 & $-9,63$ \\
\hline Shopping center "B" & 0,1487 & 17,36 \\
\hline Shopping center "C" & 0,1168 & $-7,81$ \\
\hline Média & $\mathbf{0 , 1 2 6 7}$ & $-9,63$ \\
\hline Valor mínimo & 0,1145 & 17,36 \\
\hline Valor máximo & 0,1487 & \\
\hline Desvio médio & 0,0147 & \\
\hline Desvio padrão & 0,0191 & \\
\hline Coeficiente de Variação [\%] & 15,10 & \\
\hline
\end{tabular}

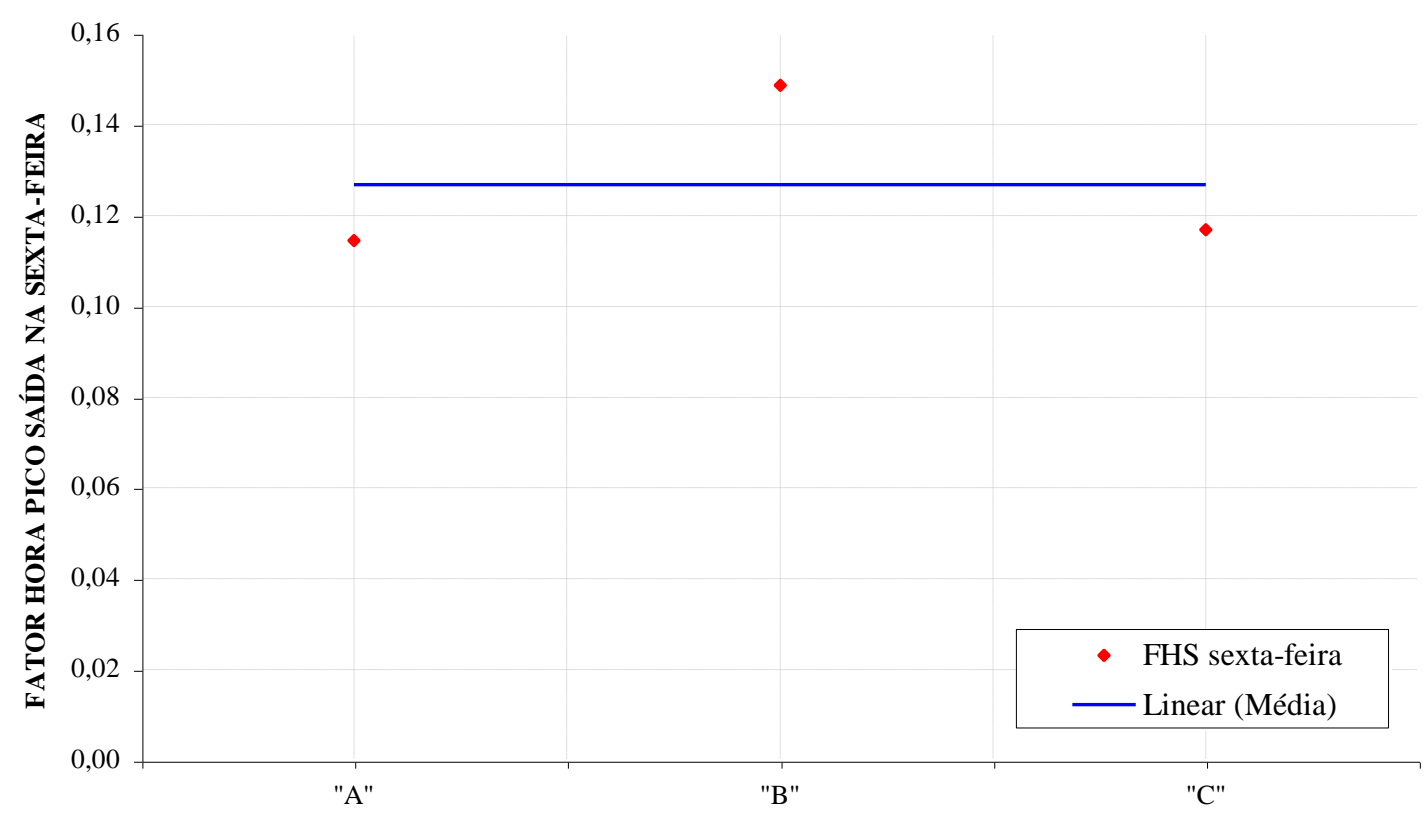

SHOPPING CENTER

Figura 5.7 - Fator hora pico de saída na sexta-feira. 
A relação dos valores observados dos fatores hora pico de saída na sexta-feira possui média igual a 0,1267 e grau de concentração de 0,0147, medido pelo desvio médio, e de 0,0191, medido pelo desvio padrão.

Observa-se que os graus de variabilidade dos valores observados em torno da média apresentam dispersão média, se considerado o coeficiente de variação, que se apresenta superior a $15 \%$ e inferior a $30 \%$. Nota-se, ainda, que o valor mais discrepante é apresentado pelo shopping center "B", no entanto, os valores apresentados nos empreendimentos "A" e " $\mathrm{C}$ " apresentam baixa dispersão.

Assim, considera-se o valor médio de 0,1267, com amplitude dos desvios variando de $-9,63 \%$ a $17,36 \%$, como um valor aceitável para estimar as viagens geradas na hora pico de saída em relação ao fluxo total de saída na sexta-feira.

Na Tabela 5.8 são apresentados os valores da relação entre o total de viagens (entrada mais saída) na hora pico da sexta-feira e o número total de viagens na sexta-feira (FHT sexta-feira) e alguns parâmetros estatísticos pertinentes. Na Figura 5.8 os resultados são representados graficamente.

Tabela 5.8 - Fator hora pico total na sexta-feira (FHT sexta-feira).

\begin{tabular}{|l|l|c|}
\hline Shopping centers & \multicolumn{1}{|c|}{ FHT sexta-feira } & Desvio [\%] \\
\hline Shopping center “A” & 0,2440 & $-5,74$ \\
\hline Shopping center "B" & 0,2835 & 9,51 \\
\hline Shopping center “C” & 0,2492 & $-3,74$ \\
\hline Média & $\mathbf{0 , 2 5 8 9}$ & $-5,74$ \\
\hline Valor mínimo & 0,2440 & 9,51 \\
\hline Valor máximo & 0,2835 & \\
\hline Desvio médio & 0,0164 & \\
\hline Desvio padrão & 0,0215 & \\
\hline Coeficiente de Variação [\%] & 8,29 & \\
\hline
\end{tabular}

A relação dos valores observados dos fatores hora pico total na sexta-feira possui média igual a 0,2589 e grau de concentração de 0,0164, medido pelo desvio médio, e de 0,0215, medido pelo desvio padrão.

Observa-se que os graus de variabilidade dos valores observados em torno da média apresentam dispersão baixa, se considerado o coeficiente de variação, que se apresenta inferior a $15 \%$. 


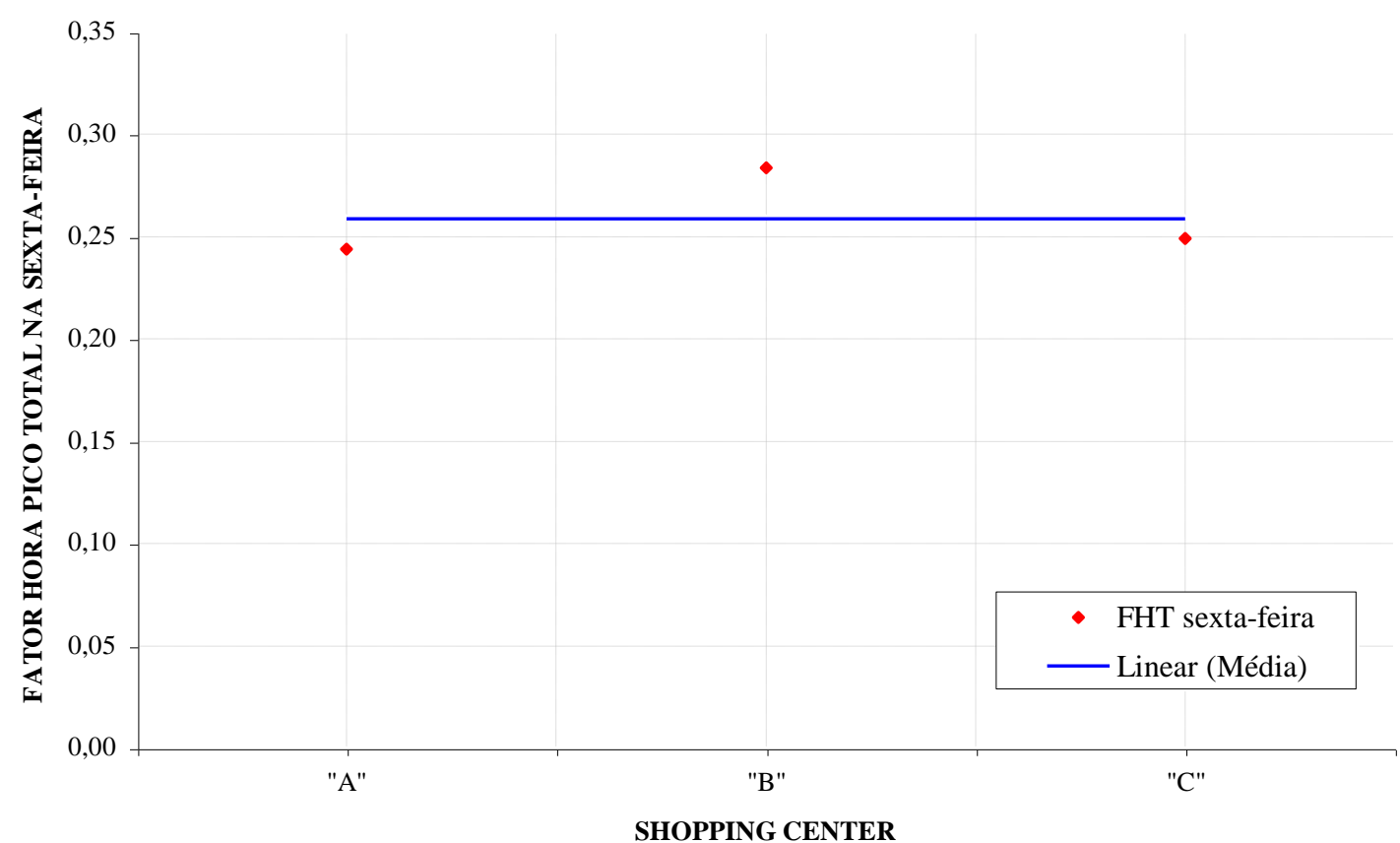

Figura 5.8 - Fator hora pico total na sexta-feira.

Assim, considera-se o valor médio de 0,2589, com amplitude dos desvios variando de $-5,74 \%$ a $9,51 \%$, como um valor aceitável para estimar as viagens geradas na hora pico do total de entrada e saída em relação ao fluxo total de veículos na sexta-feira.

\subsubsection{SÁBADO}

Na Tabela 5.9 são apresentados os valores da relação entre as viagens na hora pico de entrada e as viagens no sábado (FHE sábado) e alguns parâmetros estatísticos pertinentes. Na Figura 5.9 os resultados são representados graficamente.

Tabela 5.9 - Fator hora pico de entrada no sábado (FHE sábado).

\begin{tabular}{|l|l|c|}
\hline Shopping centers & FHE sábado & Desvio [\%] \\
\hline Shopping center "A" & 0,1058 & $-15,43$ \\
\hline Shopping center "B" & 0,1549 & 23,82 \\
\hline Shopping center "C" & 0,1252 & 0,08 \\
\hline Shopping center "F" & 0,1147 & $-8,31$ \\
\hline Média & $\mathbf{0 , 1 2 5 1}$ & $-15,43$ \\
\hline Valor mínimo & 0,1058 & 23,82 \\
\hline Valor máximo & 0,1549 & \\
\hline Desvio médio & 0,0149 & \\
\hline Desvio padrão & 0,0214 & \\
\hline Coeficiente de Variação [\%] & 17,08 & \\
\hline
\end{tabular}




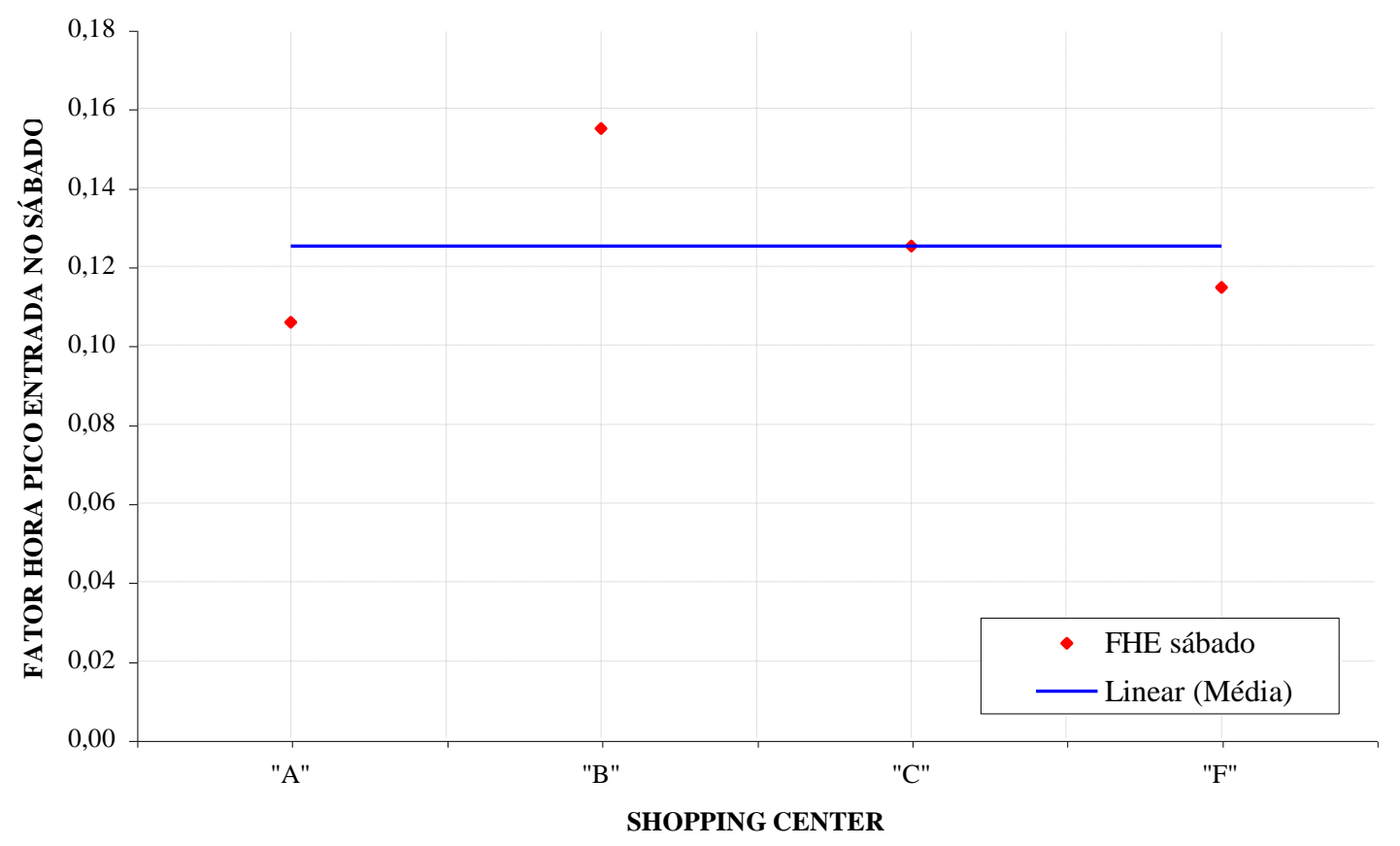

Figura 5.9 - Fator hora pico de entrada no sábado.

A relação dos valores observados dos fatores hora pico de entrada no sábado possui média igual a 0,1251 e grau de concentração de 0,0149 , medido pelo desvio médio, e de 0,0214 , medido pelo desvio padrão.

Observa-se que os graus de variabilidade dos valores observados em torno da média apresentam dispersão média, se considerado o coeficiente de variação, que se apresenta superior a $15 \%$ e inferior a $30 \%$. Nota-se, ainda, que o valor mais discrepante é apresentado pelo shopping center "B", no entanto, os valores apresentados nos empreendimentos " $\mathrm{C}$ " e " $\mathrm{F}$ " apresentam baixa dispersão.

Assim, considera-se o valor médio de 0,1251, com amplitude dos desvios variando de $-15,43 \%$ a $23,82 \%$, como um valor aceitável para estimar as viagens geradas na hora pico de entrada em relação ao fluxo total de entrada no sábado.

$\mathrm{Na}$ Tabela 5.10 são apresentados os valores da relação entre as viagens na hora pico de saída e as viagens no sábado (FHS sábado) e alguns parâmetros estatísticos pertinentes. Na Figura 5.10 os resultados são representados graficamente. 
Tabela 5.10 - Fator hora pico de saída no sábado (FHS sábado).

\begin{tabular}{|l|r|r|}
\hline Shopping centers & \multicolumn{1}{|c|}{ FHS sábado } & Desvio [\%] \\
\hline Shopping center “A" & 0,0939 & $-13,85$ \\
\hline Shopping center "B" & 0,1383 & 26,88 \\
\hline Shopping center "C" & 0,0949 & $-12,94$ \\
\hline Média & $\mathbf{0 , 1 0 9 0}$ & $-13,85$ \\
\hline Valor mínimo & 0,0939 & 26,88 \\
\hline Valor máximo & 0,1383 & \\
\hline Desvio médio & 0,0195 & \\
\hline Desvio padrão & 0,0253 & \\
\hline Coeficiente de Variação [\%] & 23,24 & \\
\hline
\end{tabular}

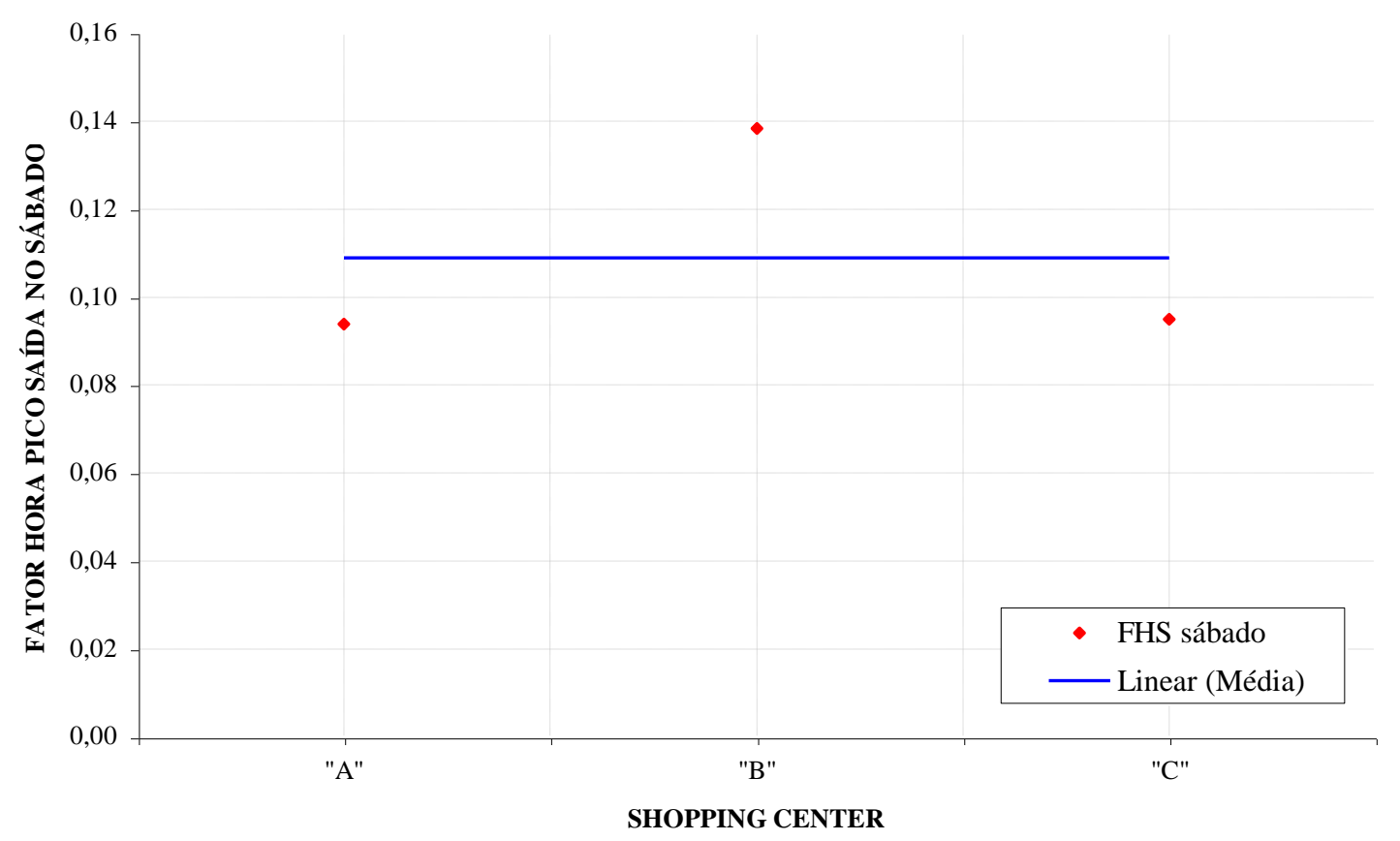

Figura 5.10 - Fator hora pico de saída no sábado.

A relação dos valores observados dos fatores hora pico de saída na sexta-feira possui média igual a 0,1090 e grau de concentração de 0,0195, medido pelo desvio médio, e de 0,0253, medido pelo desvio padrão.

Observa-se que os graus de variabilidade dos valores observados em torno da média apresentam dispersão média, se considerado o coeficiente de variação, que se apresenta superior a $15 \%$ e inferior a $30 \%$. Identifica-se, ainda, maior dispersão no shopping center "B".

Assim, considera-se o valor médio de 0,1090, com amplitude dos desvios variando de $-13,85 \%$ a $26,88 \%$, como um valor aceitável para estimar as viagens geradas na hora pico de saída em relação ao fluxo total de saída no sábado. 
Na Tabela 5.11 são apresentados os valores da relação entre o total de viagens (entrada mais saída) na hora pico do sábado e o número total de viagens no sábado (FHT sábado) e alguns parâmetros estatísticos pertinentes. Na Figura 5.11 os resultados são representados graficamente.

Tabela 5.11 - Fator hora pico total no sábado (FHT sábado).

\begin{tabular}{|l|c|c|}
\hline Shopping centers & \multicolumn{1}{|c|}{ FHT sábado } & Desvio [\%] \\
\hline Shopping center “A" & 0,1947 & $-16,47$ \\
\hline Shopping center "B" & 0,2932 & 25,77 \\
\hline Shopping center "C" & 0,2113 & $-9,35$ \\
\hline Média & $\mathbf{0 , 2 3 3 1}$ & $-16,47$ \\
\hline Valor mínimo & 0,1947 & 25,77 \\
\hline Valor máximo & 0,2932 & \\
\hline Desvio médio & 0,0401 & \\
\hline Desvio padrão & 0,0527 & \\
\hline Coeficiente de Variação [\%] & 22,62 & \\
\hline
\end{tabular}

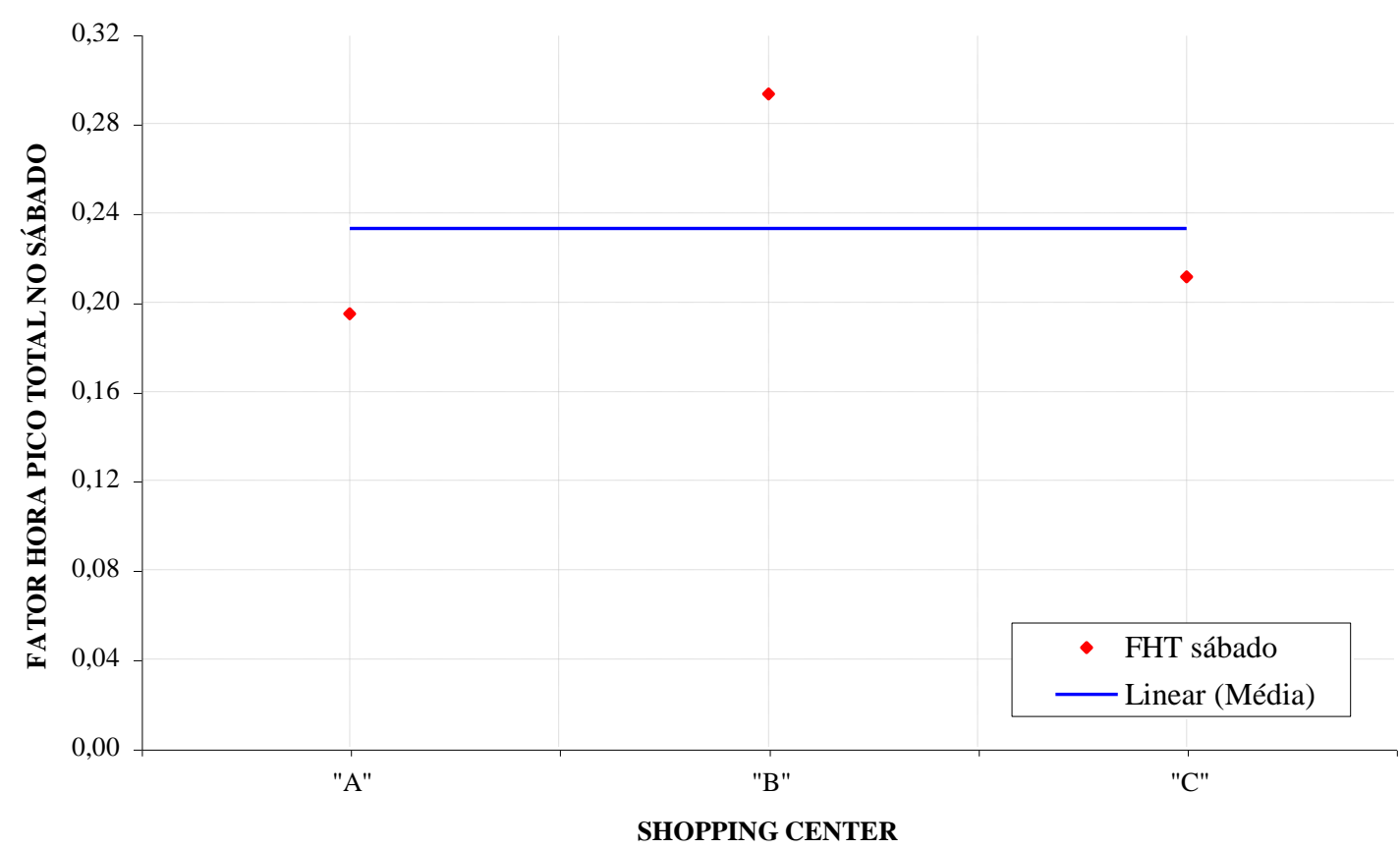

Figura 5.11 - Fator hora pico total no sábado.

A relação dos valores observados dos fatores hora pico total no sábado possui média igual a 0,2331 e grau de concentração de 0,0401, medido pelo desvio médio, e de 0,0527, medido pelo desvio padrão. 
Observa-se que os graus de variabilidade dos valores observados em torno da média apresentam dispersão média, se considerado o coeficiente de variação, que se apresenta superior a $15 \%$ e inferior a $30 \%$.

Assim, considera-se o valor médio de 0,2331, com amplitude dos desvios variando de $-16,47 \%$ a $25,77 \%$, como um valor aceitável para estimar as viagens geradas na hora pico do total de entrada mais saída em relação ao fluxo total de veículos no sábado.

No geral, conclui-se que os valores médios dos fatores horários de pico de entrada, saída e total, apresentados para sexta-feira, são os valores que melhor relacionam as viagens na hora pico com as viagens na sexta-feira. No entanto, o valor médio dos fatores horários de saída apresenta dispersão média de 15,10\% para os empreendimentos pesquisados.

\subsection{FATORES HORÁRIOS PARA ANÁLISE DO IMPACTO VIÁRIO}

Na Tabela 5.12 são apresentados os valores da relação entre as viagens horárias de entrada (VHE) e as viagens na sexta-feira (VDsex), que correspondem aos fatores horários de entrada (FHE) para o período compreendido entre 18:00 e 19:00 horas - considerado por GOLDNER (1994) para análise de impacto viário e alguns parâmetros estatísticos pertinentes. Na Figura 5.12 os resultados são representados graficamente.

Tabela 5.12 - Fator horário de entrada no período das 18:00 às 19:00h $\left(\mathrm{FHE}_{18-19}\right)$.

\begin{tabular}{|l|c|c|}
\hline Shopping centers & FHE $_{\mathbf{1 8 - 1 9}}$ & Desvio [\%] \\
\hline Shopping center “A" & 0,1182 & 15,83 \\
\hline Shopping center "B" & 0,1320 & 29,35 \\
\hline Shopping center "C" & 0,0786 & $-22,98$ \\
\hline Shopping center "F" & 0,0794 & $-22,20$ \\
\hline Média & $\mathbf{0 , 1 0 2 1}$ & $-22,98$ \\
\hline Valor mínimo & 0,0786 & 29,35 \\
\hline Valor máximo & 0,1320 & \\
\hline Desvio médio & 0,0230 & \\
\hline Desvio padrão & 0,0272 & \\
\hline Coeficiente de Variação [\%] & 26,64 & \\
\hline
\end{tabular}

A relação dos valores observados dos fatores horários de entrada na sexta-feira possui média igual a 0,1021 e grau de concentração de 0,0230, medido pelo desvio médio, e de 0,0272, medido pelo desvio padrão.

Observa-se que os graus de variabilidade dos valores observados em torno da média apresentam dispersão média, se considerado o coeficiente de variação, que se apresenta superior a $15 \%$ e inferior a $30 \%$. Identifica-se, ainda, maior dispersão no shopping center "B”. 


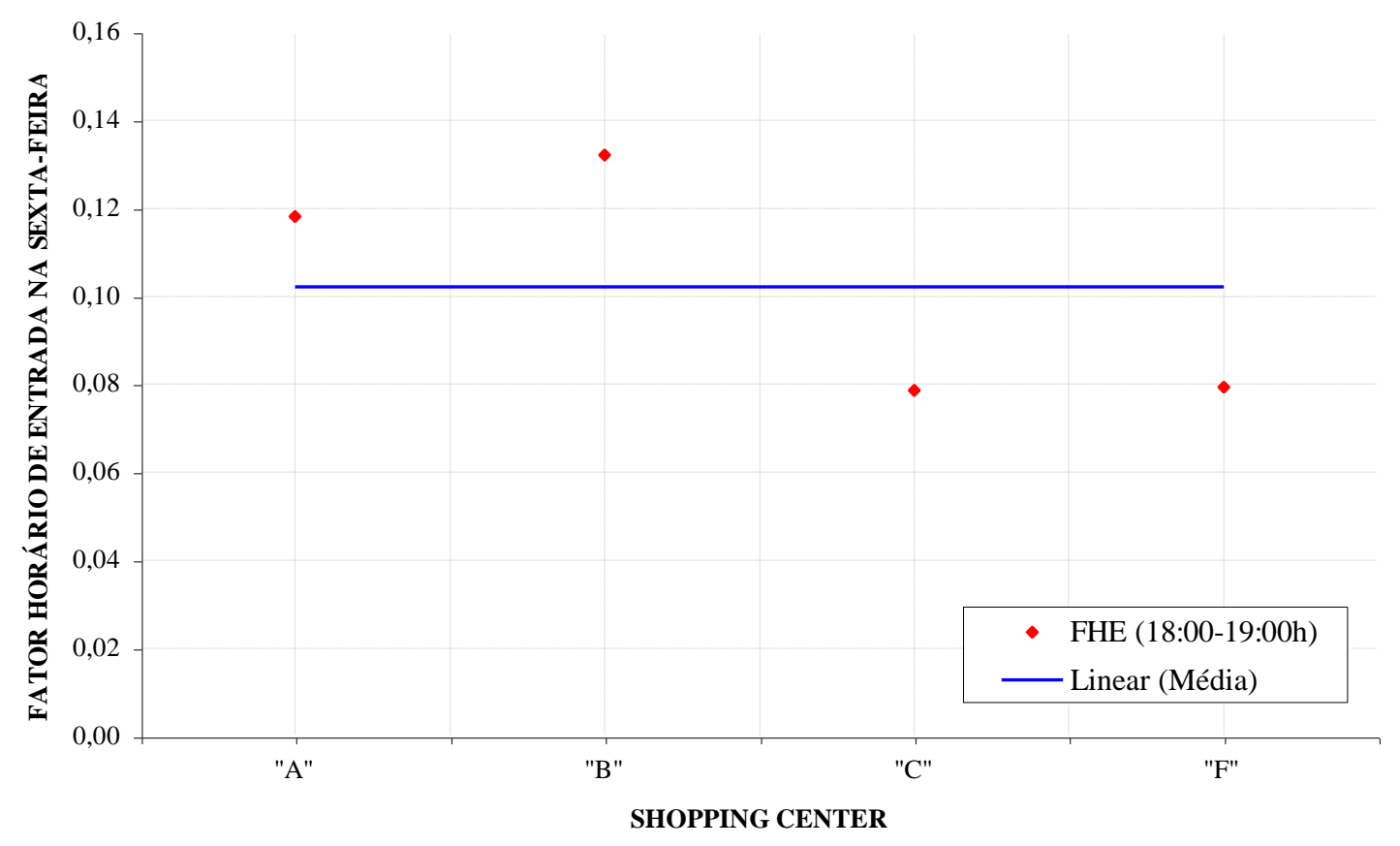

Figura 5.12 - Fator horário de entrada no período das 18:00 às 19:00h.

Assim, considera-se o valor médio de 0,1021, com amplitude dos desvios variando de $-22,98 \%$ a $29,35 \%$, como um valor aceitável para estimar as viagens geradas no horário de entrada, no período das 18:00 às 19:00h, em relação ao fluxo total de veículos na sexta-feira.

Na Tabela 5.13 são apresentados os valores da relação entre as viagens horárias de saída (VHS) e as viagens na sexta-feira (VDsex), que correspondem aos fatores horários de saída (FHS) para o período compreendido entre 18:00 e 19:00 horas e alguns parâmetros estatísticos pertinentes. Na Figura 5.13 os resultados são representados graficamente.

Tabela 5.13 - Fator horário de saída no período das 18:00 às 19:00h $\left(\right.$ FHS $\left._{18-19}\right)$.

\begin{tabular}{|l|l|r|}
\hline Shopping centers & \multicolumn{1}{|c|}{ FHS $_{\mathbf{1 8 - 1 9}}$} & Desvio [\%] \\
\hline Shopping center "A" & 0,0949 & 8,21 \\
\hline Shopping center "B" & \multicolumn{1}{|c|}{0,0950} & 8,32 \\
\hline Shopping center "C" & 0,0731 & $-16,65$ \\
\hline Média & $\mathbf{0 , 0 8 7 7}$ & \\
\hline Valor mínimo & 0,0731 & $-16,65$ \\
\hline Valor máximo & 0,0950 & 8,32 \\
\hline Desvio médio & 0,0097 & \\
\hline Desvio padrão & 0,0126 & \\
\hline Coeficiente de Variação [\%] & 14,38 & \\
\hline
\end{tabular}




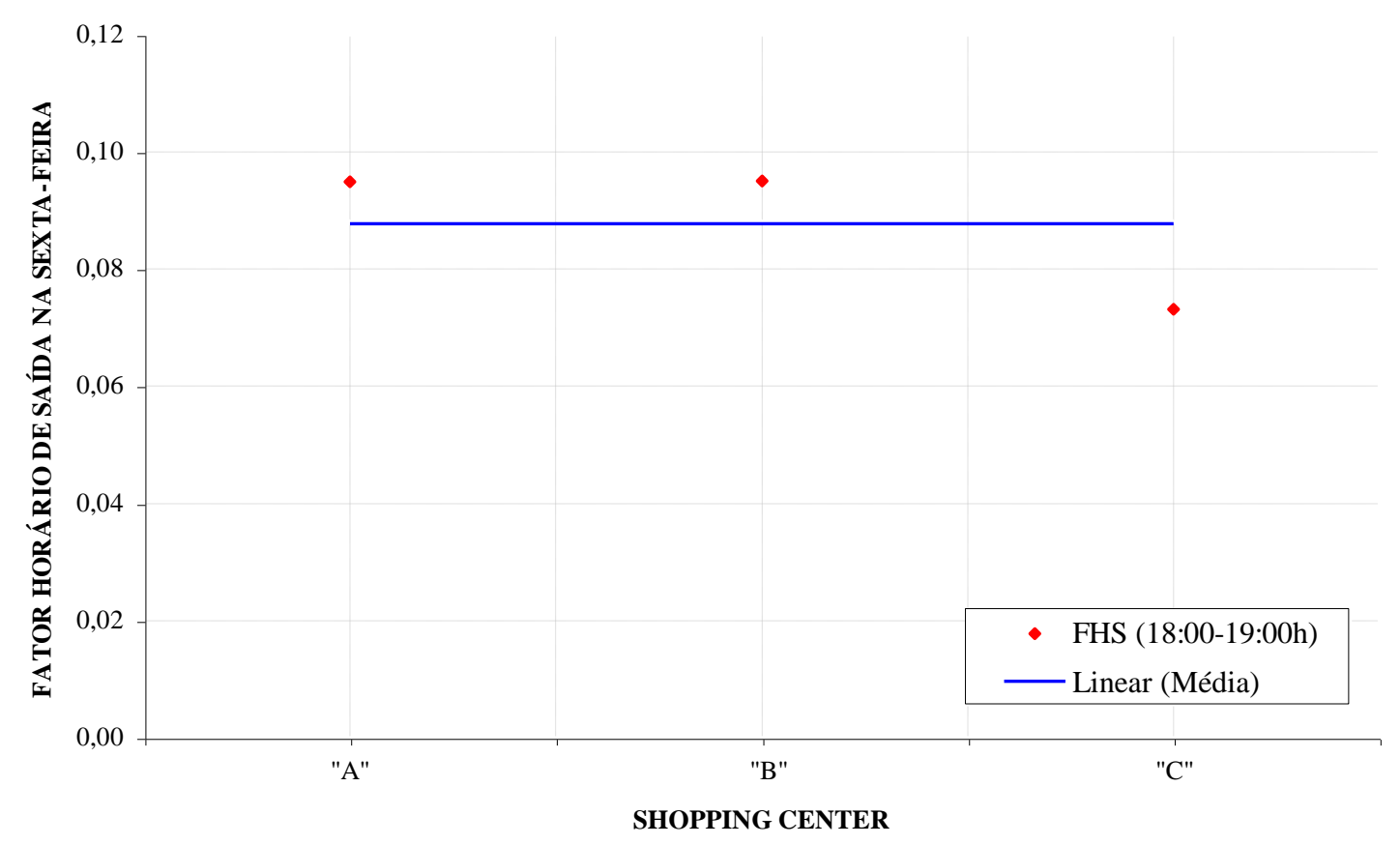

Figura 5.13 - Fator horário de saída no período das 18:00 às 19:00h.

A relação dos valores observados dos fatores horários de saída na sexta-feira possui média igual a 0,0877 e grau de concentração de 0,0097 , medido pelo desvio médio, e de 0,0126, medido pelo desvio padrão.

Observa-se que os graus de variabilidade dos valores observados em torno da média apresentam dispersão baixa, se considerado o coeficiente de variação, que se apresenta inferior a $15 \%$. Nota-se que o empreendimento "C" é o que apresenta maior dispersão.

Assim, considera-se o valor médio de 0,0877, com amplitude dos desvios variando de $-16,65 \%$ a $8,32 \%$, como um valor aceitável para estimar as viagens geradas no horário de saída, no período das 18:00 às 19:00h, em relação ao fluxo total de veículos na sexta-feira.

Na Tabela 5.14 são apresentados os valores da relação entre as viagens horárias do total de entrada e saída (VHT) e as viagens na sexta-feira (VDsex), que correspondem aos fatores horários do total (FHT) para o período compreendido entre 18:00 e 19:00 horas, e alguns parâmetros estatísticos pertinentes. Na Figura 5.14 os resultados são representados graficamente. 
Tabela 5.14 - Fator horário total no período das 18:00 às 19:00h $\left(\mathrm{FHT}_{18-19}\right)$.

\begin{tabular}{|c|c|c|}
\hline Shopping centers & FHT $_{18-19}$ & Desvio [\%] \\
\hline Shopping center "A" & 0,2131 & 8,01 \\
\hline Shopping center "B" & 0,2270 & 15,03 \\
\hline Shopping center "C" & 0,1517 & $-23,09$ \\
\hline Média & $\mathbf{0 , 1 9 7 3}$ & \\
\hline Valor mínimo & 0,1517 & $-23,09$ \\
\hline Valor máximo & 0,2270 & 15,03 \\
\hline Desvio médio & 0,0303 & \\
\hline Desvio padrão & 0,0400 & \\
\hline Coeficiente de Variação [\%] & 20,29 & \\
\hline
\end{tabular}

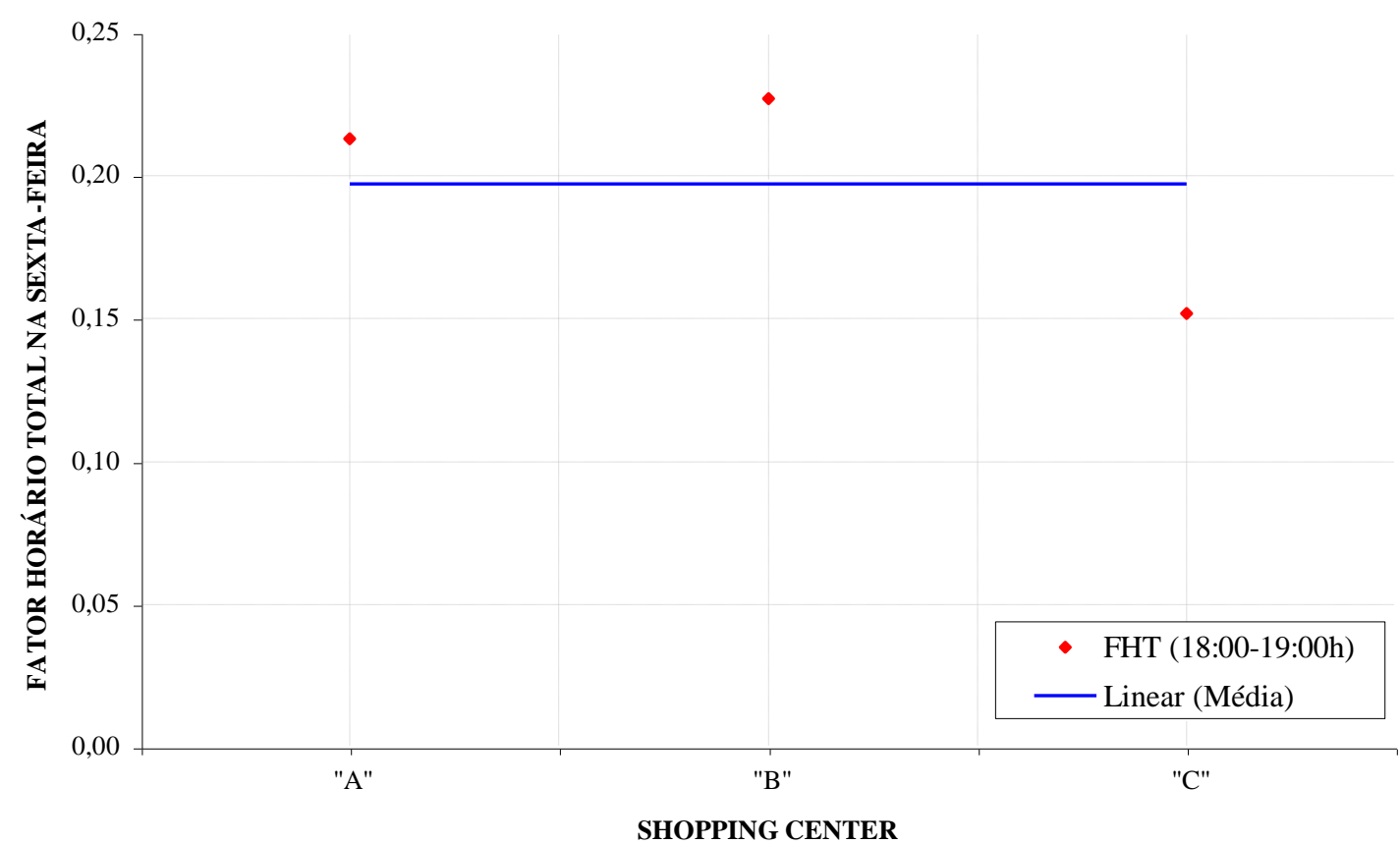

Figura 5.14 - Fator horário total no período das 18:00 às 19:00h.

A relação dos valores observados dos fatores horários do total de entrada e saída na sexta-feira possui média igual a 0,1973 e grau de concentração de 0,0303, medido pelo desvio médio, e de 0,0400 , medido pelo desvio padrão.

Observa-se que os graus de variabilidade dos valores observados em torno da média apresentam dispersão média, se considerado o coeficiente de variação, que se apresenta superior a $15 \%$ e inferior a $30 \%$. Nota-se que o empreendimento "C" é o que apresenta maior dispersão, no entanto os shopping centers " $A$ " e "B" apresentam dispersão baixa.

Assim, considera-se o valor médio de 0,1973, com amplitude dos desvios variando de $-23,09 \%$ a $15,03 \%$, como um valor aceitável para estimar o total de viagens por 
hora de entrada e saída geradas no período das 18:00 às 19:00h, em relação ao fluxo total de veículos na sexta-feira.

No geral, conclui-se que o valor médio do fator horário de saída, correspondente a 0,0877 , é o valor que melhor relaciona as viagens horárias com as viagens diárias para o período compreendido entre 18:00 e 19:00h.

\subsection{RELAÇÃO ENTRE O ACÚMULO MÁXIMO DE VEÍCULOS E O TAMANHO DO SHOPPING CENTER}

Na Tabela 5.15 são apresentados os valores da relação entre o acúmulo máximo de veículos no estacionamento (No) e a Área Bruta Locável (ABL), para sábado, e alguns parâmetros estatísticos pertinentes. Na Figura 5.15 os resultados são representados graficamente.

Tabela 5.15 - Relação entre o acúmulo máximo de veículos e a área bruta locável.

\begin{tabular}{|l|c|c|}
\hline Shopping centers & No / ABL/ 100 & Desvio [\%] \\
\hline Shopping center “A" & 3,0753 & $-44,34$ \\
\hline Shopping center "B" & \multicolumn{1}{|c|}{7,4762} & 35,30 \\
\hline Shopping center "C" & 6,0249 & 9,04 \\
\hline Média & $\mathbf{5 , 5 2 5 5}$ & \\
\hline Valor mínimo & 3,0753 & $-44,34$ \\
\hline Valor máximo & 7,4762 & 35,30 \\
\hline Desvio médio & 1,6335 & \\
\hline Desvio padrão & 2,2426 & \\
\hline Coeficiente de Variação [\%] & 40,59 & \\
\hline
\end{tabular}

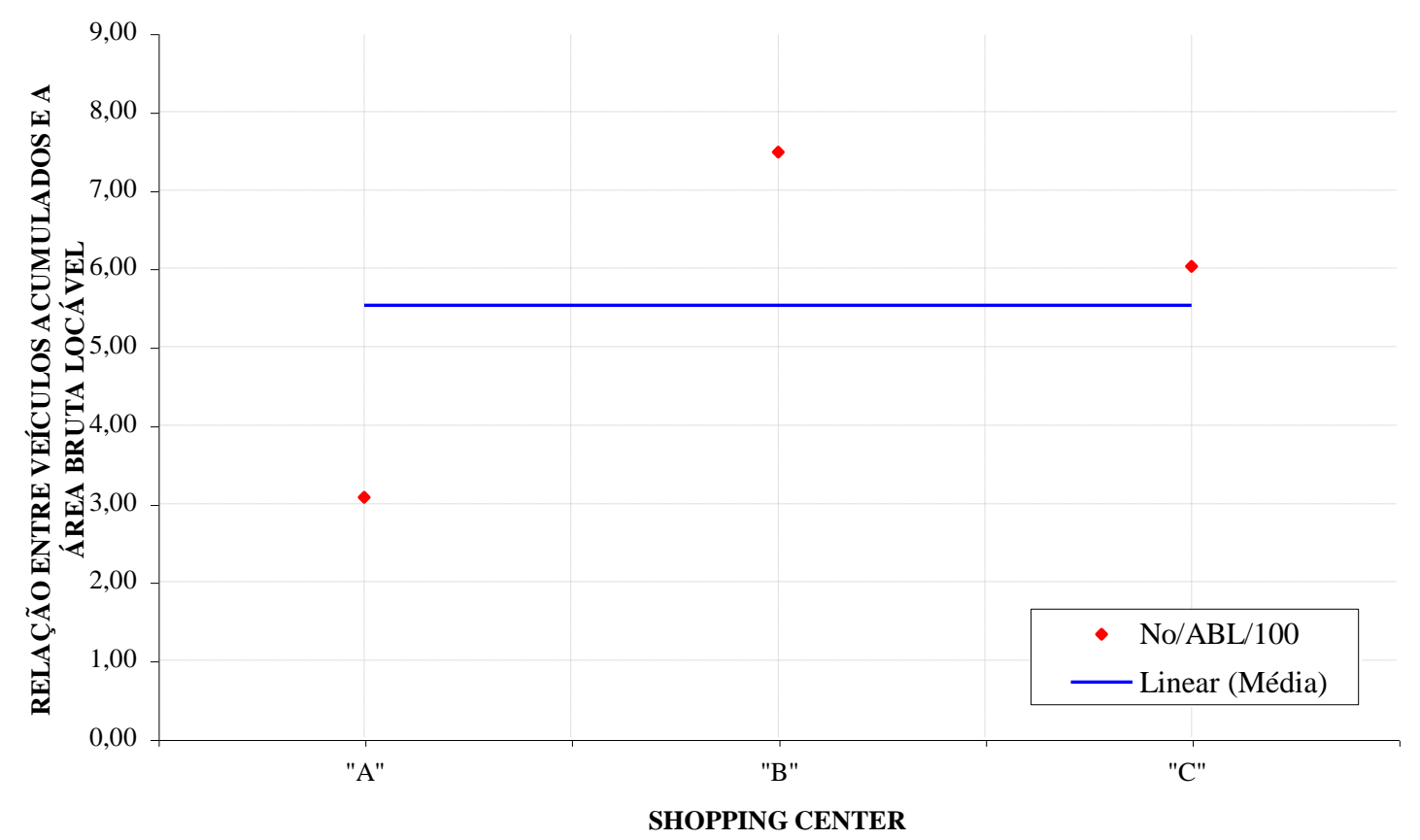

Figura 5.15 - Relação entre o acúmulo máximo de veículos e a área bruta locável. 
A relação dos valores observados das relações entre o acúmulo máximo de veículos e a área bruta locável no sábado possui média igual a 5,5255 e grau de concentração de 1,6335, medido pelo desvio médio, e de 2,2426, medido pelo desvio padrão.

Observa-se que os graus de variabilidade dos valores observados em torno da média apresentam dispersão alta, se considerado o coeficiente de variação, que se apresenta superior a 30\%. Nota-se que o empreendimento "A" é o que apresenta maior dispersão, entretanto, o shopping center " $\mathrm{C}$ " apresenta dispersão baixa.

Assim, considera-se o valor médio de 5,53 veículos acumulados por $100 \mathrm{~m}^{2}$ de ABL, com amplitude dos desvios variando de $-44,34 \%$ a $35,30 \%$, como um valor não recomendável para estimar o acúmulo máximo de veículos por hora em relação à área bruta locável do empreendimento.

Na Tabela 5.16 são apresentados os valores da relação entre o acúmulo máximo de veículos (No) e a Área Total Construída (ATC) e alguns parâmetros estatísticos pertinentes. Na Figura 5.16 os resultados são representados graficamente.

Tabela 5.16 - Relação entre o acúmulo máximo de veículos e a área total construída.

\begin{tabular}{|l|c|c|}
\hline Shopping centers & \multicolumn{1}{|c|}{ No / ATC / 100 } & Desvio [\%] \\
\hline Shopping center “A" & \multicolumn{1}{|c|}{0,9781} & $-61,06$ \\
\hline Shopping center "B" & 2,7069 & 7,78 \\
\hline Shopping center "C" & 3,8494 & 53,27 \\
\hline Média & $\mathbf{2 , 5 1 1 5}$ & $-61,06$ \\
\hline Valor mínimo & 0,9781 & 53,27 \\
\hline Valor máximo & 3,8494 & \\
\hline Desvio médio & 1,0222 & \\
\hline Desvio padrão & 1,4456 & \\
\hline Coeficiente de Variação [\%] & 57,56 & \\
\hline
\end{tabular}

A relação dos valores observados das relações entre o acúmulo máximo de veículos e a área total construída para sábado possui média igual a 2,5115 e grau de concentração de 1,0222, medido pelo desvio médio, e de 1,4456, medido pelo desvio padrão.

Observa-se que os graus de variabilidade dos valores observados em torno da média apresentam dispersão alta, se considerado o coeficiente de variação, que se apresenta superior a 30\%. Nota-se que o empreendimento "A" é o que apresenta maior dispersão, entretanto, o shopping center " $C$ " apresenta dispersão baixa. 


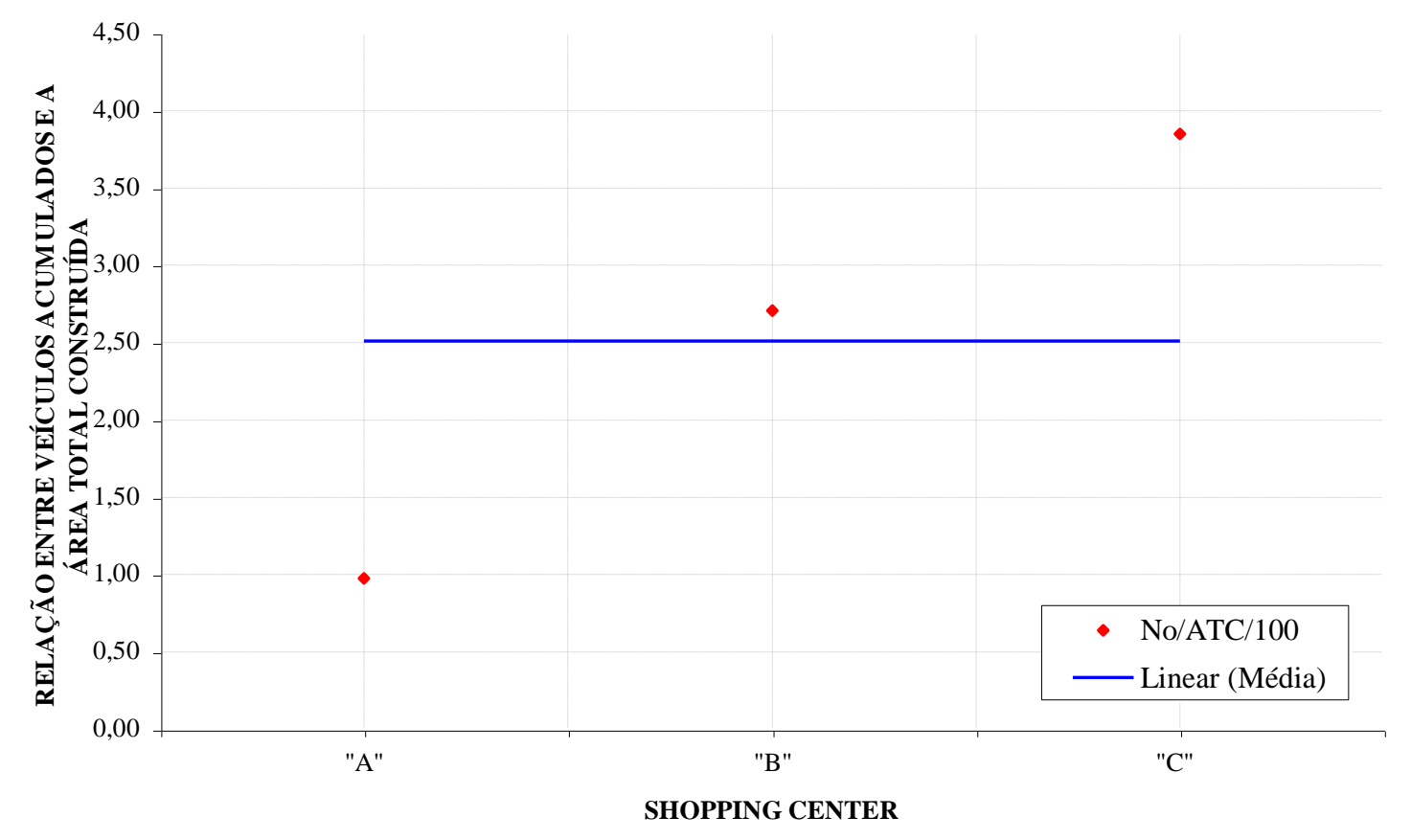

Figura 5.16 - Relação entre o acúmulo máximo de veículos e a área total construída.

Assim, considera-se o valor médio de 2,51 veículos acumulados por $100 \mathrm{~m}^{2} \mathrm{de}$ ATC, com amplitude dos desvios variando de $-61,06 \%$ a $53,27 \%$, como um valor não recomendável para estimar o acúmulo máximo de veículos por hora em relação à área total construída do empreendimento.

No geral, conclui-se que o valores médios das relações entre o acúmulo máximo de veículos no estacionamento e o tamanho do empreendimento, correspondentes a 5,53 veículos por $100 \mathrm{~m}^{2}$ de $\mathrm{ABL}$ e 2,51 veículos por $100 \mathrm{~m}^{2}$ de $\mathrm{ATC}$, não são recomendáveis como estimativas para índices de estacionamento, devido à alta dispersão apresentada.

\subsection{RELAÇÃO ENTRE O ACÚMULO MÁXIMO DE VEÍCULOS E AS VIAGENS DIÁRIAS NO SÁBADO}

Na Tabela 5.17 são apresentados os valores da relação entre o acúmulo máximo de veículos no estacionamento (No) e as viagens no sábado (VDsab) e alguns parâmetros estatísticos pertinentes. Na Figura 5.17 os resultados são representados graficamente. 
Tabela 5.17 - Relação entre o acúmulo máximo de veículos e as viagens no sábado.

\begin{tabular}{|l|l|c|}
\hline Shopping centers & No/VDsab [vagas/viagens dia] & Desvio [\%] \\
\hline Shopping center “A" & \multicolumn{1}{|c|}{0,1017} & $-33,00$ \\
\hline Shopping center "B" & 0,1801 & 18,64 \\
\hline Shopping center "C" & 0,1735 & 14,30 \\
\hline Média & $\mathbf{0 , 1 5 1 8}$ & $-33,00$ \\
\hline Valor mínimo & 0,1017 & 18,64 \\
\hline Valor máximo & 0,1801 & \\
\hline Desvio médio & 0,0334 & \\
\hline Desvio padrão & 0,0435 & \\
\hline Coeficiente de Variação [\%] & 28,65 & \\
\hline
\end{tabular}

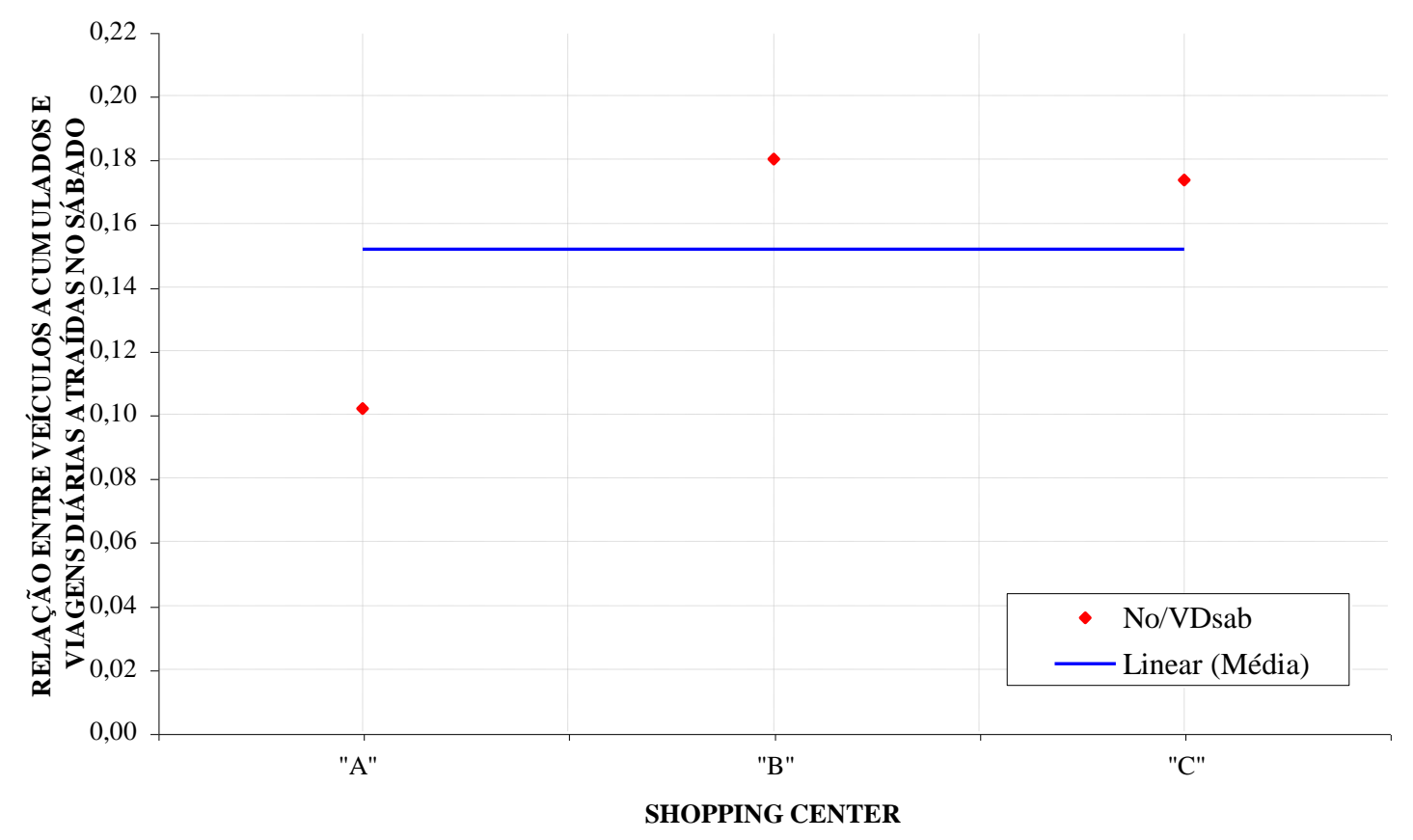

Figura 5.17 - Relação entre o acúmulo máximo de veículos e as viagens no sábado.

A relação dos valores observados das relações entre o acúmulo máximo de veículos e as viagens diárias no sábado possui média igual a 0,1518 e grau de concentração de 0,0334, medido pelo desvio médio, e de 0,0435 , medido pelo desvio padrão.

Observa-se que os graus de variabilidade dos valores observados em torno da média apresentam dispersão média, se considerado o coeficiente de variação, que se apresenta superior a $15 \%$ e inferior a $30 \%$. Nota-se que o empreendimento "A" é o que apresenta maior dispersão, entretanto, o shopping center " $C$ " apresenta dispersão baixa.

Assim, considera-se o valor médio de 0,1518 veículos acumulados para as viagens geradas no sábado, com amplitude dos desvios variando de $-33,00 \%$ a 18,64\%, como 
um valor aceitável para estimar o acúmulo máximo de veículos em relação as viagens por veículos atraídas pelo empreendimento no sábado. Portanto, considera-se apropriado usar esse valor de 0,15 [vagas/viagens dia] como relação entre ocupação máxima de vagas e demanda diária de veículos atraídos para estimar a demanda por estacionamento através da expressão fornecida pela CET-SP (2000).

\subsection{TEMPO MÉDIO DE PERMANÊNCIA DOS VEÍCULOS NO ESTACIONAMENTO}

Na Tabela 5.18 são apresentados os valores da média ponderada do tempo de permanência dos veículos no estacionamento (Tm) e alguns parâmetros estatísticos pertinentes. Na Figura 5.18 os resultados são representados graficamente.

Tabela 5.18 - Relação do tempo médio de permanência dos veículos no sábado (Tm).

\begin{tabular}{|l|l|l|}
\hline Shopping centers & Tm [hora] & Desvio [\%] \\
\hline Shopping center “A" & 0,8962 & $-4,45$ \\
\hline Shopping center "B" & 0,8578 & $-8,54$ \\
\hline Shopping center "C" & 1,0598 & 13,00 \\
\hline Média & $\mathbf{0 , 9 3 7 9}$ & \\
\hline Valor mínimo & 0,8578 & $-8,54$ \\
\hline Valor máximo & 1,0598 & 13,00 \\
\hline Desvio médio & 0,0812 & \\
\hline Desvio padrão & 0,1073 & \\
\hline Coeficiente de Variação [\%] & 11,44 & \\
\hline
\end{tabular}

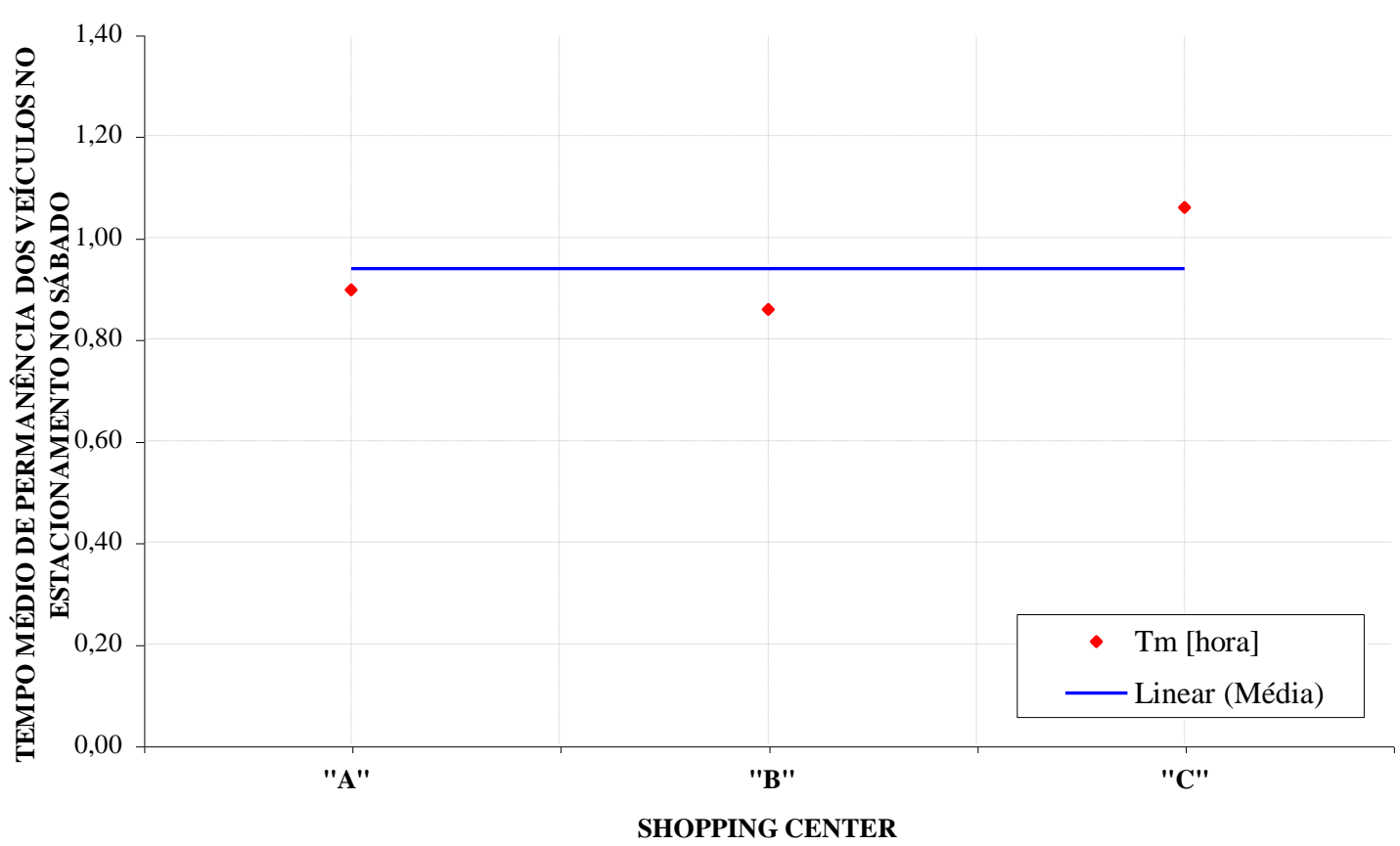

Figura 5.18 - Relação do tempo médio de permanência dos veículos no sábado. 
A relação dos valores observados dos tempos de permanência dos veículos no estacionamento no sábado possui média igual a 0,9379 e grau de concentração de 0,0812, medido pelo desvio médio, e de 0,1073 , medido pelo desvio padrão.

Observa-se que os graus de variabilidade dos valores observados em torno da média apresentam dispersão baixa, se considerado o coeficiente de variação, que se apresenta inferior a $15 \%$.

Assim, considera-se o valor médio de $0,94 \mathrm{~h}$, com amplitude dos desvios variando de $-8,54 \%$ a $13,00 \%$, como um valor aceitável para estimar o tempo médio de permanência dos veículos no estacionamento no sábado.

\subsection{RELAÇÃO ENTRE O ACÚMULO MÁXIMO DE VEÍCULOS COM O TEMPO MÉDIO DE PERMANÊNCIA E AS VIAGENS NA HORA PICO}

Na Tabela 5.19 são apresentados os valores da relação entre o acúmulo máximo de veículos no estacionamento (No) e o tempo de permanência dos veículos no estacionamento (Tm) multiplicado pelas viagens na hora pico de entrada do sábado (VHEsab) e alguns parâmetros estatísticos pertinentes. Na Figura 5.19 os resultados são representados graficamente.

Tabela 5.19 - Relação entre o acúmulo máximo de veículos com o tempo médio de permanência e as viagens atraídas na hora pico do sábado.

\begin{tabular}{|l|c|c|}
\hline Shopping centers & No / (Tm x VHEsab) & Desvio [\%] \\
\hline Shopping center “A" & \multicolumn{1}{|c|}{1,0730} & $-13,86$ \\
\hline Shopping center "B” & 1,3558 & 8,85 \\
\hline Shopping center "C" & 1,3080 & 5,01 \\
\hline Média & $\mathbf{1 , 2 4 5 6}$ & $-13,86$ \\
\hline Valor mínimo & 1,0730 & 8,85 \\
\hline Valor máximo & 1,3558 & \\
\hline Desvio médio & 0,1151 & \\
\hline Desvio padrão & 0,1514 & \\
\hline Coeficiente de Variação [\%] & 12,15 & \\
\hline
\end{tabular}

A relação dos valores observados das relações entre o acúmulo máximo de veículos com o tempo médio de permanência e as viagens atraídas na hora pico possui média igual a 1,2456 e grau de concentração de 0,1151, medido pelo desvio médio, e de 0,1514, medido pelo desvio padrão. 
Observa-se que os graus de variabilidade dos valores observados em torno da média apresentam dispersão baixa, se considerado o coeficiente de variação, que se apresenta inferior a $15 \%$.

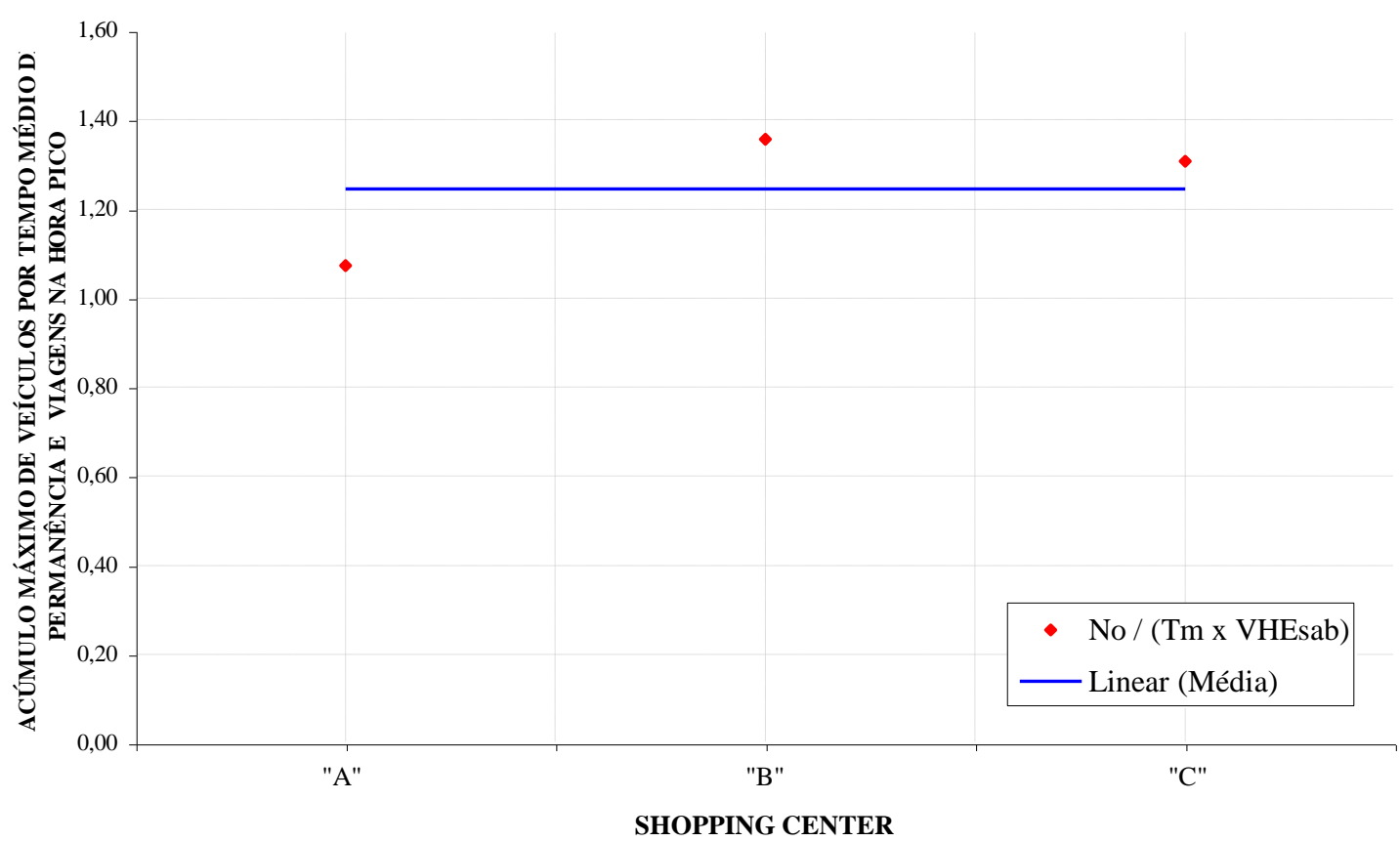

Figura 5.19 - Relação entre o acúmulo máximo de veículos no estacionamento com o tempo médio de permanência e as viagens atraídas na hora pico do sábado.

Assim, considera-se o valor médio de 1,25, com amplitude dos desvios variando de $-13,86 \%$ a $8,85 \%$, como um valor aceitável para estimar o acúmulo máximo de veículos no estacionamento em relação ao tempo de permanência dos veículos multiplicado pelo volume de veículos atraídos pelo empreendimento na hora pico de entrada no sábado. No entanto, esse valor torna-se incoerente ao considerar que a demanda por estacionamento pode ser estimada pelo tempo de permanência dos veículos no estacionamento multiplicado pelo volume de veículos na hora pico. Sendo assim, considera-se apropriado usar esse valor de 1,25 como fator de multiplicação para estimar a demanda por estacionamento através das expressões fornecidas por CET-SP (1983), GRANDO (1986) e GOLDNER (1994). 


\subsection{RELAÇÕES ENTRE VIAGENS DIÁRIAS E TAMANHO DOS EMPREENDIMENTOS}

Neste item são apresentadas expressões que relacionam o número total de viagens diárias com o tamanho do empreendimento (caracterizado pela área bruta locável ou pela área total construída), utilizando a técnica de regressão linear simples.

Também são apresentadas expressões que relacionam o número total de viagens diárias com os tamanhos das áreas individualizadas de comércio, lazer e serviços do empreendimento, utilizando a técnica de regressão linear múltipla.

Antes, contudo, são apresentados os conceitos básicos sobre regressão linear.

A técnica de Regressão Linear é utilizada para estudar a relação entre uma variável dependente e variáveis independentes. Procura-se explicar como as viagens diárias atraídas pelos shopping centers variam de acordo com o tamanho do empreendimento. Sua representação é a seguinte:

$$
\mathrm{Yi}=f\left(\mathrm{x}_{\mathrm{i} 1}, \mathrm{x}_{\mathrm{i} 2}, \ldots, \mathrm{x}_{\mathrm{ik}}\right)+\varepsilon_{\mathrm{i}}=\beta_{1} \mathrm{x}_{\mathrm{i} 1}+\beta_{2} \mathrm{x}_{\mathrm{i} 2}+\ldots+\beta_{\mathrm{k}} \mathrm{x}_{\mathrm{ik}}+\varepsilon_{\mathrm{i}}, \quad \mathrm{i}=1,2, \ldots \mathrm{n}
$$

Sendo, Y: a variável dependente ou explicada;

$\mathrm{x}_{1}, \mathrm{x}_{2}, \ldots, \mathrm{x}_{\mathrm{k}}$ : as variáveis independentes ou explicativas; $\mathrm{e}$

عi: representa o distúrbio aleatório, que pode se originar devido a diversas circunstâncias, tais como a ausência de fatores influentes no modelo e distúrbios causados por erros de medida.

As estimativas dos parâmetros dos modelos foram realizadas através do software STATISTICA. A avaliação dos modelos foi baseada nos seguintes parâmetros estatísticos: o valor de F (análise de variância), o valor de t (teste t, de Student), o coeficiente de correlação $R$, o coeficiente de determinação $R^{2}$, o coeficiente $R^{2}$ ajustado e o nível de significância estatística p.

O teste $\mathrm{t}$, de Student, avalia se a variável em questão contribui de forma significativa para o poder de explicação do modelo. Valores do teste t maiores que os valores tabulados (valor teórico que seria encontrado se a distribuição amostral seguisse uma determinada distribuição matemática teórica previamente conhecida) significam que a variável tem um efeito significativo e deve ser incluída no modelo, com nível de confiança de $95 \%$.

O teste $\mathrm{F}$, analisa a variância dos erros controlados e não controlados (resíduo). Os valores de $\mathrm{F}$ maiores que os tabulados significam que a variável tem um efeito significativo, podendo ser incluída no modelo, com nível de confiança de $95 \%$. 
$O$ coeficiente de correlação $R$ varia entre -1 (correlação negativa) e 1 (correlação positiva), representando o valor 0 a falta de correlação entre as variáveis.

$\mathrm{O}$ coeficiente de determinação $\mathrm{R}^{2}$ avalia o ajuste geral do modelo, isto é, expressa a correlação entre as variáveis em questão e varia entre 0 (nenhum ajuste) e 1 (ajuste perfeito).

O coeficiente de determinação $\mathrm{R}^{2}$ ajustado torna-se mais preciso pois leva em conta o número de variáveis explicativas em relação ao número de observações.

O p-nível é o nível de significância estatística que representa a probabilidade do relacionamento ou diferença observada entre as variáveis ocorrer por acaso. Para $p \leq 0,05$ as variáveis são consideradas estatisticamente aceitáveis, mas envolve $5 \%$ de probabilidade de erro. Para $\mathrm{p} \leq 0,01$ as variáveis são consideradas estatisticamente significantes; para $\mathrm{p} \leq 0,005$, são consideradas altamente significativas.

Alguns desses modelos não passaram nos testes, mas apresentam-se como ilustração para identificar as relações entre as viagens diárias geradas pelo shopping center e o tamanho total do empreendimento, em área bruta locável e área total construída. E, ainda, identificar a relação existente entre as viagens diárias e o tamanho desagregado do empreendimentos por ramos de atividade.

\subsubsection{VIAGENS DIÁRIAS x ÁREA BRUTA LOCÁVEL}

As Tabelas 5.20 e 5.21 apresentam a calibração dos modelos de regressão linear simples, considerando como variável explicativa a Área Bruta Locável.

Tabela 5.20 - Resultado da calibração do primeiro modelo de regressão linear simples.

\begin{tabular}{|c|l|c|c|c|}
\hline \multicolumn{2}{|c|}{ Variável } & \multirow{2}{*}{ Coeficientes } & Teste t & $\begin{array}{c}\text { Significância } \\
\text { (p-nível) }\end{array}$ \\
\hline \multicolumn{1}{|c|}{ Dependente } & \multicolumn{1}{|c|}{ Independente } & & & 0,561655 \\
\hline \multirow{2}{*}{$\begin{array}{l}\text { Número de veículos na } \\
\text { sexta-feira }\end{array}$} & Interseção & 409,2308 & 0,632088 & 0,56267 \\
\cline { 2 - 5 } & Área Bruta Locável & 0,2147 & 6,288339 & 0,003267 \\
\hline
\end{tabular}

Número de casos $=6$

Nível de confiança de $95 \%$

$\mathrm{t}_{\text {min }}=2,7764$

$\mathrm{F}(1,4)=39,543 \quad \mathrm{p}<0,00327 \quad \mathrm{~F}_{\min }=7,71$

$\mathrm{R}=0,99529633 \quad \mathrm{R}^{2}=0,90813721 \quad \mathrm{R}^{2}$ ajustado $=0,88517151$

Erro padrão de estimativa $=578,60$ 
Tabela 5.21 - Resultado da calibração do segundo modelo de regressão linear simples.

\begin{tabular}{|l|l|c|c|c|}
\hline \multicolumn{1}{|c|}{ Variável } & \multirow{2}{*}{ coeficientes } & Teste t & \multirow{2}{*}{$\begin{array}{c}\text { Significância } \\
\text { (p-nível) }\end{array}$} \\
\hline \multicolumn{1}{|c|}{ Dependente } & \multicolumn{1}{|c|}{ Independente } & & & 0,312916 \\
Número de veículos no & Interseção & 1190,423 & 1,153563 & 0,007393 \\
\cline { 2 - 5 } & Área Bruta Locável & 0,273 & 5,018539 & 0,0073 \\
\hline
\end{tabular}

Número de casos $=6$

Nível de confiança de $95 \%$

$\mathrm{t}_{\min }=2,7764$

$\mathrm{F}(1,4)=25,186 \quad \mathrm{p}<0,00739 \quad \mathrm{~F}_{\min }=7,71$

$\mathrm{R}=0,92894926 \quad \mathrm{R}^{2}=0,86294673 \quad \mathrm{R}^{2}$ ajustado $=0,82868342$

Erro padrão de estimativa $=922,24$

Nas Tabelas 5.20 e 5.21 identifica-se que a variável independente, Área Bruta Locável, passa no teste t, de Student, e no valor de F, para sexta-feira e sábado. Nota-se ainda que os coeficientes de determinação são altos. Assim, os modelos são aceitáveis para estimativa do número de viagens em função da área bruta locável, na sexta-feira e no sábado.

As equações correspondentes são as seguintes:

$$
\begin{gathered}
V D \text { sex }=409,2308+0,2147 A B L \\
V D s a b=1190,423+0,273 A B L
\end{gathered}
$$

Sendo, VDsex: estimativa das viagens atraídas pelo shopping center na sexta-feira [viagens/dia]; $V D s a b$ : estimativa das viagens atraídas pelo shopping center no sábado [viagens/dia];

$A B L$ : área bruta locável $\left[\mathrm{m}^{2}\right]$

\subsubsection{VIAGENS DIÁRIAS x ÁREA TOTAL CONSTRUÍDA}

As Tabelas 5.22 e 5.23 apresentam a calibração dos modelos de regressão linear simples, considerando como variável explicativa a Área Total Construída.

Tabela 5.22 - Resultado da calibração do terceiro modelo de regressão linear simples.

\begin{tabular}{|l|l|c|c|c|}
\hline \multicolumn{2}{|c|}{ Variável } & \multirow{2}{*}{ Coeficientes } & Teste t & $\begin{array}{c}\text { Significância } \\
\text { (p-nível) }\end{array}$ \\
\hline \multicolumn{1}{|c|}{ Dependente } & \multicolumn{1}{|c|}{ Independente } & & & 0,223603 \\
\hline \multirow{2}{*}{$\begin{array}{l}\text { Número de veículos na } \\
\text { sexta-feira }\end{array}$} & Interseção & 1808,941 & 1,438806 & 0,103277 \\
\cline { 2 - 5 } & Área Total Construída & 0,060 & 2,103221 & 0,103 \\
\hline
\end{tabular}

Número de casos $=6$

Nível de confiança de $95 \%$

$\mathrm{t}_{\min }=2,7764$

$\mathrm{F}(1,4)=4,4235 \quad \mathrm{p}<0,10328 \quad \mathrm{~F}_{\min }=7,71$

$\mathrm{R}=0,72466549 \quad \mathrm{R}^{2}=0,0,52514007 \quad \mathrm{R}^{2}$ ajustado $=0,40642509$

Erro padrão de estimativa $=1315,5$ 
Tabela 5.23 - Resultado da calibração do quarto modelo de regressão linear simples.

\begin{tabular}{|c|c|c|c|c|}
\hline \multicolumn{2}{|c|}{ Variável } & \multirow{2}{*}{ coeficientes } & \multirow[t]{2}{*}{ Teste $t$} & \multirow{2}{*}{$\begin{array}{c}\text { Significância } \\
\text { (p-nível) }\end{array}$} \\
\hline Dependente & Independente & & & \\
\hline \multirow{2}{*}{$\begin{array}{l}\text { Número de veículos no } \\
\text { sábado }\end{array}$} & Interseção & 3002,004 & 1,763647 & 0,152566 \\
\hline & Área Total Construída & 0,075 & 1,955967 & 0,122118 \\
\hline
\end{tabular}

Número de casos $=6$

Nível de confiança de $95 \%$

$\mathrm{t}_{\text {min }}=2,7764$

$\mathrm{F}(1,4)=3,8258 \quad \mathrm{p}<0,12212 \quad \mathrm{~F}_{\min }=7,71$

$\mathrm{R}=0,69919274 \quad \mathrm{R}^{2}=0,48887049 \quad \mathrm{R}^{2}$ ajustado $=0,36108811$

Erro padrão de estimativa $=1781,0$

Observa-se nas Tabelas 5.22 e 5.23, através do valor de p-nível, que não existe uma relação estatisticamente significativa entre a variável Área Total Construída com o número de veículos na sexta-feira e no sábado. Identifica-se ainda que nenhuma das variáveis passa no teste t, de Student, nem passam no valor de F. Os valores dos coeficientes de determinação também apresentam-se baixos, portanto não é recomendável o emprego das equações obtidas para as estimativas do número de viagens na sexta-feira e no sábado.

As equações correspondentes são as seguintes:

$$
\begin{gathered}
\text { VDsex }=1808,941+0,060 \text { ATC } \\
V D s a b=3002,004+0,075 \text { ATC }
\end{gathered}
$$

Sendo, VDsex: viagens atraídas pelo shopping center na sexta-feira [viagens/dia];

$V D s a b$ : viagens atraídas pelo shopping center no sábado [viagens/dia];

$A T C$ : área total construída $\left[\mathrm{m}^{2}\right]$

\subsubsection{VIAGENS DIÁRIAS x ÁREAS DESAGREGADAS}

Para os modelos de regressão linear múltipla foram consideradas como variáveis explicativas as áreas dos estabelecimentos por ramos de atividade, como indicado na Tabela 5.24.

Tabela 5.24 - Distribuição das áreas por ramos de atividade nos shopping centers

\begin{tabular}{|c|c|c|c|}
\hline Shopping center & Comércio $\left[\mathbf{m}^{\mathbf{2}}\right]$ & Lazer $\left[\mathbf{m}^{\mathbf{2}}\right]$ & Serviços $\left[\mathbf{m}^{\mathbf{2}}\right]$ \\
\hline “A" & $19.486,57$ & 244,33 & 625,34 \\
\hline "B" & $2.438,00$ & 993,00 & 769,00 \\
\hline "C" & $13.631,31$ & $2.939,93$ & $1.420,76$ \\
\hline "D" & $14.693,00$ & $6.405,00$ & $6.451,00$ \\
\hline "E" & $6.222,88$ & $3.518,31$ & $8.752,10$ \\
\hline
\end{tabular}


As Tabelas 5.25 e 5.26 apresentam a calibração dos modelos de regressão linear múltipla, considerando como variáveis explicativas as áreas de comercio, lazer e serviços, para sexta-feira e sábado respectivamente.

Tabela 5.25 - Resultado da calibração do primeiro modelo de regressão linear múltipla.

\begin{tabular}{|c|l|c|c|c|}
\hline \multicolumn{2}{|c|}{ Variável } & \multirow{2}{*}{ Coeficientes } & Teste t & \multicolumn{1}{c|}{$\begin{array}{c}\text { Significância } \\
\text { (p-nível) }\end{array}$} \\
\hline \multicolumn{1}{|c|}{ Dependente } & \multicolumn{1}{|c|}{ Independente } & & & \\
\hline \multirow{2}{*}{$\begin{array}{l}\text { Número de veículos na } \\
\text { sexta-feira }\end{array}$} & Interseção & 456,6103 & 8,44490 & 0,075036 \\
\cline { 2 - 5 } & Área de comercio & 0,1607 & 43,57142 & 0,014608 \\
\cline { 2 - 5 } & Área de lazer & 0,4384 & 29,27859 & 0,021735 \\
\cline { 2 - 5 } & Área de serviços & 0,1727 & 17,58010 & 0,036174 \\
\hline
\end{tabular}

Número de casos $=5$

Nível de confiança de $95 \%$

$\mathrm{t}_{\min }=12,706$

$\mathrm{F}(3,1)=2166,3 \quad \mathrm{p}<0,01579 \quad \mathrm{~F}_{\min }=215,7$

$\mathrm{R}=0,99992307 \quad \mathrm{R}^{2}=0,99984615 \quad \mathrm{R}^{2}$ ajustado $=0,99938461$

Erro padrão de estimativa $=47,121$

Identifica-se na Tabela 5.25, através do valor de p-nível, que existe uma relação estatisticamente significativa entre as variáveis áreas de comércio, lazer e serviços com o número de veículos gerados sexta-feira. Observa-se que todas as variáveis passam no teste $\mathrm{t}$, de Student e no valor de F. Nota-se, ainda, que a calibração do modelo apresenta valores altos para os coeficientes de determinação. Assim, o modelo é aceitável para estimativa do número de viagens na sexta-feira em função das áreas desagregadas de comércio, serviços e lazer.

A equação correspondente é a seguinte:

$$
\text { VDsex }=456,6103+0,1607 A_{C}+0,4384 A_{L}+0,1727 A_{S}
$$

Sendo, VDsex: estimativa da geração de viagens atraídas pelo shopping center para uma sexta-feira [viagens/dia];

$A_{C}:$ área de comércio $\left[\mathrm{m}^{2}\right]$

$A_{L}$ : área de lazer $\left[\mathrm{m}^{2}\right]$

$A_{S}$ : área de serviços $\left[\mathrm{m}^{2}\right]$

Tabela 5.26 - Resultado da calibração do segundo modelo de regressão linear múltipla.

\begin{tabular}{|l|l|c|c|c|}
\hline \multicolumn{2}{|c|}{ Variável } & \multirow{2}{*}{ Coeficientes } & Teste t & $\begin{array}{c}\text { Significância } \\
\text { (p-nível) }\end{array}$ \\
\hline \multicolumn{1}{|c|}{ Dependente } & \multicolumn{1}{|c|}{ Independente } & & & 0,505523 \\
\hline \multirow{2}{*}{$\begin{array}{l}\text { Número de veículos no } \\
\text { sábado }\end{array}$} & Interseção & 849,3843 & 0,982799 & 0,137561 \\
\cline { 2 - 5 } & Área de comercio & 0,2685 & 4,555657 & 0,507249 \\
\cline { 2 - 5 } & Área de lazer & 0,2340 & 0,977482 & 0,283382 \\
\cline { 2 - 5 } & Área de serviços & 0,3292 & 2,096130 & 0 \\
\hline
\end{tabular}

Número de casos $=5$

Nível de confiança de $95 \%$

$\mathrm{t}_{\text {min }}=12,706$

$\mathrm{F}(3,1)=12,833 \quad \mathrm{p}<0,20173 \quad \mathrm{~F}_{\min }=215,7$

$\mathrm{R}=0,98726078 \quad \mathrm{R}^{2}=0,97468385 \quad \mathrm{R}^{2}$ ajustado $=0,89873539$

Erro padrão de estimativa $=753,19$ 
Observa-se na Tabela 5.26, através do valor de p-nível, que não existe uma relação estatisticamente significativa entre as variáveis áreas de comércio, lazer e serviços com o número de veículos para sábado. Identifica-se ainda que nenhuma das variáveis passa no teste $\mathrm{t}$, de Student, nem passam no valor de F. Assim, apesar dos valores dos coeficientes de determinação serem altos, não é recomendável o emprego da equação obtida para a estimativa do número de viagens no sábado em função das áreas desagregadas de comércio, serviços e lazer.

A equação correspondente é a seguinte:

$$
V D s a b=849,3843+0,2685 A_{C}+0,2340 A_{L}+0,3292 A_{S}
$$

Sendo, VDsab: estimativa da geração de viagens atraídas pelo shopping center para um sábado [viagens/dia];

$A_{C}$ : área de comércio $\left[\mathrm{m}^{2}\right]$

$A_{L}$ : área de lazer $\left[\mathrm{m}^{2}\right]$

$A_{S}:$ área de serviços $\left[\mathrm{m}^{2}\right]$

Identifica-se, nas tentativas realizadas para obter novos modelos de geração de viagens através de regressão linear simples, que as expressões obtidas para o número total de viagens diárias em função da área bruta locável são aceitáveis, para sexta-feira e sábado. Em função da área total construída, as expressões obtidas para sexta-feira e sábado não são recomendáveis, devido a que não existe uma relação estatisticamente significativa entre as variáveis e os modelos não passam pelos testes de significância estatística.

Nas tentativas realizadas para obter modelos de geração de viagens através de regressão linear múltipla, considerando como variáveis independentes as áreas por ramos de atividade (comércio, lazer e serviços), verificou-se que a expressão obtida para as viagens diárias de sexta-feira é aceitável, no entanto, a expressão obtida para as viagens diárias no sábado não passa pelos testes de significância estatística, portanto o modelo não é recomendável.

Assim, verifica-se para o universo estudado, considerando as variáveis independentes área bruta locável e área total construída dos shopping centers, que a área bruta locável é um fator mais significativo a ser considerado na estimativa da geração de viagens. Constata-se, ainda, que é possível obter uma relação mais significativa entre as viagens diárias geradas e as áreas desagregadas por ramos de atividade. Isto para empreendimentos com tamanho inferior a $27.550 \mathrm{~m}^{2}$ de ABL e localizados em cidades de médio porte, no interior do estado de São Paulo. 


\section{COMPARAÇÃO DOS VALORES OBTIDOS COM OS DE OUTROS TRABALHOS NACIONAIS}

Neste capítulo, os resultados dos principais padrões de viagens obtidos no estudo são comparados com os valores apresentados em outros trabalhos desenvolvidos no país. Os parâmetros considerados são: fator hora pico, fator horário de geração de viagens (para análise do impacto viário), tempo médio de permanência dos veículos no estacionamento, relação entre o número de viagens na sexta-feira e no sábado e função linear relacionando o número de viagens diárias e o tamanho do empreendimento.

\subsection{FATOR HORA PICO}

\subsubsection{SEXTA-FEIRA}

$\mathrm{Na}$ Tabela 6.1 apresenta-se os valores de fator hora pico observados na sexta-feira (FHPsex), o valor médio, os valores obtidos em alguns trabalhos desenvolvidos no país e os desvios correspondentes aos valores observados e à média. A Figura 6.1 representa graficamente esses valores.

Tabela 6.1 - Relação de fatores hora pico na sexta-feira (FHPsex).

\begin{tabular}{|l|c|c|c|c|c|}
\hline & \multirow{2}{*}{ FHPsex } & \multicolumn{4}{|c|}{ Desvio [\%] } \\
\cline { 3 - 6 } & & Média & Grando (1986) & Goldner (1994) & CET-SP (2000) \\
\hline Shopping center "A" & 0,1347 & 1,63 & $-22,05$ & $-24,94$ & $-4,38$ \\
\hline Shopping center "B" & 0,1425 & $-3,93$ & $-26,32$ & $-29,05$ & $-9,61$ \\
\hline Shopping center "C" & 0,1534 & $-10,76$ & $-31,55$ & $-34,09$ & $-16,04$ \\
\hline Shopping center "F" & 0,1170 & 17,01 & $-10,26$ & $-13,59$ & 10,09 \\
\hline Média & 0,1369 & & $-23,30$ & $-26,15$ & $-5,92$ \\
\hline Grando (1986) & 0,1050 & & & & \\
\hline Goldner (1994) & 0,1011 & & & & \\
\hline CET-SP (2000) & 0,1288 & & & & \\
\hline
\end{tabular}




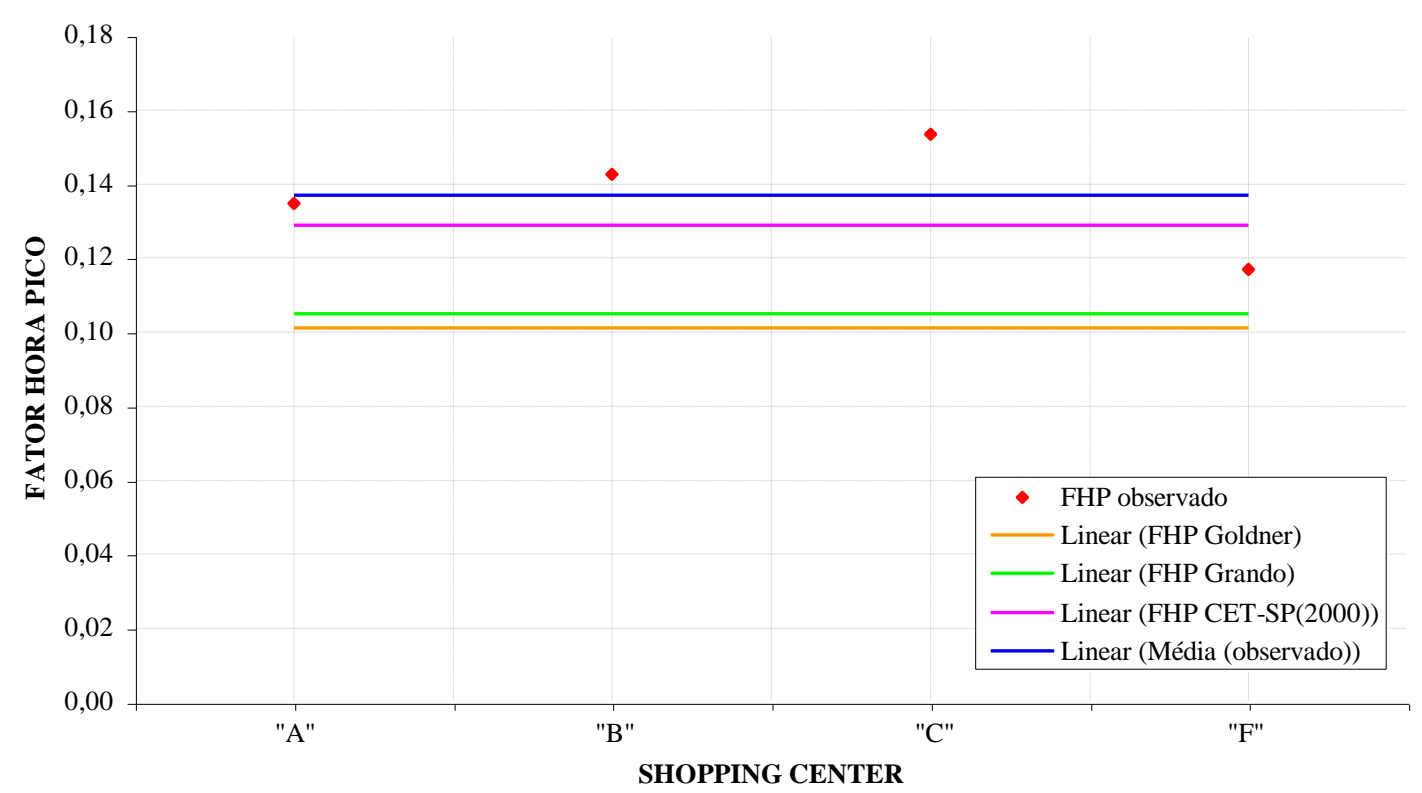

Figura 6.1 - Relação de fatores hora pico na sexta-feira.

Em relação ao valor médio observado nos empreendimentos estudados, o valor proposto por CET (2000) é 5,92\% inferior, o proposto por GRANDO (1986) é 23,30\% inferior e o valor proposto por GOLDNER (1994) é 26,15\% inferior.

Identifica-se, em geral, que os valores observados apresentam menor discrepância em relação ao valor médio observado. No entanto, o valor apresentado pelo empreendimento "F" é menos discrepante com os valores adotados por GRANDO (1986), GOLDNER (1994) e CET-SP (2000) do que com o valor médio, sendo mais próximo do valor adotado por CET-SP (2000).

Assim, conclui-se que o valor médio dos fatores hora pico observados na sexta-feira é o que apresenta melhor estimativa para os empreendimentos pesquisados, podendo ser considerado para shopping centers com características similares.

\subsubsection{SÁBADO}

Na Tabela 6.2 apresentam-se os valores do fator hora pico observados no sábado (FHPsab), o valor médio, os valores obtidos em alguns trabalhos desenvolvidos no país e os desvios correspondentes aos valores observados e à média. A Figura 6.2 representa graficamente esses valores. 
Tabela 6.2 - Relação de fatores hora pico no sábado (FHPsab).

\begin{tabular}{|l|c|c|c|c|c|}
\hline & \multirow{2}{*}{ FHPsab } & \multicolumn{4}{|c|}{ Desvio [\%] } \\
\cline { 3 - 6 } & & Média & Grando (1986) & Goldner (1994) & CET-SP (2000) \\
\hline Shopping center “A" & 0,1058 & 18,24 & $-0,76$ & $-15,12$ & $-7,66$ \\
\hline Shopping center "B" & 0,1549 & $-19,24$ & $-32,21$ & $-42,03$ & $-36,93$ \\
\hline Shopping center "C" & 0,1252 & $-0,08$ & $-16,13$ & $-28,27$ & $-21,96$ \\
\hline Shopping center "F" & 0,1147 & 9,07 & $-8,46$ & $-21,71$ & $-14,82$ \\
\hline Média & 0,1251 & & $-16,07$ & $-28,22$ & $-21,90$ \\
\hline Grando (1986) & 0,1050 & & & & \\
\hline Goldner (1994) & 0,0898 & & & & \\
\hline CET-SP (2000) & 0,0977 & & & & \\
\hline
\end{tabular}

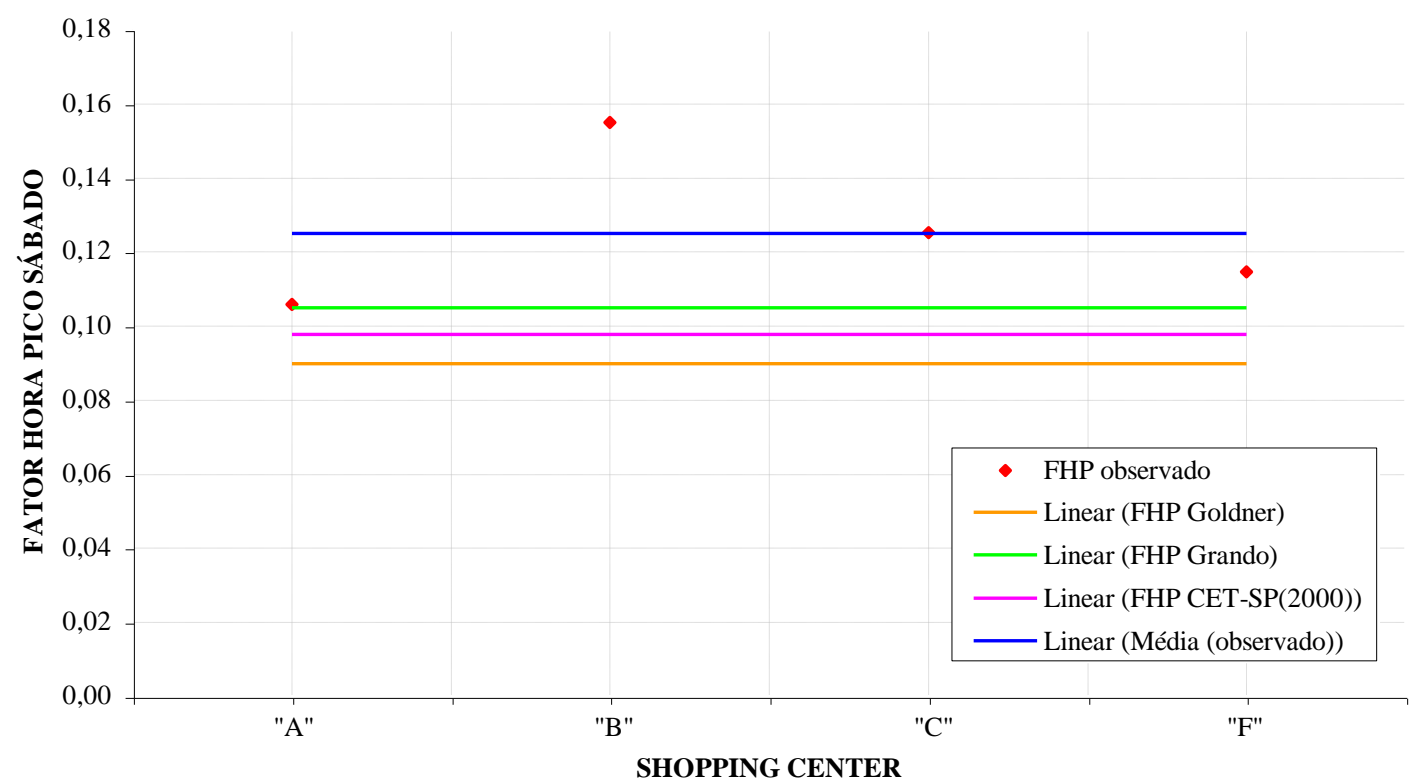

Figura 6.2 - Relação de fatores hora pico no sábado.

Em relação ao valor médio observado nos empreendimentos estudados, o valor proposto por GRANDO (1986) é 16,07\% inferior, o proposto por CET (2000) é 21,90\% inferior e o valor proposto por GOLDNER (1994) é $28,22 \%$ inferior.

Identifica-se que os valores observados nos empreendimentos "B" e "C" apresentam menor discrepância em relação ao valor médio observado. Já, os valores apresentados pelos empreendimentos "A" e "F" são menos discrepantes com o valor adotado por GRANDO (1986), no entanto, os empreendimentos "B" e "C" apresentam valores muito discrepantes em relação ao valor adotado por Grando. 
Assim, conclui-se que o valor médio dos fatores hora pico observados no sábado é o que apresenta melhor estimativa para os empreendimentos pesquisados, podendo ser considerado para shopping centers com características similares.

\subsection{FATOR HORÁRIO PARA ANÁLISE DE IMPACTO VIÁRIO}

Na Tabela 6.3 apresentam-se os valores de fator horário de viagens atraídas entre 18:00 e 19:00 horas da sexta-feira $\left(\mathrm{FHE}_{18-19}\right)$ - período adotado por GOLDNER (1994) para análise do impacto dos shopping centers no trânsito das vias adjacentes. Também são apresentados o valor médio, os valores obtidos por GRANDO (1986), Goldner e CET-SP (2000) e os desvios correspondentes aos valores observados e à média. A Figura 6.3 representa graficamente esses valores.

Tabela 6.3 - Relação de fatores horários de entrada na sexta-feira $\left(\mathrm{FHE}_{18-19}\right)$.

\begin{tabular}{|l|c|c|c|c|c|}
\hline & \multirow{2}{*}{ FHE $_{\mathbf{1 8 - 1 9}}$} & \multicolumn{4}{|c|}{ Desvio [\%] } \\
\cline { 3 - 6 } & & Média & Grando (1986) & Goldner (1994) & CET-SP (2000) \\
\hline Shopping center “A" & 0,1182 & $-13,62$ & $-11,17$ & $-16,41$ & $-20,30$ \\
\hline Shopping center "B" & 0,1320 & $-22,65$ & $-20,45$ & $-25,15$ & $-28,64$ \\
\hline Shopping center “C” & 0,0786 & 29,90 & 33,59 & 25,70 & 19,85 \\
\hline Shopping center "F" & 0,0794 & 28,59 & 32,24 & 24,43 & 18,64 \\
\hline Média & 0,1021 & & 2,84 & $-3,23$ & $-7,74$ \\
\hline Grando (1986) & 0,1050 & & & & \\
\hline Goldner (1994) & 0,0988 & & & & \\
\hline CET-SP (2000) & 0,0942 & & & & \\
\hline
\end{tabular}

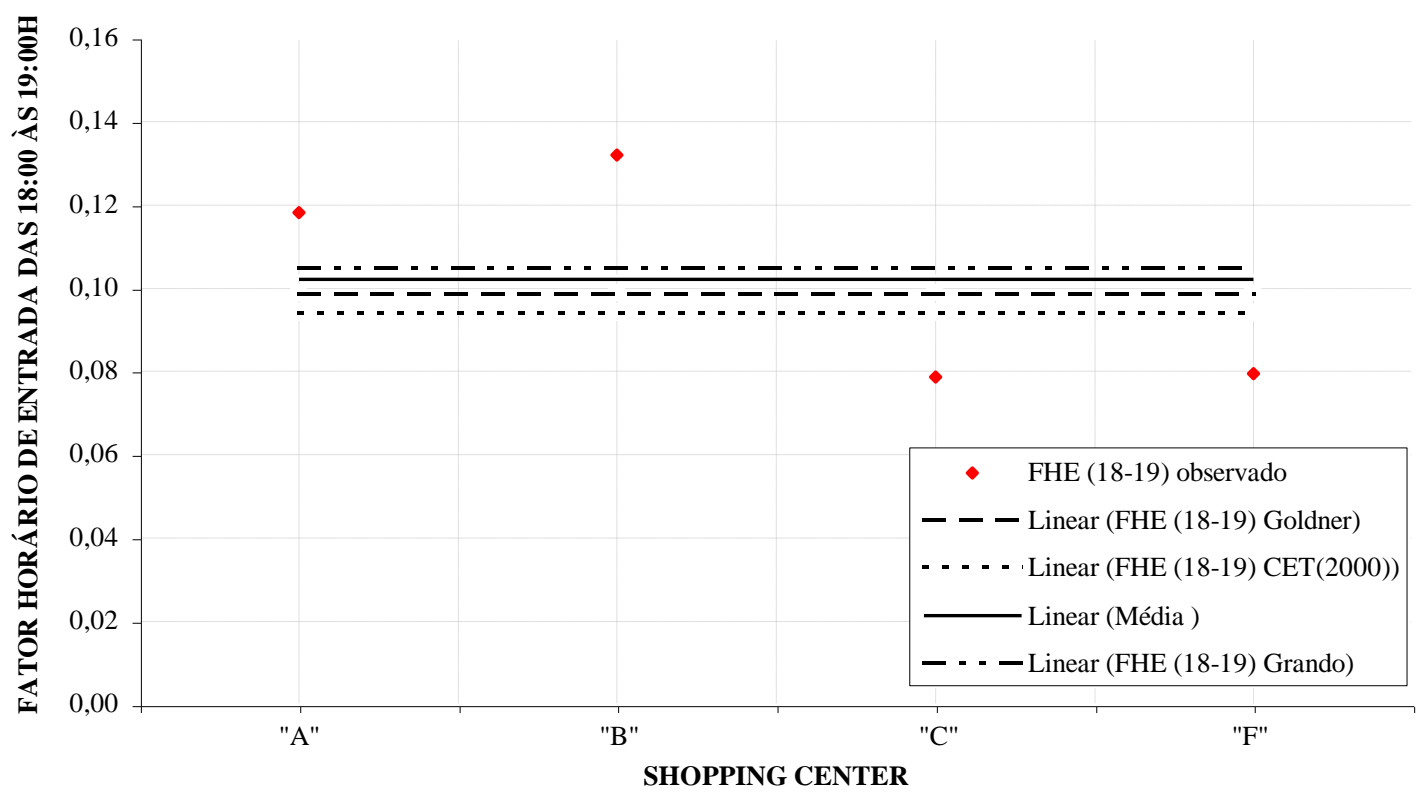

Figura 6.3 - Relação de fatores horários de entrada das 18:00 às 19:00h. 
Em relação ao valor médio observado nos empreendimentos estudados, o valor proposto por GRANDO (1986) é 2,84\% superior, o proposto por GOLDNER (1994) é 3,23\% inferior e o proposto por CET (2000) é 7,74\% inferior.

Identifica-se que o valor observado no empreendimento " $A$ " apresenta menor discrepância com o valor adotado por GRANDO (1986), o valor observado no shopping center "B" apresenta menor discrepância com o valor médio observado e os valores observados nos empreendimentos "C" e "F" apresentam menor discrepância em relação ao valor adotado por CET-SP (2000). No entanto, os valores apresentados pelos empreendimentos "A" e "B" são inferiores e mais discrepantes com o valor adotado por CET-SP (2000).

Assim, conclui-se que o valor médio dos fatores horários de entrada observados na sexta-feira, entre 18:00 e 19:00h, é o que apresenta melhor estimativa para os empreendimentos pesquisados, podendo ser considerado para shopping centers com características similares.

Na Tabela 6.4 apresentam-se os valores de fator horário de saída entre 18:00 e 19:00 horas da sexta-feira $\left(\mathrm{FHS}_{18-19}\right)$, o valor médio, o valor obtido por CET-SP (2000) e os desvios correspondentes aos valores observados e à média. A Figura 6.4 representa graficamente esses valores.

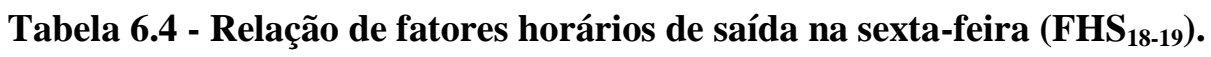

\begin{tabular}{|l|c|c|c|c|c|}
\hline & \multirow{2}{*}{ FHS $_{\mathbf{1 8 - 1 9}}$} & \multicolumn{4}{|c|}{ Desvio [\%] } \\
\cline { 3 - 6 } & & Média & Grando (1986) & Goldner (1994) & CET-SP (2000) \\
\hline Shopping center "A" & 0,0949 & $-7,59$ & $-11,49$ & $-16,75$ & $-18,02$ \\
\hline Shopping center "B" & 0,0950 & $-7,68$ & $-11,58$ & $-16,84$ & $-18,11$ \\
\hline Shopping center “C” & 0,0731 & 19,97 & 14,91 & 8,07 & 6,43 \\
\hline Média & 0,0877 & & $-4,22$ & $-9,92$ & $-11,29$ \\
\hline Grando (1986) & 0,0840 & & & & \\
\hline Goldner (1994) & 0,0790 & & & & \\
\hline CET-SP (2000) & 0,0778 & & & & \\
\hline
\end{tabular}

Em relação ao valor médio observado nos empreendimentos estudados, o valor proposto por Grando (1986) é 4,22\% inferior, o proposto por Goldner (1994) é 9,92\% inferior e o proposto por CET-SP (2000) é 11,29\% inferior.

Identifica-se, em geral, que os valores observados apresentam menor discrepância em relação ao valor médio observado. No entanto, o valor apresentado pelo empreendimento "C" é menos discrepante com os valores adotados por GRANDO (1986), GOLDNER (1994) e CET-SP (2000) do que com o valor médio, sendo mais próximo do valor adotado por CET-SP (2000). 


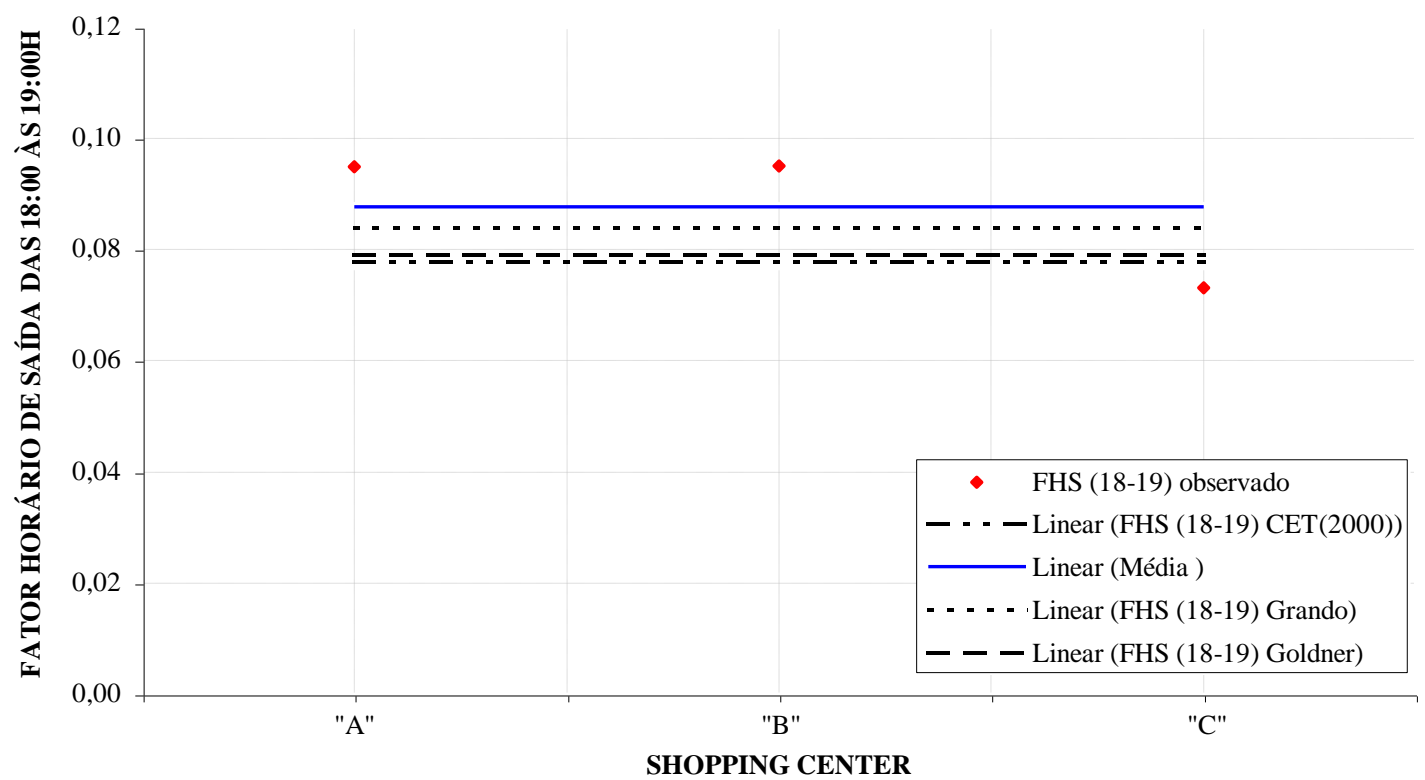

Figura 6.4 - Relação de fatores horários de saída das 18:00 às 19:00h.

Assim, conclui-se que o valor médio dos fatores horários de saída observados na sexta-feira, entre 18:00 e 19:00h, é o que apresenta melhor estimativa para os empreendimentos pesquisados, podendo ser considerado para shopping centers com características similares.

\subsection{TEMPO MÉDIO DE PERMANÊNCIA NO ESTACIONAMENTO}

A Tabela 6.5 apresenta os valores do tempo médio de permanência dos veículos no estacionamento no sábado, a média desses valores, os valores obtidos em alguns trabalhos desenvolvidos no país e os desvios correspondentes aos valores observados e à média. A Figura 6.5 representa graficamente esses valores.

Tabela 6.5 - Relação de tempos médios de permanência dos veículos (Tm).

\begin{tabular}{|l|c|c|c|c|c|}
\hline & \multirow{2}{*}{ Tm [hora] } & \multicolumn{4}{|c|}{ Desvio [\%] } \\
\cline { 3 - 6 } & & Média & CET-SP (1983) & Grando (1986) & Goldner (1994) \\
\hline Shopping center “A” & 0,8962 & 4,65 & 11,58 & 118,70 & 118,70 \\
\hline Shopping center "B" & 0,8578 & 9,34 & 16,58 & 128,49 & 128,49 \\
\hline Shopping center "C" & 1,0598 & $-11,50$ & $-5,64$ & 84,94 & 84,94 \\
\hline Média & 0,9379 & & 6,62 & 108,98 & 108,98 \\
\hline CET-SP (1983) & 1,0000 & & & & \\
\hline Grando (1986) & 1,9600 & & & & \\
\hline Goldner (1994) & 1,9600 & & & & \\
\hline
\end{tabular}




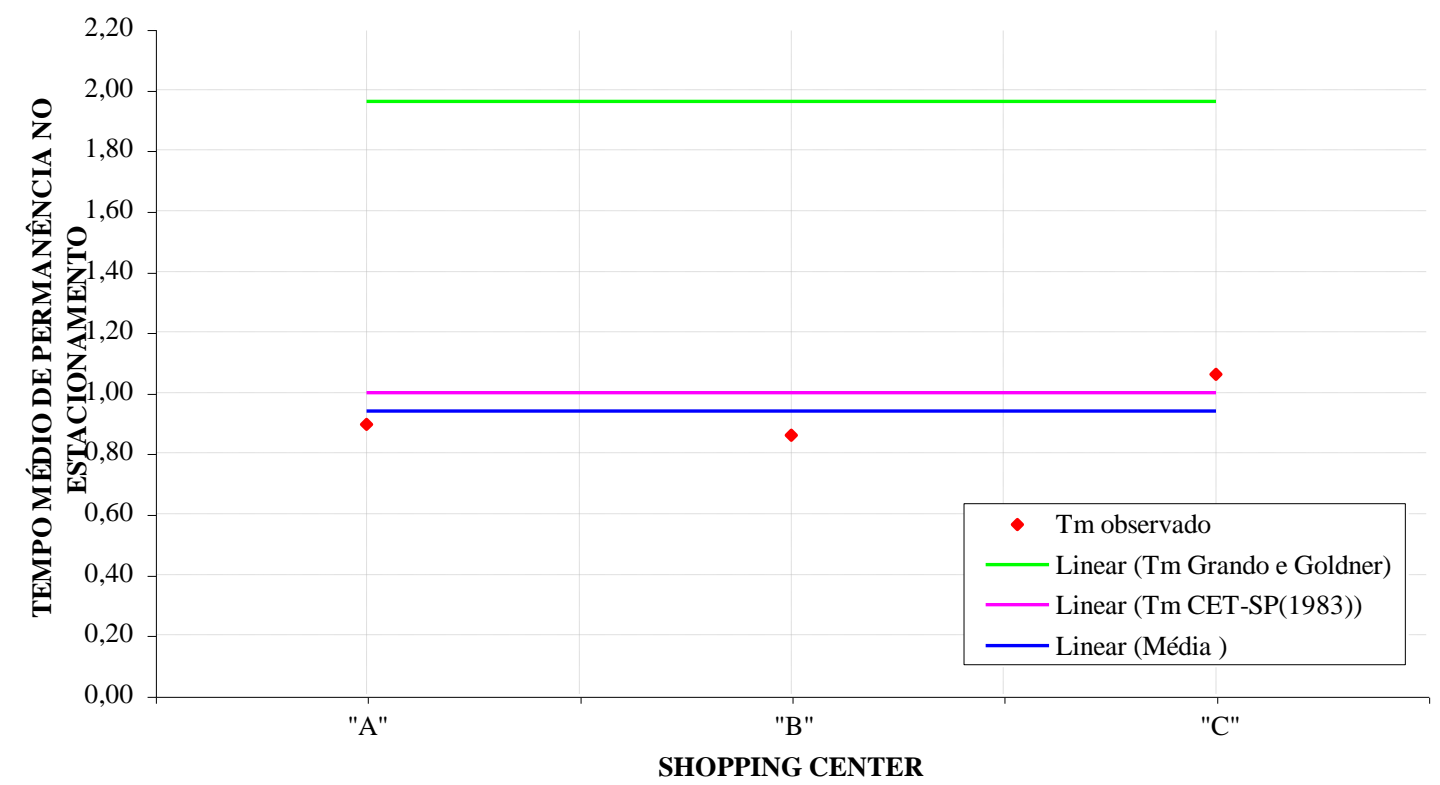

Figura 6.5 - Relação de tempos médios de permanência de veículos no estacionamento.

Em relação ao valor médio observado nos empreendimentos estudados, o valor proposto por CET-SP (1983) é 6,62\% superior e o proposto por GRANDO (1986) e GOLDNER (1994) é 108,98\% superior.

Identifica-se, em geral, que os valores observados apresentam menor discrepância em relação ao valor médio observado. No entanto, o valor apresentado pelo empreendimento "C" é menos discrepante com o valor adotado por CET-SP (1983) do que com o valor médio observado.

Assim, sugere-se o valor médio dos valores observados como estimativa do tempo médio de permanência de veículos no estacionamento, no sábado, para empreendimentos com características similares aos shopping centers pesquisados.

\subsection{RELAÇÃO ENTRE O NÚMERO DE VIAGENS NA SEXTA-FEIRA E NO SÁBADO}

A Tabela 6.6 apresenta os valores da relação entre as viagens na sexta-feira e no sábado, a média desses valores, os valores obtidos em alguns trabalhos desenvolvidos no país e os desvios correspondentes aos valores observados e à média. A Figura 6.6 representa graficamente esses valores. 
Tabela 6.6 - Relação entre as viagens diárias da sexta-feira e do sábado (VDsex / VDsab).

\begin{tabular}{|l|c|c|c|c|}
\hline & \multirow{2}{*}{ VDsex / VDsab } & \multicolumn{3}{|c|}{ Desvio [\%] } \\
\cline { 3 - 5 } & & Média & Grando (1986) & Goldner (1994) \\
\hline Shopping center “A" & 0,6200 & 14,37 & 19,35 & 19,35 \\
\hline Shopping center "B" & 0,8216 & $-13,69$ & $-9,93$ & ------ \\
\hline Shopping center "C" & 0,6635 & 6,87 & 11,53 & 11,53 \\
\hline Shopping center "D" & 0,8346 & $-15,04$ & $-11,33$ & $-11,33$ \\
\hline Shopping center "E" & 0,7031 & 0,85 & 5,25 & ------ \\
\hline Shopping center "F" & 0,6119 & 15,88 & 20,93 & 20,93 \\
\hline Média & 0,7091 & & 4,36 & 4,36 \\
\hline Grando (1986) & 0,7400 & & & \\
\hline Goldner (1994) & 0,7400 & & & \\
\hline
\end{tabular}

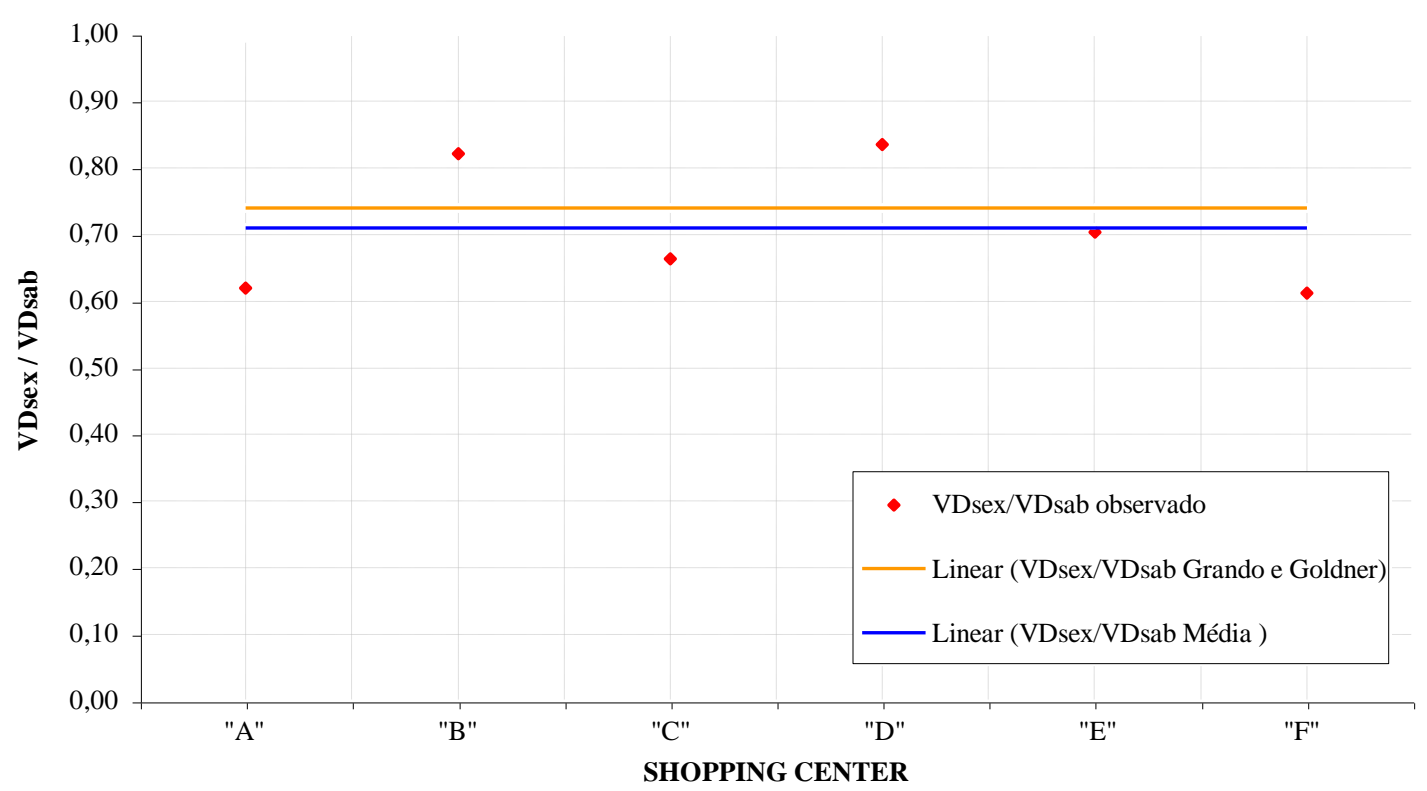

Figura 6.6 - Relação entre as viagens diárias da sexta-feira e do sábado.

Em relação ao valor médio observado nos empreendimentos estudados, o valor proposto por GRANDO (1986) e GOLDNER (1994) é 4,36\% superior.

Identifica-se, em geral, que os valores observados apresentam menor discrepância em relação ao valor médio observado. No entanto, os valores apresentados pelos empreendimentos "B" e "D" são menos discrepantes com o valor adotado por GRANDO (1986) do que com o valor médio.

Assim, sugere-se o valor médio dos valores observados como estimativa para a relação entre as viagens diárias geradas na sexta-feira e no sábado, para empreendimentos com características similares aos shopping centers pesquisados. 


\subsection{FUNÇÃO LINEAR RELACIONANDO O NÚMERO DIÁRIO DE VIAGENS E O TAMANHO DO EMPREENDIMENTO}

\subsubsection{SEXTA-FEIRA}

Na Tabela 6.7 apresentam-se os valores observados das viagens diárias atraídas na sexta-feira (VDsex), os valores obtidos através da expressão fornecida por regressão linear simples (eq.(27)), os valores fornecidos pelas expressões propostas por GRANDO (1986) e GOLDNER (1994) em função da área bruta locável e os valores dos desvios correspondentes em relação aos valores observados. A Figura 6.7 representa graficamente esses valores.

Tabela 6.7 - Relação das viagens diárias atraídas na sexta-feira e desvios de estimativas do modelo da eq.(27) e modelos nacionais (VDsex).

\begin{tabular}{|c|c|c|r|r|r|r|r|}
\hline \multirow{2}{*}{$\begin{array}{l}\text { Shopping } \\
\text { center }\end{array}$} & \multicolumn{3}{|c|}{ VDsex [veículos/dia] } & \multicolumn{3}{c|}{ Desvio [\%] } \\
\cline { 2 - 8 } & observado & eq.(27) & Grando & Goldner & eq.(27) & \multicolumn{1}{c|}{ Grando } & Goldner \\
\hline "A" & 3815 & 4780 & 4449 & 5883 & 25,29 & 16,62 & 54,20 \\
\hline "B" & 1432 & 1311 & -296 & 1524 & $-8,45$ & $-120,66$ & 6,42 \\
\hline "C" & 4145 & 4272 & 3755 & 5348 & 3,07 & $-9,41$ & 29,03 \\
\hline "D" & 6760 & 6324 & 6562 & 7508 & $-6,45$ & $-2,93$ & 11,07 \\
\hline "E" & 4500 & 4380 & 3902 & 5236 & $-2,67$ & $-13,28$ & 16,36 \\
\hline "F" & 4547 & 4131 & 3562 & 5200 & $-9,15$ & $-21,67$ & 14,35 \\
\hline
\end{tabular}

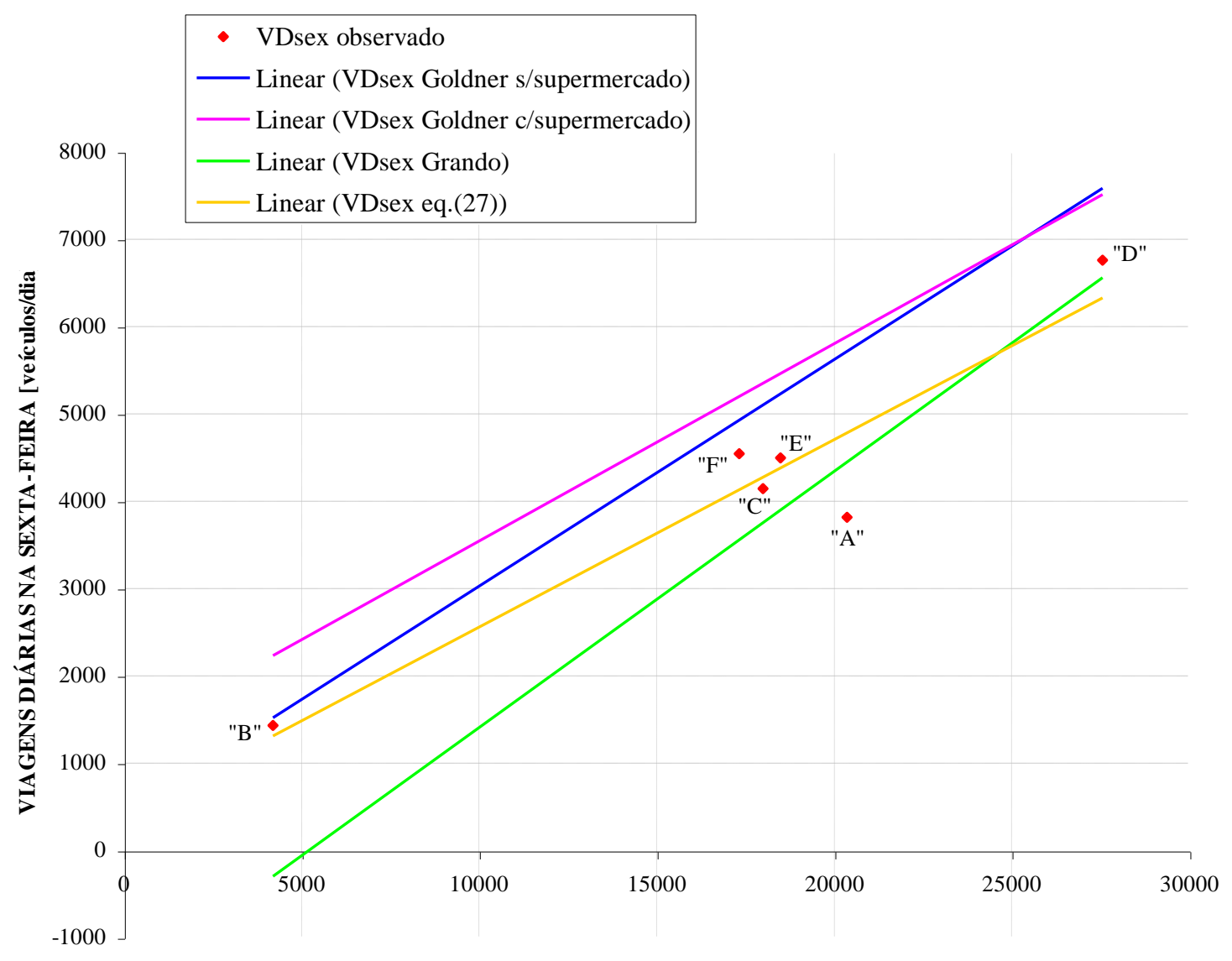

ÁREA BRUTA LOCÁVEL [m²]

Figura 6.7 - Relação das viagens diárias atraídas na sexta-feira observadas e estimadas pela eq.(27) e modelos nacionais. 
Identifica-se, em geral, que os valores apresentados pela aplicação do modelo de GRANDO (1986) mostram grande discrepância com os valores observados, no entanto, no empreendimento "D" o desvio é de 2,93\% do valor observado, sendo bem menor a discrepância. Em relação aos valores estimados por GOLDNER (1994), os valores também apresentam discrepância com os valores observados, sendo menor no shopping center "B". A eq.(27) mostra, em geral, melhor desempenho que os valores obtidos através da aplicação dos modelos de Grando e Goldner.

Assim, sugere-se a eq.(27) como estimativa para as viagens diárias atraídas na sexta-feira, para empreendimentos com características similares aos shopping centers pesquisados.

Na Tabela 6.8 apresentam-se os valores observados das viagens diárias atraídas na sexta-feira (VDsex), os valores fornecidos pela expressão propostas por CET (2000) em função da área total construída e os valores dos desvios correspondentes em relação aos valores observados. A Figura 6.8 representa graficamente esses valores.

Tabela 6.8 - Relação das viagens diárias atraídas na sexta-feira e desvios de estimativas do modelo da CET-SP (2000) (VDsex).

\begin{tabular}{|c|c|c|c|}
\hline \multirow{2}{*}{ Shopping center } & \multicolumn{2}{|c|}{ VDsex [veículos/dia] } & \multirow{2}{*}{ Desvio [\%] } \\
\cline { 2 - 3 } & observado & CET-SP (2000) & 333,92 \\
\hline "A" & 3815 & 16554 & 31,42 \\
\hline "B" & 1432 & 1882 & 57,27 \\
\hline "C" & 4145 & 6518 & 143,22 \\
\hline "D" & 6760 & 16442 & 111,81 \\
\hline "E" & 4500 & 9531 & 73,17 \\
\hline "F" & 4547 & 7874 & \\
\hline
\end{tabular}

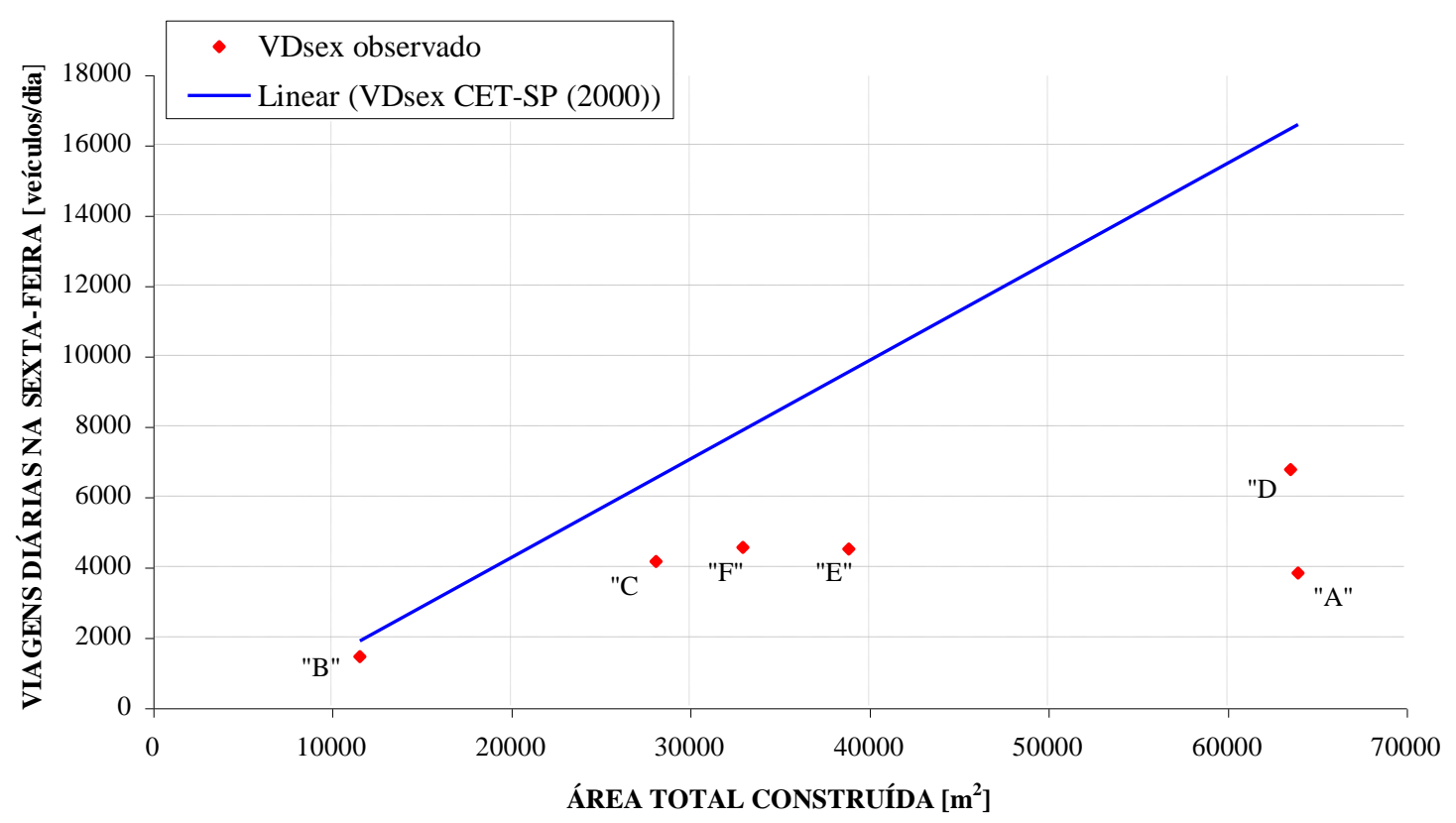

Figura 6.8 - Relação das viagens diárias atraídas na sexta-feira observadas e estimadas pelo modelo da CET-SP (2000). 
Identifica-se que os valores apresentados pela aplicação do modelo da CET-SP (2000) mostram grande discrepância com os valores observados. Portanto, esse modelo apresenta-se inapropriado para estimar as viagens diárias atraídas na sexta-feira em função da área total construída.

Na Tabela 6.9 apresentam-se os valores observados das viagens diárias atraídas na sexta-feira (VDsex), os valores obtidos através da expressão fornecida por regressão linear múltipla (eq.(31)), os valores fornecidos pelas expressões propostas por GRANDO (1986) e GOLDNER (1994), bem como os valores dos desvios correspondentes em relação aos valores observados. A Figura 6.9 representa graficamente esses valores.

Tabela 6.9 - Relação das viagens diárias atraídas na sexta-feira e desvios de estimativas do modelo da eq.(31) e modelos nacionais (VDsex).

\begin{tabular}{|c|c|c|r|r|r|r|r|}
\hline \multirow{2}{*}{$\begin{array}{l}\text { Shopping } \\
\text { center }\end{array}$} & \multicolumn{4}{|c|}{ VDsex [veículos/dia] } & \multicolumn{3}{c|}{ Desvio [\%] } \\
\cline { 2 - 8 } & observado & eq.(31) & Grando & Goldner & eq.(31) & Grando & Goldner \\
\hline "A" & 3815 & 3803 & 4449 & 5883 & $-0,31$ & 16,62 & 54,20 \\
\hline "B" & 1432 & 1417 & -296 & 1524 & $-1,08$ & $-120,66$ & 6,42 \\
\hline "C" & 4145 & 4181 & 3755 & 5348 & 0,88 & $-9,41$ & 29,03 \\
\hline "D" & 6760 & 6740 & 6562 & 7508 & $-0,30$ & $-2,93$ & 11,07 \\
\hline "E" & 4500 & 4511 & 3902 & 5236 & 0,23 & $-13,28$ & 16,36 \\
\hline
\end{tabular}

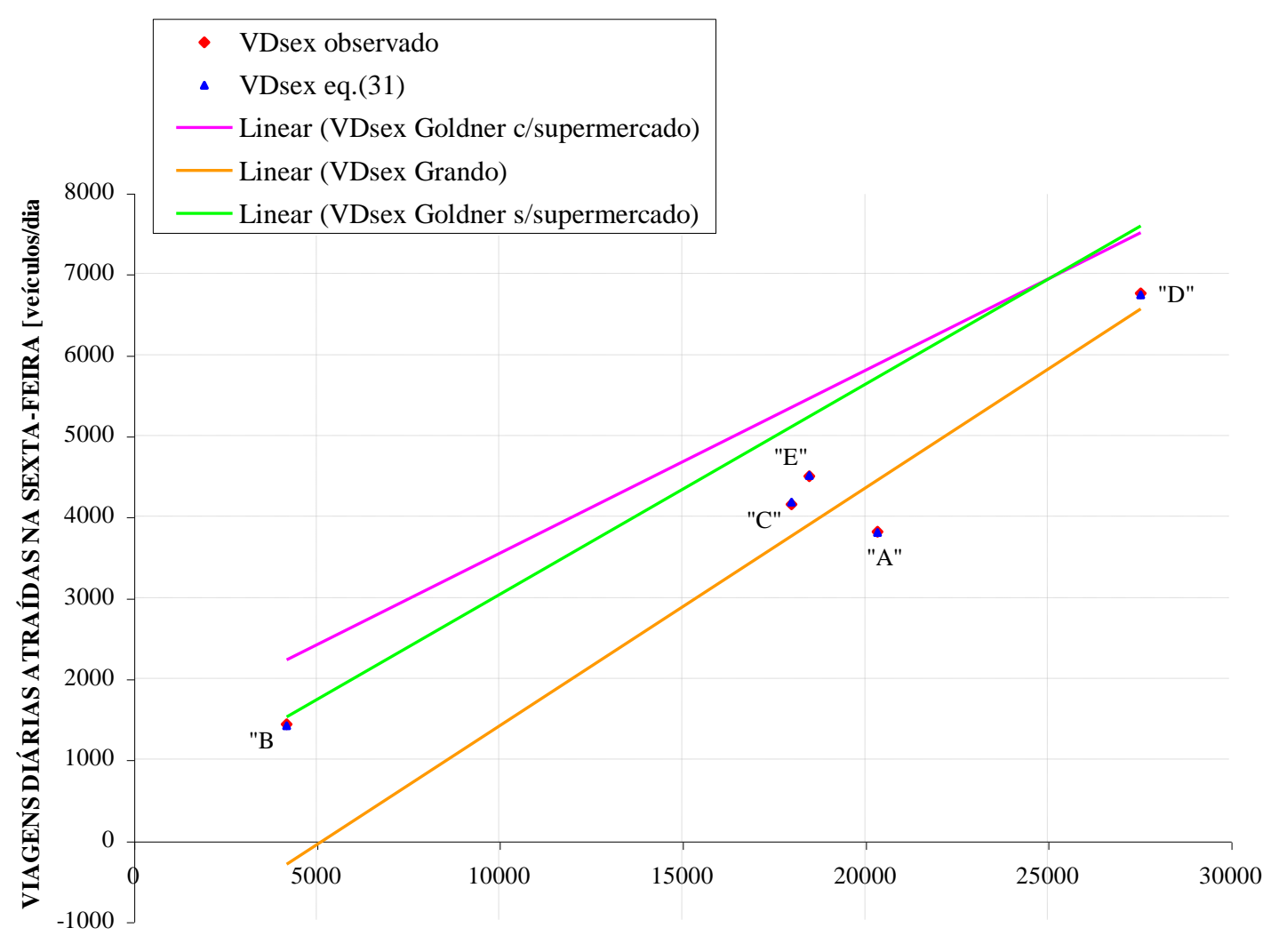

ÁREA BRUTA LOCÁVEL $\left[\mathrm{m}^{2}\right]$

Figura 6.9 - Relação das viagens diárias atraídas na sexta-feira observadas e estimadas pela eq.(31) e modelos nacionais. 
Identifica-se, em geral, que os valores dos desvios apresentados pela aplicação do modelo de GRANDO (1986) mostram grande discrepância com os valores observados, sendo menor no empreendimento "D". Em relação aos valores estimados pela aplicação do modelo de GOLDNER (1994), para empreendimentos com e sem supermercado, os valores dos desvios também apresentam discrepância, apresentando menor diferença com o valor observado no shopping center "B". Os valores apresentados pela aplicação da eq.(31) mostram melhor desempenho que os valores obtidos através da aplicação dos modelos de Grando e Goldner.

Assim, sugere-se a eq.(31) como estimativa para as viagens diárias atraídas na sexta-feira, para empreendimentos com características similares aos shopping centers pesquisados, quanto às áreas dos estabelecimentos por ramos de atividade (comércio, lazer e serviços).

\subsubsection{SÁBADO}

$\mathrm{Na}$ Tabela 6.10 apresentam-se os valores observados das viagens diárias atraídas no sábado, os valores obtidos através da expressão fornecida por regressão linear simples (eq.(28)), os valores fornecidos pelas expressões propostas por GRANDO (1986) e GOLDNER (1994) em função da área bruta locável, bem como os valores dos desvios correspondentes. A Figura 6.10 representa graficamente esses valores.

Tabela 6.10 - Relação das viagens diárias atraídas no sábado e desvios de estimativas do modelo da eq.(28) e modelos nacionais (VDsab).

\begin{tabular}{|c|c|c|c|c|c|c|c|}
\hline \multirow{2}{*}{$\begin{array}{l}\text { Shopping } \\
\text { center }\end{array}$} & \multicolumn{4}{|c|}{ VDsab [veículos/dia] } & \multicolumn{3}{c|}{ Desvio [\%] } \\
\cline { 2 - 8 } & observado & eq.(28) & Grando & Goldner & eq.(28) & Grando & Goldner \\
\hline “A" & 6153 & 6748 & 6012 & 7950 & 9,66 & $-2,29$ & 29,21 \\
\hline "B" & 1743 & 2337 & -400 & 3351 & 34,08 & $-122,95$ & 92,25 \\
\hline “C" & 6247 & 6102 & 5074 & 7228 & $-2,32$ & $-18,78$ & 15,70 \\
\hline "D" & 8100 & 8711 & 8867 & 10146 & 7,55 & 9,47 & 25,26 \\
\hline "E" & 6400 & 6239 & 5273 & 7754 & $-2,51$ & $-17,61$ & 21,16 \\
\hline "F" & 7431 & 5923 & 4813 & 7027 & $-20,30$ & $-35,23$ & $-5,44$ \\
\hline
\end{tabular}

Identifica-se, em geral, que os valores apresentados pela aplicação do modelo de GRANDO (1986) mostram grande discrepância com os valores observados, no entanto, no empreendimento "A" o valor estimado é 2,29\% inferior ao valor observado. Em relação aos valores estimados por GOLDNER (1994), os valores também apresentam discrepância com os valores observados, sendo menor no shopping center "F". A eq.(28) mostra, em geral, melhor desempenho que os valores obtidos através da aplicação dos modelos de Grando e Goldner. 


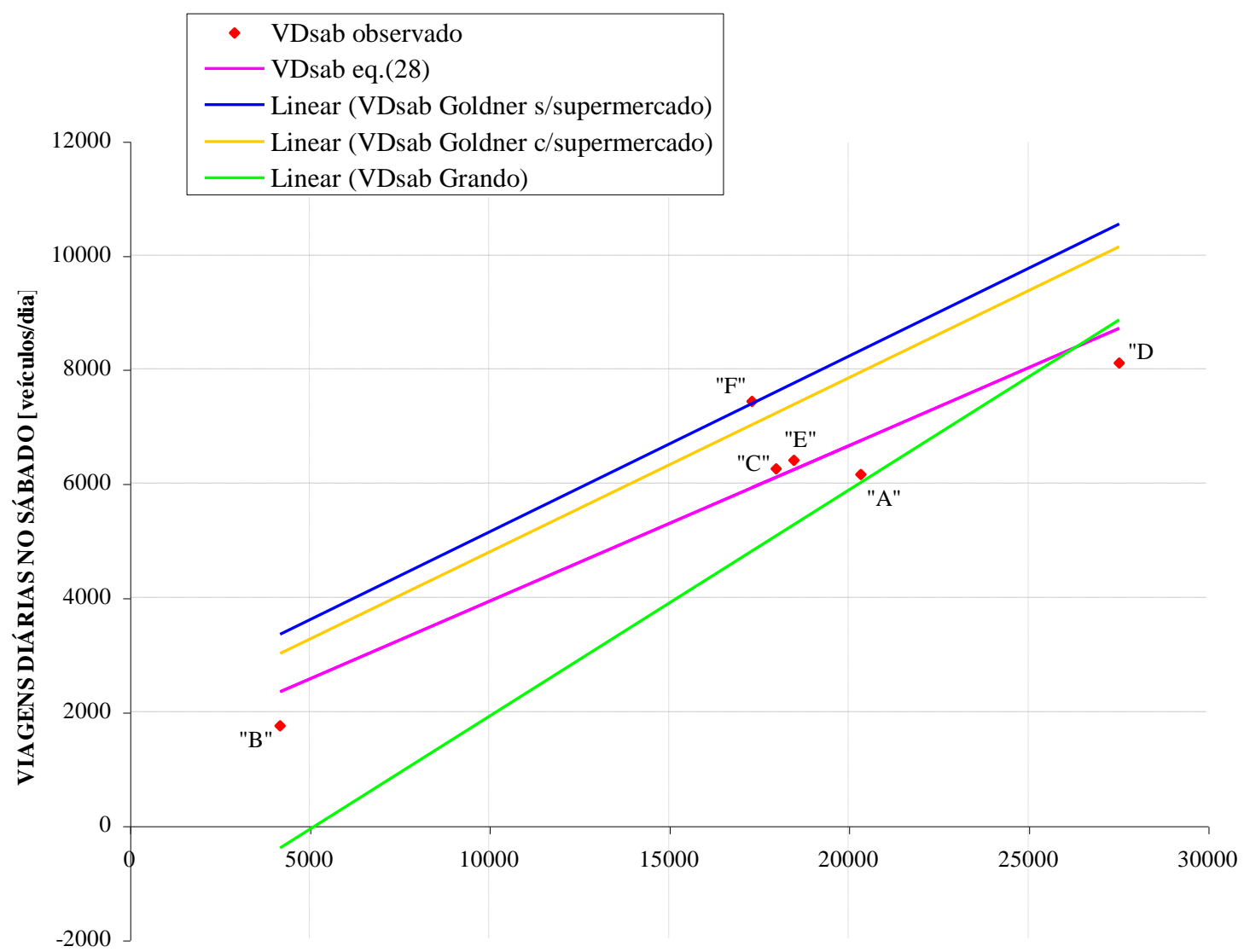

ÁREA BRUTA LOCÁVEL $\left[\mathrm{m}^{2}\right]$

Figura 6.10 - Relação das viagens diárias atraídas no sábado observadas e estimadas pela eq.(28) e modelos nacionais.

Assim, sugere-se a eq.(28) como estimativa para as viagens diárias atraídas no sábado, para empreendimentos com características similares aos shopping centers pesquisados.

$\mathrm{Na}$ Tabela 6.11 apresentam-se os valores observados das viagens diárias atraídas no sábado (VDsab), os valores obtidos através da expressão proposta por CET-SP (2000) em função da área total construída, bem como os valores dos desvios correspondentes em relação aos valores observados. A Figura 6.11 representa graficamente esses valores. 
Tabela 6.11 - Relação das viagens diárias atraídas no sábado e desvios de estimativas do modelo da CET-SP (2000) (VDsab).

\begin{tabular}{|c|c|c|c|}
\hline \multirow{2}{*}{ Shopping center } & \multicolumn{2}{|c|}{ VDsab [veículos/dia] } & \multirow{2}{*}{ Desvio [\%] } \\
\cline { 2 - 3 } & observado & CET-SP (2000) & 205,09 \\
\hline "A" & 6153 & 18772 & $-15,06$ \\
\hline "B" & 1743 & 1480 & 11,18 \\
\hline "C" & 6247 & 6945 & 130,13 \\
\hline "D" & 8100 & 18640 & 64,00 \\
\hline "E" & 6400 & 10496 & 14,96 \\
\hline "F" & 7431 & 8542 & \\
\hline
\end{tabular}

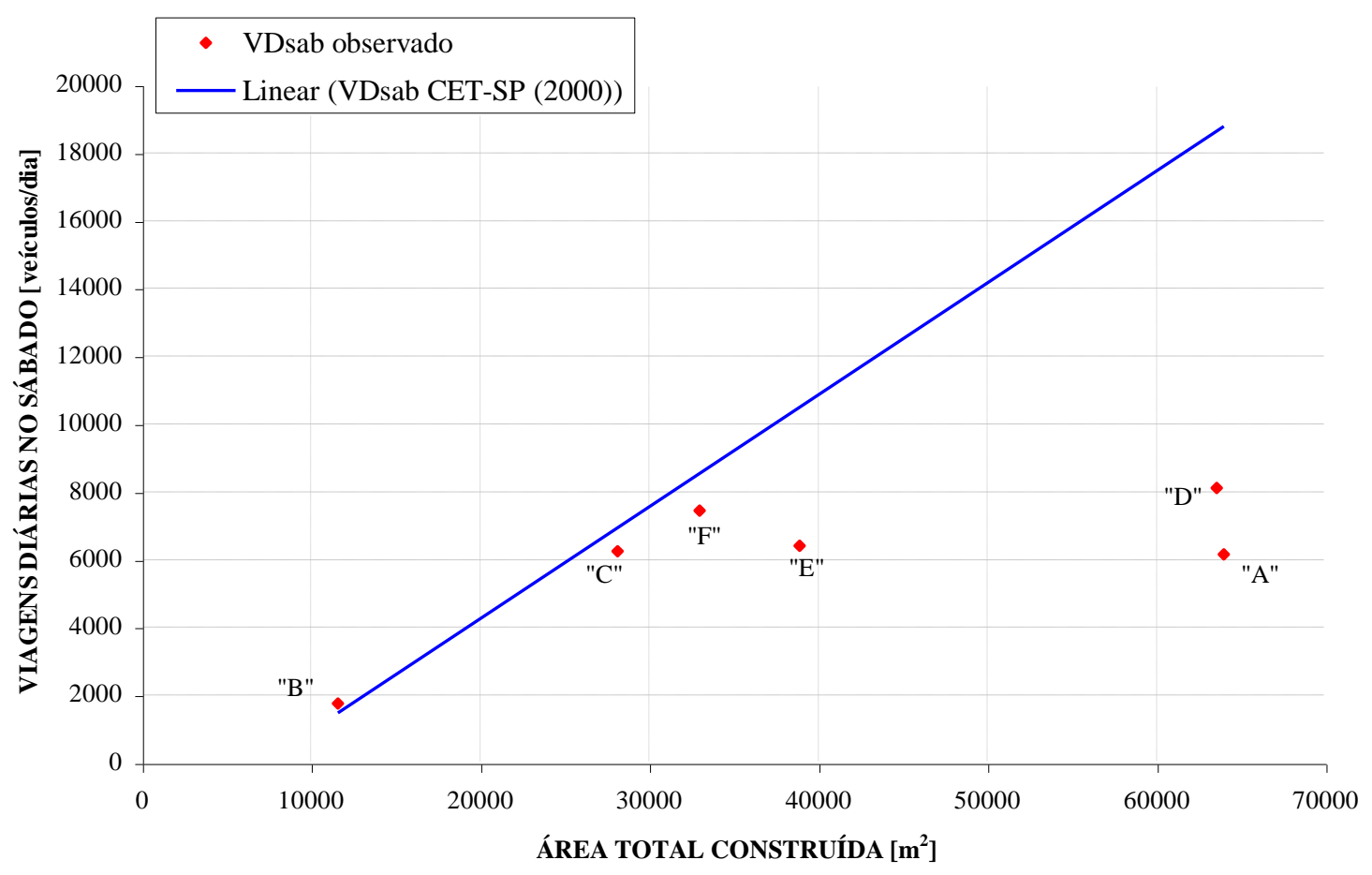

Figura 6.11 - Relação das viagens diárias atraídas no sábado observadas e estimadas pela modelo da CET-SP (2000).

Identifica-se que os valores apresentados pela aplicação do modelo da CET-SP (2000) mostram grande discrepância com os valores observados, apresentando maior dispersão nos empreendimentos "A", "D" e "E". Portanto, esse modelo mostra-se inapropriado para estimar as viagens diárias atraídas no sábado em função da área total construída.

Em geral, nos parâmetros comparados com o valor médio e com valores adotados por autores nacionais, identificou-se que os valores médios para fator hora pico, fator horário de geração de viagens, tempo médio de permanência dos veículos no estacionamento e para a relação entre as viagens diárias geradas na sexta-feira e no sábado são os que apresentam melhor estimativa para os shopping centers pesquisados, podendo ser considerados para shopping centers com características similares. 
Nas comparações realizadas de valores observados para as viagens diárias atraídas pelos empreendimentos com valores obtidos através da aplicação de modelos nacionais e de modelos desenvolvidos para os shopping centers pesquisados, é possível sugerir como melhores estimativas para as viagens diárias atraídas, enquanto não surgirem novos estudos, para sexta-feira a eq.(27) obtida através de regressão linear simples, em função da área bruta locável, e a eq.(31) obtida através de regressão linear múltipla, considerando as áreas desagregadas de comércio, lazer e serviços. Para estimar as viagens diárias atraídas no sábado é possível sugerir como melhor estimativa a eq.(28) obtida através de regressão linear simples, em função da área bruta locável.

Os modelos sugeridos pela CET-SP (2000), em função da área total construída, ao serem aplicados aos empreendimentos pesquisados apresentaram grande discrepância com os valores observados. Portanto, consideram-se inapropriados para estimar as viagens diárias atraídas na sexta-feira e no sábado, em empreendimentos com as características apresentadas nesta pesquisa. 


\section{MÉTODO PROPOSTO PARA DIMENSIONAR ALGUNS PARÂMETROS DE PROJETO DE SHOPPING CENTERS}

\subsection{CONSIDERAÇÕES INICIAIS}

Na literatura pesquisada, quanto à variação da demanda de tráfego em shopping centers, identificou-se alguns critérios adotados como dias típicos de projeto. Entretanto, nesta pesquisa não foi possível obter dias de projeto para o universo estudado, devido a que os shopping centers pesquisados, localizados em cidades de médio porte no interior do estado de São Paulo, não apresentaram registros de dados anuais do fluxo de veículos atraídos, nem apresentaram registros diários de movimentação de veículos. Nessa situação, considera-se apropriado adotar as seguintes hipóteses:

1. A variação diária das viagens ao longo do ano - expressa pela relação entre o número de viagens num dia qualquer e o número de viagens no sábado médio - segue a curva dos valores médios dos dados referentes aos três casos distintos (dois deles referentes ao mesmo shopping center em anos diferentes) apresentados por GRANDO (1986), e relacionados no capítulo 2.

2. O número de viagens no sábado obtido no estudo para cada shopping center corresponde ao valor do sábado médio do ano. Da mesma forma, o número de viagens na sexta-feira obtido no estudo para cada shopping corresponde ao valor da sexta-feira média do ano.

3. A variação horária do fluxo de veículos ao longo dos dias de maior movimento - que são os sábados e alguns dias especiais (feriados, vésperas do natal, do dia das mães, do dia dos pais, etc) - segue o padrão médio obtido nos sábados pesquisados.

4. A variação horária do fluxo de veículos ao longo das sextas-feiras segue o padrão médio obtido nas sextas-feiras pesquisadas.

5. O valor médio da relação entre o número total de viagens na sexta-feira e no sábado obtidos no estudo $(0,71)$ se mantém o mesmo nas sextas-feiras e nos sábados correspondentes em termos de movimento ( $1^{\text {a }}$ sexta-feira de maior movimento do ano com $1^{\circ}$ sábado de maior movimento, $2^{\mathrm{a}}$ sexta-feira de maior movimento do ano com $2^{\circ}$ sábado de maior movimento, etc). 
6. A eq.(28) apresentada no capítulo 5, obtida através da técnica de regressão linear simples, fornece uma estimativa satisfatória do número de viagens no sábado médio em função da área bruta locável.

Com essas hipóteses e considerando, ainda, os registros diários de movimentação de veículos nos shopping centers pesquisados, torna-se possível formular um método para dimensionar alguns parâmetros de projeto de shopping centers localizados em cidades de médio porte, no interior do estado de São Paulo, definidos para uma determinada hora de projeto.

A formulação do método proposto consiste nos seguintes passos:

- Relacionar os valores médios dos fatores diários de projeto para os dias do ano mais movimentados;

- Relacionar os valores médios dos fatores horários de projeto nos empreendimentos pesquisados para as horas mais movimentadas do dia;

- Relacionar os valores médios dos fatores diários e horários de projeto, de modo a obter os fatores horários de projeto associados às horas do ano mais movimentadas;

- Definir determinada hora de projeto para os fatores horários de projeto associados às horas do ano mais movimentadas; e

- Relacionar o fator horário de projeto associado a determinada hora do ano mais movimentada com as viagens no sábado médio, de modo a obter os valores de alguns parâmetros de projeto de shopping centers.

Assim, com os valores obtidos, pressupõe-se possível dimensionar adequadamente as instalações e equipamentos de entrada e saída do shopping center, as instalações de eventuais cruzamentos por onde passam os fluxos de entrada e saída do empreendimento, as instalações e equipamentos de passagem e controle nos acessos de entrada e saída do estacionamento, a capacidade do estacionamento e dimensionar dispositivos de acesso viário e adequação de serviços e/ou infra-estrutura de transportes (tratamento viário, sinalização, etc). 


\subsection{ESTUDO DO DIA DE PROJETO}

Na Tabela 7.1 encontram-se reproduzidos os valores da Tabela 2.2, apresentados por GRANDO (1986), bem como os valores médios da relação entre o número de viagens nos dias de maior movimento e o número de viagens no sábado médio, isto é:

$$
F D_{i}=V D_{i} / V s m
$$

Sendo, $F D_{i}$ : fator diário de viagens associado ao dia i do ano;

$V D_{i}$ : número de viagens no dia i do ano; e

$V s m$ : número de viagens no sábado médio do ano.

Também na Tabela 7.1 estão indicados os desvios dos valores reais em relação ao valor médio.

Tabela 7.1 - Fatores diários e desvios.

\begin{tabular}{|c|c|c|c|c|c|c|c|}
\hline \multirow{2}{*}{$\begin{array}{l}\text { Dia } \\
\text { (i) }\end{array}$} & \multicolumn{4}{|c|}{$F D_{i}=V D_{i} / V s m$} & \multicolumn{3}{|l|}{ Desvio [\%] } \\
\hline & Rio Sul(1983) & Rio Sul(1994) & Recife(1985) & média & Rio Sul(1983) & Rio Sul(1994) & Recife(1985) \\
\hline 1 & 1,86 & 1,68 & 1,83 & 1,79 & 3,91 & $-6,15$ & 2,23 \\
\hline 2 & 1,84 & 1,65 & 1,54 & 1,68 & 9,74 & $-1,59$ & $-8,15$ \\
\hline 3 & 1,82 & 1,50 & 1,51 & 1,61 & 13,04 & $-6,83$ & $-6,21$ \\
\hline 4 & 1,79 & 1,49 & 1,41 & 1,56 & 14,50 & $-4,69$ & $-9,81$ \\
\hline 5 & 1,75 & 1,43 & 1,40 & 1,53 & 14,63 & $-6,33$ & $-8,30$ \\
\hline 6 & 1,64 & 1,39 & 1,38 & 1,47 & 11,56 & $-5,44$ & $-6,12$ \\
\hline 7 & 1,58 & 1,37 & 1,33 & 1,43 & 10,75 & $-3,97$ & $-6,78$ \\
\hline 8 & 1,56 & 1,34 & 1,32 & 1,41 & 10,90 & $-4,74$ & $-6,16$ \\
\hline 9 & 1,54 & 1,33 & 1,30 & 1,39 & 10,79 & $-4,32$ & $-6,47$ \\
\hline 10 & 1,50 & 1,31 & 1,28 & 1,36 & 10,02 & $-3,91$ & $-6,11$ \\
\hline 11 & 1,36 & 1,30 & 1,26 & 1,31 & 4,08 & $-0,51$ & $-3,57$ \\
\hline 12 & 1,34 & 1,28 & 1,25 & 1,29 & 3,88 & $-0,78$ & $-3,10$ \\
\hline 13 & 1,30 & 1,27 & 1,24 & 1,27 & 2,36 & 0,00 & $-2,36$ \\
\hline 14 & 1,29 & 1,26 & 1,22 & 1,26 & 2,65 & 0,27 & $-2,92$ \\
\hline 15 & 1,28 & 1,24 & 1,17 & 1,23 & 4,07 & 0,81 & $-4,88$ \\
\hline 16 & 1,24 & 1,23 & 1,17 & 1,21 & 2,20 & 1,37 & $-3,57$ \\
\hline 17 & 1,24 & 1,16 & 1,12 & 1,17 & 5,68 & $-1,14$ & $-4,55$ \\
\hline 18 & 1,22 & 1,15 & 1,11 & 1,16 & 5,17 & $-0,86$ & $-4,31$ \\
\hline 19 & 1,20 & 1,14 & 1,09 & 1,14 & 4,96 & $-0,29$ & $-4,66$ \\
\hline 20 & 1,16 & 1,14 & 1,07 & 1,12 & 3,26 & 1,48 & $-4,75$ \\
\hline 21 & 1,15 & 1,13 & 1,06 & 1,11 & 3,29 & 1,50 & $-4,79$ \\
\hline 22 & 1,14 & 1,12 & 1,06 & 1,11 & 3,01 & 1,20 & $-4,22$ \\
\hline 23 & 1,13 & 1,11 & 1,05 & 1,10 & 3,04 & 1,22 & $-4,26$ \\
\hline 24 & 1,12 & 1,10 & 1,05 & 1,09 & 2,75 & 0,92 & $-3,67$ \\
\hline 25 & 1,12 & 1,07 & 1,05 & 1,08 & 3,70 & $-0,93$ & $-2,78$ \\
\hline 26 & 1,10 & 1,05 & 1,05 & 1,07 & 3,13 & $-1,56$ & $-1,56$ \\
\hline 27 & 1,09 & 1,04 & 1,05 & 1,06 & 2,83 & $\begin{array}{r}-1,89 \\
\end{array}$ & $-0,94$ \\
\hline 28 & 1,06 & 1,03 & 1,04 & 1,04 & 1,60 & $-1,28$ & $-0,32$ \\
\hline 29 & 1,04 & 1,02 & 1,04 & 1,03 & 0,65 & $-1,29$ & 0,65 \\
\hline 30 & 1,03 & 1,02 & 1,04 & 1,03 & 0,00 & $-0,97$ & 0,97 \\
\hline 31 & 1,02 & 1,01 & 1,03 & 1,02 & 0,00 & $-0,98$ & 0,98 \\
\hline 32 & 1,02 & 1,01 & 1,02 & 1,02 & 0,00 & $-0,98$ & 0,00 \\
\hline 33 & 1,02 & 1,00 & 1,02 & 1,01 & 0,99 & $-0,99$ & 0,99 \\
\hline 34 & 1,00 & 1,00 & 1,02 & 1,01 & $-0,99$ & $-0,99$ & 0,99 \\
\hline 35 & 0,99 & 1,00 & 1,02 & 1,00 & $-1,00$ & 0,00 & 2,00 \\
\hline 36 & 0,98 & 0,99 & 1,02 & 1,00 & $-2,00$ & $-1,00$ & 2,00 \\
\hline 37 & 0,95 & 0,99 & 1,01 & 0,98 & $-3,06$ & 1,02 & 3,06 \\
\hline 38 & 0,95 & 0,99 & 1,01 & 0,98 & $-3,06$ & 1,02 & 3,06 \\
\hline 39 & 0,94 & 0,98 & 1,01 & 0,98 & $-4,08$ & 0,00 & 3,06 \\
\hline 40 & 0,94 & 0,98 & 1,00 & 0,97 & $-3,09$ & 1,03 & 3,09 \\
\hline 41 & 0,93 & 0,98 & 0,99 & 0,97 & $-4,12$ & 1,03 & 2,06 \\
\hline
\end{tabular}


Na Figura 7.1 estão representados graficamente os valores dos fatores diários.

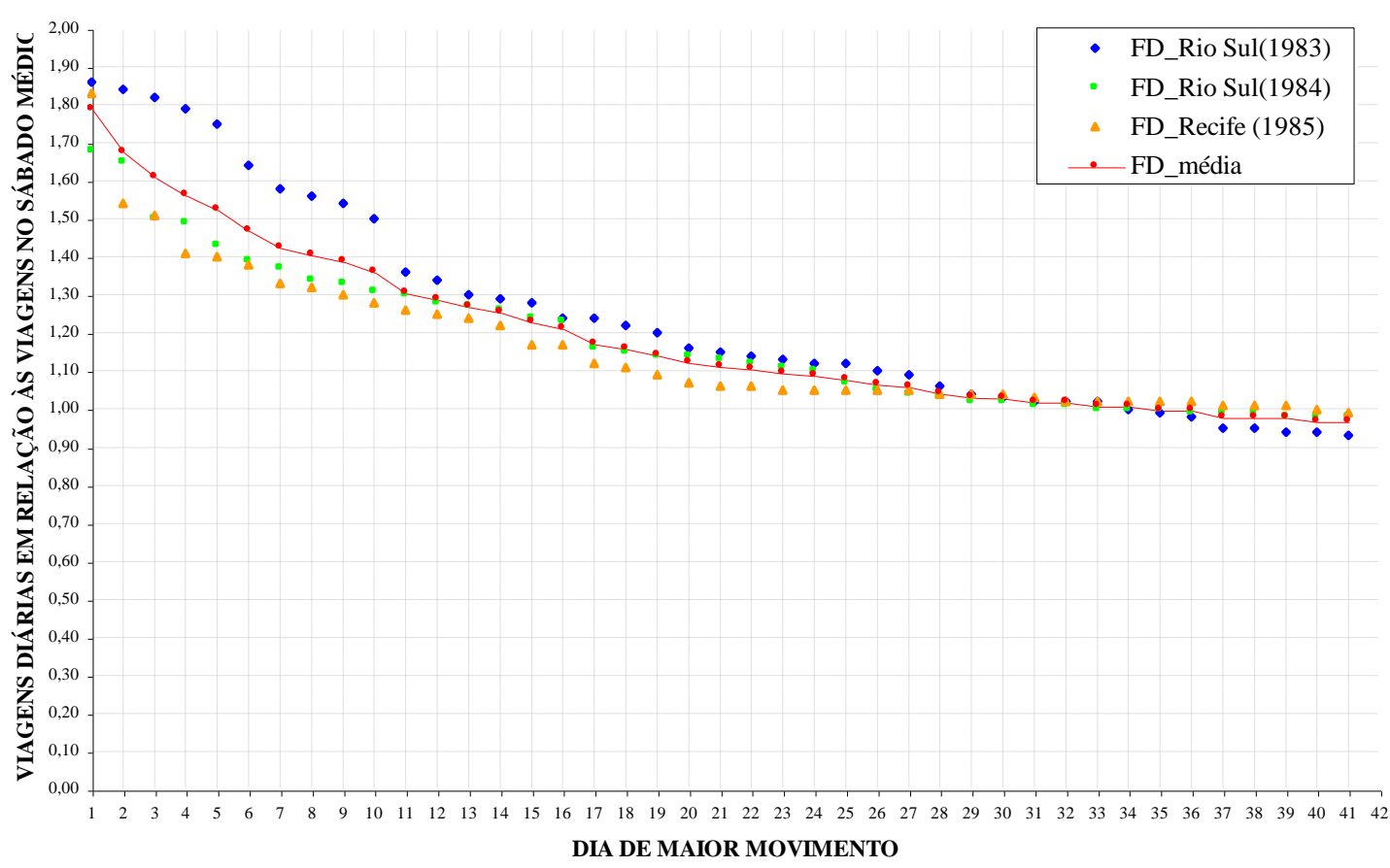

Figura 7.1 - Fatores diários para os dias de maior movimento.

\subsection{ESTUDO DA HORA DE PROJETO}

\subsubsection{FATORES DE ENTRADA}

Na Tabela 7.2 encontram-se reproduzidos os valores da relação entre o número de viagens horárias e o número total de viagens no sábado, referentes às horas de maior movimento de entrada, obtidos nas pesquisas realizadas nos shoppings centers. Também nessa tabela estão indicados os valores médios dessas relações correspondentes a cada hora denominados de fatores horários de entrada e definidos como:

$$
F H E_{j}^{s m}=\left(V H E_{j} / V s m\right) \times 100
$$

Sendo, $F H E_{j}^{s m}$ : fator horário de entrada associado à hora j do sábado médio [\%];

$V H E_{j}$ : número de viagens na hora j do sábado médio [veículos/hora]; e

Vsm: número de viagens no sábado médio [veículos/dia].

Também na Tabela 7.2 estão indicados os desvios dos valores reais em relação ao valor médio. 
Tabela 7.2 - Fatores horários de entrada $\left(F_{H} E_{j}^{s m}\right)$.

\begin{tabular}{|c|c|c|c|c|c|c|c|c|c|}
\hline \multirow{2}{*}{$\begin{array}{c}\text { Maior } \\
\text { hora (j) }\end{array}$} & \multicolumn{5}{|c|}{$F H E_{j}^{s m}[\%]=\left(V H E_{j} / V s m\right) \times 100$} & \multicolumn{4}{|c|}{ Desvio [\%] } \\
\hline & "F" & "A" & "B" & "C" & média & "F" & "A" & "B" & "C"' \\
\hline 1 & 11,47 & 10,58 & 15,49 & 12,52 & 12,52 & $-8,35$ & $-15,46$ & 23,77 & 0,04 \\
\hline 2 & 8,90 & 10,06 & 13,02 & 10,84 & 10,71 & $-16,86$ & $-6,03$ & 21,63 & 1,26 \\
\hline 3 & 8,65 & 9,62 & 12,16 & 9,91 & 10,09 & $-14,23$ & $-4,61$ & 20,58 & $-1,74$ \\
\hline 4 & 7,16 & 9,56 & 11,36 & 8,84 & 9,23 & $-22,43$ & 3,58 & 23,08 & $-4,23$ \\
\hline 5 & 6,90 & 8,63 & 6,83 & 7,97 & 7,58 & $-9,00$ & 13,81 & $-9,92$ & 5,11 \\
\hline 6 & 6,72 & 8,37 & 6,71 & 7,94 & 7,44 & $-9,62$ & 12,58 & $-9,75$ & 6,79 \\
\hline 7 & 6,50 & 7,41 & 5,91 & 7,78 & 6,90 & $-5,80$ & 7,39 & $-14,35$ & 12,75 \\
\hline 8 & 6,42 & 6,68 & 5,85 & 7,60 & 6,64 & $-3,28$ & 0,64 & $-11,86$ & 14,50 \\
\hline 9 & 6,06 & 6,44 & 5,34 & 7,16 & 6,25 & $-3,04$ & 3,04 & $-14,56$ & 14,56 \\
\hline 10 & 5,84 & 6,31 & 5,34 & 6,66 & 6,04 & $-3,27$ & 4,51 & $-11,55$ & 10,31 \\
\hline 11 & 5,64 & 6,22 & 4,70 & 6,13 & 5,67 & $-0,57$ & 9,65 & $-17,14$ & 8,07 \\
\hline 12 & 3,92 & 4,45 & 4,19 & 4,56 & 4,28 & $-8,41$ & 3,97 & $-2,10$ & 6,54 \\
\hline 13 & 2,74 & 4,21 & 3,10 & 2,09 & 3,04 & $-9,72$ & 38,71 & 2,14 & $-31,14$ \\
\hline demais horas & 13,09 & 1,46 & 0,00 & 0,00 & 3,64 & & & & \\
\hline total & 100,00 & 100,00 & 100,00 & 100,00 & 100,00 & & & & \\
\hline
\end{tabular}

Na Figura 7.2 estão representados graficamente os valores dos fatores horários de entrada.

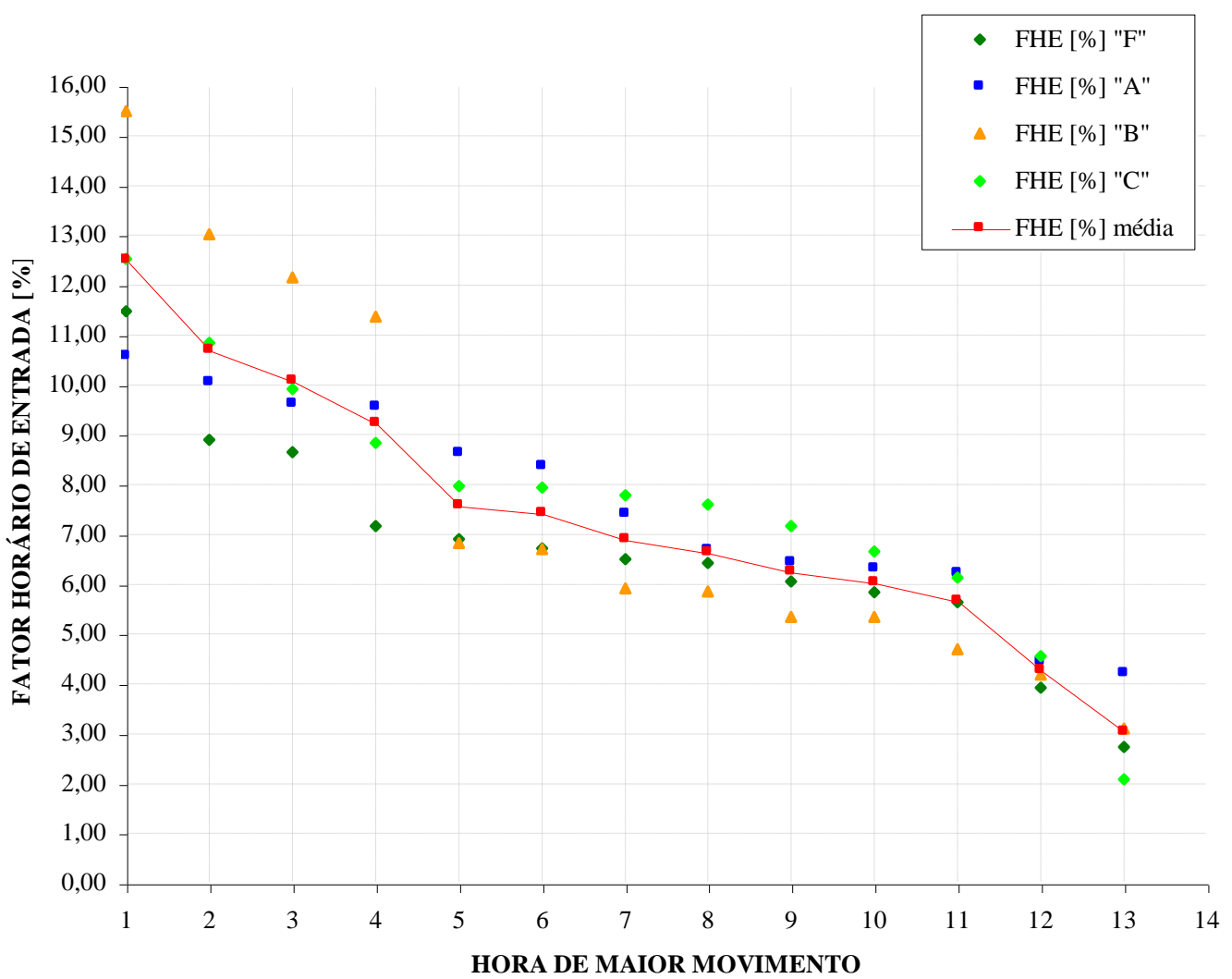

Figura 7.2 - Fatores horários de entrada. 
Com base na hipótese 3 estabelecida no item 7.1, pode-se escrever que o fator horário de entrada para a hora j do dia i vale:

$$
F H E_{j}^{i}=F H E_{j}^{s m} \times F D_{i}
$$

Sendo, $F H E_{j}^{i}$ : fator horário de entrada para a hora j do dia i [\%];

$F H E_{j}^{s m}$ : fator horário de entrada associado à hora $\mathrm{j}$ do sábado médio [\%];

$F D_{i}$ : fator diário de viagens associado ao dia i do ano.

Isso significa que:

$$
V H E_{j}^{i}=F H E_{j}^{i} \times V s m
$$

Sendo, $V H E_{j}^{i}$ : número de viagens na hora j do dia i do ano [veículos/hora];

$F H E_{j}^{i}$ : fator horário de entrada para a hora j do dia i;

Vsm: número de viagens no sábado médio [veículos/dia].

Na Tabela 7.3 e na Figura 7.3 estão indicados os valores de $F H E_{j}^{i}$.

Tabela 7.3 - Fatores de entrada $\left(F H E_{j}^{i}\right)$.

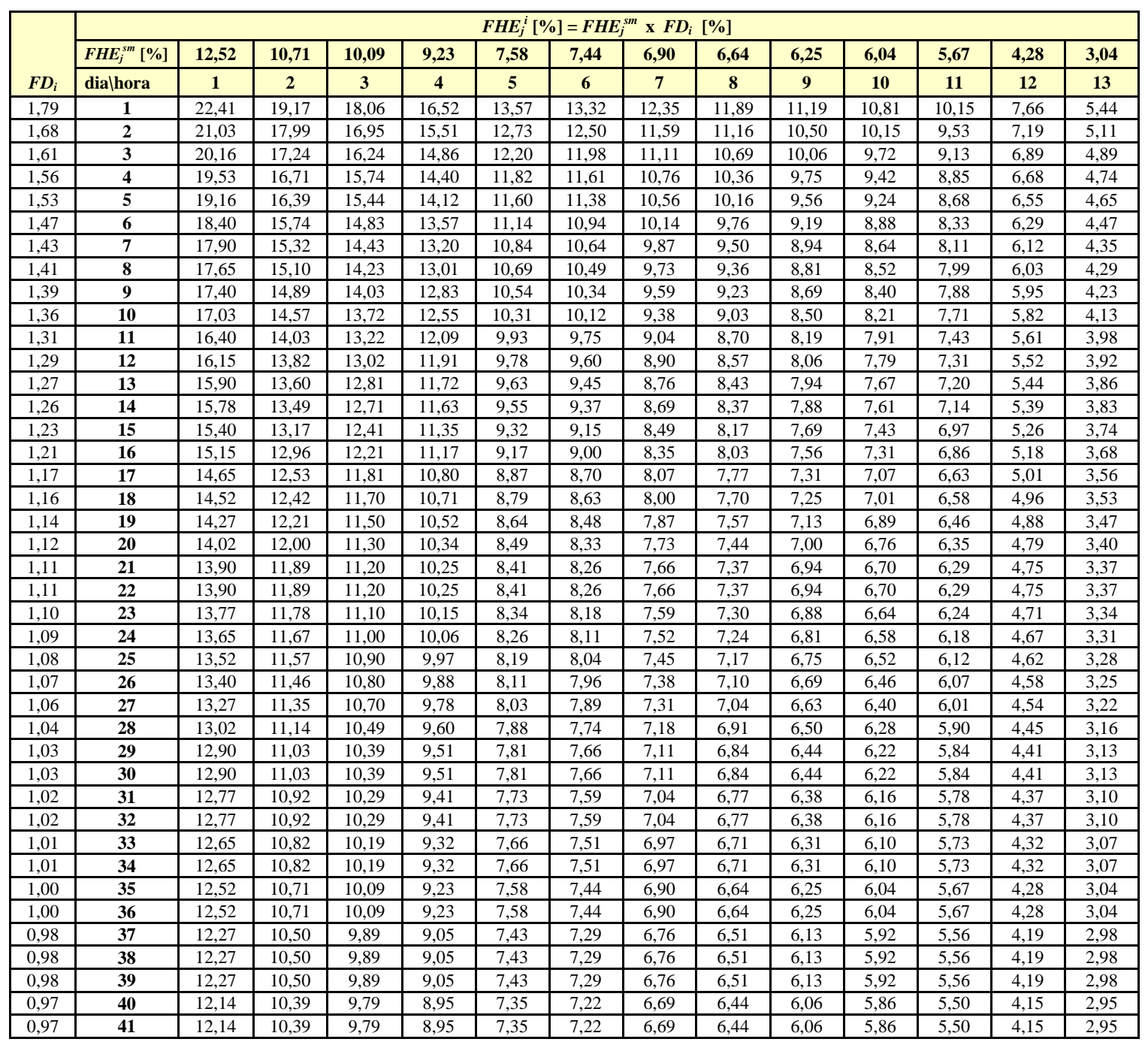




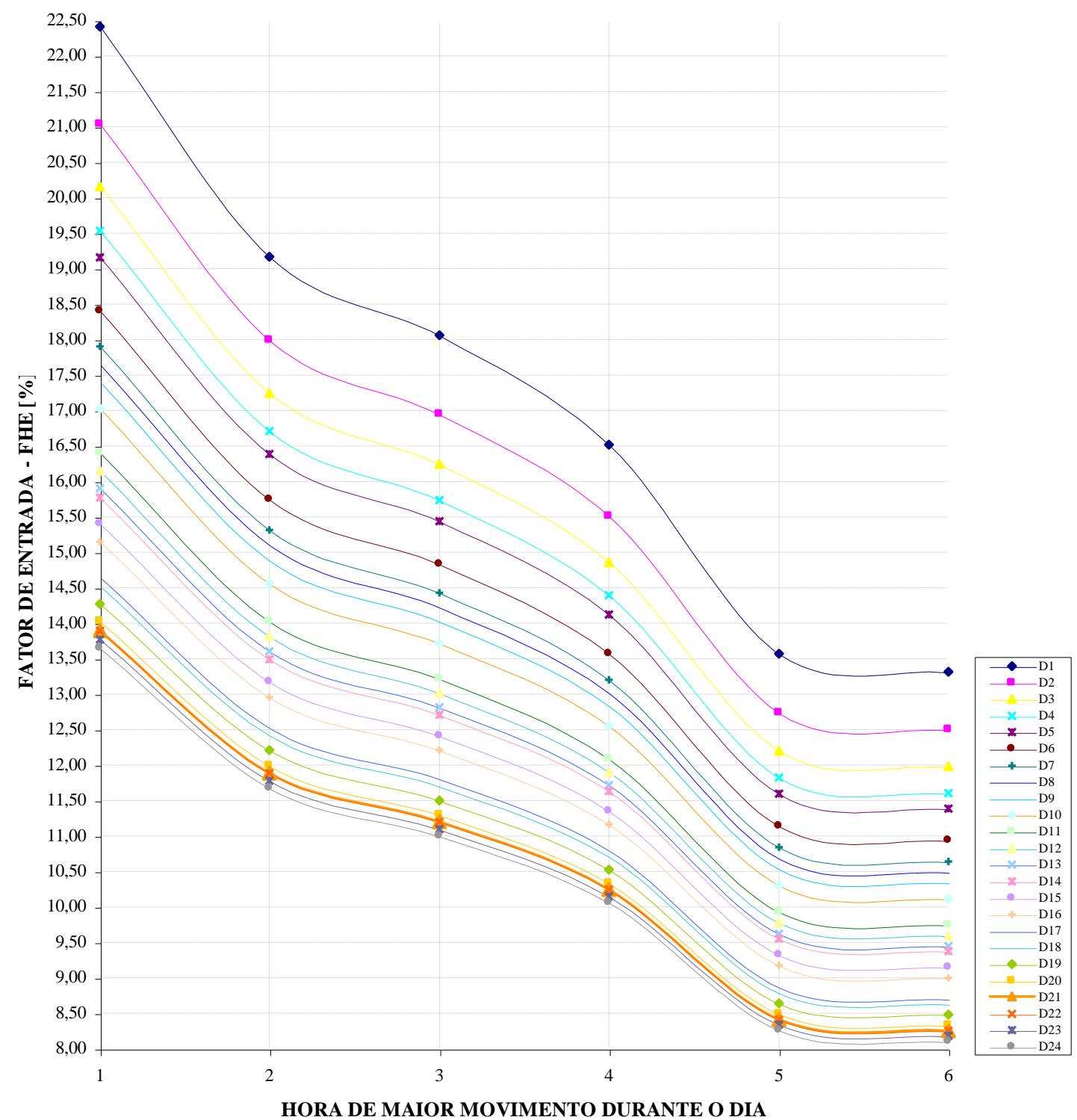

Figura 7.3 - Fatores de entrada.

Na Tabela 7.4 e na Figura 7.4 são mostrados os valores dos fatores de entrada $\left(F H E_{j}^{i}\right)$ associados às horas do ano de maior movimento - referidos a partir daqui simplesmente por FHE.

Tabela 7.4 - Relação dos fatores de entrada para as horas de maior movimento (FHE).

\begin{tabular}{|c|c|c|}
\hline Hora de maior movimento (j) & $\boldsymbol{F H E}[\boldsymbol{\%}]$ & Dia i em que ocorre a hora j \\
\hline 1 & 22,41 & 2 \\
\hline 2 & 21,03 & 3 \\
\hline 3 & 20,16 & 4 \\
\hline 4 & 19,53 & 1 \\
\hline 5 & 19,17 & 5 \\
\hline 7 & 19,16 & 6 \\
\hline 8 & 18,40 & 1 \\
\hline 9 & 18,06 & 2 \\
\hline 10 & 17,99 & 7 \\
\hline 11 & 17,90 & 8 \\
\hline 12 & 17,65 & 9 \\
\hline 13 & 17,40 & 3 \\
\hline 14 & 17,24 & 10 \\
\hline 15 & 17,03 & 2 \\
\hline
\end{tabular}


Tabela 7.4 - Relação dos fatores de entrada para as horas de maior movimento $(F H E)$.

\begin{tabular}{|c|c|c|}
\hline Hora de maior movimento $(j)$ & $F H E[\%]$ & Dia $\mathbf{i}$ em que ocorre a hora $\mathbf{j}$ \\
\hline 16 & 16,71 & 4 \\
\hline 17 & 16,52 & 1 \\
\hline 18 & 16,40 & 11 \\
\hline 19 & 16,39 & 5 \\
\hline 20 & 16,24 & 3 \\
\hline 21 & 16,15 & 12 \\
\hline 22 & 15,90 & 13 \\
\hline 23 & 15,78 & 14 \\
\hline 24 & 15,74 & 4 \\
\hline 25 & 15,74 & 6 \\
\hline 26 & 15,51 & 2 \\
\hline 27 & 15,44 & 5 \\
\hline 28 & 15,40 & 15 \\
\hline 29 & 15,32 & 7 \\
\hline 30 & 15,15 & 16 \\
\hline 31 & 15,10 & 8 \\
\hline 32 & 14,89 & 9 \\
\hline 33 & 14,86 & 3 \\
\hline 34 & 14,83 & 6 \\
\hline 35 & 14,65 & 17 \\
\hline 36 & 14,57 & 10 \\
\hline 37 & 14,52 & 18 \\
\hline 38 & 14,43 & 7 \\
\hline 39 & 14,40 & 4 \\
\hline 40 & 14,27 & 19 \\
\hline 41 & 14,23 & 8 \\
\hline 42 & 14,12 & 5 \\
\hline 43 & 14,03 & 9 \\
\hline 44 & 14,03 & 11 \\
\hline 45 & 14,02 & 20 \\
\hline 46 & 13,90 & 21 \\
\hline 47 & 13,90 & 22 \\
\hline 48 & 13,82 & 12 \\
\hline 49 & 13,77 & 23 \\
\hline 50 & 13,72 & 10 \\
\hline 51 & 13,65 & 24 \\
\hline 52 & 13,60 & 13 \\
\hline 53 & 13,57 & 1 \\
\hline 54 & 13,57 & 6 \\
\hline 55 & 13,52 & 25 \\
\hline 56 & 13,49 & 14 \\
\hline 57 & 13,40 & 26 \\
\hline 58 & 13,32 & 1 \\
\hline 59 & 13,27 & 27 \\
\hline 60 & 13,22 & 11 \\
\hline 61 & 13,20 & 7 \\
\hline 62 & 13,17 & 15 \\
\hline 63 & 13,02 & 12 \\
\hline 64 & 13,02 & 28 \\
\hline 65 & 13,01 & 8 \\
\hline 66 & 12,96 & 16 \\
\hline 67 & 12,90 & 29 \\
\hline 68 & 12,90 & 30 \\
\hline 69 & 12,83 & 9 \\
\hline 70 & 12,81 & 13 \\
\hline 71 & 12,77 & 31 \\
\hline 72 & 12,77 & 32 \\
\hline 73 & 12,73 & 2 \\
\hline 74 & 12,71 & 14 \\
\hline 75 & 12,65 & 33 \\
\hline 76 & 12,65 & 34 \\
\hline 77 & 12,55 & 10 \\
\hline 78 & 12,53 & 17 \\
\hline 79 & 12,52 & 35 \\
\hline 80 & 12,52 & 36 \\
\hline 81 & 12,50 & 2 \\
\hline 82 & 12,42 & 18 \\
\hline 83 & 12,41 & 15 \\
\hline 84 & 12,35 & 1 \\
\hline 85 & 12,27 & 37 \\
\hline 86 & 12,27 & 38 \\
\hline 87 & 12,27 & 39 \\
\hline 88 & 12,21 & 19 \\
\hline 89 & 12,21 & 16 \\
\hline 90 & 12,20 & 3 \\
\hline 91 & 12,14 & 40 \\
\hline
\end{tabular}




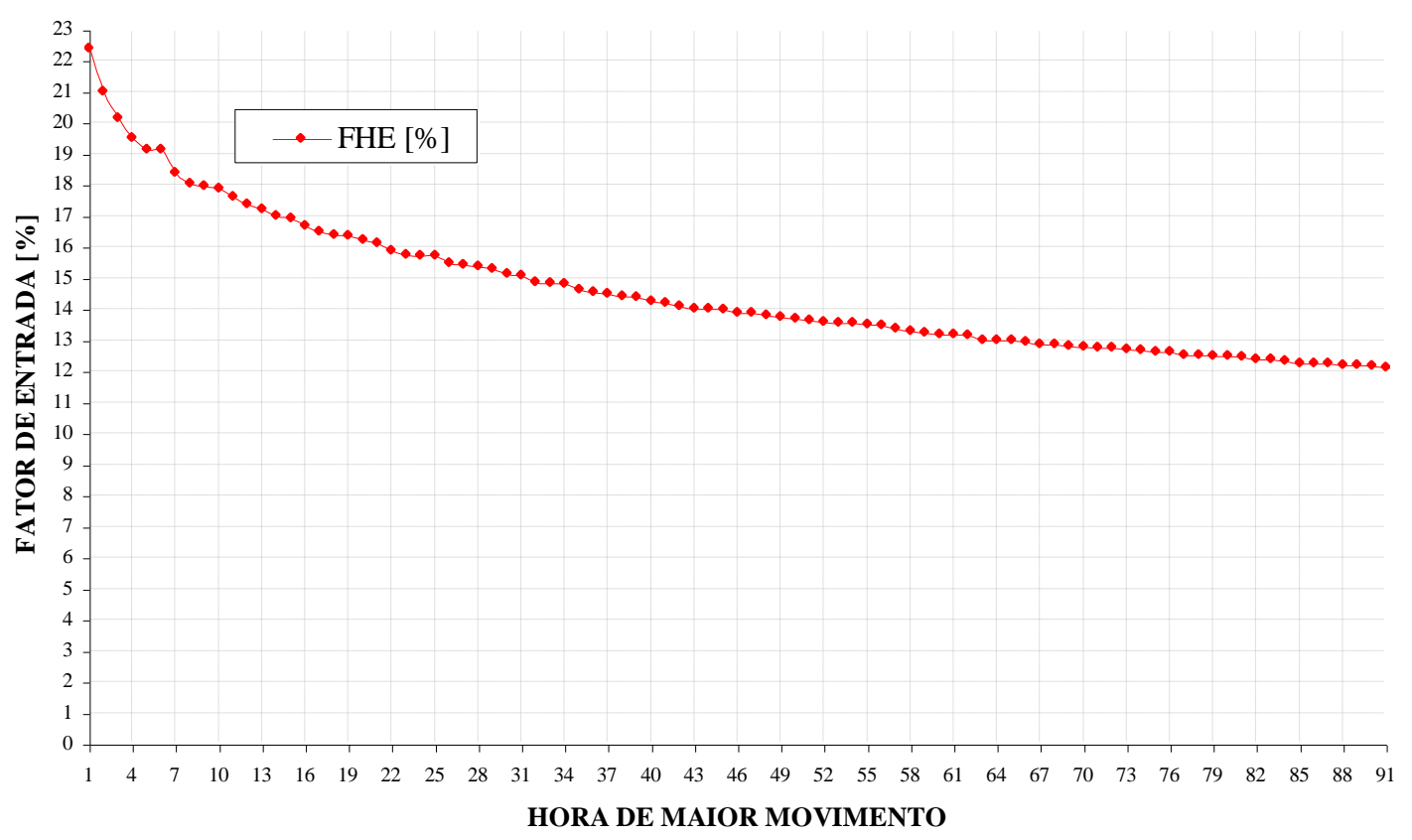

Figura 7.4 - Relação dos fatores de entrada para as horas do ano de maior movimento.

Na Tabela 7.5 estão indicados os valores dos fatores de entrada associados ao número de horas não atendidas.

Tabela 7.5 - Valores dos fatores de entrada x Número de horas não atendidas.

\begin{tabular}{|c|c|c|c|}
\hline Horas não atendidas & $\boldsymbol{F H E}[\boldsymbol{\%}]$ & Horas não atendidas [\%] & Horas atendidas [\%] \\
\hline 0 & 22,41 & 0,00 & 100,00 \\
\hline 5 & 19,16 & 0,10 & 99,90 \\
\hline 10 & 17,65 & 0,20 & 99,80 \\
\hline 15 & 16,71 & 0,29 & 99,71 \\
\hline 20 & 16,15 & 0,39 & 99,61 \\
\hline 25 & 15,51 & 0,49 & 99,51 \\
\hline 30 & 15,10 & 0,59 & 99,41 \\
\hline 35 & 14,57 & 0,68 & 99,32 \\
\hline 40 & 14,23 & 0,78 & 99,22 \\
\hline 45 & 13,90 & 0,88 & 99,12 \\
\hline 50 & 13,65 & 0,98 & 99,02 \\
\hline 55 & 13,49 & 1,08 & 98,92 \\
\hline 60 & 13,20 & 1,17 & 98,83 \\
\hline 65 & 12,96 & 1,27 & 98,73 \\
\hline 70 & 12,77 & 1,37 & 98,63 \\
\hline 75 & 12,65 & 1,47 & 98,53 \\
\hline 80 & 12,50 & 1,57 & 98,43 \\
\hline 85 & 12,27 & 1,66 & 98,34 \\
\hline 90 & 12,14 & 1,76 & 98,24 \\
\hline
\end{tabular}

Seguindo o padrão dos projetos de rodovias e vias urbanas, de adotar para o dimensionamento da infra-estrutura (instalações e equipamentos) um valor próximo ao joelho da curva de variação do fluxo (onde a taxa de variação do fluxo passa a ser menor), pode-se adotar como hora de projeto a $10^{\text {a }}$ hora, onde $F H E=17,90 \%$. Nesse caso, apenas nas 9 horas de 
maior movimento do ano a capacidade de atendimento das instalações e equipamentos de passagem e controle na entrada do shopping será superada. Na Tabela 7.4 podem ser identificados os dias do ano em que as 9 horas que superam a capacidade ocorrem, no caso: 3 horas ocorrem no $1^{\circ}$ dia de maior movimento, 2 horas no $2^{\circ}$ dia, 1 hora no $3^{\circ}, 1$ hora no $4^{\circ}$, 1 hora no $5^{\circ}$ e 1 hora no $6^{\circ}$ dia.

Assumindo como hora de projeto a $30^{\mathrm{a}}$ hora, como é comum no projeto de rodovias, resulta $F H E=15,15 \%$. Contudo, no caso de rodovias o dimensionamento é feito normalmente para o nível de serviço " $\mathrm{D}$ ”, muito aquém da capacidade da via. Isso significa que em grande parte das 29 horas de maior movimento, o fluxo não supera a capacidade, ocorrendo apenas uma deterioração do nível de serviço - congestionamento real apenas numas poucas horas. Não é o caso do dimensionamento das instalações e equipamentos de entrada dos shopping centers aqui utilizados - onde o limite considerado é a capacidade. Assim, para shopping centers não é indicado adotar a $30^{\mathrm{a}}$ hora como hora de projeto.

Outra forma de abordagem da questão é fixar uma porcentagem para o número de horas do ano não atendidas e determinar o valor de $F H E$ correspondente. Assumindo, por exemplo, que apenas em $1 \%$ das horas (aproximadamente 50 horas) a capacidade seria excedida (em 99\% das horas o fluxo de veículos estaria abaixo da capacidade), resulta $F H E=13,65 \%$. Assumindo que em apenas $0,5 \%$ das horas (aproximadamente 25 horas) a capacidade seria excedida, resulta $F H E=15,51 \%$.

VOORHEESS \& CROW (1966) propuseram a $10^{\mathrm{a}}$ hora mais movimentada como hora de projeto, que como visto coincide com o joelho da curva e leva a um valor de $F H E=17,90 \%$.

O URBAN LAND INSTITUTE (1982) propõe a $19^{\mathrm{a}}$ hora mais movimentada do ano como hora de projeto, resultando nesse caso um $F H E=16,39 \%$.

À luz das considerações feitas, e considerando que a existência de congestionamento na entrada é indesejável por prejudicar o trânsito na parte externa e desagradar os clientes do empreendimento e a comunidade, a princípio parece razoável adotar como hora de projeto a $10^{\mathrm{a}}$ hora mais movimentada. Neste caso, o valor de $F H E=17,90 \%$ representa 79,88\% do valor de FHEmáx $=22,41 \%$ (que corresponde ao valor em que o fluxo de veículos não supera a capacidade em nenhuma hora do ano). Isso significa, a princípio, uma redução física, e possivelmente do custo, de $20,12 \%$ das instalações e equipamentos na entrada do empreendimento. 
Na realidade, no planejamento e na análise da operação de vias urbanas e rodovias, é considerado o fluxo no período de pico (período de 15 minutos de maior movimento dentro da hora pico) e não o fluxo na hora pico.

O valor entre os fluxos na hora pico e no período de pico é referido como fator de hora pico (peak hour factor), ou seja:

$$
F H P=V H P / V P P
$$

Sendo, FHP: fator de hora pico;

$V H P$ : volume na hora pico [veículos/hora]; e

$V P P$ : volume no período de pico (15 minutos de maior movimento dentro da hora pico) [veículos/fração horária].

No caso do planejamento viário de shopping centers, considerando a relativamente alta incerteza na estimativa da quantidade e variação temporal das viagens e a elevada quantidade de veículos em circulação na área de estacionamento, não vale a pena retirar o cálculo a ponto de considerar o período de pico em vez da hora de pico.

\subsubsection{FATORES DE SAÍDA}

Na Tabela 7.6 encontram-se reproduzidos os valores da relação entre o número de viagens horárias e o número total de viagens no sábado, referentes às horas de maior movimento de saída, obtidos nas pesquisas realizadas nos shoppings centers. São também apresentados os valores médios dessas relações correspondentes a cada hora - denominados de fatores horários de saída e definidos como:

$$
F H S_{j}^{s m}=\left(V H S_{j} / V s m\right) \times 100
$$

Sendo, $F H S_{j}^{s m}$ : fator horário de saída associado à hora j do sábado médio [\%];

$V H S_{j}$ : número de viagens de saída na hora j do sábado médio [veículos/hora]; e

Vsm: número de viagens no sábado médio [veículos/dia].

São indicados ainda na Tabela 7.6, os desvios dos valores reais em relação ao valor médio. 
Tabela 7.6 - Fatores horários de saída $\left(F H S_{j}^{s m}\right)$.

\begin{tabular}{|c|c|c|c|c|c|c|c|}
\hline \multirow{2}{*}{$\begin{array}{c}\text { Maior } \\
\text { hora (j) }\end{array}$} & \multicolumn{4}{|c|}{$F H S_{j}^{s m}[\%]=\left(V H S_{j} / V s m\right) \times 100$} & \multicolumn{3}{|c|}{ Desvio [\%] } \\
\hline & "A" & "B" & "C" & média & "A" & "B" & "C" \\
\hline 1 & 9,39 & 13,83 & 9,49 & 10,90 & $-13,88$ & 26,84 & $-12,96$ \\
\hline 2 & 9,23 & 9,29 & 8,61 & 9,04 & 2,06 & 2,73 & $-4,79$ \\
\hline 3 & 9,20 & 7,80 & 8,42 & 8,47 & 8,58 & $-7,95$ & $-0,63$ \\
\hline 4 & 8,89 & 7,80 & 8,05 & 8,25 & 7,80 & $-5,42$ & $-2,38$ \\
\hline 5 & 8,61 & 7,69 & 7,65 & 7,98 & 7,85 & $-3,67$ & $-4,18$ \\
\hline 6 & 8,22 & 7,52 & 7,62 & 7,79 & 5,57 & $-3,42$ & $-2,14$ \\
\hline 7 & 7,57 & 6,60 & 7,49 & 7,22 & 4,85 & $-8,59$ & 3,74 \\
\hline 8 & 7,57 & 4,93 & 7,43 & 6,64 & 13,95 & $-25,79$ & 11,84 \\
\hline 9 & 6,70 & 4,65 & 5,68 & 5,68 & 18,03 & $-18,09$ & 0,06 \\
\hline 10 & 6,44 & 4,42 & 5,25 & 5,37 & 19,93 & $-17,69$ & $-2,23$ \\
\hline 11 & 6,06 & 3,44 & 4,08 & 4,53 & 33,87 & $-24,01$ & $-9,87$ \\
\hline 12 & 4,37 & 3,16 & 2,18 & 3,24 & 35,02 & $-2,37$ & $-32,65$ \\
\hline 13 & 1,91 & 0,86 & 0,69 & 1,15 & 65,61 & $-25,43$ & $-40,17$ \\
\hline demais horas & 5,84 & 18,01 & 17,36 & 13,74 & & & \\
\hline total & 100,00 & 100,00 & 100,00 & 100,00 & & & \\
\hline
\end{tabular}

Na Figura 7.5 estão representados graficamente os valores dos fatores horários de saída.

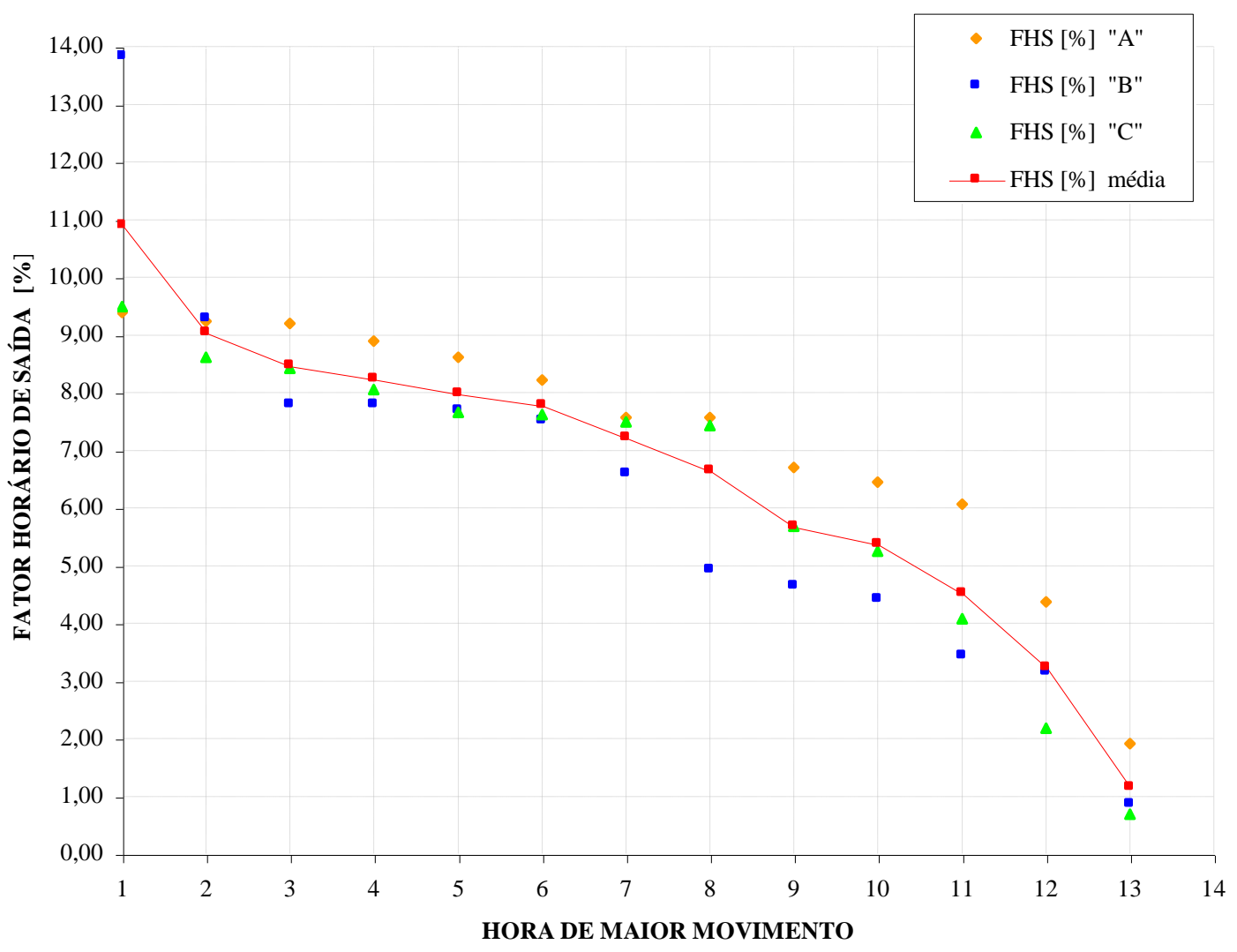

Figura 7.5 - Fatores horários de saída. 
Com base na hipótese 3 estabelecida no item 7.1, pode-se escrever que o fator horário de saída para a hora j do dia i vale:

$$
F H S_{j}^{i}=F H S_{j}^{s m} \times F D_{i}
$$

Sendo, $F H S_{j}{ }^{i}$ : fator horário de saída para a hora j do dia i [\%];

$F H S_{j}^{s m}$ : fator horário de saída associado à hora j do sábado médio [\%];

$F D_{i}$ : fator diário de viagens associado ao dia i do ano.

Isso significa que:

$$
V H S_{j}^{i}=F H S_{j}^{i} x V s m
$$

Sendo, $V H S_{j}^{i}$ : número de viagens na hora j do dia i do ano [veículos/hora];

$F H S_{j}^{i}$ : fator horário de saída para a hora j do dia i;

Vsm: número de viagens no sábado médio [veículos/dia].

Na Tabela 7.7 e na Figura 7.6 estão indicados os valores de $F H S_{j}^{i}$.

Tabela 7.7 - Fatores de saída $\left(F H S_{j}^{i}\right)$.

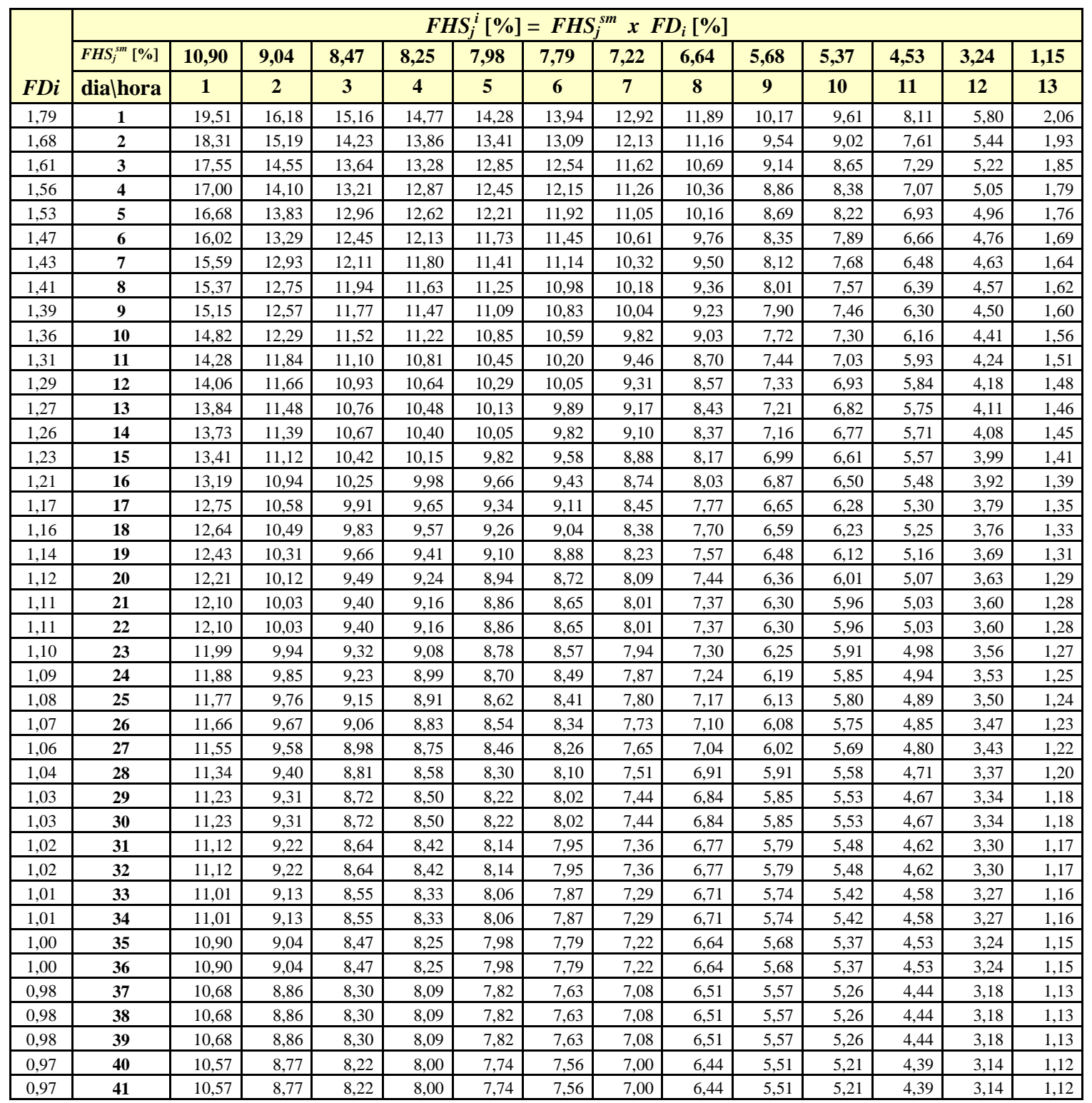




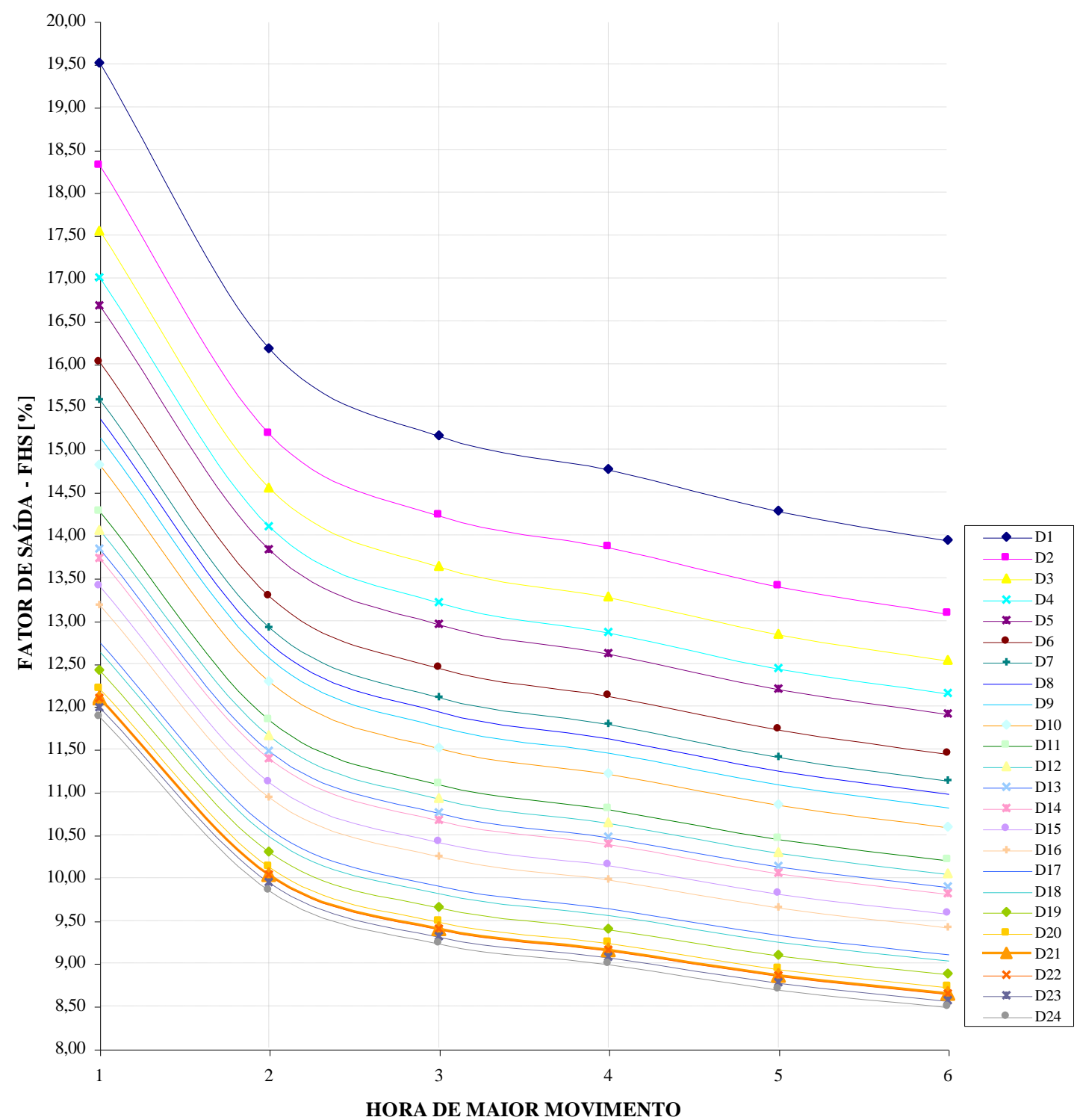

Figura 7.6 - Fatores de saída.

Na Tabela 7.8 e na Figura 7.7 são mostrados os valores dos fatores de saída $\left(F H S_{j}^{i}\right)$ associados às horas do ano mais movimentadas - referidas a partir daqui simplesmente por $F H S$.

Tabela 7.8 - Relação dos fatores de saída para as horas de maior movimento $(F H S)$.

\begin{tabular}{|c|c|c|}
\hline Hora de maior movimento $(\mathbf{j})$ & $\boldsymbol{F H} \boldsymbol{S}[\boldsymbol{\%}]$ & Dia i em que ocorre a hora \\
\hline 1 & 19,51 & 2 \\
\hline 2 & 18,31 & 3 \\
\hline 3 & 17,55 & 4 \\
\hline 4 & 17,00 & 5 \\
\hline 5 & 16,68 & 1 \\
\hline 6 & 16,18 & 6 \\
\hline 7 & 16,02 & 7 \\
\hline 8 & 15,59 & 2 \\
\hline 9 & 15,37 & 1 \\
\hline 10 & 15,19 & 9 \\
\hline 11 & 15,16 & 10 \\
\hline 12 & 15,15 & 1 \\
\hline 14 & 14,82 & 3 \\
\hline 15 & 14,77 & 2 \\
\hline
\end{tabular}


Tabela 7.8 - Relação dos fatores de saída para as horas de maior movimento (FHS).

\begin{tabular}{|c|c|c|}
\hline Hora de maior movimento $(\mathbf{j})$ & FHS [\%] & Dia i em que ocorre a hora \\
\hline 16 & 14,28 & 1 \\
\hline 17 & 14,28 & 11 \\
\hline 18 & 14,23 & 2 \\
\hline 19 & 14,10 & 4 \\
\hline 20 & 14,06 & 12 \\
\hline 21 & 13,94 & 1 \\
\hline 22 & 13,86 & 2 \\
\hline 23 & 13,84 & 13 \\
\hline 24 & 13,83 & 5 \\
\hline 25 & 13,73 & 14 \\
\hline 26 & 13,64 & 3 \\
\hline 27 & 13,41 & 2 \\
\hline 28 & 13,41 & 15 \\
\hline 29 & 13,29 & 6 \\
\hline 30 & 13,28 & 3 \\
\hline 31 & 13,21 & 4 \\
\hline 32 & 13,19 & 16 \\
\hline 33 & 13,09 & 2 \\
\hline 34 & 12,96 & 5 \\
\hline 35 & 12,93 & 7 \\
\hline 36 & 12,92 & 1 \\
\hline 37 & 12,87 & 4 \\
\hline 38 & 12,85 & 3 \\
\hline 39 & 12,75 & 8 \\
\hline 40 & 12,75 & 17 \\
\hline 41 & 12,64 & 18 \\
\hline 42 & 12,62 & 5 \\
\hline 43 & 12,57 & 9 \\
\hline 44 & 12,54 & 3 \\
\hline 45 & 12,45 & 4 \\
\hline 46 & 12,45 & 6 \\
\hline 47 & 12,43 & 19 \\
\hline 48 & 12,29 & 10 \\
\hline 49 & 12,21 & 5 \\
\hline 50 & 12,21 & 20 \\
\hline 51 & 12,15 & 4 \\
\hline 52 & 12,13 & 2 \\
\hline 53 & 12,13 & 6 \\
\hline 54 & 12,11 & 7 \\
\hline 55 & 12,10 & 21 \\
\hline 56 & 12,10 & 22 \\
\hline 57 & 11,99 & 23 \\
\hline 58 & 11,94 & 8 \\
\hline 59 & 11,92 & 5 \\
\hline 60 & 11,89 & 1 \\
\hline 61 & 11,88 & 24 \\
\hline 62 & 11,84 & 11 \\
\hline 63 & 11,80 & 7 \\
\hline 64 & 11,77 & 9 \\
\hline 65 & 11,77 & 25 \\
\hline 66 & 11,73 & 6 \\
\hline 67 & 11,66 & 12 \\
\hline 68 & 11,66 & 26 \\
\hline 69 & 11,63 & 8 \\
\hline 70 & 11,62 & 3 \\
\hline 71 & 11,55 & 27 \\
\hline 72 & 11,52 & 10 \\
\hline 73 & 11,48 & 13 \\
\hline 74 & 11,47 & 9 \\
\hline 75 & 11,45 & 6 \\
\hline 76 & 11,41 & 7 \\
\hline 77 & 11,39 & 14 \\
\hline 78 & 11,34 & 28 \\
\hline 79 & 11,26 & 4 \\
\hline 80 & 11,25 & 8 \\
\hline 81 & 11,23 & 29 \\
\hline 82 & 11,23 & 30 \\
\hline 83 & 11,22 & 10 \\
\hline 84 & 11,16 & 2 \\
\hline 85 & 11,14 & 7 \\
\hline 86 & 11,12 & 15 \\
\hline 87 & 11,12 & 31 \\
\hline 88 & 11,12 & 32 \\
\hline 89 & 11,10 & 11 \\
\hline 90 & 11,09 & 9 \\
\hline 91 & 11,05 & 5 \\
\hline
\end{tabular}




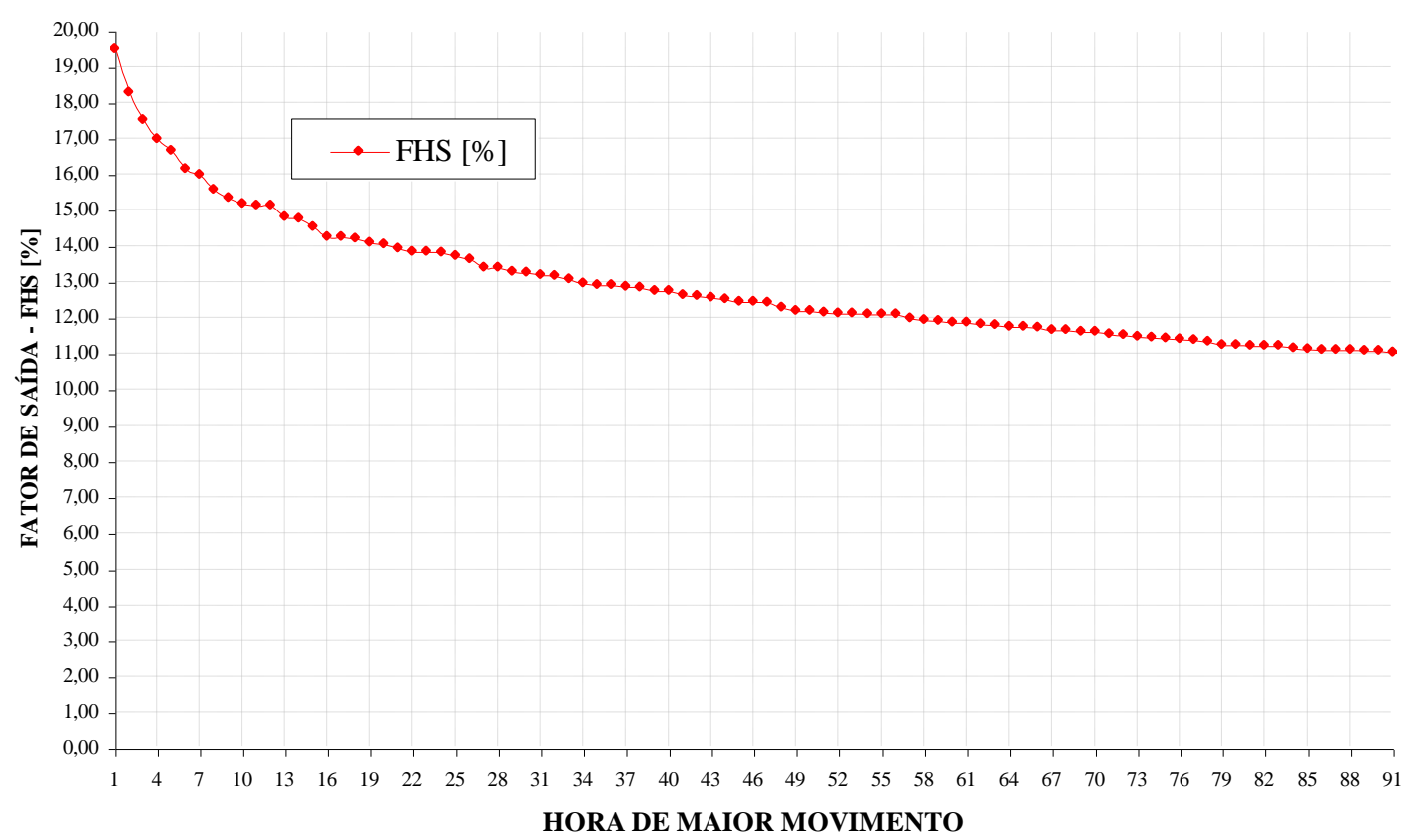

Figura 7.7 - Relação dos fatores de saída para as horas do ano de maior movimento.

Na Tabela 7.9 estão indicados os valores dos fatores de saída associados ao número de horas não atendidas.

Tabela 7.9 - Valores dos fatores de saída x Número de horas não atendidas.

\begin{tabular}{|c|c|c|c|}
\hline Horas não atendidas & $\boldsymbol{F H S}$ [\%] & Horas não atendidas [\%] & Horas atendidas [\%] \\
\hline 0 & 19,51 & 0,00 & 100,00 \\
\hline 5 & 16,18 & 0,10 & 99,90 \\
\hline 10 & 15,16 & 0,20 & 99,80 \\
\hline 15 & 14,28 & 0,29 & 99,71 \\
\hline 20 & 13,94 & 0,39 & 99,61 \\
\hline 25 & 13,64 & 0,49 & 99,51 \\
\hline 30 & 13,21 & 0,59 & 99,41 \\
\hline 35 & 12,92 & 0,68 & 99,32 \\
\hline 40 & 12,64 & 0,78 & 99,22 \\
\hline 45 & 12,45 & 0,88 & 99,12 \\
\hline 50 & 12,15 & 0,98 & 99,02 \\
\hline 55 & 12,10 & 1,08 & 98,92 \\
\hline 60 & 11,88 & 1,17 & 98,83 \\
\hline 65 & 11,73 & 1,27 & 98,73 \\
\hline 70 & 11,55 & 1,37 & 98,63 \\
\hline 75 & 11,41 & 1,47 & 98,53 \\
\hline 80 & 11,23 & 1,57 & 98,43 \\
\hline 85 & 11,12 & 1,66 & 98,34 \\
\hline 90 & 11,05 & 1,76 & 98,24 \\
\hline
\end{tabular}

Seguindo o padrão dos projetos de rodovias e vias urbanas, de adotar para o dimensionamento da infra-estrutura (instalações e equipamentos) um valor próximo ao joelho da curva de variação do fluxo (onde a taxa de variação do fluxo passa a ser menor), pode-se adotar como hora de projeto a $10^{\mathrm{a}}$ hora, onde $F H S=15,19 \%$. Nesse caso, apenas nas 9 horas de 
maior movimento do ano a capacidade de atendimento das instalações e equipamentos de passagem e controle na saída do shopping será superada. Na Tabela 7.8 podem ser identificados os dias em que as 9 horas que superam a capacidade ocorrem, no caso: 2 horas ocorrem no $1^{\circ}$ dia de maior movimento, 1 hora no $2^{\circ}$ dia, 1 hora no $3^{\circ}, 1$ hora no $4^{\circ}, 1$ hora no $5^{\circ}, 1$ hora no $6^{\circ}$, 1 hora no $7^{\circ}$ e 1 hora no $8^{\circ}$ dia.

Assumindo como hora de projeto a $30^{\mathrm{a}}$ hora, como é comum no projeto de rodovias, resulta $F H S=13,28 \%$. Contudo, no caso de rodovias o dimensionamento é feito normalmente para o nível de serviço " $\mathrm{D}$ ”, muito aquém da capacidade da via. Isso significa que em grande parte das 29 horas, o fluxo não supera a capacidade, ocorrendo apenas uma deterioração do nível de serviço - congestionamento real apenas numas poucas horas. Não é o caso do dimensionamento das instalações e equipamentos de saída dos shopping centers aqui utilizados - onde o limite considerado é a capacidade. Assim, para shopping centers não é indicado adotar a $30^{\mathrm{a}}$ hora como hora de projeto.

Outra forma de abordagem da questão é fixar uma porcentagem para o número de horas não atendidas e determinar o valor de $F H S$ correspondente. Assumindo, por exemplo, que apenas em $1 \%$ das horas (aproximadamente 50 horas) a capacidade seria excedida (em 99\% das horas o fluxo de veículos estaria abaixo da capacidade), resulta $F H S=12,15 \%$. Assumindo que em apenas $0,5 \%$ das horas (aproximadamente 25 horas) a capacidade seria excedida, resulta $F H S=13,64 \%$.

VOORHEESS \& CROW (1966) propuseram a $10^{\mathrm{a}}$ hora mais movimentada do ano como hora de projeto, que como visto coincide com o joelho da curva e leva a um valor de $F H S=15,19 \%$

O URBAN LAND INSTITUTE (1982) propõe a $19^{\mathrm{a}}$ hora mais movimentada do ano como hora de projeto, resultando nesse caso um $F H S=14,10 \%$.

Em função das considerações feitas, e considerando que a existência de congestionamento na saída do shopping prejudica o trânsito interno e desagrada os clientes do empreendimento, a princípio parece razoável adotar como hora de projeto a $10^{\mathrm{a}}$ hora mais movimentada. Neste caso, o valor de $F H S=15,19 \%$ equivale a 77,86\% do valor de FHSmáx $=19,51 \%$ (que corresponde ao valor em que o fluxo de veículos não supera a capacidade em nenhuma hora do ano). Isso significa, a princípio, uma redução física, e possivelmente do custo, de $22,14 \%$ das instalações e equipamentos na saída do empreendimento. 


\subsubsection{FATORES DO TOTAL DE ENTRADA E SAÍDA}

Na Tabela 7.10 encontram-se reproduzidos os valores da relação entre o número de viagens horárias e o número total de viagens no sábado, referentes às horas de maior movimento do total de entrada e saída, obtidos nas pesquisas realizadas nos shoppings centers. São também apresentados os valores médios dessas relações correspondentes a cada hora denominados de fatores horários do total de entrada e saída e definidos como:

$$
F H T_{j}^{s m}=(V H T j / V s m) \times 100
$$

Sendo, $F H T_{j}^{s m}$ : fator horário do total de entrada e saída associado à hora j do sábado médio [\%];

VHTj: número de viagens de entrada mais saída na hora j do sábado médio

[veículos/hora];

Vsm: número de viagens no sábado médio [veículos/dia].

São indicados ainda na Tabela 7.10, os desvios dos valores reais em relação ao valor médio.

Tabela 7.10 - Fatores horários do total de entrada e saída $\left(F H T_{j}^{s m}\right)$.

\begin{tabular}{|c|c|c|c|c|c|c|c|}
\hline \multirow{2}{*}{$\begin{array}{c}\text { Maior hora } \\
\text { (j) }\end{array}$} & \multicolumn{4}{|c|}{$F H T_{j}^{s m}[\%]=(V H T j / V s m) \times 100$} & \multicolumn{3}{|c|}{ Desvio [\%] } \\
\hline & “A" & "B" & “C" & média & "A" & "B" & "C" \\
\hline 1 & 19,47 & 29,32 & 21,13 & 23,31 & $-16,46$ & 25,80 & $-9,34$ \\
\hline 2 & 19,29 & 22,32 & 20,33 & 20,65 & $-6,57$ & 8,10 & $-1,53$ \\
\hline 3 & 18,24 & 19,16 & 17,56 & 18,32 & $-0,44$ & 4,59 & $-4,15$ \\
\hline 4 & 17,57 & 18,76 & 16,46 & 17,60 & $-0,15$ & 6,61 & $-6,46$ \\
\hline 5 & 17,13 & 14,63 & 15,58 & 15,78 & 8,56 & $-7,29$ & $-1,27$ \\
\hline 6 & 16,85 & 13,54 & 15,37 & 15,25 & 10,47 & $-11,23$ & 0,76 \\
\hline 7 & 14,98 & 13,43 & 15,27 & 14,56 & 2,88 & $-7,76$ & 4,88 \\
\hline 8 & 13,85 & 11,65 & 14,71 & 13,40 & 3,33 & $-13,08$ & 9,75 \\
\hline 9 & 13,38 & 9,98 & 13,65 & 12,34 & 8,46 & $-19,10$ & 10,65 \\
\hline 10 & 12,66 & 9,75 & 12,85 & 11,75 & 7,71 & $-17,04$ & 9,33 \\
\hline 11 & 12,50 & 8,15 & 10,21 & 10,29 & 21,52 & $-20,77$ & $-0,75$ \\
\hline 12 & 10,68 & 7,34 & 6,74 & 8,25 & 29,40 & $-11,07$ & $-18,34$ \\
\hline 13 & 6,11 & 3,96 & 2,79 & 4,29 & 42,53 & $-7,62$ & $-34,91$ \\
\hline demais horas & 7,29 & 18,01 & 17,35 & 14,22 & & & \\
\hline total & 200,00 & 200,00 & 200,00 & 200,00 & & & \\
\hline
\end{tabular}

Na Figura 7.8 estão representados graficamente os valores dos fatores horários do total de entrada e saída. 


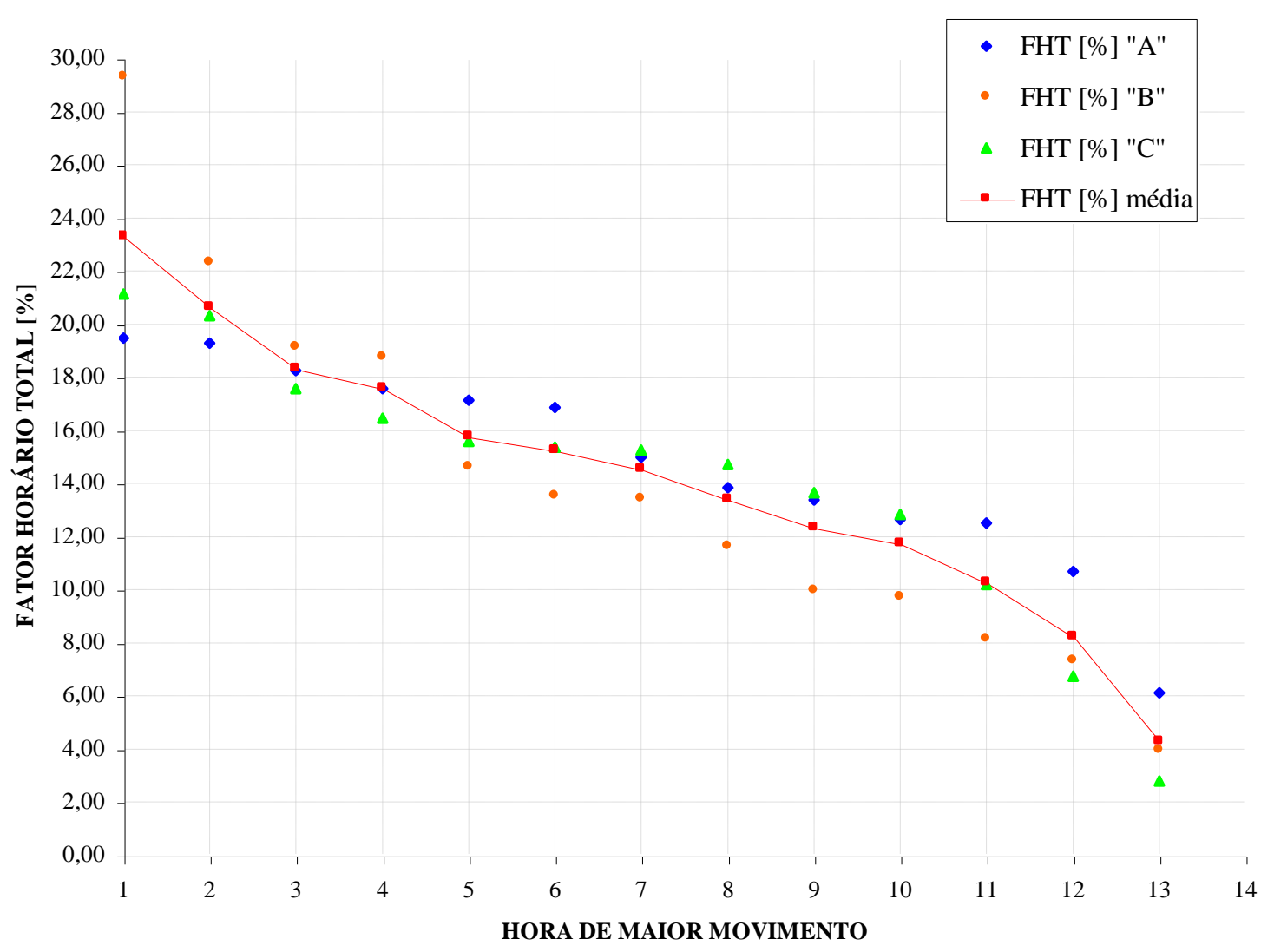

Figura 7.8 - Fatores horários do total de entrada e saída.

Com base na hipótese 3 estabelecida no item 7.1, pode-se escrever que o fator horário total de entrada mais saída para a hora j do dia i vale:

$$
F H T_{j}^{i}=F H T_{j}^{s m} \times F D_{i}
$$

Sendo, $F H T_{j}^{i}$ : fator horário do total de entrada mais saída para a hora j do dia i [\%];

$F H T_{j}^{s m}$ : fator horário do total de entrada e saída associado à hora j do sábado médio [\%];

$F D_{i}$ : fator diário de viagens associado ao dia i do ano.

Isso significa que:

$$
V H T_{j}^{i}=F H T_{j}^{i} x V s m
$$

Sendo, $V H T_{j}^{i}$ : número de viagens na hora j do dia i do ano [veículos/hora];

$F H T_{j}^{i}$ : fator horário do total de entrada e saída para a hora j do dia i; Vsm: número de viagens no sábado médio [veículos/dia].

Na Tabela 7.11 e na Figura 7.9 estão indicados os valores de $F H T_{j}^{i}$. 
Tabela 7.11 - Fatores do total de entrada e saída $\left(F H T_{j}^{i}\right)$.

\begin{tabular}{|c|c|c|c|c|c|c|c|c|c|c|c|c|c|c|}
\hline \multirow[b]{3}{*}{$F D i$} & \multicolumn{14}{|c|}{$\mathrm{FHT}_{j}^{i}[\%]=\mathrm{FHT}_{j}^{s m} \times \mathrm{FD}_{i}[\%]$} \\
\hline & $F H T_{j}^{s m}[\%]$ & 23,31 & 20,65 & 18,32 & 17,60 & 15,78 & 15,25 & 14,56 & 13,40 & 12,34 & 11,75 & 10,29 & 8,25 & 4,29 \\
\hline & dialhora & 1 & 2 & 3 & 4 & 5 & 6 & 7 & 8 & 9 & 10 & 11 & 12 & 13 \\
\hline 1,79 & 1 & 41,72 & 36,96 & 32,79 & 31,50 & 28,25 & 27,30 & 26,06 & 23,99 & 22,09 & 21,03 & 18,42 & 14,77 & 7,68 \\
\hline 1,68 & 2 & 39,16 & 34,69 & 30,78 & 29,57 & 26,51 & 25,62 & 24,46 & 22,51 & 20,73 & 19,74 & 17,29 & 13,86 & 7,21 \\
\hline 1,61 & 3 & 37,53 & 33,25 & 29,50 & 28,34 & 25,41 & 24,55 & 23,44 & 21,57 & 19,87 & 18,92 & 16,57 & 13,28 & 6,91 \\
\hline 1,56 & 4 & 36,36 & 32,21 & 28,58 & 27,46 & 24,62 & 23,79 & 22,71 & 20,90 & 19,25 & 18,33 & 16,05 & 12,87 & 6,69 \\
\hline 1,53 & 5 & 35,66 & 31,59 & 28,03 & 26,93 & 24,14 & 23,33 & 22,28 & 20,50 & 18,88 & 17,98 & 15,74 & 12,62 & 6,56 \\
\hline 1,47 & 6 & 34,27 & 30,36 & 26,93 & 25,87 & 23,20 & 22,42 & 21,40 & 19,70 & 18,14 & 17,27 & 15,13 & 12,13 & 6,31 \\
\hline 1,43 & 7 & 33,33 & 29,53 & 26,20 & 25,17 & 22,57 & 21,81 & 20,82 & 19,16 & 17,65 & 16,80 & 14,71 & 11,80 & 6,13 \\
\hline 1,41 & 8 & 32,87 & 29,12 & 25,83 & 24,82 & 22,25 & 21,50 & 20,53 & 18,89 & 17,40 & 16,57 & 14,51 & 11,63 & 6,05 \\
\hline 1,39 & 9 & 32,40 & 28,70 & 25,46 & 24,46 & 21,93 & 21,20 & 20,24 & 18,63 & 17,15 & 16,33 & 14,30 & 11,47 & 5,96 \\
\hline 1,36 & 10 & 31,70 & 28,08 & 24,92 & 23,94 & 21,46 & 20,74 & 19,80 & 18,22 & 16,78 & 15,98 & 13,99 & 11,22 & 5,83 \\
\hline 1,31 & 11 & 30,54 & 27,05 & 24,00 & 23,06 & 20,67 & 19,98 & 19,07 & 17,55 & 16,17 & 15,39 & 13,48 & 10,81 & 5,62 \\
\hline 1,29 & 12 & 30,07 & 26,64 & 23,63 & 22,70 & 20,36 & 19,67 & 18,78 & 17,29 & 15,92 & 15,16 & 13,27 & 10,64 & 5,53 \\
\hline 1,27 & 13 & 29,60 & 26,23 & 23,27 & 22,35 & 20,04 & 19,37 & 18,49 & 17,02 & 15,67 & 14,92 & 13,07 & 10,48 & 5,45 \\
\hline 1,26 & 14 & 29,37 & 26,02 & 23,08 & 22,18 & 19,88 & 19,22 & 18,35 & 16,88 & 15,55 & 14,81 & 12,97 & 10,40 & 5,41 \\
\hline 1,23 & 15 & 28,67 & 25,40 & 22,53 & 21,65 & 19,41 & 18,76 & 17,91 & 16,48 & 15,18 & 14,45 & 12,66 & 10,15 & 5,28 \\
\hline 1,21 & 16 & 28 & 24,99 & 22,17 & 21,30 & 19,09 & 18,45 & 17,62 & 16,21 & 14,93 & 14,22 & 12,45 & 9,98 & 5,19 \\
\hline 1,17 & 17 & 27,27 & 24,16 & 21,43 & 20,59 & 18,46 & 17,84 & 17,04 & 15,68 & 14,44 & 13,75 & 12,04 & 9,65 & 5,02 \\
\hline 1,16 & 18 & 27,04 & 23,95 & 21,25 & 20,42 & 18,30 & 17,69 & 16,89 & 15,54 & 14,31 & 13,63 & 11,94 & 9,57 & 4,98 \\
\hline 1,14 & 19 & 26,57 & 23,54 & 20,88 & 20,06 & 17,99 & 17,39 & 16,60 & 15,28 & 14,07 & 13,40 & 11,73 & 9,41 & 4,89 \\
\hline 1,12 & 20 & 26,11 & 23,13 & 20,52 & 19,71 & 17,67 & 17,08 & 16,31 & 15,01 & 13,82 & 13,16 & 11,52 & 9,24 & 4,80 \\
\hline 1,1 & 21 & 2 & 92 & 2 & 19,54 & 17,52 & 16,93 & 16,16 & 4,87 & 3,70 & 3,04 & 11,42 & 9,16 & 4,76 \\
\hline 1,11 & 22 & 25,87 & 22,92 & 20,34 & 19,54 & 17,52 & 16,93 & 16,16 & 14,87 & 13,70 & 13,04 & 11,42 & 9,16 & 4,76 \\
\hline 1,10 & 23 & 25,64 & 22,72 & 20,15 & 19,36 & 17,36 & 16,78 & 16,02 & 14,74 & 13,57 & 12,93 & 11,32 & 9,08 & 4,72 \\
\hline 1,09 & 24 & 25,41 & 22,51 & 19,97 & 19,18 & 17,20 & 16,62 & 15,87 & 14,61 & 13,45 & 12,81 & 11,22 & 8,99 & 4,68 \\
\hline 1,08 & 25 & 25,17 & 22,30 & 19,79 & 19,01 & 17,04 & 16,47 & 15,72 & 14,47 & 13,33 & 12,69 & 11,11 & 8,91 & 4,63 \\
\hline 1,07 & 20 & 24,94 & 22,10 & 19,60 & 18,83 & 16,88 & 16,32 & 15,58 & 14,34 & 13,20 & 12,57 & 11,01 & 8,83 & 4,59 \\
\hline 1,06 & 27 & 24,71 & 21,89 & 19,42 & 18,66 & 16,73 & 16,17 & 15,43 & 14,20 & 13,08 & 12,46 & 10,91 & 8,75 & 4,55 \\
\hline 1,04 & 28 & 24,24 & 21,48 & 19,05 & 18,30 & 16,41 & 15,86 & 15,14 & 13,94 & 12,83 & 12,22 & 10,70 & 8,58 & 4,46 \\
\hline 1,03 & 29 & 24,01 & 21,27 & 18,87 & 18,13 & 16,25 & 15,71 & 15,00 & 13,80 & 12,71 & 12,10 & 10,60 & 8,50 & 4,42 \\
\hline 1,03 & 30 & 24,01 & 21,27 & 18,87 & 18,13 & 16,25 & 15,71 & 15,00 & 13,80 & 12,71 & 12,10 & 10,60 & 8,50 & 4,42 \\
\hline 1,02 & 31 & 23,78 & 21,06 & 18,69 & 17,95 & 16,10 & 15,56 & 14,85 & 13,67 & 12,59 & 11,99 & 10,50 & 8,42 & 4,38 \\
\hline 1,02 & 32 & 23,78 & 21,06 & 18,69 & 17,95 & 16,10 & 15,56 & 14,85 & 13,67 & 12,59 & 11,99 & 10,50 & 8,42 & 4,38 \\
\hline 1,01 & 33 & 23,54 & 20,86 & 18,50 & 17,78 & 15,94 & 15,40 & 14,71 & 13,53 & 12,46 & 11,87 & 10,39 & 8,33 & 4,33 \\
\hline 1,01 & 34 & 23,54 & 20,86 & 18,50 & 17,78 & 15,94 & 15,40 & 14,71 & 13,53 & 12,46 & 11,87 & 10,39 & 8,33 & 4,33 \\
\hline 1,00 & 35 & 23,31 & 20,65 & 18,32 & 17,60 & 15,78 & 15,25 & 14,56 & 13,40 & 12,34 & 11,75 & 10,29 & 8,25 & 4,29 \\
\hline 1,00 & 36 & 23,31 & 20,65 & 18,32 & 17,60 & 15,78 & 15,25 & 14,56 & 13,40 & 12,34 & 11,75 & 10,29 & 8,25 & 4,29 \\
\hline 0,98 & 37 & 22,84 & 20,24 & 17,95 & 17,25 & 15,46 & 14,95 & 14,27 & 13,13 & 12,09 & 11,52 & 10,08 & 8,09 & 4,20 \\
\hline 0,98 & 38 & 22,84 & 20,24 & 17,95 & 17,25 & 15,46 & 14,95 & 14,27 & 13,13 & 12,09 & 11,52 & 10,08 & 8,09 & 4,20 \\
\hline 0,98 & 39 & 22,84 & 20,24 & 17,95 & 17,25 & 15,46 & 14,95 & 14,27 & 13,13 & 12,09 & 11,52 & 10,08 & 8,09 & 4,20 \\
\hline 0,97 & 40 & 22,61 & 20,03 & 17,77 & 17,07 & 15,31 & 14,79 & 14,12 & 13,00 & 11,97 & 11,40 & 9,98 & 8,00 & 4,16 \\
\hline 0,97 & 41 & 22,61 & 20,03 & 17,77 & 17,07 & 15,31 & 14,79 & 14,12 & 13,00 & 11,97 & 11,40 & 9,98 & 8,00 & 4,16 \\
\hline
\end{tabular}




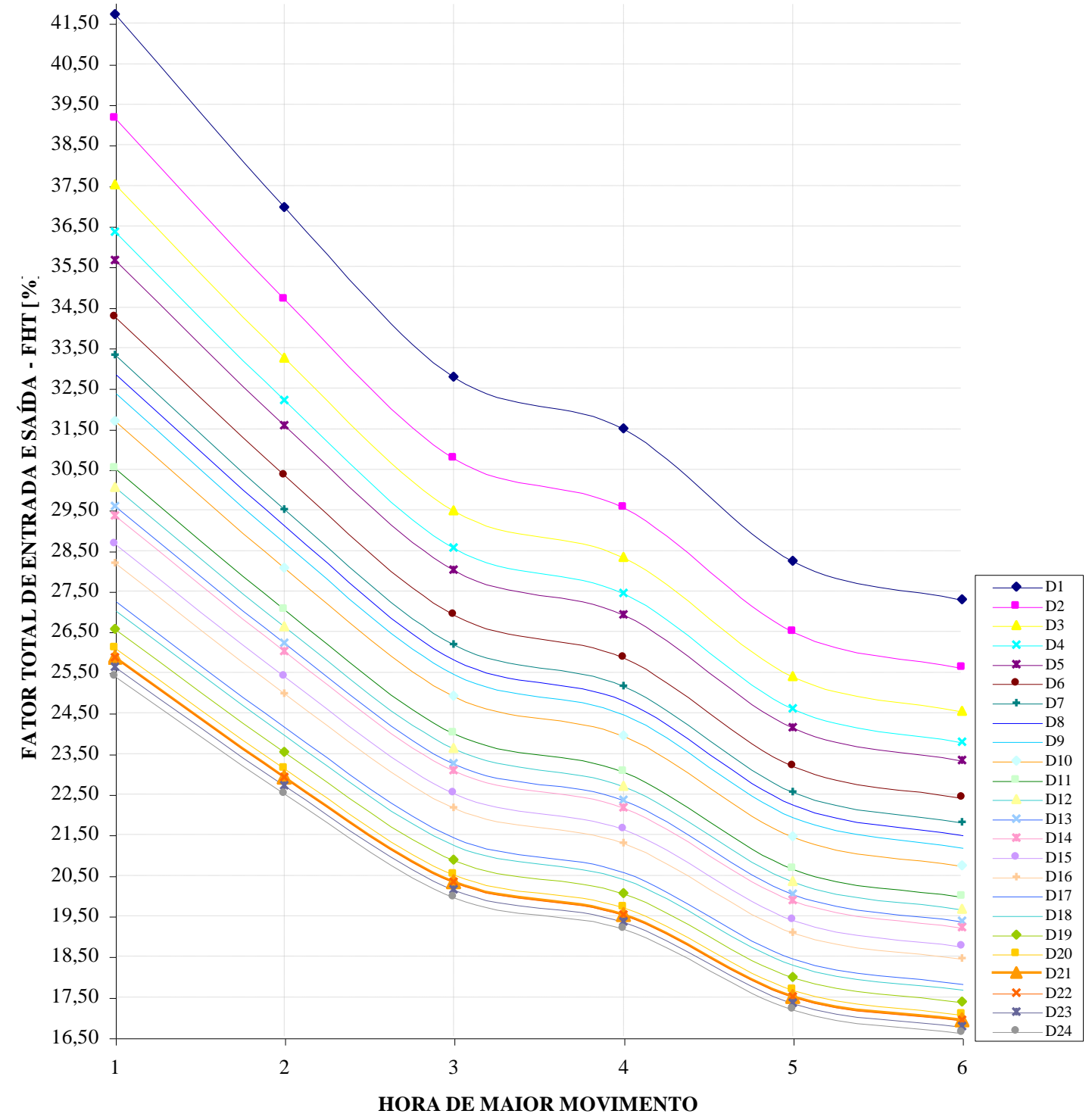

Figura 7.9 - Fatores do total de entrada e saída.

Na Tabela 7.12 e na Figura 7.10 são mostrados os valores dos fatores do total de entrada e saída $\left(F H T_{j}^{i}\right)$ associados às horas do ano de maior movimento - referidas a partir daqui simplesmente por FHT.

Tabela 7.12 - Relação dos fatores do total para as horas de maior movimento (FHT).

\begin{tabular}{|c|c|c|}
\hline Hora de maior movimento (j) & $\boldsymbol{F H T}[\boldsymbol{\%}]$ & Dia i em que ocorre a hora \\
\hline 1 & 41,72 & 1 \\
\hline 2 & 39,16 & 2 \\
\hline 3 & 37,53 & 3 \\
\hline 4 & 36,96 & 4 \\
\hline 5 & 36,36 & 5 \\
\hline 6 & 35,66 & 2 \\
\hline 7 & 34,69 & 6 \\
\hline 8 & 34,27 & 7 \\
\hline 9 & 33,33 & 3 \\
\hline 10 & 33,25 & 8 \\
\hline 11 & 32,87 & 1 \\
\hline 12 & 32,79 & 9 \\
\hline 13 & 32,40 & 4 \\
\hline 15 & 32,21 & 10 \\
\hline & 31,70 & \\
\hline & & \\
\hline
\end{tabular}


Tabela 7.12 - Relação dos fatores do total para as horas de maior movimento (FHT).

\begin{tabular}{|c|c|c|}
\hline Hora de maior movimento (j) & $F H T[\%]$ & Dia i em que ocorre a hora \\
\hline 16 & 31,59 & 5 \\
\hline 17 & 31,50 & 1 \\
\hline 18 & 30,78 & 2 \\
\hline 19 & 30,54 & 11 \\
\hline 20 & 30,36 & 6 \\
\hline 21 & 30,07 & 12 \\
\hline 22 & 29,60 & 13 \\
\hline 23 & 29,57 & 2 \\
\hline 24 & 29,53 & 7 \\
\hline 25 & 29,50 & 3 \\
\hline 26 & 29,37 & 14 \\
\hline 27 & 29,12 & 8 \\
\hline 28 & 28,70 & 9 \\
\hline 29 & 28,67 & 15 \\
\hline 30 & 28,58 & 4 \\
\hline 31 & 28,34 & 3 \\
\hline 32 & 28,25 & 1 \\
\hline 33 & 28,21 & 16 \\
\hline 34 & 28,08 & 10 \\
\hline 35 & 28,03 & 5 \\
\hline 36 & 27,46 & 4 \\
\hline 37 & 27,30 & 1 \\
\hline 38 & 27,27 & 17 \\
\hline 39 & 27,05 & 11 \\
\hline 40 & 27,04 & 18 \\
\hline 41 & 26,93 & 5 \\
\hline 42 & 26,93 & 6 \\
\hline 43 & 26,64 & 12 \\
\hline 44 & 26,57 & 19 \\
\hline 45 & 26,51 & 2 \\
\hline 46 & 26,23 & 13 \\
\hline 47 & 26,20 & 7 \\
\hline 48 & 26,11 & 20 \\
\hline 49 & 26,06 & 1 \\
\hline 50 & 26,02 & 14 \\
\hline 51 & 25,87 & 6 \\
\hline 52 & 25,87 & 21 \\
\hline 53 & 25,87 & 22 \\
\hline 54 & 25,83 & 8 \\
\hline 55 & 25,64 & 23 \\
\hline 56 & 25,62 & 2 \\
\hline 57 & 25,46 & 9 \\
\hline 58 & 25,41 & 3 \\
\hline 59 & 25,41 & 24 \\
\hline 60 & 25,40 & 15 \\
\hline 61 & 25,17 & 7 \\
\hline 62 & 25,17 & 25 \\
\hline 63 & 24,99 & 16 \\
\hline 64 & 24,94 & 26 \\
\hline 65 & 24,92 & 10 \\
\hline 66 & 24,82 & 8 \\
\hline 67 & 24,71 & 27 \\
\hline 68 & 24,62 & 4 \\
\hline 69 & 24,55 & 3 \\
\hline 70 & 24,46 & 2 \\
\hline 71 & 24,46 & 9 \\
\hline 72 & 24,24 & 28 \\
\hline 73 & 24,16 & 17 \\
\hline 74 & 24,14 & 5 \\
\hline 75 & 24,01 & 29 \\
\hline 76 & 24,01 & 30 \\
\hline 77 & 24,00 & 11 \\
\hline 78 & 23,99 & 1 \\
\hline 79 & 23,95 & 18 \\
\hline 80 & 23,94 & 10 \\
\hline 81 & 23,79 & 4 \\
\hline 82 & 23,78 & 31 \\
\hline 83 & 23,78 & 32 \\
\hline 84 & 23,63 & 12 \\
\hline 85 & 23,54 & 19 \\
\hline 86 & 23,54 & 33 \\
\hline 87 & 23,54 & 34 \\
\hline 88 & 23,44 & 3 \\
\hline 89 & 23,33 & 5 \\
\hline 90 & 23,31 & 35 \\
\hline 91 & 23,31 & 36 \\
\hline
\end{tabular}




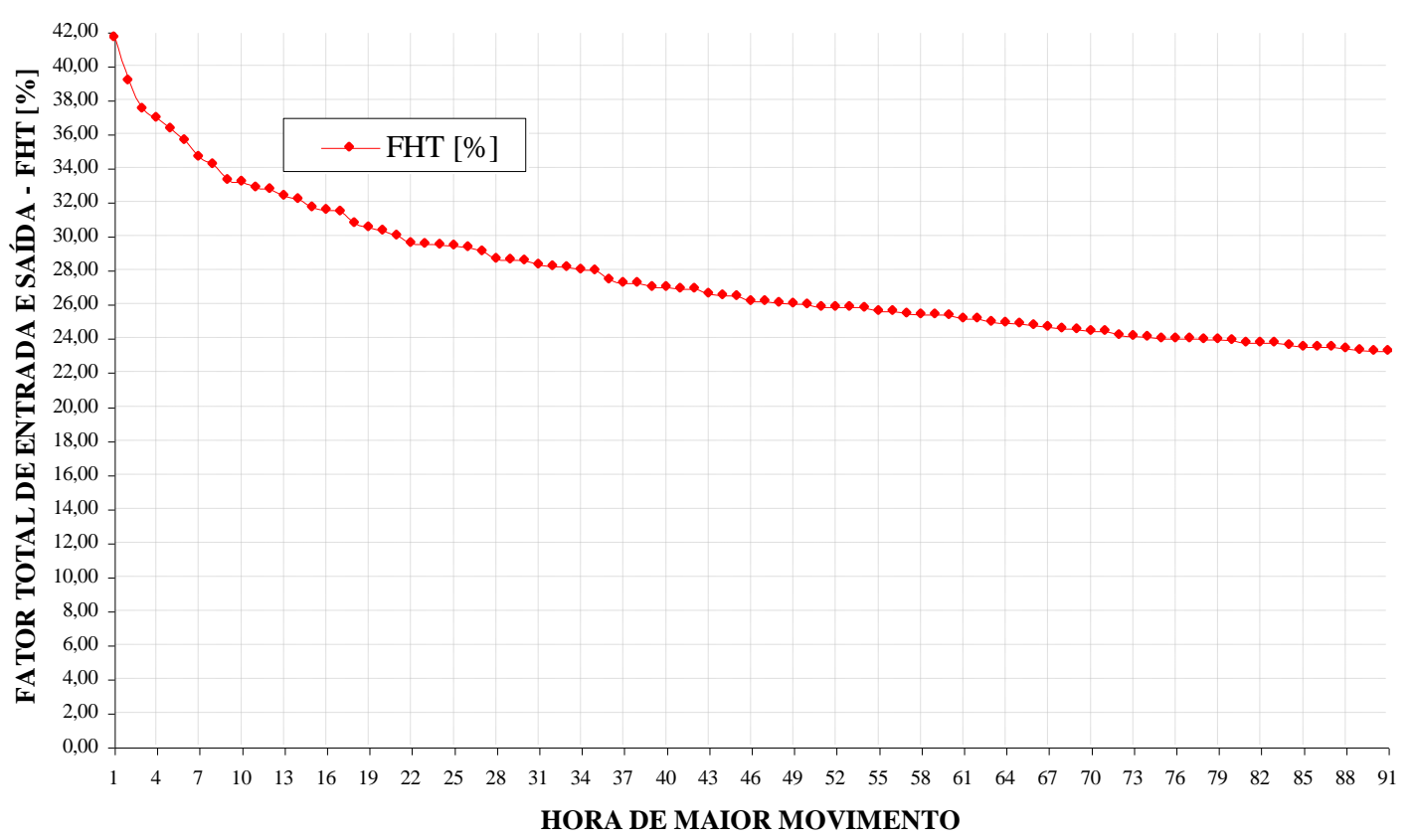

Figura 7.10 - Relação dos fatores do total de entrada e saída para as horas do ano de maior movimento.

Na Tabela 7.13 estão indicados os valores dos fatores do total de entrada e saída associados ao número de horas não atendidas.

Tabela 7.13 - Valores dos fatores do total x Número de horas não atendidas.

\begin{tabular}{|c|c|c|c|}
\hline Horas não atendidas & FHT [\%] & Horas não atendidas [\%] & Horas atendidas [\%] \\
\hline 0 & 41,72 & 0,00 & 100,00 \\
\hline 5 & 35,66 & 0,10 & 99,90 \\
\hline 10 & 32,87 & 0,20 & 99,80 \\
\hline 15 & 31,59 & 0,29 & 99,71 \\
\hline 20 & 30,07 & 0,39 & 99,61 \\
\hline 25 & 29,37 & 0,49 & 99,51 \\
\hline 30 & 28,34 & 0,59 & 99,41 \\
\hline 35 & 27,46 & 0,68 & 99,32 \\
\hline 40 & 26,93 & 0,78 & 99,22 \\
\hline 45 & 26,23 & 0,88 & 99,12 \\
\hline 50 & 25,87 & 0,98 & 99,02 \\
\hline 55 & 25,62 & 1,08 & 98,92 \\
\hline 60 & 25,17 & 1,17 & 98,83 \\
\hline 65 & 24,82 & 1,27 & 98,73 \\
\hline 70 & 24,46 & 1,37 & 98,63 \\
\hline 75 & 24,01 & 1,47 & 98,53 \\
\hline 80 & 23,79 & 1,57 & 98,43 \\
\hline 85 & 23,54 & 1,66 & 98,34 \\
\hline 90 & 23,31 & 1,76 & 98,24 \\
\hline
\end{tabular}

Seguindo o padrão dos projetos de rodovias e vias urbanas, de adotar para o dimensionamento da infra-estrutura (instalações e equipamentos) um valor próximo ao joelho da curva de variação do fluxo (onde a taxa de variação do fluxo passa a ser menor), pode-se 
adotar como hora de projeto a $10^{\text {a }}$ hora, onde $F H T=33,25 \%$. Nesse caso, apenas nas 9 horas de maior movimento do ano a capacidade de atendimento dos equipamentos de passagem e controle nos acessos de entrada e saída do shopping center será superada. Na Tabela 7.12 podem ser identificados os dias em que as 9 horas que superam a capacidade ocorrem, no caso: 2 horas ocorrem no $1^{\circ}$ dia de maior movimento, 2 horas no $2^{\circ}$ dia, 1 hora no $3^{\circ}, 1$ hora no $4^{\circ}, 1$ hora no $5^{\circ}, 1$ hora no $6^{\circ}$ e 1 hora no $7^{\circ}$ dia.

Assumindo como hora de projeto a $30^{\mathrm{a}}$ hora, como é comum no projeto de rodovias, resulta $F H T=28,58 \%$. Contudo, no caso de rodovias o dimensionamento é feito normalmente para o nível de serviço " $\mathrm{D}$ ”, muito aquém da capacidade da via. Isso significa que em grande parte das 29 horas de maior movimento, o fluxo não supera a capacidade, ocorrendo apenas uma deterioração do nível de serviço - congestionamento real apenas numas poucas horas. Não é o caso do dimensionamento das instalações e equipamentos do total de entrada e saída dos shopping centers aqui utilizados - onde o limite considerado é a capacidade. Assim, para shopping centers não é indicado adotar a $30^{\mathrm{a}}$ hora como hora de projeto.

Outra forma de abordagem da questão é fixar uma porcentagem para o número de horas não atendidas e determinar o valor de $F H T$ correspondente. Assumindo, por exemplo, que apenas em 1\% das horas (aproximadamente 50 horas) a capacidade seria excedida (em 99\% das horas o fluxo de veículos estaria abaixo da capacidade), resulta $F H T=25,87 \%$. Assumindo que em apenas $0,5 \%$ das horas (aproximadamente 25 horas) a capacidade seria excedida, resulta $F H T=29,37 \%$.

VOORHEESS \& CROW (1966) propuseram a $10^{a}$ hora mais movimentada do ano como hora de projeto, que como visto coincide com o joelho da curva e leva a um valor de $F H T=33,25 \%$

O URBAN LAND INSTITUTE (1982) propõe a $19^{\mathrm{a}}$ hora mais movimentada do ano como hora de projeto, resultando nesse caso um $F H T=30,54 \%$.

Em função das considerações feitas, e considerando que a existência de congestionamento em eventuais cruzamentos por onde passam os fluxos de entrada e saída prejudica o trânsito no local e desagrada os clientes e a comunidade, a princípio parece razoável adotar como hora de projeto a $10^{\mathrm{a}}$ hora mais movimentada. Neste caso, o valor de $F H T=33,25 \%$ equivale a 79,70\% do valor de FHTmáx $=41,72 \%$ (que corresponde ao valor em que o fluxo de veículos não supera a capacidade em nenhuma hora do ano). Isso significa, a princípio, uma redução física, e possivelmente do custo, de $20,30 \%$ das instalações e equipamentos desses cruzamentos. 


\subsubsection{FATORES DE ACÚMULO DE VEÍCULOS}

Na Tabela 7.14 encontram-se reproduzidos os valores da relação entre o número de veículos acumulados por hora e o número total de viagens no sábado, referentes às horas de maior movimento, obtidos nas pesquisas realizadas nos shoppings centers. São também apresentados os valores médios dessas relações correspondentes a cada hora - denominados de fatores horários de acúmulo e definidos como:

$$
F H A_{j}^{s m}=\left(V H A_{j} / V s m\right) \times 100
$$

Sendo, $F H A_{j}^{s m}$ : fator horário de acúmulo de veículos associado à hora j do sábado médio [\%];

$V H A_{j}$ : número de veículos acumulados no estacionamento na hora j do sábado médio

[veículos/hora]; e

Vsm: número de viagens no sábado médio [veículos/dia].

São indicados ainda na Tabela 7.14, os desvios dos valores reais em relação ao valor médio.

Tabela 7.14 - Fatores horários de acúmulo de veículos $\left(F H A_{j}^{s m}\right)$.

\begin{tabular}{|c|c|c|c|c|c|c|c|}
\hline \multirow{2}{*}{$\begin{array}{c}\text { Maior hora } \\
\text { (j) }\end{array}$} & \multicolumn{4}{|c|}{$F H A_{j}^{s m}[\%]=\left(V H A_{j} / V s m\right) \times 100$} & \multicolumn{3}{|c|}{ Desvio [\%] } \\
\hline & "A" & "B" & "C" & média & "A" & "B" & "C" \\
\hline 1 & 10,17 & 18,01 & 17,35 & 15,18 & $-32,99$ & 18,67 & 14,32 \\
\hline 2 & 9,35 & 16,35 & 16,01 & 13,90 & $-32,75$ & 17,60 & 15,15 \\
\hline 3 & 7,65 & 13,60 & 12,21 & 11,15 & $-31,41$ & 21,94 & 9,47 \\
\hline 4 & 7,07 & 12,62 & 12,10 & 10,60 & $-33,28$ & 19,09 & 14,19 \\
\hline 5 & 6,65 & 11,47 & 11,00 & 9,71 & $-31,49$ & 18,17 & 13,32 \\
\hline 6 & 6,24 & 9,64 & 10,95 & 8,94 & $-30,23$ & 7,79 & 22,44 \\
\hline 7 & 5,27 & 8,03 & 10,49 & 7,93 & $-33,54$ & 1,26 & 32,28 \\
\hline 8 & 5,25 & 7,92 & 9,84 & 7,67 & $-31,55$ & 3,26 & 28,29 \\
\hline 9 & 5,23 & 6,14 & 9,56 & 6,98 & $-25,04$ & $-11,99$ & 37,03 \\
\hline 10 & 5,10 & 5,45 & 8,20 & 6,25 & $-18,40$ & $-12,80$ & 31,20 \\
\hline 11 & 5,09 & 4,53 & 5,84 & 5,15 & $-1,23$ & $-12,10$ & 13,32 \\
\hline 12 & 4,89 & 3,50 & 3,79 & 4,06 & 20,44 & $-13,79$ & $-6,65$ \\
\hline 13 & 3,17 & 2,24 & 1,41 & 2,27 & 39,44 & $-1,47$ & $-37,98$ \\
\hline demais horas & 0,86 & 0,00 & 0,00 & 0,29 & & & \\
\hline total & 81,99 & 119,50 & 128,75 & 110,08 & & & \\
\hline
\end{tabular}

Na Figura 7.11 estão representados graficamente os valores dos fatores horários de acúmulo de veículos. 


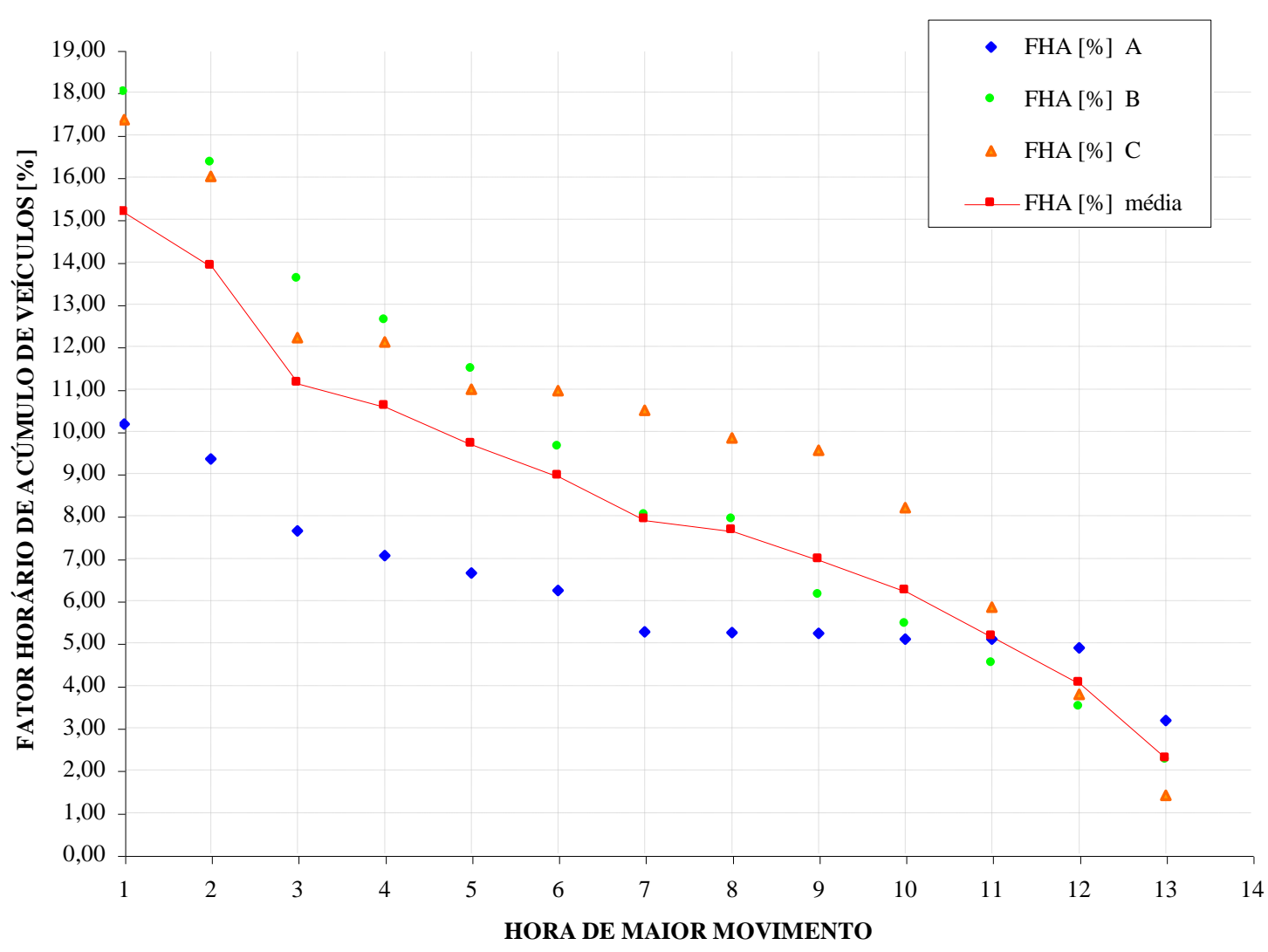

Figura 7.11 - Fatores horários de acúmulo de veículos.

Com base na hipótese 3 estabelecida no item 7.1, pode-se escrever que o fator horário de acúmulo de veículos para a hora j do dia i vale:

$$
F H A_{j}^{i}=F H A_{j}^{s m} \times F D_{i}
$$

Sendo, $F H A_{j}^{i}$ : fator horário de acúmulo de veículos para a hora j do dia i [\%];

$F H A_{j}^{s m}$ : fator horário de acúmulo de veículos associado à hora j do sábado médio [\%];

$F D_{i}$ : fator diário de viagens associado ao dia i do ano.

Isso significa que:

$$
V H A_{j}^{i}=F H A_{j}^{i} \times V s m
$$

Sendo, $V H A_{j}^{i}$ : número de veículos acumulados na hora j do dia i do ano [veículos/hora];

$F H A_{j}{ }_{j}$ : fator horário de acúmulo de veículos para a hora j do dia i;

Vsm: número de viagens no sábado médio [veículos/dia].

Na Tabela 7.15 e na Figura 7.12 estão indicados os valores de $F H A_{j}^{i}$. 
Tabela 7.15 - Fatores de acúmulo de veículos $\left(F H A_{j}{ }_{j}^{i}\right)$.

\begin{tabular}{|c|c|c|c|c|c|c|c|c|c|c|c|c|c|c|}
\hline \multirow[b]{3}{*}{$F D i$} & \multicolumn{14}{|c|}{$F H A_{j}^{i}[\%]=F H A_{j}^{s m} x F_{i}[\%]$} \\
\hline & $F H A_{j}^{s m}[\%]$ & 15,18 & 13,90 & 11,15 & 10,60 & 9,71 & 8,94 & 7,93 & 7,67 & 6,98 & 6,25 & 5,15 & 4,06 & 2,27 \\
\hline & dialhora & 1 & 2 & 3 & 4 & 5 & 6 & 7 & 8 & 9 & 10 & 11 & 12 & 13 \\
\hline 1,79 & 1 & 27,17 & 24,88 & 19,96 & 18,97 & 17,38 & 16,00 & 14,19 & 13,73 & 12,49 & 11,19 & 9,22 & 7,27 & 4,06 \\
\hline 1,68 & 2 & 25,50 & 23,35 & 18,73 & 17,81 & 16,31 & 15,02 & 13,32 & 12,89 & 11,73 & 10,50 & 8,65 & 6,82 & 3,81 \\
\hline 1,61 & 3 & 24,44 & 22,38 & 17,95 & 17,07 & 15,63 & 14,39 & 12,77 & 12,35 & 11,24 & 10,06 & 8,29 & 6,54 & 3,65 \\
\hline 1,56 & 4 & 23,68 & 21,68 & 17,39 & 16,54 & 15,15 & 13,95 & 12,37 & 11,97 & 10,89 & 9,75 & 8,03 & 6,33 & 3,54 \\
\hline 1,53 & 5 & 23,23 & 21,27 & 17,06 & 16,22 & 14,86 & 13,68 & 12,13 & 11,74 & 10,68 & 9,56 & 7,88 & 6,21 & 3,47 \\
\hline 1,47 & 6 & 22,31 & 20,43 & 16,39 & 15,58 & 14,27 & 13,14 & 11,66 & 11,27 & 10,26 & 9,19 & 7,57 & 5,97 & 3,34 \\
\hline 1,43 & 7 & 21,71 & 19,88 & 15,94 & 15,16 & 13,89 & 12,78 & 11,34 & 10,97 & 9,98 & 8,94 & 7,36 & 5,81 & 3,25 \\
\hline 1,41 & 8 & 21,40 & 19,60 & 15,72 & 14,95 & 13,69 & 12,61 & 11,18 & 10,81 & 9,84 & 8,81 & 7,26 & 5,72 & 3,20 \\
\hline 1,39 & 9 & 21,10 & 19,32 & 15,50 & 14,73 & 13,50 & 12,43 & 11,02 & 10,66 & 9,70 & 8,69 & 7,16 & 5,64 & 3,16 \\
\hline 1,36 & 10 & 20,64 & 18,90 & 15,16 & 14,42 & 13,21 & 12,16 & 10,78 & 10,43 & 9,49 & 8,50 & 7,00 & 5,52 & 3,09 \\
\hline 1,31 & 11 & 19,89 & 18,21 & 14,61 & 13,89 & 12,72 & 11,71 & 10,39 & 10,05 & 9,14 & 8,19 & 6,75 & 5,32 & 2,97 \\
\hline 1,29 & 12 & 19,58 & 17,93 & 14,38 & 13,67 & 12,53 & 11,53 & 10,23 & 9,89 & 9,00 & 8,06 & 6,64 & 5,24 & 2,93 \\
\hline 1,27 & 13 & 19,28 & 17,65 & 14,16 & 13,46 & 12,33 & 11,35 & 10,07 & 9,74 & 8,86 & 7,94 & 6,54 & 5,16 & 2,88 \\
\hline 1,26 & 14 & 19,13 & 17,51 & 14,05 & 13,36 & 12,23 & 11,26 & 9,99 & 9,66 & 8,79 & 7,88 & 6,49 & 5,12 & 2,86 \\
\hline 1,23 & 15 & 18,67 & 17,10 & 13,71 & 13,04 & 11,94 & 11,00 & 9,75 & 9,43 & 8,59 & 7,69 & 6,33 & 4,99 & 2,79 \\
\hline 1,21 & 16 & 18,37 & 16,82 & 13,49 & 12,83 & 11,75 & 10,82 & 9,60 & 9,28 & 8,45 & 7,56 & 6,23 & 4,91 & 2,75 \\
\hline 1,17 & 17 & 17,76 & 16,26 & 13,05 & 12,40 & 11,36 & 10,46 & 9,28 & 8,97 & 8,17 & 7,31 & 6,03 & 4,75 & 2,66 \\
\hline 1,16 & 18 & 17,61 & 16,12 & 12,93 & 12,30 & 11,26 & 10,37 & 9,20 & 8,90 & 8,10 & 7,25 & 5,97 & 4,71 & 2,63 \\
\hline 1,14 & 19 & 17,31 & 15,85 & 12,71 & 12,08 & 11,07 & 10,19 & 9,04 & 8,74 & 7,96 & 7,13 & 5,87 & 4,63 & 2,59 \\
\hline 1,12 & 20 & 17,00 & 15,57 & 12,49 & 11,87 & 10,88 & 10,01 & 8,88 & 8,59 & 7,82 & 7,00 & 5,77 & 4,55 & 2,54 \\
\hline 1,11 & 21 & 16,85 & 15,43 & 12,38 & 11,77 & 10,78 & 9,92 & 8,80 & 8,51 & 7,75 & 6,94 & 5,72 & 4,51 & 2,52 \\
\hline 1,11 & 22 & 16,85 & 15,43 & 12,38 & 11,77 & 10,78 & 9,92 & 8,80 & 8,51 & 7,75 & 6,94 & 5,72 & 4,51 & 2,52 \\
\hline 1,10 & 23 & 16,70 & 15,29 & 12,27 & 11,66 & 10,68 & 9,83 & 8,72 & 8,44 & 7,68 & 6,88 & 5,67 & 4,47 & 2,50 \\
\hline 1,09 & 24 & 16,55 & 15,15 & 12,15 & 11,55 & 10,58 & 9,74 & 8,64 & 8,36 & 7,61 & 6,81 & 5,61 & 4,43 & 2,47 \\
\hline 1,08 & 25 & 16,39 & 15,01 & 12,04 & 11,45 & 10,49 & 9,66 & 8,56 & 8,28 & 7,54 & 6,75 & 5,56 & 4,38 & 2,45 \\
\hline 1,07 & 26 & 16,24 & 14,87 & 11,93 & 11,34 & 10,39 & 9,57 & 8,49 & 8,21 & 7,47 & 6,69 & 5,51 & 4,34 & 2,43 \\
\hline 1,06 & 27 & 16,09 & 14,73 & 11,82 & 11,24 & 10,29 & 9,48 & 8,41 & 8,13 & 7,40 & 6,63 & 5,46 & 4,30 & 2,41 \\
\hline 1,04 & 28 & 15,79 & 14,46 & 11,60 & 11,02 & 10,10 & 9,30 & 8,25 & 7,98 & 7,26 & 6,50 & 5,36 & 4,22 & 2,36 \\
\hline 1,03 & 29 & 15,64 & 14,32 & 11,48 & 10,92 & 10,00 & 9,21 & 8,17 & 7,90 & 7,19 & 6,44 & 5,30 & 4,18 & 2,34 \\
\hline 1,03 & 30 & \begin{tabular}{ll|}
15,64 \\
\end{tabular} & 14,32 & 11,48 & 10,92 & 10,00 & 9,21 & 8,17 & 7,90 & 7,19 & 6,44 & 5,30 & 4,18 & 2,34 \\
\hline 1,02 & 31 & 15,48 & 14,18 & 11,37 & 10,81 & 9,90 & 9,12 & 8,09 & 7,82 & 7,12 & 6,38 & 5,25 & 4,14 & 2,32 \\
\hline 1,02 & 32 & 15,48 & 14,18 & 11,37 & 10,81 & 9,90 & 9,12 & 8,09 & 7,82 & 7,12 & 6,38 & 5,25 & 4,14 & 2,32 \\
\hline 1,01 & 33 & 15,33 & 14,04 & 11,26 & 10,71 & 9,81 & 9,03 & 8,01 & 7,75 & 7,05 & 6,31 & 5,20 & 4,10 & 2,29 \\
\hline 1,01 & 34 & 15,33 & 14,04 & 11,26 & 10,71 & 9,81 & 9,03 & 8,01 & 7,75 & 7,05 & 6,31 & 5,20 & 4,10 & 2,29 \\
\hline 1,00 & 35 & 15,18 & 13,90 & 11,15 & 10,60 & 9,71 & 8,94 & 7,93 & 7,67 & 6,98 & 6,25 & 5,15 & 4,06 & 2,27 \\
\hline 1,00 & 36 & 15,18 & 13,90 & 11,15 & 10,60 & 9,71 & 8,94 & 7,93 & 7,67 & 6,98 & 6,25 & 5,15 & 4,06 & 2,27 \\
\hline 0,98 & 37 & 14,88 & 13,62 & 10,93 & 10,39 & 9,52 & 8,76 & 7,77 & 7,52 & 6,84 & 6,13 & 5,05 & 3,98 & 2,22 \\
\hline 0,98 & 38 & 14,88 & 13,62 & 10,93 & 10,39 & 9,52 & 8,76 & 7,77 & 7,52 & 6,84 & 6,13 & 5,05 & 3,98 & 2,22 \\
\hline 0,98 & 39 & 14,88 & 13,62 & 10,93 & 10,39 & 9,52 & 8,76 & 7,77 & 7,52 & 6,84 & 6,13 & 5,05 & 3,98 & 2,22 \\
\hline 0,97 & 40 & 14,72 & 13,48 & 10,82 & 10,28 & 9,42 & 8,67 & 7,69 & 7,44 & 6,77 & 6,06 & 5,00 & 3,94 & 2,20 \\
\hline 0,97 & 41 & 14,72 & 13,48 & 10,82 & 10,28 & 9,42 & 8,67 & 7,69 & 7,44 & 6,77 & 6,06 & 5,00 & 3,94 & 2,20 \\
\hline
\end{tabular}




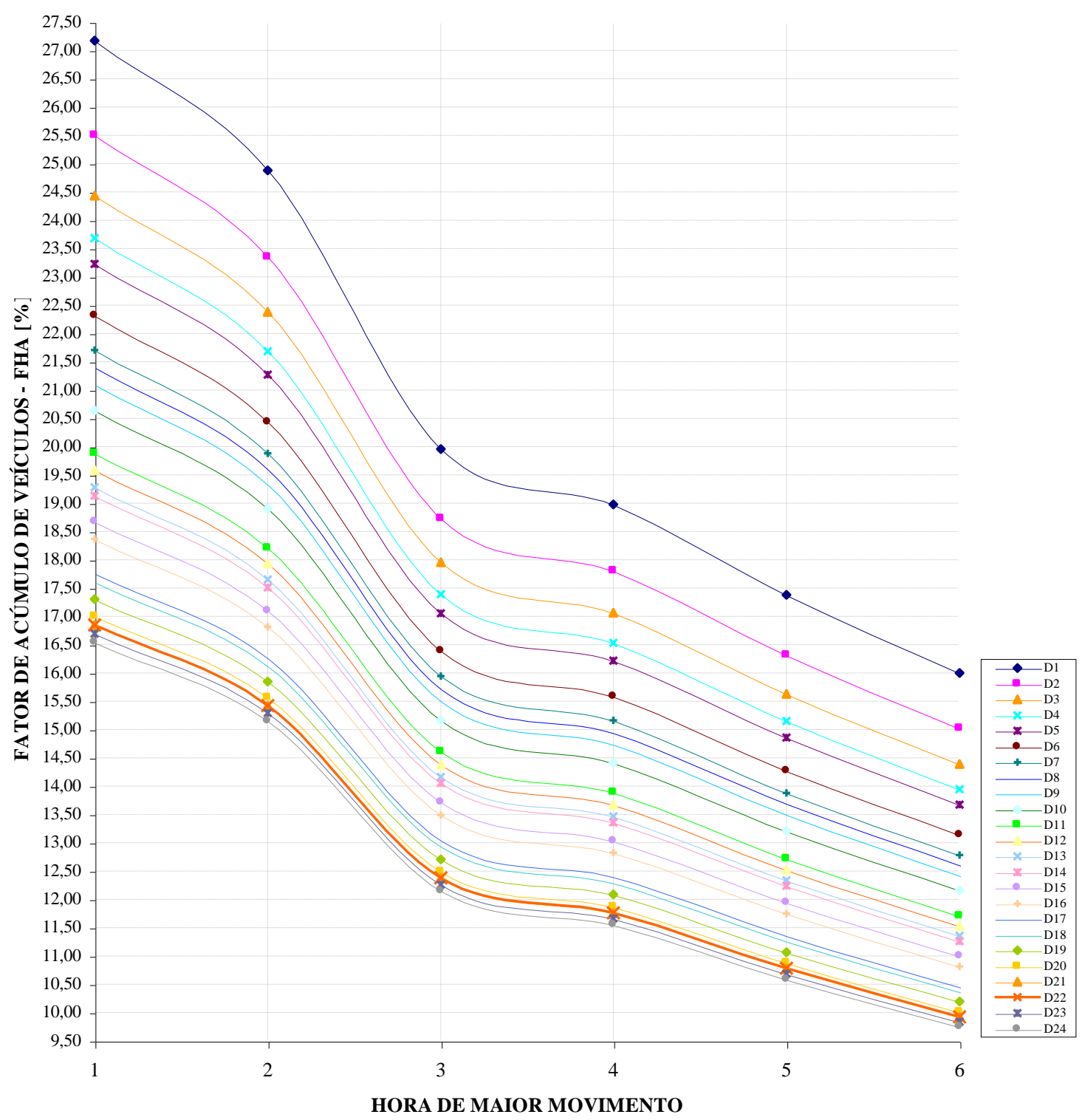

Figura 7.12 - Fatores de acúmulo de veículos.

Na Tabela 7.16 e na Figura 7.13 são mostrados os valores dos fatores de acúmulo $\left(F H A_{j}^{i}\right)$ associados às horas do ano de maior movimento - referidas a partir daqui simplesmente por FHA.

Tabela 7.16 - Relação dos fatores de acúmulo para as horas de maior movimento (FHA).

\begin{tabular}{|c|c|c|}
\hline Hora de maior movimento $(\mathbf{j})$ & $\boldsymbol{F H A}[\boldsymbol{~} \boldsymbol{0}$ & Dia i em que ocorre a hora \\
\hline 1 & 27,17 & 1 \\
\hline 2 & 25,50 & 2 \\
\hline 3 & 24,88 & 1 \\
\hline 4 & 24,44 & 3 \\
\hline 5 & 23,68 & 2 \\
\hline 6 & 23,35 & 5 \\
\hline 7 & 23,23 & 3 \\
\hline 8 & 22,38 & 6 \\
\hline 10 & 22,31 & 7 \\
\hline 11 & 21,71 & 4 \\
\hline 12 & 21,68 & 8 \\
\hline 13 & 21,40 & 5 \\
\hline 14 & 21,27 & 9 \\
\hline 15 & 21,10 & 10 \\
\hline
\end{tabular}


Tabela 7.16 - Relação dos fatores de acúmulo para as horas de maior movimento (FHA).

\begin{tabular}{|c|c|c|}
\hline Hora de maior movimento $(\mathrm{j})$ & FHA [\%] & Dia i em que ocorre a hora \\
\hline 16 & 20,43 & 6 \\
\hline 17 & 19,96 & 1 \\
\hline 18 & 19,89 & 11 \\
\hline 19 & 19,88 & 7 \\
\hline 20 & 19,60 & 8 \\
\hline 21 & 19,58 & 12 \\
\hline 22 & 19,32 & 9 \\
\hline 23 & 19,28 & 13 \\
\hline 24 & 19,13 & 14 \\
\hline 25 & 18,97 & 1 \\
\hline 26 & 18,90 & 10 \\
\hline 27 & 18,73 & 2 \\
\hline 28 & 18,67 & 15 \\
\hline 29 & 18,37 & 16 \\
\hline 30 & 18,21 & 11 \\
\hline 31 & 17,95 & 3 \\
\hline 32 & 17,93 & 12 \\
\hline 33 & 17,81 & 2 \\
\hline 34 & 17,76 & 17 \\
\hline 35 & 17,65 & 13 \\
\hline 36 & 17,61 & 18 \\
\hline 37 & 17,51 & 14 \\
\hline 38 & 17,39 & 4 \\
\hline 39 & 17,38 & 1 \\
\hline 40 & 17,31 & 19 \\
\hline 41 & 17,10 & 15 \\
\hline 42 & 17,07 & 3 \\
\hline 43 & 17,06 & 5 \\
\hline 44 & 17,00 & 20 \\
\hline 45 & 16,85 & 21 \\
\hline 46 & 16,85 & 22 \\
\hline 47 & 16,82 & 16 \\
\hline 48 & 16,70 & 23 \\
\hline 49 & 16,55 & 24 \\
\hline 50 & 16,54 & 4 \\
\hline 51 & 16,39 & 6 \\
\hline 52 & 16,39 & 25 \\
\hline 53 & 16,31 & 2 \\
\hline 54 & 16,26 & 17 \\
\hline 55 & 16,24 & 26 \\
\hline 56 & 16,22 & 5 \\
\hline 57 & 16,12 & 18 \\
\hline 58 & 16,09 & 27 \\
\hline 59 & 16,00 & 1 \\
\hline 60 & 15,94 & 7 \\
\hline 61 & 15,85 & 19 \\
\hline 62 & 15,79 & 28 \\
\hline 63 & 15,72 & 8 \\
\hline 64 & 15,64 & 29 \\
\hline 65 & 15,64 & 30 \\
\hline 66 & 15,63 & 3 \\
\hline 67 & 15,58 & 6 \\
\hline 68 & 15,57 & 20 \\
\hline 69 & 15,50 & 9 \\
\hline 70 & 15,48 & 31 \\
\hline 71 & 15,48 & 32 \\
\hline 72 & 15,43 & 21 \\
\hline 73 & 15,43 & 22 \\
\hline 74 & 15,33 & 33 \\
\hline 75 & 15,33 & 34 \\
\hline 76 & 15,29 & 23 \\
\hline 77 & 15,18 & 35 \\
\hline 78 & 15,18 & 36 \\
\hline 79 & 15,16 & 7 \\
\hline 80 & 15,16 & 10 \\
\hline 81 & 15,15 & 4 \\
\hline 82 & 15,15 & 24 \\
\hline 83 & 15,02 & 2 \\
\hline 84 & 15,01 & 25 \\
\hline 85 & 14,95 & 8 \\
\hline 86 & 14,88 & 37 \\
\hline 87 & 14,88 & 38 \\
\hline 88 & 14,88 & 39 \\
\hline 89 & 14,87 & 26 \\
\hline 90 & 14,86 & 5 \\
\hline 91 & 14,73 & 9 \\
\hline
\end{tabular}




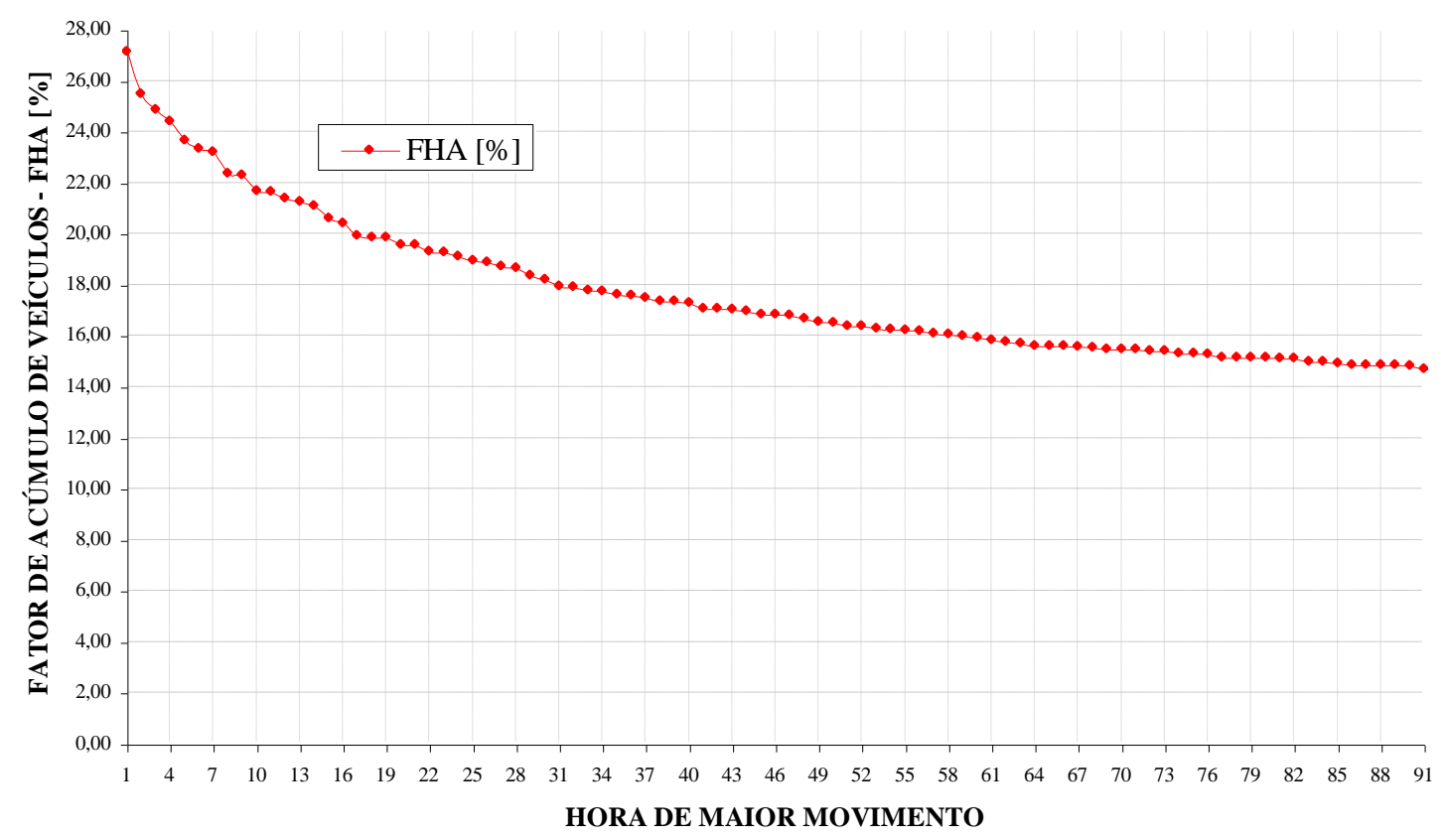

Figura 7.13 - Relação dos fatores de acúmulo para as horas do ano de maior movimento.

Na Tabela 7.17 estão indicados os valores dos fatores de acúmulo associados ao número de horas não atendidas.

Tabela 7.17 - Valores dos fatores de acúmulo x Número de horas não atendidas.

\begin{tabular}{|c|c|c|c|}
\hline Horas não atendidas & FHA [\%] & Horas não atendidas [\%] & Horas atendidas [\%] \\
\hline 0 & 27,17 & 0,00 & 100,00 \\
\hline 5 & 23,35 & 0,10 & 99,90 \\
\hline 10 & 21,68 & 0,20 & 99,80 \\
\hline 15 & 20,43 & 0,29 & 99,71 \\
\hline 20 & 19,58 & 0,39 & 99,61 \\
\hline 25 & 18,90 & 0,49 & 99,51 \\
\hline 30 & 17,95 & 0,59 & 99,41 \\
\hline 35 & 17,61 & 0,68 & 99,32 \\
\hline 40 & 17,10 & 0,78 & 99,22 \\
\hline 45 & 16,85 & 0,88 & 99,12 \\
\hline 50 & 16,39 & 0,98 & 99,02 \\
\hline 55 & 16,22 & 1,08 & 98,92 \\
\hline 60 & 15,85 & 1,17 & 98,83 \\
\hline 65 & 15,63 & 1,27 & 98,73 \\
\hline 70 & 15,48 & 1,37 & 98,63 \\
\hline 75 & 15,29 & 1,47 & 98,53 \\
\hline 80 & 15,15 & 1,57 & 98,43 \\
\hline 85 & 14,88 & 1,66 & 98,34 \\
\hline 90 & 14,73 & 1,76 & 98,24 \\
\hline
\end{tabular}

Seguindo o padrão dos projetos de rodovias e vias urbanas, de adotar para o dimensionamento da infra-estrutura (instalações e equipamentos) um valor próximo ao joelho da curva de variação do fluxo (onde a taxa de variação do fluxo passa a ser menor), pode-se 
adotar como hora de projeto a $10^{\mathrm{a}}$ hora, onde $F H A=21,71 \%$. Nesse caso, apenas nas 9 horas de maior movimento do ano a capacidade de atendimento das instalações e equipamentos de passagem e controle na entrada e saída do shopping será superada. Na Tabela 7.16 podem ser identificados os dias em que as 9 horas que superam a capacidade ocorrem, no caso: 2 horas ocorrem no $1^{\circ}$ dia de maior movimento, 2 horas no $2^{\circ}$ dia, 2 horas no $3^{\circ}$ dia, 1 hora no $4^{\circ}, 1$ hora no $5^{\circ}$ e 1 hora no $6^{\circ}$ dia.

Assumindo como hora de projeto a $30^{\mathrm{a}}$ hora, como é comum no projeto de rodovias, resulta $F H A=18,21 \%$. Contudo, no caso de rodovias o dimensionamento é feito normalmente para o nível de serviço " $D$ ”, muito aquém da capacidade da via. Isso significa que em grande parte das 29 horas de maior movimento, o fluxo não supera a capacidade, ocorrendo apenas uma deterioração do nível de serviço. Não é o caso do dimensionamento das instalações e equipamentos dos estacionamentos nos shopping centers aqui utilizados - onde o limite considerado é a capacidade. Assim, para shopping centers não é indicado adotar a $30^{\mathrm{a}}$ hora como hora de projeto.

Outra forma de abordagem da questão é fixar uma porcentagem para o número de horas não atendidas e determinar o valor de FHA correspondente. Assumindo, por exemplo, que apenas em $1 \%$ das horas (aproximadamente 50 horas) a capacidade seria excedida (em 99\% das horas o fluxo de veículos estaria abaixo da capacidade), resulta $F H A=16,39 \%$. Assumindo que em apenas $0,5 \%$ das horas (aproximadamente 25 horas) a capacidade seria excedida, resulta $F H A=18,90 \%$.

VOORHEESS \& CROW (1966) propuseram a $10^{\text {a }}$ hora mais movimentada do ano como hora de projeto, que como visto coincide com o joelho da curva e leva a um valor de $F H A=21,71 \%$

O URBAN LAND INSTITUTE (1982) propõe a $19^{\mathrm{a}}$ hora mais movimentada do ano como hora de projeto, resultando nesse caso um $F H A=19,88 \%$.

Em função das considerações feitas, e considerando que a falta de capacidade de atendimento da demanda por estacionamento provoca congestionamentos e desagrada os clientes do empreendimento e a comunidade, a princípio parece razoável adotar como hora de projeto a $10^{\mathrm{a}}$ hora mais movimentada. Neste caso, o valor de $F H A=21,71 \%$ representa $79,90 \%$ do valor de FHAmáx $=27,17 \%$ (que corresponde ao valor em que o fluxo de veículos não supera a capacidade em nenhuma hora do ano). Isso significa, a princípio, uma redução física, e possivelmente do custo, de $20,10 \%$ das instalações e equipamentos do estacionamento do shopping center. 


\subsubsection{FATORES DE IMPACTO VIÁRIO}

Em consonância com o critério adotado por GOLDNER (1994) - que sugere o fluxo horário de veículos no período compreendido entre 18:00 e 19:00h da sexta-feira para avaliação de impacto viário, e admitindo igual a 0,71 a relação entre as viagens de sexta-feira e sábado (conforme a hipótese 5 estabelecida no item 7.1), a seguir são determinados os fatores de impacto viário.

O fator horário de impacto é definido como:

$$
\mathrm{FHI}_{18-19^{\text {sexm }}}=\left(\mathrm{VHI}_{18-19}{ }^{\text {sexm }} / \text { Vsexm }\right) \times 100
$$

Sendo, $F_{18 I_{18-19}}^{\text {sexm }}$ : fator horário de impacto associado ao horário das 18:00 às 19:00h da sexta-feira média, correspondendo a 10,21\%,8,77\% e 17,42\%, para entrada, saída e total de entrada mais saída, respectivamente [\%];

$V H_{18-19}{ }^{\text {sexm }}$ : número de viagens no horário das 18:00 às 19:00h na sexta-feira média [veículos/hora]; e

Vsexm: número de viagens na sexta-feira média [veículos/dia].

Com base nas hipóteses 3 e 5, estabelecidas no item 7.1, pode-se escrever que o fator horário de impacto de veículos para o dia i vale:

$$
F H I_{18-19^{i}}=F H I_{18-19}^{\text {sexm }} \times F D_{i} \times 0,71
$$

Sendo, $F H I_{18-19}$ : fator horário de impacto de veículos para o dia i [\%];

$\mathrm{FHI}_{18-19}{ }^{\text {sexm }}$ : fator horário de impacto de veículos na sexta-feira média [\%];

$F D_{i}$ : fator diário de viagens associado ao dia i do ano.

Isso significa que:

$$
\mathrm{VHI}_{18-19^{i}}=\mathrm{FHI}_{18-19^{i}} \times \mathrm{Vsm}
$$

Sendo, $V I_{18-19}{ }^{i}$ : número de veículos das 18:00 às 19:00h do dia i do ano [veículos/hora];

$\mathrm{FHI}_{18-19}$ : fator horário de impacto de veículos para o dia i [\%];

Vsm: número de viagens no sábado médio [veículos/dia].

Na Tabela 7.18 e na Figura 7.14 estão indicados os valores dos fatores de impacto $\left(F H I_{18-19}{ }^{i}\right)$ - referidos a partir daqui simplesmente por $F H I$. 
Tabela 7.18 - Fatores de impacto $(F H I)$.

\begin{tabular}{|c|c|c|c|c|c|}
\hline \multirow{3}{*}{$F D i$} & \multirow{3}{*}{$F D i \times 0,71$} & \multicolumn{4}{|c|}{$F H I[\%]=0,71 \times F D i \times F H I_{18-19}{ }^{\text {sexm }}[\%]$} \\
\hline & & $\mathrm{FHI}_{18-19^{\text {sexm }}[\%]}$ & 10,21 & $\mathbf{8 , 7 7}$ & 19,73 \\
\hline & & Dia (i) & FHIE $[\%]$ & FHIS [\%] & FHIT [\%] \\
\hline 1,79 & 1,27 & 1 & 12,96 & 11,13 & 25,07 \\
\hline 1,68 & 1,19 & 2 & 12,16 & 10,45 & 23,53 \\
\hline 1,61 & 1,14 & 3 & 11,66 & 10,01 & 22,55 \\
\hline 1,56 & 1,11 & 4 & 11,29 & 9,70 & 21,85 \\
\hline 1,53 & 1,09 & 5 & 11,08 & 9,52 & 21,43 \\
\hline 1,47 & 1,04 & 6 & 10,64 & 9,14 & 20,59 \\
\hline 1,43 & 1,02 & 7 & 10,35 & 8,89 & 20,03 \\
\hline 1,41 & 1,00 & 8 & 10,21 & 8,77 & 19,75 \\
\hline 1,39 & 0,99 & 9 & 10,06 & 8,65 & 19,47 \\
\hline 1,36 & 0,97 & 10 & 9,85 & 8,46 & 19,05 \\
\hline 1,31 & 0,93 & 11 & 9,48 & 8,15 & 18,35 \\
\hline 1,29 & 0,92 & 12 & 9,34 & 8,02 & 18,07 \\
\hline 1,27 & 0,90 & 13 & 9,19 & 7,90 & 17,79 \\
\hline 1,26 & 0,89 & 14 & 9,12 & 7,84 & 17,65 \\
\hline 1,23 & 0,87 & 15 & 8,91 & 7,65 & 17,23 \\
\hline 1,21 & 0,86 & 16 & 8,76 & 7,53 & 16,95 \\
\hline 1,17 & 0,83 & 17 & 8,47 & 7,28 & 16,39 \\
\hline 1,16 & 0,82 & 18 & 8,40 & 7,22 & 16,25 \\
\hline 1,14 & 0,81 & 19 & 8,25 & 7,09 & 15,97 \\
\hline 1,12 & 0,80 & 20 & 8,11 & 6,97 & 15,69 \\
\hline 1,11 & 0,79 & 21 & 8,04 & 6,90 & 15,55 \\
\hline 1,11 & 0,79 & 22 & 8,04 & 6,90 & 15,55 \\
\hline 1,10 & 0,78 & 23 & 7,96 & 6,84 & 15,41 \\
\hline 1,09 & 0,77 & 24 & 7,89 & 6,78 & 15,27 \\
\hline 1,08 & 0,77 & 25 & 7,82 & 6,72 & 15,13 \\
\hline 1,07 & 0,76 & 26 & 7,75 & 6,66 & 14,99 \\
\hline 1,06 & 0,75 & 27 & 7,67 & 6,59 & 14,85 \\
\hline 1,04 & 0,74 & 28 & 7,53 & 6,47 & 14,57 \\
\hline 1,03 & 0,73 & 29 & 7,46 & 6,41 & 14,43 \\
\hline 1,03 & 0,73 & 30 & 7,46 & 6,41 & 14,43 \\
\hline 1,02 & 0,72 & 31 & 7,38 & 6,34 & 14,29 \\
\hline 1,02 & 0,72 & 32 & 7,38 & 6,34 & 14,29 \\
\hline 1,01 & 0,72 & 33 & 7,31 & 6,28 & 14,15 \\
\hline 1,01 & 0,72 & 34 & 7,31 & 6,28 & 14,15 \\
\hline 1,00 & 0,71 & 35 & 7,24 & 6,22 & 14,01 \\
\hline 1,00 & 0,71 & 36 & 7,24 & 6,22 & 14,01 \\
\hline 0,98 & 0,70 & 37 & 7,10 & 6,10 & 13,73 \\
\hline 0,98 & 0,70 & 38 & 7,10 & 6,10 & 13,73 \\
\hline 0,98 & 0,70 & 39 & 7,10 & 6,10 & 13,73 \\
\hline 0,97 & 0,69 & 40 & 7,02 & 6,03 & 13,59 \\
\hline 0,97 & 0,69 & 41 & 7,02 & 6,03 & 13,59 \\
\hline
\end{tabular}




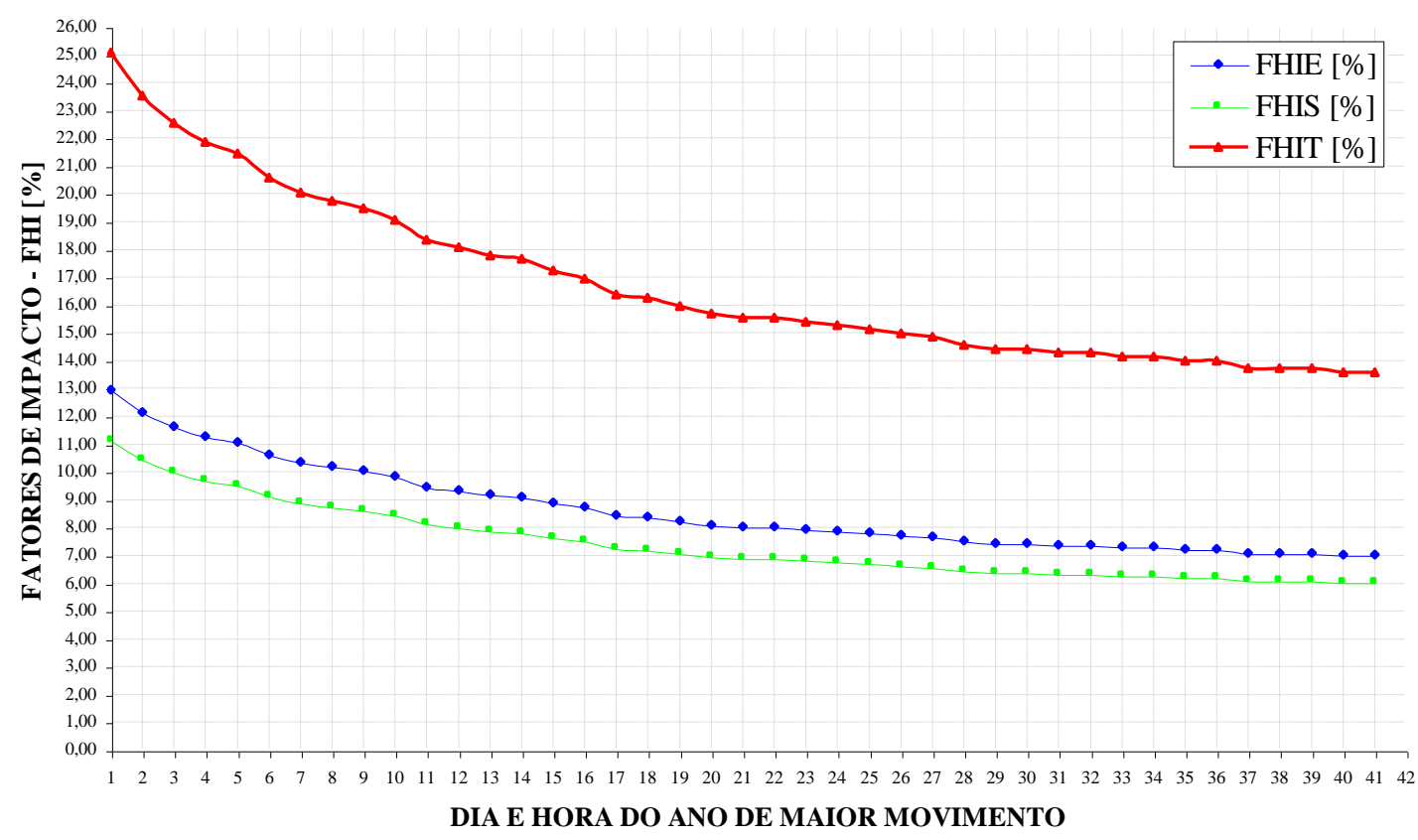

Figura 7.14 - Fatores de impacto para os dias e horas de maior movimento do ano.

Na Tabela 7.19 estão indicados os valores dos fatores de impacto associados ao número de horas não atendidas.

Tabela 7.19 - Valores dos fatores de impacto x Número de horas não atendidas.

\begin{tabular}{|c|c|c|c|c|c|}
\hline $\begin{array}{c}\text { Horas não } \\
\text { atendidas }\end{array}$ & FHIE [\%] & $\boldsymbol{F H I S}[\%]$ & $\boldsymbol{F H I T}[\%]$ & $\begin{array}{c}\text { Horas não } \\
\text { atendidas [\%] }\end{array}$ & $\begin{array}{c}\text { Horas atendidas } \\
{[\%]}\end{array}$ \\
\hline 0 & 12,96 & 11,13 & 25,07 & 0,00 & 100,00 \\
\hline 5 & 10,64 & 9,14 & 20,59 & 0,10 & 99,90 \\
\hline 10 & 9,48 & 8,15 & 18,35 & 0,20 & 99,80 \\
\hline 15 & 8,76 & 7,53 & 16,95 & 0,29 & 99,71 \\
\hline 20 & 8,04 & 6,90 & 15,55 & 0,39 & 99,61 \\
\hline 25 & 7,75 & 6,66 & 14,99 & 0,49 & 99,51 \\
\hline 30 & 7,46 & 6,41 & 14,29 & 0,59 & 99,41 \\
\hline 35 & 7,38 & 6,34 & 14,01 & 0,68 & 99,32 \\
\hline 40 & 7,17 & 6,16 & 13,59 & 0,78 & 99,22 \\
\hline
\end{tabular}

Seguindo o padrão dos projetos de rodovias e vias urbanas, de adotar para o dimensionamento da infra-estrutura (instalações e equipamentos) um valor próximo ao joelho da curva de variação do fluxo (onde a taxa de variação do fluxo passa a ser menor), pode-se adotar como hora de projeto a $10^{\mathrm{a}}$ hora, para o movimento horário no período das 18:00 às 19:00h na sexta-feira, onde $F H I E=9,85 \%$ representa o fator de impacto de entrada, $F H I S=8,46 \%$ é o fator de impacto de saída e FHIT $=19,05 \%$ corresponde ao fator de impacto total de entrada mais saída. Nesse caso, apenas nas 9 horas de maior movimento do ano, no período das 18:00 às 19:00h, os volumes de tráfego nas vias e dispositivos de acesso viário serão superados. Na Tabela 7.18 podem ser identificados os dias do ano em que essas 9 horas 
ocorrem, no caso: 1 hora ocorre no $1^{\circ}$ dia de maior movimento, 1 hora no $2^{\circ}, 1$ horas no $3^{\circ}, 1$ hora no $4^{\circ}, 1$ hora no $5^{\circ}, 1$ hora no $6^{\circ}, 1$ hora no $7^{\circ}, 1$ hora no $8^{\circ}$ e 1 hora no $9^{\circ}$ dia.

Assumindo como hora de projeto a $30^{\mathrm{a}}$ hora, como é comum no projeto de rodovias, resulta $F H I E=7,46 \%, F H I S=6,41 \%$ e $F H I T=14,43 \%$.

Outra forma de abordagem da questão é fixar uma porcentagem para o número de horas não atendidas e determinar o valor de FHI correspondente. Assumindo, por exemplo, que em apenas $0,5 \%$ das horas (aproximadamente 25 horas) o volume adicionado seria excedido, resulta $F H I E=7,75 \%, F H I S=6,66 \%, F H I T=14,99 \%$.

Em função das considerações feitas, a princípio parece razoável adotar como hora de projeto a $10^{\mathrm{a}}$ hora mais movimentada. Neste caso, o valor de $F H I E=9,85 \%$ equivale a $76,00 \%$ do valor de FHIEmáx $=12,96 \%$ (que corresponde ao valor em que o fluxo de veículos de entrada na hora de projeto não é superada em nenhuma hora do ano), significando uma redução física, e possivelmente do custo, de $24,00 \%$ para adequação do sistema viário na implantação do shopping center. O valor de $F H I S=8,46 \%$ representa $76,01 \%$ do valor de FHISmáx $=11,13 \%$ (que corresponde ao valor em que o fluxo de veículos de saída na hora de projeto não é superada em nenhuma hora do ano), significando uma redução física, e possivelmente do custo, de $23,99 \%$ da infra-estrutura nas vias adjacentes ao empreendimento. $\mathrm{O}$ valor de FHIT $=19,05 \%$ representa $75,99 \%$ do valor de FHITmá $x=25,07 \%$ (que corresponde ao valor em que o fluxo de veículos de entrada mais saída na hora de projeto não é superada em nenhuma hora do ano), significando uma redução física, e possivelmente do custo de $24,01 \%$ para adequação dos serviços e/ou infra-estrutura do transporte (tratamento viário, sinalização, etc).

\subsection{ESTIMATIVA DO VOLUME DE VIAGENS NO SÁBADO MÉDIO}

Considerando a magnitude das incertezas dos parâmetros no planejamento do sistema viário de shopping centers, optou-se por adotar para a estimativa das viagens no sábado a relação obtida através de regressão linear simples para este parâmetro e a área bruta locável (ABL) do empreendimento, apresentada na eq.(28).

Assim, o fluxo total no sábado médio deve ser estimado pela expressão:

$$
V s m=1.190,423+0,273 A B L
$$

Sendo, Vsm: estimativa das viagens atraídas no sábado médio [viagens/dia];

$A B L$ : área bruta locável do empreendimento $\left[\mathrm{m}^{2}\right]$ 


\subsection{COMPARAÇÃO DOS RESULTADOS: MÉTODO PROPOSTO $x$ OUTROS MODELOS DESENVOLVIDOS NO PAÍS}

Na Tabela 7.20 estão indicados os resultados obtidos com o método proposto neste trabalho, os valores fornecidos pelos outros modelos desenvolvidos no país e, quando existentes, os valores observados nas pesquisas realizadas.

Tabela 7.20 - Síntese dos resultados obtidos.

\begin{tabular}{|c|c|c|c|c|c|c|c|c|c|}
\hline \multicolumn{4}{|c|}{ Shopping centers } & "A" & "B" & "C" & "D" & "E" & "F" \\
\hline \multicolumn{4}{|c|}{ Área Total Construída $\left[\mathrm{m}^{2}\right]$} & 64.000 & 11.600 & 28.160 & 63.600 & 38.920 & 33.000 \\
\hline \multicolumn{4}{|c|}{ Área Bruta Locável $\left[\mathrm{m}^{2}\right]$} & 20.356 & 4.200 & 17.992 & 27.549 & 18.949 & 17.334 \\
\hline \multirow{5}{*}{ 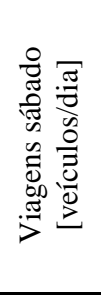 } & \multicolumn{3}{|c|}{ Observado } & 6.153 & 1.743 & 6.247 & 8.100 & 6.400 & 7.431 \\
\hline & \multirow{4}{*}{ 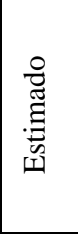 } & \multicolumn{2}{|c|}{ GRANDO (1983) } & 6.012 & -400 & 5.074 & 8.867 & 5.273 & 4.813 \\
\hline & & \multicolumn{2}{|c|}{ GOLDNER (1994) } & 7.950 & 3.351 & 7.228 & 10.146 & 7.754 & 7.027 \\
\hline & & \multicolumn{2}{|c|}{ CET-SP (2000) } & 18.772 & 1.480 & 6.945 & 18.640 & 10.496 & 8.542 \\
\hline & & \multicolumn{2}{|l|}{ MISP* } & 6.748 & 2.337 & 6.102 & 8.711 & 6.239 & 5.923 \\
\hline \multirow{5}{*}{ 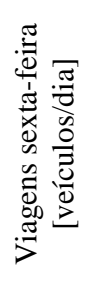 } & \multicolumn{3}{|c|}{ Observado } & 3.815 & 1.432 & 4.145 & 6.760 & 4.500 & 4.547 \\
\hline & \multirow{4}{*}{ 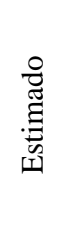 } & \multicolumn{2}{|c|}{ GRANDO (1983) } & 4.449 & -296 & 3.755 & 6.562 & 3.902 & 3.562 \\
\hline & & \multicolumn{2}{|c|}{\begin{tabular}{|l|} 
GOLDNER (1994) \\
\end{tabular}} & 5.883 & 1.524 & 5.348 & 7.508 & 5.236 & 5.200 \\
\hline & & \multicolumn{2}{|c|}{ CET-SP (2000) } & 16.554 & 1.882 & 6.518 & 16.442 & 9.531 & 7.874 \\
\hline & & \multicolumn{2}{|l|}{ MISP* } & 4.761 & 1.659 & 4.332 & 6.185 & 4.430 & 4.205 \\
\hline \multirow{15}{*}{\multicolumn{2}{|c|}{ 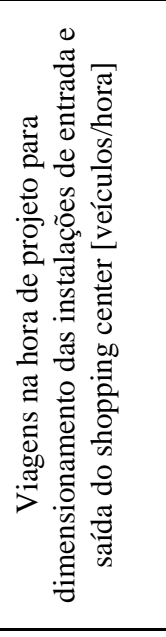 }} & \multirow{3}{*}{\begin{tabular}{|l} 
CET-SP \\
$(1983)$
\end{tabular}} & Entrada & 2.372 & 747 & 1.260 & 2.359 & 1.594 & 1.411 \\
\hline & & & \begin{tabular}{|l|} 
Saída \\
\end{tabular} & $\begin{array}{ll}----- \\
-1\end{array}$ & ------ & $\begin{array}{l}---- \\
--\end{array}$ & ------ & ------ & ----- \\
\hline & & & Total & ------ & ------ & ----- & ------ & ----- & $-\cdots$ \\
\hline & & \multirow{3}{*}{\begin{tabular}{|l} 
GRANDO \\
$(1986)$
\end{tabular}} & Entrada & 631 & -42 & 533 & 931 & 554 & 505 \\
\hline & & & \begin{tabular}{|l|} 
Saída \\
\end{tabular} & 505 & -34 & 426 & 745 & 443 & 404 \\
\hline & & & \begin{tabular}{|l|} 
Total \\
\end{tabular} & $\begin{array}{l}----- \\
\end{array}$ & $\begin{array}{ll}----- \\
\end{array}$ & $\begin{array}{ll}----- \\
\end{array}$ & $\begin{array}{l}---- \\
--\end{array}$ & $\begin{array}{ll}---- \\
\end{array}$ & $-\cdots$ \\
\hline & & \multirow{3}{*}{\begin{tabular}{|l} 
GOLDNER \\
(1994)
\end{tabular}} & Entrada & 714 & 301 & 649 & 911 & 696 & 631 \\
\hline & & & \begin{tabular}{|l|} 
Saída \\
\end{tabular} & 571 & 241 & 519 & 729 & 557 & 505 \\
\hline & & & Total & ------ & ------ & ------ & ------ & ------ & $-\cdots---$ \\
\hline & & \multirow{3}{*}{\begin{tabular}{|l} 
CET-SP \\
$(2000)$
\end{tabular}} & \begin{tabular}{|l|} 
Entrada \\
\end{tabular} & 1.834 & 145 & 679 & 1.821 & 1.025 & 835 \\
\hline & & & \begin{tabular}{|l|} 
Saída \\
\end{tabular} & 1.911 & 151 & 707 & 1.898 & 1.068 & 870 \\
\hline & & & Total & ----- & ------ & ------ & ------ & ----- & ----- \\
\hline & & \multirow[t]{3}{*}{ MISP* } & Entrada & 1.208 & 418 & 1.092 & 1.559 & 1.117 & 1.060 \\
\hline & & & \begin{tabular}{|l|} 
Saída \\
\end{tabular} & 1.025 & 355 & 927 & 1.323 & 948 & 900 \\
\hline & & & Total & 2.244 & 777 & 2.029 & 2.896 & 2.075 & 1.969 \\
\hline \multicolumn{4}{|c|}{ Oferta de estacionamento [vagas] } & 2.000 & 200 & 1.100 & 796 & 1.230 & 1.067 \\
\hline \multirow{5}{*}{\multicolumn{2}{|c|}{ 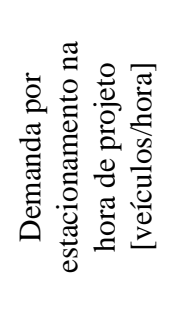 }} & \multicolumn{2}{|c|}{ CET-SP (1983) } & 2.372 & 747 & 1.260 & 2.359 & 1.594 & 1.411 \\
\hline & & \multicolumn{2}{|c|}{ GRANDO (1986) } & 1.237 & -82 & 1.044 & 1.825 & 1.086 & 990 \\
\hline & & GOLDNER & 994) & 1.399 & 590 & 1.272 & 1.786 & 1.364 & 1.237 \\
\hline & & CET-SP (20 & & 3.004 & 504 & 1.224 & 2.765 & 1.692 & 1.435 \\
\hline & & MISP* & & 1.465 & 507 & 1.325 & 1.891 & 1.354 & 1.286 \\
\hline
\end{tabular}

Nota: *Método proposto neste trabalho para shopping centers localizados em cidades do interior do estado de São Paulo. 
Tabela 7.20 - Síntese dos resultados obtidos.

\begin{tabular}{|c|c|c|c|c|c|c|c|c|}
\hline \multicolumn{3}{|c|}{ Shopping centers } & "A" & "B" & "C" & "D" & "E" & "F" \\
\hline \multirow{12}{*}{ 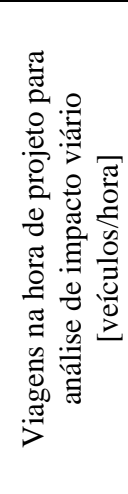 } & \multirow{3}{*}{\begin{tabular}{|l} 
GRANDO \\
$(1986)$
\end{tabular}} & Entrada & 467 & -31 & 394 & 689 & 410 & 374 \\
\hline & & Saída & 374 & -25 & 315 & 551 & 328 & 299 \\
\hline & & Total & $\begin{array}{ll}----- \\
\end{array}$ & ----- & +----- & +---- & ------ & ------ \\
\hline & \multirow{3}{*}{$\begin{array}{l}\text { GOLDNER } \\
(1994)\end{array}$} & Entrada & 581 & 151 & 528 & 742 & 517 & 514 \\
\hline & & Saída & 465 & 121 & 422 & 594 & 414 & 411 \\
\hline & & Total & +---- & $\begin{array}{ll}----- \\
\end{array}$ & ------ & +---- & $\begin{array}{ll}----- \\
\end{array}$ & $\begin{array}{ll}----- \\
\end{array}$ \\
\hline & \multirow{3}{*}{\begin{tabular}{|l} 
CET-SP \\
$(2000)$
\end{tabular}} & Entrada & 1.559 & 177 & 614 & 1.549 & 898 & 742 \\
\hline & & Saída & 1.288 & 146 & 507 & 1.279 & 742 & 613 \\
\hline & & Total & $\begin{array}{ll}----- \\
\end{array}$ & $\begin{array}{ll}----- \\
\end{array}$ & ------ & $\begin{array}{ll}----- \\
\end{array}$ & $\begin{array}{ll}----- \\
\end{array}$ & $\begin{array}{ll}----- \\
\end{array}$ \\
\hline & \multirow[t]{3}{*}{ MISP* } & Entrada & 665 & 230 & 601 & 858 & 614 & 583 \\
\hline & & Saída & 570 & 197 & 517 & 737 & 528 & 501 \\
\hline & & Total & 1.286 & 445 & 1.162 & 1.659 & 1.188 & 1.128 \\
\hline
\end{tabular}

Nota: *Método proposto neste trabalho para shopping centers localizados em cidades do interior do estado de São Paulo.

A Figura 7.15 mostra graficamente os resultados do número de viagens no sábado médio obtidos com o método proposto, os valores fornecidos pelos outros modelos desenvolvidos no país e os valores observados nas pesquisas realizadas.

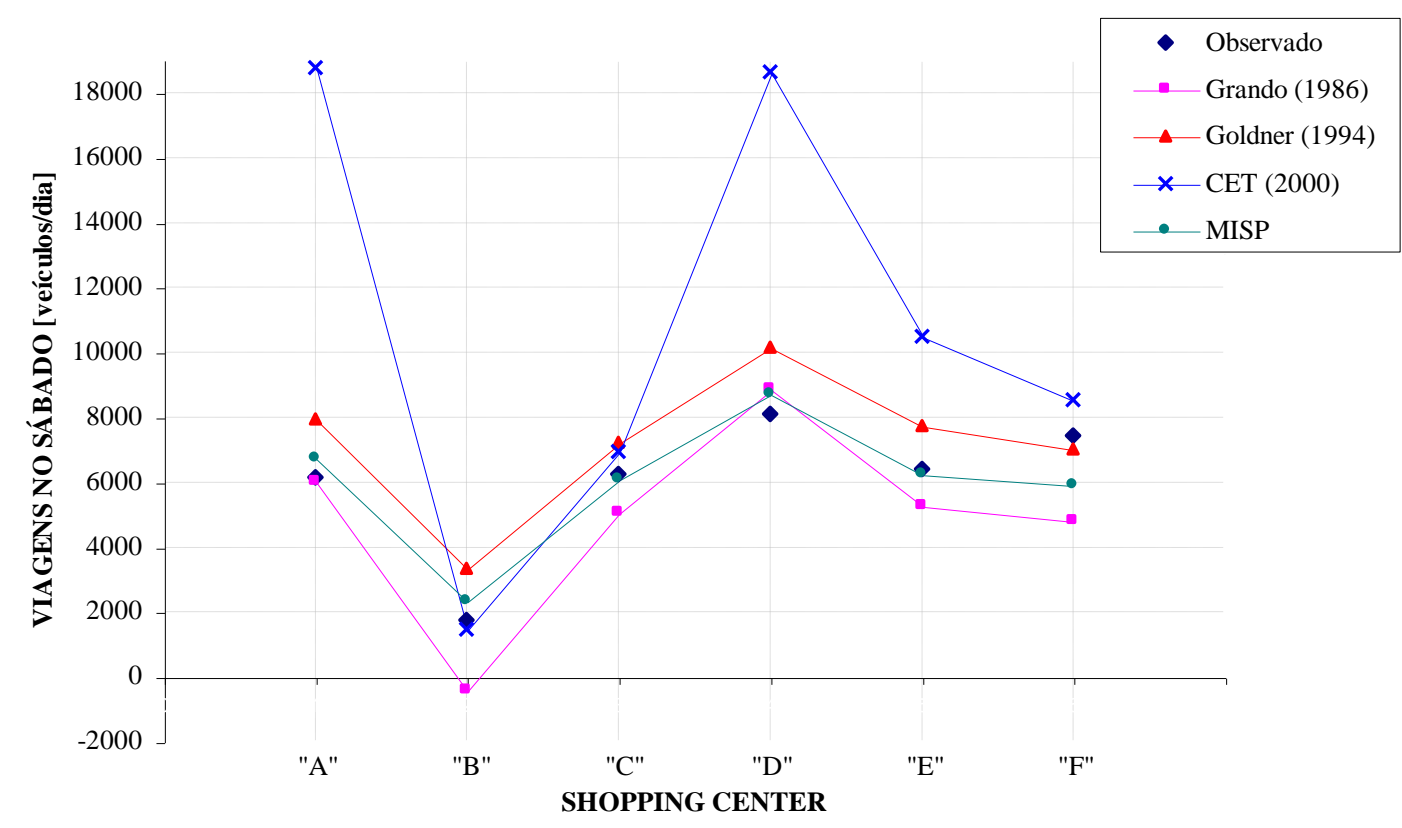

Figura 7.15 - Volume de veículos no sábado.

As considerações que se seguem baseiam-se nos valores da Tabela 7.20 e na Figura 7.15:

- Os valores de CET (2000) são, em geral, muito altos e bastante discrepantes em relação aos resultados dos outros métodos. 
- Os valores de GRANDO (1986) são, em geral, os menores. O resultado apresentado para o shopping "B" é incoerente (negativo), devido a que a expressão para estimar a geração de viagens no sábado só é valida para empreendimentos com área bruta locável superior a $5.207 \mathrm{~m}^{2}$.

- Os valores do método proposto e do método de GOLDNER (1994) são relativamente próximos - os de Goldner sempre maiores - e situam-se, em geral, numa faixa de valores intermediários em relação aos resultados apresentados pelos métodos CET (2000) e GRANDO (1986).

A Figura 7.16 mostra graficamente os resultados do número de viagens na sexta-feira média obtidos com o método proposto, os valores fornecidos pelos outros modelos desenvolvidos no país e os valores observados nas pesquisas realizadas.

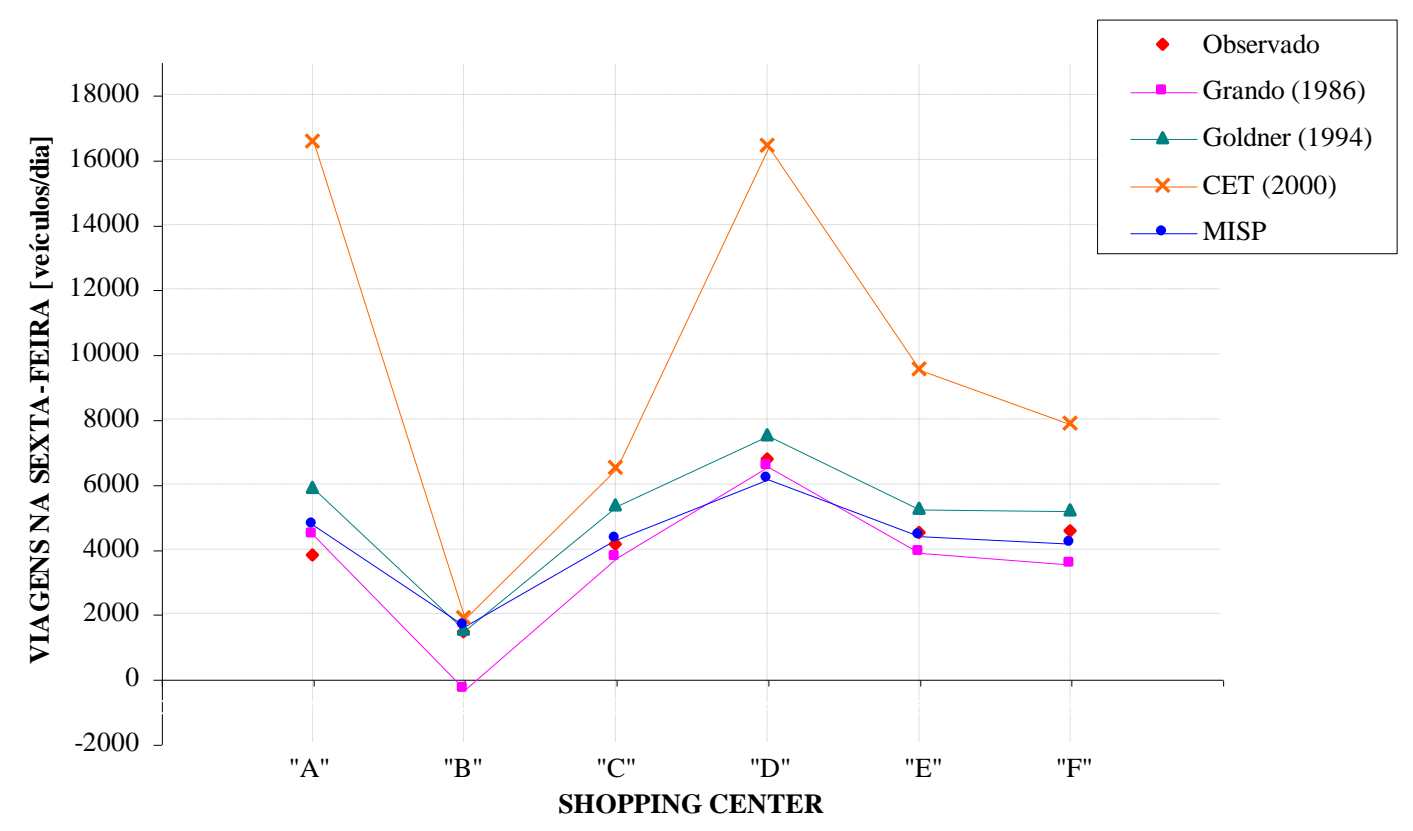

Figura 7.16 - Volume de veículos na sexta-feira.

As considerações que se seguem baseiam-se nos valores da Tabela 7.20 e na Figura 7.16:

- Os valores de CET (2000) são, em geral, muito altos e bastante discrepantes em relação aos resultados dos outros métodos.

- Os valores de GRANDO (1986) são, em geral, os menores. O resultado apresentado para o shopping "B" é incoerente (negativo), devido a que a expressão para estimar a geração de 
viagens na sexta-feira só é valida para empreendimentos com área bruta locável superior a $5.207 \mathrm{~m}^{2}$.

- Os valores do método proposto e do método de GOLDNER (1994) são relativamente próximos - os de Goldner sempre maiores, salvo no shopping "B" onde o resultado de Goldner é ligeiramente menor - e situam-se, em geral, numa faixa de valores intermediários em relação aos resultados apresentados pelos métodos CET (2000) e GRANDO (1986).

A Figura 7.17 mostra graficamente os resultados do volume de chegadas de veículos na hora de projeto para dimensionamento da infra-estrutura obtidos com o método proposto e os valores fornecidos pelos outros modelos desenvolvidos no país.

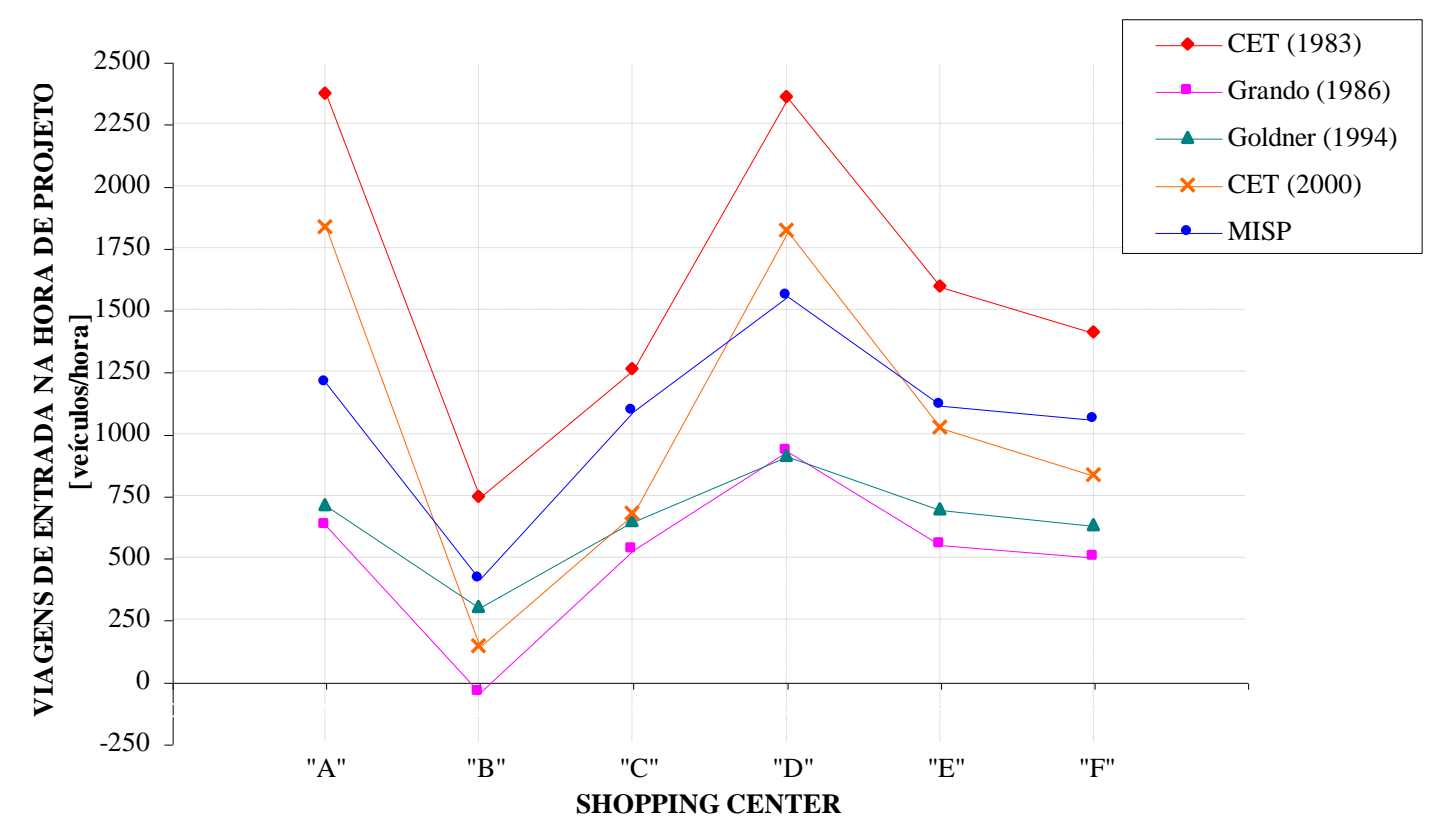

Figura 7.17 - Volume de chegadas na hora de projeto para dimensionamento da infra-estrutura.

As considerações que se seguem baseiam-se nos valores da Tabela 7.20 e na Figura 7.17:

- Os valores extremos mais elevados são os de CET (1983).

- Os valores extremos mais baixos são, em geral, os de GRANDO (1986). O resultado apresentado por este método para o shopping "B" é incoerente (negativo), devido a que a 
expressão para estimar a geração de viagens no sábado só é valida para empreendimentos com área bruta locável superior a $5.207 \mathrm{~m}^{2}$.

- Os valores do método proposto, do método de GOLDNER (1994) e do modelo CET (2000) situam-se, em geral, numa faixa de valores intermediários em relação aos resultados apresentados pelos métodos CET (1983) e GRANDO (1986).

- Os resultados do método proposto estão numa faixa mais próxima dos valores médios considerando os outros métodos.

A Figura 7.18 mostra graficamente os resultados do volume de saídas de veículos na hora de projeto para dimensionamento da infra-estrutura obtidos com o método proposto e os valores fornecidos pelo modelo CET (2000) desenvolvido no país.

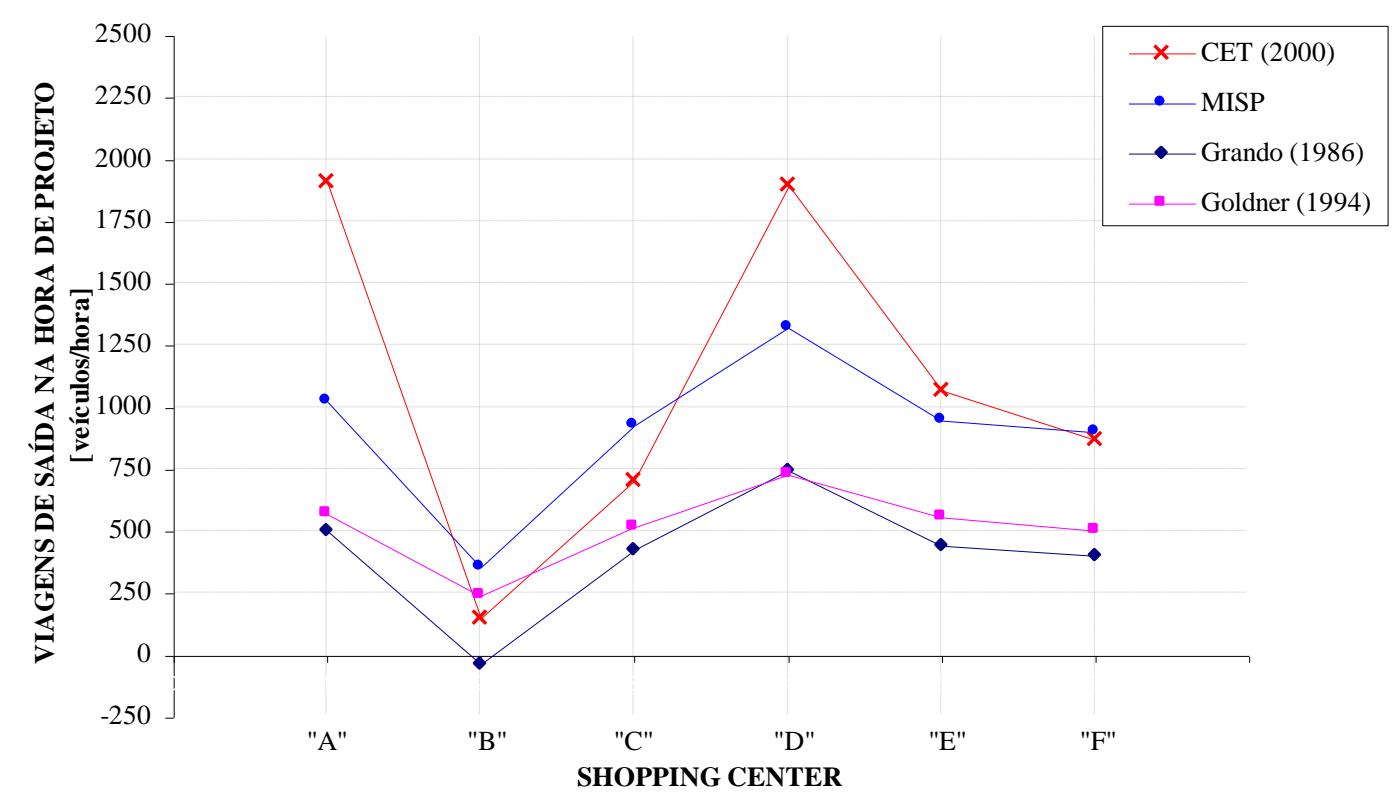

\section{Figura 7.18 - Volume de saídas na hora de projeto para} dimensionamento da infra-estrutura.

As considerações que se seguem baseiam-se nos valores da Tabela 7.20 e na Figura 7.18:

- Os valores extremos mais elevados são os de CET (2000).

- Os valores extremos mais baixos são, em geral, os de GRANDO (1986). O resultado apresentado por este método para o shopping "B" é incoerente (negativo), devido a que a 
expressão para estimar a geração de viagens no sábado só é valida para empreendimentos com área bruta locável superior a $5.207 \mathrm{~m}^{2}$.

- Os valores do método proposto e do método de GOLDNER (1994) situam-se, em geral, numa faixa de valores intermediários em relação aos resultados apresentados pelos métodos CET (2000) e GRANDO (1986).

- Os resultados do método proposto estão numa faixa mais próxima dos valores médios considerando os outros métodos.

A Figura 7.19 mostra graficamente os resultados da demanda por estacionamento na hora de projeto obtidos com o método proposto e os valores fornecidos pelos outros modelos desenvolvidos no país.

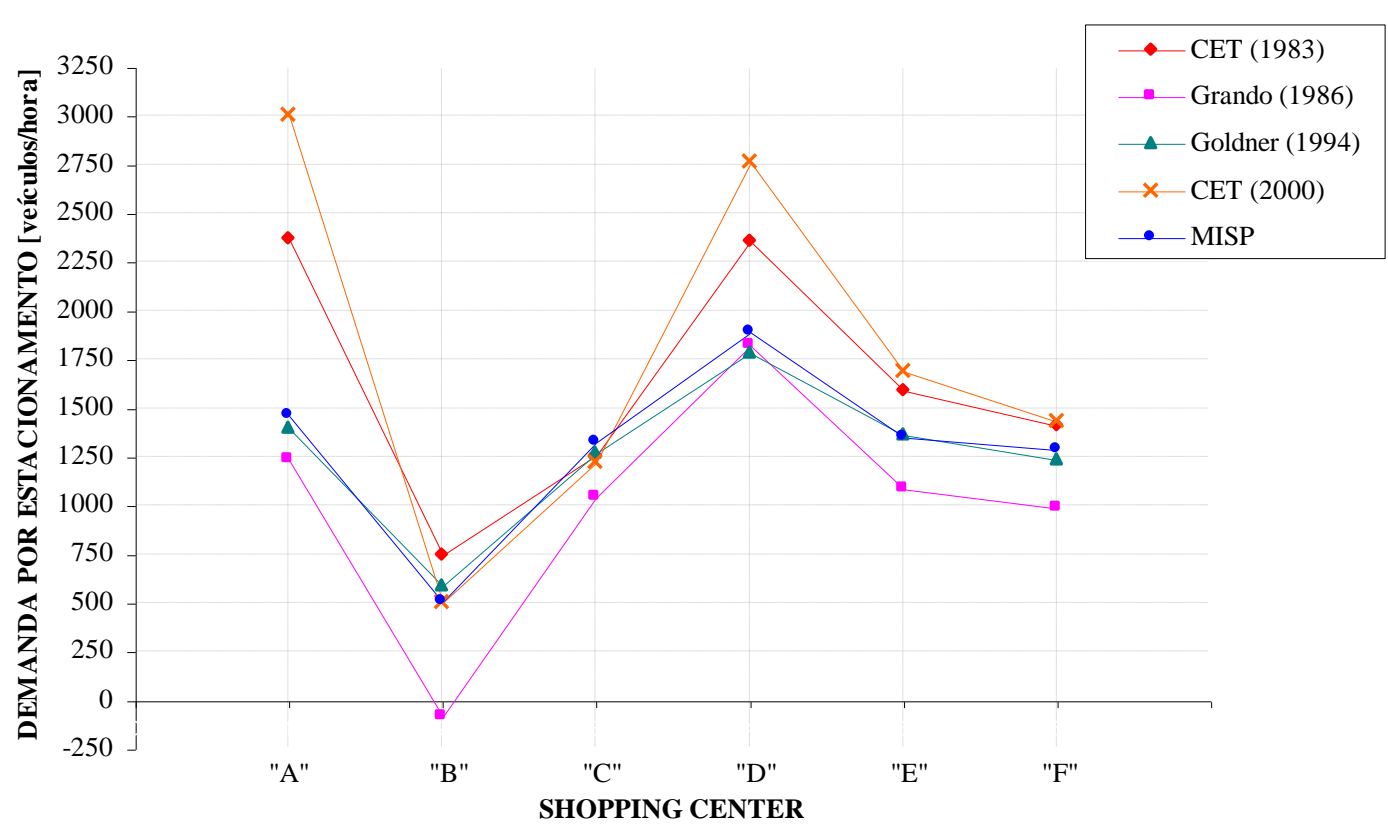

Figura 7.19 - Demanda por estacionamento na hora de projeto.

As considerações que se seguem baseiam-se nos valores da Tabela 7.20 e na Figura 7.19:

- Os valores extremos mais elevados são, em geral, os de CET (2000).

- Os valores extremos mais baixos são, em geral, os de GRANDO (1986). O resultado apresentado por este método para o shopping "B" é incoerente (negativo), devido a que a 
expressão para estimar a geração de viagens no sábado só é valida para empreendimentos com área bruta locável superior a $5.207 \mathrm{~m}^{2}$.

- Os valores do método proposto, do método de GOLDNER (1994) e do modelo CET (1983) situam-se, em geral, numa faixa de valores intermediários em relação aos resultados apresentados pelos métodos CET (2000) e GRANDO (1986).

- Os resultados do método proposto e do método de GOLDNER (1994) são muito similares e estão numa faixa mais próxima dos valores médios considerando os outros métodos.

A Figura 7.20 mostra graficamente os resultados do volume de chegadas de veículos na hora de projeto (18:00 - 19:00 horas de sexta-feira) para efeito de avaliação do impacto viário obtidos com o método proposto e os valores fornecidos pelos outros modelos desenvolvidos no país.

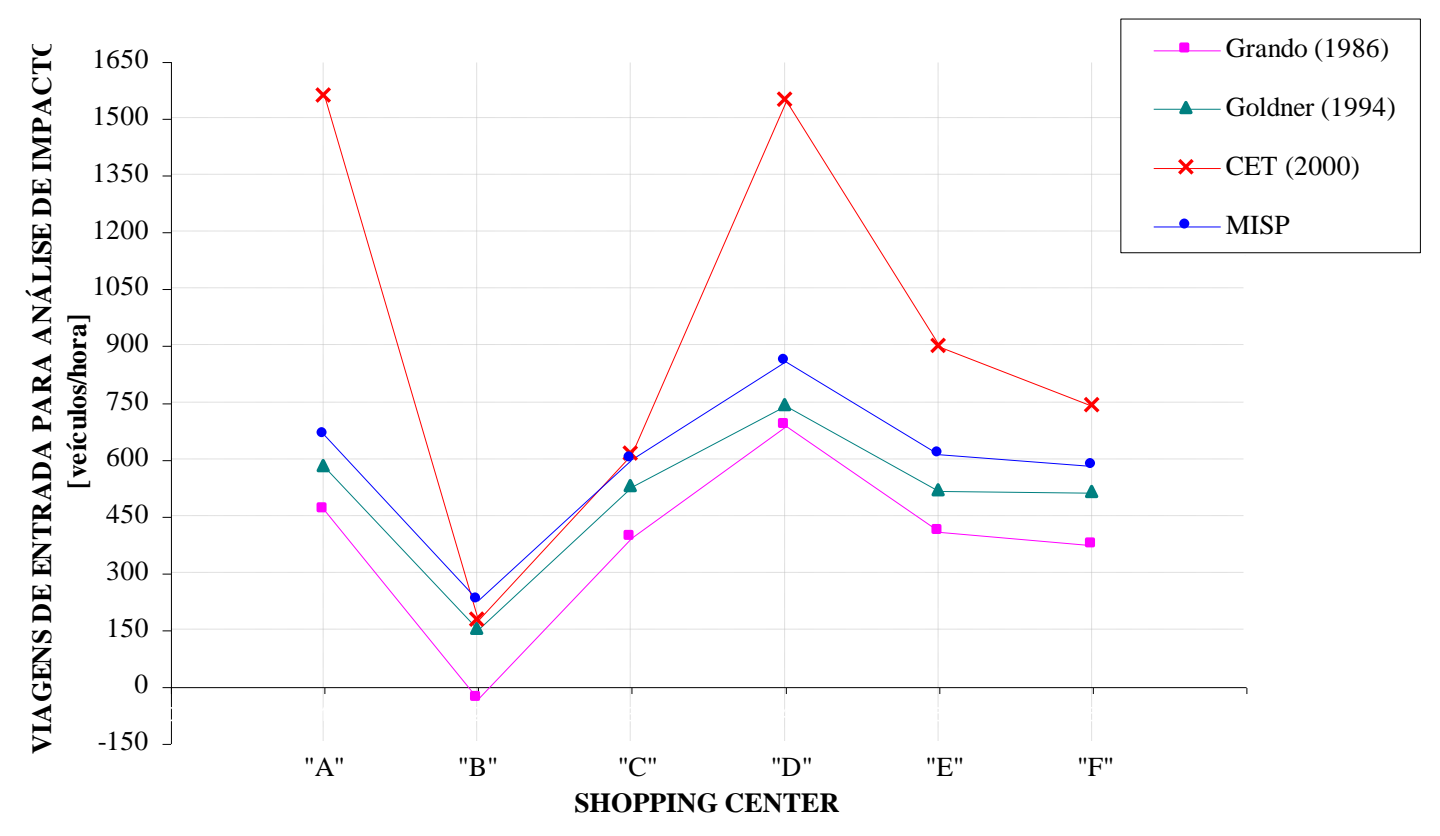

Figura 7.20 - Volume de chegadas na hora de projeto para avaliação do impacto viário.

As considerações que se seguem baseiam-se nos valores da Tabela 7.20 e na Figura 7.20:

- Os valores de CET (2000) são, em geral, muito altos e bastante discrepantes em relação aos resultados dos outros métodos.

- Os valores de GRANDO (1986) são, em geral, os menores. O resultado apresentado para o shopping "B" é incoerente (negativo), devido a que a expressão para estimar a geração de 
viagens na sexta-feira só é valida para empreendimentos com área bruta locável superior a $5.207 \mathrm{~m}^{2}$.

- Os valores do método proposto e do método de GOLDNER (1994) são relativamente próximos - os de Goldner sempre menores - e situam-se, em geral, numa faixa de valores intermediários em relação aos resultados apresentados pelos métodos CET (2000) e GRANDO (1986).

A Figura 7.21 mostra graficamente os resultados do volume de saídas de veículos na hora de projeto (18:00 - 19:00 horas de sexta-feira) para efeito de avaliação do impacto viário obtidos com o método proposto e os valores fornecidos pelo modelo CET (2000) desenvolvido no país.

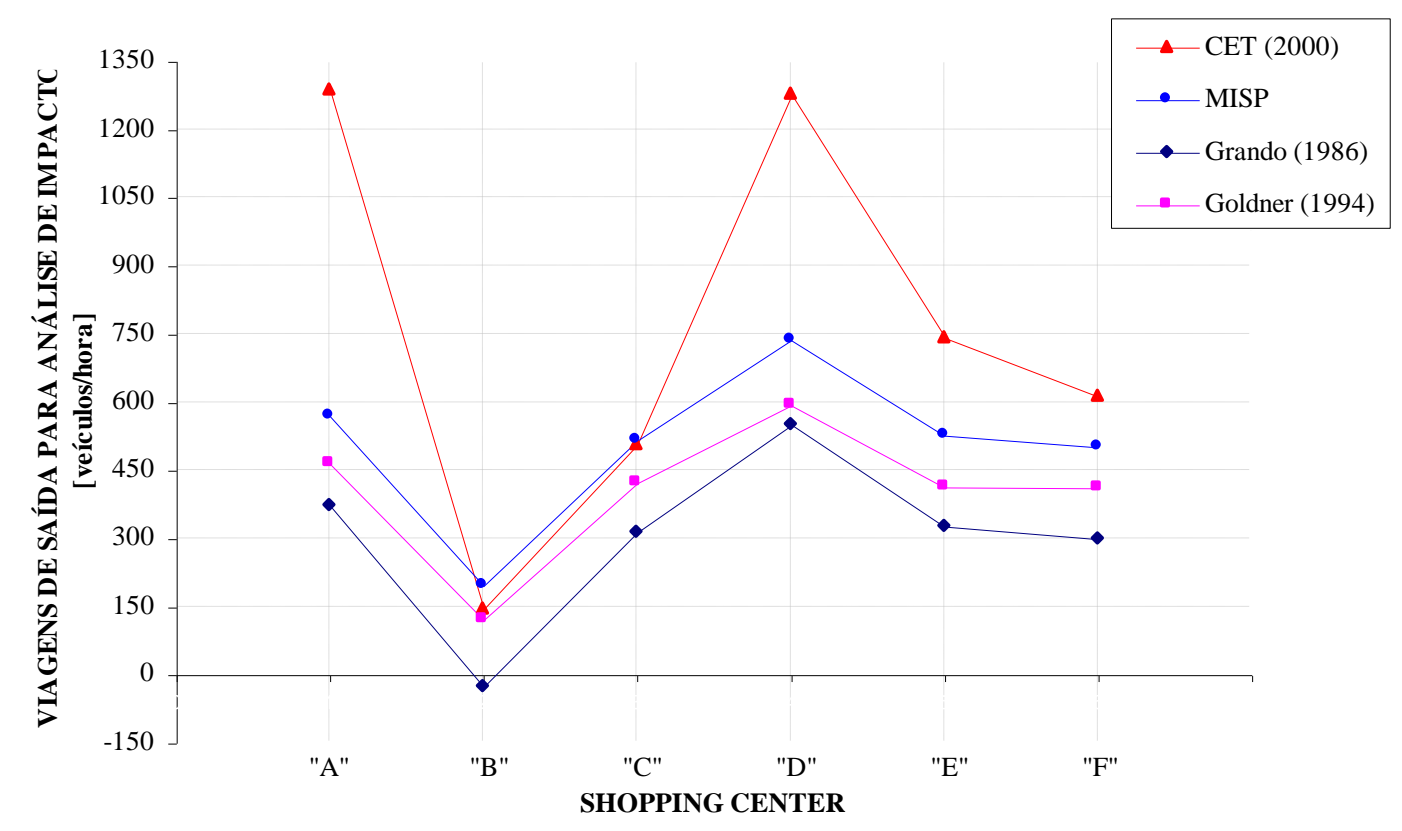

Figura 7.21 - Volume de saídas na hora de projeto para avaliação do impacto viário.

As considerações que se seguem baseiam-se nos valores da Tabela 7.20 e na Figura 7.21:

- Os valores extremos mais elevados são os de CET (2000).

- Os valores extremos mais baixos são, em geral, os de GRANDO (1986). O resultado apresentado por este método para o shopping "B" é incoerente (negativo), devido a que a 
expressão para estimar a geração de viagens na sexta-feira só é valida para empreendimentos com área bruta locável superior a $5.207 \mathrm{~m}^{2}$.

- Os valores do método proposto e do método de GOLDNER (1994) situam-se, em geral, numa faixa de valores intermediários em relação aos resultados apresentados pelos métodos CET (2000) e GRANDO (1986).

- Os resultados do método proposto estão numa faixa mais próxima dos valores médios considerando os outros métodos.

Com base nas análises comparativas efetuadas, pode-se, a princípio, dizer que o método proposto e o método de GOLDNER (1994) apresentam os resultados mais razoáveis.

A aplicação do método proposto para estimar as viagens geradas sexta-feira e sábado, nos empreendimentos pesquisados, apresenta valores inferiores aos valores obtidos através da aplicação do modelo de Goldner. Isto é possível que se deva ao fato do tamanho dos empreendimentos utilizados para desenvolver os modelos de estimativas das viagens. Goldner utilizou shopping centers com tamanho variando de 3.155 a $73.312 \mathrm{~m}^{2}$ de ABL, localizados em cidades grandes, entretanto, no método proposto usaram-se empreendimentos com tamanho inferior, variando de 4.200 a $27.549 \mathrm{~m}^{2}$ de $\mathrm{ABL}$, localizados em cidades de médio porte.

$\mathrm{Na}$ aplicação do método proposto para estimar as viagens na hora pico e as viagens horárias para avaliação de impacto viário, nos empreendimentos pesquisados, os valores apresentam-se superiores aos valores obtidos através da aplicação do modelo de Goldner. Nesta caso, é possível que se deva ao fato dos fatores de projeto apresentarem valores superiores aos adotados por Goldner.

Para estimar a demanda por estacionamento, a aplicação do método proposto e do método de Goldner apresentam semelhanças. No entanto, as expressões usadas para determinar a demanda são diferentes. No caso do método proposto utiliza-se o fator de projeto de acúmulo de veículos e as viagens geradas no sábado médio. No método de Goldner usa-se o tempo médio de permanência dos veículos e as viagens geradas na hora pico do sábado.

Contudo, os resultados do método proposto, para a $10^{\mathrm{a}}$ hora mais movimentada do ano, oferecem resultados superiores e mais próximos dos valores observados. 


\section{CONSIDERAÇÕES FINAIS}

Neste trabalho, a análise de cada um dos aspectos tratados exigiu que as proposições conclusivas fossem feitas no desenrolar de cada assunto apresentado. Entretanto, algumas considerações finais tornam-se necessárias.

No desenvolvimento das análises realizadas, procurou-se mostrar que as dificuldades enfrentadas pela implantação de shopping centers no meio urbano, no que diz respeito à geração de viagens e demanda por estacionamento, representam aspectos de profundo interesse para órgãos municipais, planejadores de transportes e empreendedores.

A maior dificuldade enfrentada é o pouco conhecimento registrado desses empreendimentos. Assim, procurou-se através da bibliografia disponível, apresentar neste trabalho elementos que permitissem uma análise e aperfeiçoamento de métodos utilizados para estimar a geração de viagens e demanda por estacionamento em shopping centers.

A revisão bibliográfica realizada permitiu identificar uma grande quantidade de fatores que influem na quantidade e na distribuição no tempo das viagens atraídas por shopping centers - parâmetros decisivos para o dimensionamento da infra-estrutura viária, instalações e equipamentos, bem como para a análise do impacto no trânsito da região.

Os principais fatores que influenciam no número e na distribuição no tempo das viagens geradas são o porte global e o tamanho individual dos setores de comércio, serviços e lazer. Além desses, outros fatores também têm grande influência na quantidade e no padrão temporal das viagens, tais como: características sócio-econômicas da população da cidade e da região de influência, nível de concorrência com outros empreendimentos ou áreas comerciais da cidade, facilidade de acesso, oferta de estacionamento, etc.

Dessa forma, é bastante difícil determinar com precisão a quantidade e a distribuição temporal das viagens a serem geradas por um novo shopping a ser construído. No entanto, é absolutamente necessário dispor de métodos para estimativa desses parâmetros, 
visando o dimensionamento da infra-estrutura viária, instalações e equipamentos, assim como para análise do impacto no trânsito da região.

No Brasil, os principais estudos desenvolvidos para estimativa da quantidade e padrão de viagens geradas por shopping centers são: CET-SP (1983), GRANDO (1986), GOLDNER (1994) e CET-SP (2000). Os trabalhos da CET-SP foram desenvolvidos com base em dados coletados em shopping centers localizados na cidade de São Paulo. Os trabalhos de Grando e Goldner foram desenvolvidos através de dados obtidos em shopping centers, localizados principalmente em cidades grandes, em diversas regiões do país, e alguns padrões de viagens foram obtidos com base em dados coletados em shopping centers localizados no Rio de Janeiro e Recife. Em todos eles, na estimativa do número de veículos atraídos pelo shopping center é considerado apenas o tamanho total do empreendimento (área bruta locável - ABL ou área total construída - ATC).

Assim, pressupondo que o comportamento dos veículos atraídos por shopping centers apresenta diferenças quanto à região onde se localiza o empreendimento, foram pesquisados empreendimentos localizados numa determinada região, no interior do estado de São Paulo, em cidades de médio porte. Na amostra estudada verificou-se a aplicabilidade de alguns valores adotados como padrões de viagem e modelos nacionais utilizados para estimar a geração de viagens e demanda por estacionamento em shopping centers. Os resultados obtidos permitiram constatar que as viagens geradas por empreendimentos localizados no interior do estado de São Paulo apresentam comportamento diferenciado.

A incidência dos picos horários na movimentação de veículos aos shopping centers pesquisados apresenta-se diferente dos períodos identificados por GRANDO (1986) e GOLDNER (1994). No entanto, apresenta certa semelhança com a incidência dos picos identificados por CET-SP (2000). Isto comprova um comportamento da demanda diária de veículos para o universo estudado diferente de empreendimentos localizados na cidade do Rio de Janeiro. Constatou-se, ainda, que a incidência do acúmulo máximo de veículos no estacionamento varia entre 20:00 e 22:00h, nos empreendimentos pesquisados, o que não foi constatado em nenhum estudo a nível nacional.

Os resultados obtidos em cada empreendimento permitiram determinar valores médios para alguns padrões de viagens, tais como: a relação de número de veículos atraídos na sexta-feira e no sábado, correspondendo a 0,71 , a porcentagem de pico horário na sexta-feira, correspondendo a 13,69\% das viagens atraídas, com incidência entre 19:00 e 21:00h, a porcentagem de pico horário no sábado, correspondendo a 12,51\%, com incidência entre 19:00 e 22:00h, o fator horário de geração de viagens, para estimar o impacto de tráfego nas vias 
adjacentes aos empreendimentos, na sexta-feira, entre 18:00 e 19:00h, correspondendo a $10,21 \%$, e o do tempo médio de permanência dos veículos no estacionamento, correspondendo a 0,94h, no sábado.

A comparação de valores adotados por autores nacionais para alguns padrões de viagens para shopping centers com os resultados obtidos nos empreendimentos pesquisados, permitiu constatar que os valores adotados para porcentagem de pico horário, fator horário de geração de viagens para análise de impacto viário e tempo médio de permanência dos veículos no estacionamento, não se ajustam aos valores reais observados.

A aplicação dos modelos nacionais aos dados observados nos shopping centers pesquisados mostrou que esses modelos fornecem valores discrepantes com os valores observados do volume de veículos diários, volume de veículos horários e demanda por estacionamento.

As tentativas realizadas para obter novos modelos de geração de viagens através de regressão linear simples, considerando a área bruta locável e área total construída dos shopping centers, mostram que a área bruta locável é um fator mais significativo a ser considerado na estimativa da geração de viagens. Constata-se, ainda, que é possível obter uma relação mais significativa entre as viagens diárias em função das áreas desagregadas por ramos de atividade.

Nas comparações realizadas de valores observados para as viagens diárias atraídas pelos empreendimentos com valores obtidos através da aplicação de modelos nacionais e dos modelos desenvolvidos para os shopping centers pesquisados, sugerem-se como melhores estimativas para sexta-feira a eq.(27) obtida através de regressão linear simples, em função da área bruta locável, e a eq.(31) obtida através de regressão linear múltipla, considerando as áreas desagregadas de comércio, lazer e serviços. Para estimar as viagens diárias atraídas no sábado sugere-se como melhor estimativa a eq.(28) obtida através de regressão linear simples, em função da área bruta locável.

Os modelos sugeridos pela CET-SP (2000), aplicados aos empreendimentos pesquisados, consideram-se inapropriados para estimar as viagens diárias atraídas na sexta-feira e no sábado, devido à grande discrepância com os valores observados.

O método proposto para dimensionar alguns parâmetros de projeto de shopping centers sugere a utilização de fatores de projeto para a $10^{\mathrm{a}}$ hora mais movimentada do ano. Isto considerando que em cidades de porte médio, localizadas no interior do estado de São Paulo, parece razoável dimensionar a infra-estrutura, instalações e equipamentos, para atender 
praticamente a capacidade máxima, levando em conta que o congestionamento nos acessos do estacionamento é indesejável por prejudicar o trânsito adjacente.

Contudo, os resultados obtidos nos empreendimentos pesquisados, a definição de alguns parâmetros, o desenvolvimento de alguns modelos de geração de viagens, principalmente o modelo que considera as áreas desagregadas dos estabelecimentos por ramos de atividades, e o método proposto para dimensionar alguns parâmetros de projeto de shopping centers, representam uma grande contribuição para shopping centers localizados em cidades de médio porte no interior do estado de São Paulo, considerando que atualmente nenhuma informação existe ao respeito para esse tipo de empreendimentos.

Considerando que os shopping centers representam sistemas muito complexos, devido principalmente aos ramos de atividade oferecidos, sugere-se para futuros pesquisadores desagregar o tamanho geral dos empreendimentos em mais ramos de atividade, destacando a presença de cinemas, e a adoção de Redes Neurais Artificiais ou outras técnicas na estimativa da geração de viagens e demanda por estacionamento, que possibilitem o relacionamento de variáveis não-lineares. Para essas estimativas recomenda-se, ainda, a realização de uma pesquisa mais ampla e abrangente, envolvendo um número maior de shopping centers e de outras variáveis que interferem na geração de viagens e demanda por estacionamento, de modo a identificar padrões de comportamento mais apurados e obter resultados e conclusões mais confiáveis, bem como para elaborar modelos de previsão de demanda que apresentem maior confiabilidade, permitindo um melhor dimensionamento da infra-estrutura e das instalações e equipamentos nos acessos de entrada e saída do estacionamento e do sistema viário associado aos shopping centers.

Sendo constatado, ainda, que a maior dificuldade enfrentada para obter conhecimento em shopping centers é a falta de consciência por parte de órgãos públicos, empreendedores e especialmente administradores de shopping centers, de atitudes que facilitem as pesquisas nesses empreendimentos, sugere-se, ainda, a conscientização destes para mudar de comportamento, procurando atitudes que superem as dificuldades enfrentadas por pesquisadores que procuram aprimorar o conhecimento nesses empreendimentos. No entanto, é possível destacar a participação da administração dos shopping centers que colaboraram para a realização deste trabalho. 


\section{REFERÊNCIAS BIBLIOGRÁFICAS}

ASSOCIAÇÃO BRASILEIRA DE SHOPPING CENTERS (2003). Shopping Associados Segmentação por Tipo. http: //www.abrasce.com.br . (2 abr.).

ASSOCIAÇÃO BRASILEIRA DE SHOPPING CENTERS (2003). Grandes Números do Setor. http: //www.abrasce.com.br . (2 abr.).

AL-MASAEID, H. R.; AL-OMARI, B. \& AL-HARAHSHEH, A. (1999). Vehicle parking demand for different land uses in Jordan. ITE Journal. Institute of Transportation Engineers, Washington, D. C., p.79-84

BARRET, R. (1975). Trip generation and modal split of shopping trips. Traffic Engineering \& Control. Febr.

BREVIS, C. B. e FERRAZ, A. C. P. (2001). Proyecto de estacionamiento en centros comerciales: Um estúdio de caso. (CD-ROM). V Congreso de Ingeniería del Transporte. Buenos Aires.

CET-SP (2000). Pólos Geradores de Tráfego II. Companhia de Engenharia de Tráfego, São Paulo / Boletim Técnico 36.

CET-SP (1986). Áreas de Estacionamento e Gabaritos de Curvas Horizontais. Companhia de Engenharia de Tráfego, São Paulo / Boletim Técnico 33.

CET-SP (1983). Pólos Geradores de Tráfego. Companhia de Engenharia de Tráfego, São Paulo / Boletim Técnico 32.

CONCEIÇÃO, I. (1984). Shopping Centers: desenvolvimento, localização e impacto do tráfego no sistema viário. Rio de Janeiro, 148p. Dissertação (Mestrado). COPPE, Universidade Federal do Rio de Janeiro.

CORREA, M. M. D. \& GOLDNER, L. G. (1999). Uma metodologia para delimitação da área de influência de shopping centers. Anais do XIII Congresso da Associação Nacional de Pesquisa e Ensino em Transportes (ANPET), São Carlos, v.1, p.62-71

DENATRAN (2001). Manual de Procedimentos para o Tratamento de Pólos Geradores de Tráfego. Departamento Nacional de Trânsito, Brasília: Denatran/FGV/ Boletim Técnico.

DUNN, R. C. M. \& HAMILTON, G. D. (1971). Transportation Engineering Design for Shopping Centers. Traffic Engineering \& Control, p.295-6. Nov.

FAN, H. S. L. \& LAM, S. H. (1997). Parking generation of commercial developments in Singapore. Journal of Transportation Engineering. v.123, n.3, p.238-42. 
GERN, R. C. (1978). Parking demand at the regionals. ITE Journal, Washington, D.C. 48(9):19-24. Sept.

GERN, R. C. (1975). Guidelines for planning and designing access systems for shopping centers, Part I. Traffic Engineering, p.35-40, Feb.

GHEZAWI, R. S.; WEGMANN, F. J. \& CHATTERJEE, A. (1998). Convenience store trip generation. ITE Journal, Institute of Transportation Engineers, Washington, D. C.

GONÇALVES, A. A. (1990). ESTSIM: Um modelo de simulação para estacionamento de shopping centers. Rio de Janeiro, 148p. Dissertação (Mestrado). COPPE, Universidade Federal do Rio de Janeiro.

GOLDNER, L. (1994). Uma metodologia de avaliação de impactos de shopping centers sobre o sistema viário. Rio de Janeiro, 213p. Tese (Doutorado). COPPE, Universidade Federal do Rio de Janeiro.

GRANDO, L. (1986). A interferência dos pólos geradores de tráfego no sistema viário: análise e contribuição metodológica para shopping centers. Rio de Janeiro, 201p. Dissertação (Mestrado). COPPE, Universidade Federal do Rio de Janeiro.

HIGHWAY RESEARCH BOARD SPECIAL REPORT No. 125 (1971). Parking Principles. Highway Research Board, Washington, D. C.

ITE (1997). Trip Generation, $6^{\text {th }}$ ed. Institute of Transportation Engineers, Washington, D.C.

ITE (1987). Parking Generation. Institute of Transportation Engineers, Washington, D.C.

LEAKE, G. R. \& TURNER, D. J. (1982). Shopper and vehicle characteristics at large retail shopping centres. Traffic Engineering \& Control. p.12. Jan.

MARTINS, J. A. (1996). Transporte, uso do solo e auto-sustentabilidade. Rio de Janeiro, 146p. Tese (Doutorado). COPPE, Universidade Federal do Rio de Janeiro.

MACKENZIE, G. \& EASTMAN. C. (1992). Assessment of Parking Demand. Traffic Engineering \& Control. p.150-4, March.

PORTUGAL, L. S. \& GOLDNER, L. G. (2003). Estudo de Pólos Geradores de Tráfego e de seus Impactos nos Sistemas Viários e de Transportes. Ed. Edgard Blücher Ltda. São Paulo.

SILVEIRA, I. T. (1991). Análise de Pólos Geradores de Tráfego segundo sua classificação, área de influência e padrão de viagens. Rio de Janeiro, 303p. Dissertação (Mestrado). COPPE, Universidade Federal do Rio de Janeiro.

SMITH, S. A. (1986). A methodology for considerations of pass-by trips in traffic impacts analysis for shopping center. ITE Journal. August.

SMITH, W. S. (1983). Automobile Parking Trends. Transportation Quarterly, v.37, n.3, p.431-52, July.

SOARES, M. V. (1990). Método para estabelecimento da capacidade de uma rede viária: análise dos efeitos de implantação de Pólos Geradores de Tráfego. Rio de Janeiro, 187p. Dissertação (Mestrado). COPPE, Universidade Federal do Rio de Janeiro. 
STEINER, R. L. (1998). Trip generation and parking requirements in traditional shopping districts. Transportation Research Record 1617, TRB, National Research Council, Washington, D. C., p.28-37.

URBAN LAND INSTITUTE (1982). Parking Requirements for Shopping Centers: summary recommendations and research study report. Washington, D.C.

URBAN LAND INSTITUTE. (1977). Shopping Center Development Handbook. Washington, D.C.

URBAN LAND INSTITUTE. (1971). The community builders handbook. Washington, D.C.

VOORHEES, A. M. \& CROW, C. E. (1966). Shopping center parking requirements, Highway Research Record-HRB, n.130, p.20-38.

YOUNG, W. \& THOMPSON, R. (1987). PARKSIM/1: Data presentation and evaluation. Traffic Engineering and Control. May. 


\section{BIBLIOGRAFIA CONSULTADA}

AL-HARAHSHEH, A. (1997). Estimation of Vehicle Parking Demand for Different Land Uses in Jordan. M.Sc. Thesis, Civil Engineering Department, Jourdan University of Science and Technology (JUST). Dec.

ARENTZE, T.; TIMMERMANS, H.; HOFMAN, F.; KALFS, N. (2000). Data needs, data collection and data quality requirements of activity-based transport demand models. Transportation Research Circular E-C008, Transportation Research Board. 30p. Aug.

ATKINS, D. M.; BOLGER, D.; FOSTER, R. and TOTH, Z. B. (1990). Regional Shopping Center Linked Trip Distribution. ITE Journal. v.60, n.5, p.41-6.

BACON, R. W. (1992). The travel to shop behaviour of consumers in equilibrium market. Journal of Transport Economics and Policy. v.26, n.3, Sept.

BADOE, D. A.; INNES, J. D. and IRCHA, M. C. (1990). Factors affecting automobile shopping trip destinations. Journal of Urban Planning and Development. v.116, n.3, p.126-36.

BARNARD, P. O. (1987). Modeling shopping destination choice behaviour using the basic multinomial logit model and some of its extensions. Transport Reviews, v.7, n.1, p.17-51.

BATES, J. and BRADLEY, M. (1986). The clamp parking policy analysis model. Traffic Engineering \& Control. July/August.

BOX, P. C. and KENING, N. S. (1984). Parking layout dimension guidelines. ITE Journal. Institute of Transportation Engineers, Washington, D.C.

BRINDLE, R. E. (1984). Traffic Impact Analysis. In K. W. Ogden and D. W. Bennett (eds). Traffic Engineering Practice. Department of Civil Engineering, Monash University: Clayton, Vic., p.117-35.

BURT, S. and SPARKS, L. (1991). Setting standards for car parking provision: The case of Retailing. Traffic Engineering and Control. v.31, n.5, p.253-8, May.

CASAZZA, J. A. and F. H. SPINKS. (1985). Shopping Center Handbook. Urban Land Institute. Washington, D.C.

CASSADY, C. R. and KOBZA, J. E. (1998). A Probabilistic Approach to Evaluate Strategies for Selecting a Parking Space. v.32, n.1, p.30-42, Feb.

CERVERO, R. (1991). Land use and travel at suburban activity centers. Transportation Quarterly.v.45, n.4, p.479-91 
CHODASH, I. L. (1986). Relative efficiencies of various parking angles, ITE Journal, March.

CYBIS, H. B. B.; LINDAU, L. A. \& CAMPOS, D. R. (1999). Avaliando o impacto atual e futuro de um pólo gerador de tráfego na dimensão de uma rede viária abrangente. Transportes, v.7, n.1, p.64-5, maio.

DICK, A. C. (1971). Transportation Aspects of New Shopping Development. Traffic Engineering \& Control, p.251, Oct.

FAGHRI, A.; ANEJA, S. and VAZIRI, M. (1999). Estimation of percentage of pass-by trips generated by a shopping center using artificial neural networks. Transportation Planning and Technology. v.22, p.271-86.

FERRAZ, A. C. P.; FORTES, F. Q. e SIMÕES, F. A. (1990). Escritos sobre Engenharia de Tráfego - Fundamentos Práticos. São Carlos, EESC/USP.

FONSECA, J. S. (1993). Curso de estatística, 4.ed. - São Paulo: Atlas.

FORSYTH, A. (1997). Variations on a Main Street: When a Mall is an Arcade. Journal of Urban Design, v.2, n.3, p.297-307, Oct.

GEIPOT (2001). Anuário Estatístico do Transportes - Frota Nacional de Veículos Automotores. http://www.geipot.gov.br . (18 dez)

GONÇALVES, A. A.; PORTUGAL, L. S. e OLIVEIRA, M. J. F. (1988). ESTSIM: um modelo de simulação para estacionamento de shopping centers. Anais do II Workshop Brasileiro de Simulação, São José dos Campos, SP.

GRAVA, S. (1999). Mobility demands of urban fields. Transportation Quarterly. v.53, n.4, p.109-20.

GU, K. (1996). An integrated land use-transport-environment model: CityPlan. Road and Transport Research. 5(1), p.26-38.

GU, K. and YOUNG, W. (1998). Verifying and Validating a Land Use - Transport Environment Model. Transportation Planning and Technology. v.21, p.181-202.

HARRIS, M. R. e ANDREW, H. R. (1979). The traffic implications of hypermarket development. Traffic Engineering and Control, Jan.

HENSEN, Ronald J. (1988). Trip Generation Rates for Different Types of Grocery Stores. ITE Journal. v.58, n.10, p.21-2

HIGHWAY RESEARCH BOARD SPECIAL REPORT No. 474 (1973). Parking as an Alternant to the Traffic Pattern. Highway Research Board, Washington, D.C.

HIGHWAY RESEARCH BOARD SPECIAL REPORT No. 444 (1973). Parking Demand and Allocation. Highway Research Board, Washington, D.C.

HIGHWAY RESEARCH BOARD SPECIAL REPORT No. 395 (1972). Parking Allocation Techniques. Highway Research Board, Washington, D.C.

INNES, J.; IRCHA, M. \& BADOE, D. (1988). Factors Affecting Automobile Shopping Trip Destinations. Journal of Urban Planning and Development. v.116, n.3, p.126-36. 
INTERNATIONAL COUNCIL OF SHOPPING CENTERS (2000). http://www.icsc.org

ITE (1991). Trip Generation, $5^{\text {th }}$ ed. Institute of Transportation Engineers, Washington, D.C.

ITE TECHNICAL COUNCIL COMMITTEEE 6F-44 (1990). Using the ITE Parking Generation Report. ITE Journal. v.60, n.7, p.25-33

KELLY, R. W. (1979). Parking at a hypermarket - six years on. Traffic Engineering \& Control., v.20, n.5, p.257-62, May.

KITAMURA, R.; CHEN, C. \& NARAYANAN, R. (1998). Traveler Destination Choice Behavior - Effects of time of day, Activity duration, and Home location. Transportation Research Record 1645.

KITTELSON, K. \& LAWTON, T. K. (1987). Evaluation of Shopping Center Trip Types. ITE Journal. v.57, n.2, p.35-9

LANDAU, U.; PRASHKER, J. \& BERNARD, A. (1982). Evaluation of Activity Constrained Choice Sets to Shopping Destination Choice Modeling. Transportation Research A, v.16, n3, p.199-207.

LANDIS, B. W. (1993). Improved Sampling Techniques to Determine Trip Characteristics for Traffic Impact Analyses. Transportation Research Record 1400, p.78-81.

LE, H. H. and YOUNG, W. (1998). Modelling Shopping Centre Traffic Movement (2): Model Application. Transportation Planning and Technology. v.21, p.309-21

LE, H. H. and YOUNG, W. (1998). Modelling Shopping Centre Traffic Movement (1): Model Validation. Transportation Planning and Technology. v.21, p.203-33

LE, H. H. and YOUNG, W. (1994). Traffic Systems Design at a Shopping Centre. Proc. $17^{\text {th }}$ ARRB Conference, 17(6). p.73-89.

LIMA FILHO, A. O. (1971). Shopping Centers - Estados Unidos vs Brasil - uma análise mercadológica comparativa. Fundação Getúlio Vargas, Rio de Janeiro, p.60

MESQUITA, J. M. B. \& RIBEIRO, P. C. M. (1998). O estacionamento integrado: sua aplicação para o atendimento de shopping centers. Anais do XII Congresso da Associação Nacional de Pesquisa e Ensino em Transportes (ANPET), Rio de Janeiro.

MORRIS, R. L. (1974). A measure of shopping center trip distribution. Traffic Engineering. v.44, n.13, p.32, Oct.

NCHRP - REPORT 365 (1998). Travel Estimation Techniques for Urban Planning. Transportation Research Board - TRB.

NCHRP - REPORT 348 (1992). Access Management Guidelines for Activity Centers. Transportation Research Board - TRB.

PEYREBRUNE, J. C. (1996). Trip generation characteristics of shopping centers. ITE Journal. v.66, n.6, p.46. Jun.

PORTUGAL, L. S.; GONÇALVES, A. A.; OLIVEIRA, M. J. F. \& GRANDO, L. (1988). Estacionamento de Shopping Centers e seus efeitos na rede viária, Anais do $V$ Congresso Panamericano de Trânsito. 
ROBERTSON, D. I. (1984). Estimating origin-destination flows by simulating trip choice. Traffic Engineering \& Control. v.25, n.7/8, p.358-64, July/August.

SMITH, M. S. (2000). The Day of Reckoning: Is it Time to Increase Parking Stall Dimensions? Parking, v.39, n.2, p.29-35.

STEIN, H. S. (1991). Parking study of neighborhood and community shopping centers. Transportation Research Record 1299, p.19-27.

STEINER, R. L. (1996). Traditional Neighborhood Shopping Districts: Patterns of use and modes of access. Ph.D. dissertation. University of California at Berkeley.

TIMMERMANS, H. J. P. (1981). Multiattribute shopping models and ridge regression analysis. Environment and Planning A, v.13, p.43-56.

ULYSSÉA, N. I. \& CARVALHO, B. N. (1994). Influência de um Shopping Center sobre a atração de viagens, com motivo trabalho, à zona de tráfego de sua implantação. Anais do VIII Congresso da Associação Nacional de Pesquisas e Ensino em Transportes, ANPET, Recife, v.2, p.51-60.

ULYSSÉA, N. I. e GRANDO, L. (1990). Impactos provenientes de mudanças na estrutura sócio-econômica e nos padrões de acessibilidade sobre a demanda de viagens a Shopping Centers. Anais do IV Congresso da Associação Nacional de Pesquisas e Ensino em Transportes, ANPET, Porto Alegre.

URBAN LAND INSTITUTE (1999). Parking Requirements for Shopping Centers: summary recommendations and research study report. Second Ed., Washington, D.C.

WAERDEN, P. van der.; BORGES, A. and SILVA, A. N. R. DA. (1997). Dispersion of shopping center visitors related to the duration of parking. Recent Advances in Retailing \& Services Science Conference, 4. Scottsdale: EIRASS/CIRASS.

WHEELER, M. K. and MATHIESON, B. J. (1976). Parking restraint and park-and-ride modeling. Traffic Engineering \& Control. v.17, n.6, p.260-1, June.

WILSON, A. G. (1998). Land-use / Transport Interaction Models - Past and Future. Journal of Transport Economics and Policy. v.32, part 1, Jan.

WOLSHON, B. and HATIPKARASULU, Y. (2000). Results of car following analyses using Global Positioning System. Journal of Transportation Engineering. v.126, n.4, p.324-331, July/August.

YOUNG, W. and W. Yue (1992). A Study of the Performance of two Parking-lot Layouts. Traffic Engineering and Control. 33, p.434-9.

YOUNG, W. (1987). Parking Principles: some thoughts on the design of parking lots. Australian Road Research. June.

YOUNG, W. (1987). Parking Route Guidance. Australian Road Research. v.17, n1, p.40-2.

YOUNG, W. and THOMPSON, R. (1987). PARKSIM/1: A computer graphics approach for parking lot layouts. Traffic Engineering and Control. March.

YOUNG, W. (1986). PARKSIM/1: A simulation model of driver behavior in parking lots. Traffic Engineering and Control. 27(12), p.606-13. 